\title{
Análise de expressões gênicas com erros de medida e aplicação em dados reais
}

\author{
Adèle Helena Ribeiro \\ DISSERTAÇÃO APRESENTADA \\ $\mathrm{AO}$ \\ Instituto DE MATEMÁticA E EstatísticA \\ DA \\ UNIVERSIDADE DE SÃO PAULO \\ PARA \\ OBTENÇÃO DO TÍTULO \\ $\mathrm{DE}$ \\ Mestre EM CiÊnCIAS \\ Programa: Ciência da Computação \\ Orientador: Prof. Dr. Roberto Hirata Júnior
}

Durante o desenvolvimento deste trabalho o autor recebeu auxílio financeiro da CAPES e do CNPq

São Paulo, junho de 2014 


\section{Análise de expressões gênicas com erros de medida e aplicação em dados reais}

Esta versão da dissertação contém as correções e alterações sugeridas pela Comissão Julgadora durante a defesa da versão original do trabalho, realizada em 03/06/2014. Uma cópia da versão original está disponível no

Instituto de Matemática e Estatística da Universidade de São Paulo.

Comissão Julgadora:

- Prof. Dr. Roberto Hirata Júnior (Presidente) - IME-USP

- Prof ${ }^{a}$. Dra ${ }^{a}$ Júlia Maria Pavan Soler - IME-USP

- Prof. Dr. Carlos da Silva dos Santos - UFABC 


\section{Agradecimentos}

Agradeço primeiramente ao meu orientador e amigo professor Roberto Hirata Jr., que sempre me apoiou e me deu forças para continuar indo atrás de meus sonhos.

Também agradeço à professora Júlia Pavan Soler, que acompanhou de perto minha pesquisa e me deu dicas que enriqueceram muito este trabalho.

Não posso deixar de agradecer ao professor André Fujita e ao professor Anatoli Iambartsev, que, embora não tenham acompanhado todo o meu trabalho, me ajudaram e estiveram presentes quando eu precisei.

Ao Max Reinhold Jahnke, por quem tenho um imenso carinho, quero fazer um agradecimento especial por me apoiar de todas as formas, por tornar os meus dias sempre agradáveis e por me manter sempre forte e feliz.

Quero agradecer aos meus pais, que também sempre foram muito bons para mim e me ajudaram com tudo o que estava a seus alcances.

Agradeço também aos meus amigos do IME, em especial ao Luis Fernando Ragognette, ao Gabriel Araújo, ao Eric Ossami Endo e aos demais participantes do ZFC Fan Club, que me ajudaram nos seminários que apresentei e também trouxeram assuntos de matemática bem divertidos.

Finalmente, agradeço à FAPESP (processo \# 2011/50761-2), ao CNPq, à CAPES e ao NAP eScience - PRP - USP pelo apoio financeiro pessoal e pela infraestrutura que viabilizaram meus estudos e a elaboração deste trabalho. 


\section{Resumo}

RIBEIRO, A. H. Análise de expressões gênicas com erros de medida e aplicação em dados reais. 2014. Dissertação (Mestrado) - Instituto de Matemática e Estatística, Universidade de São Paulo, São Paulo, 2014.

Toda medida, desde que feita por um instrumento real, tem uma imprecisão associada. Neste trabalho, abordamos a questão das imprecisões em experimentos de microarranjos de cDNA de dois canais, uma tecnologia que tem sido muito explorada nos últimos anos e que ainda é um importante auxiliar nos estudos de expressões gênicas.

Dezenas de milhares de representantes de genes são impressos em uma lâmina de vidro e hibridizados simultaneamente com RNA mensageiro de duas amostras diferentes de células. Essas amostras são marcadas com corantes fluorescentes diferentes e a lâmina, após a hibridização, é digitalizada, obtendo-se duas imagens. As imagens são analisadas com programas especiais que segmentam os locais que estavam os genes e extraem estatísticas dos píxeis de cada local. Por exemplo, a média, a mediana e a variância das intensidades do conjunto de píxeis de cada local (o mesmo é feito normalmente para uma área em volta de cada local, chamada de fundo). Estimadores estatísticos como o da variância nos dão uma estimativa de quão precisa é uma certa medida.

Uma vez de posse das estimativas das intensidades de cada local, para se obter a efetiva expressão de um gene, algumas transformações são feitas nos dados de forma a eliminar variabilidades sistemáticas. Neste trabalho, mostramos como podem ser feitas as análises a partir de uma medida de expressão gênica com um erro estimado. Mostramos como estimar essa imprecisão e estudamos, em termos de propagação da imprecisão, os efeitos de algumas transformações realizadas nos dados, por exemplo, a remoção do viés estimado pelo método de regressão local robusta, mais conhecido como lowess.

Uma vez obtidas as estimativas das imprecisões propagadas, mostramos também como utilizá-las na determinação dos genes diferencialmente expressos entre as amostras estudadas. Por fim, comparamos os resultados com os obtidos por formas clássicas de análise, em que são desconsideradas as imprecisões das medidas.

Concluímos que a modelagem das imprecisões das medidas pode favorecer as análises, já que os resultados obtidos em uma aplicação com dados reais de expressões gênicas foram condizentes com os que encontramos na literatura.

Palavras-chave: expressão gênica, microarranjos, imprecisões. 


\section{Abstract}

RIBEIRO, A. H. Gene expression analysis taking into account measurement errors and application to real data. 2014. Master's thesis - Instituto de Matemática e Estatística, Universidade de São Paulo, São Paulo, 2014.

Any measurement, since it is made for a real instrument, has an uncertainty associated with it. In the present paper, we address this issue of uncertainty in two-channel cDNA Microarray experiments, a technology that has been widely used in recent years and is still an important tool for gene expression studies.

Tens of thousands of gene representatives are printed onto a glass slide and hybridized simultaneously with mRNA from two different cell samples. Different fluorescent dyes are used for labeling both samples. After hybridization, the glass slide is scanned yielding two images. Image processing and analysis programs are used for spot segmentation and pixel statistics computation, for instance, the mean, median and variance of pixel intensities for each spot. The same statistics are computed for the pixel intensities in the background region. Statistical estimators such as the variance gives us an estimate of the accuracy of a measurement.

Based on the intensity estimates for each spot, some data transformations are applied in order to eliminate systematic variability so we can obtain the effective gene expression. This paper shows how to analyze gene expression measurements with an estimated error. We presented an estimate of this uncertainty and we studied, in terms of error propagation, the effects of some data transformations. An example of data transformation is the correction of the bias estimated by a robust local regression method, also known as lowess.

With the propagated errors obtained, we also showed how to use them for detecting differentially expressed genes between different conditions. Finally, we compared the results with those obtained by classical analysis methods, in which the measurement errors are disregarded.

We conclude that modeling the measurements uncertainties can improve the analysis, since the results obtained in a real gene expressions data base were consistent with the literature.

Keywords: gene expression, DNA microarrays, uncertainty. 


\section{Sumário}

1 Introdução $\quad 1$

1.1 Trabalhos relacionados . . . . . . . . . . . . . . . . . . . 2

1.1.1 Representações da expressão gênica . . . . . . . . . . . . . . . . . . 3

1.1.2 Modelagem da propagação das incertezas . . . . . . . . . . . . . . 3

1.2 Organização do trabalho . . . . . . . . . . . . . . . . . . . . . 4

2 Análise de expressões gênicas $\quad \mathbf{5}$

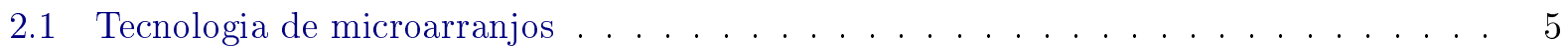

2.2 Variações indesejadas nas medidas das expressões gênicas $\ldots \ldots \ldots \ldots$

2.2 .1 Imprecisão do sistema de medição f . . . . . . . . . . . . . . . . . . . 6

2.3 Medidas de expressão gênica . . . . . . . . . . . . . . . . . 7

2.3.1 Representação das expressões gênicas . . . . . . . . . . . . . . . 7

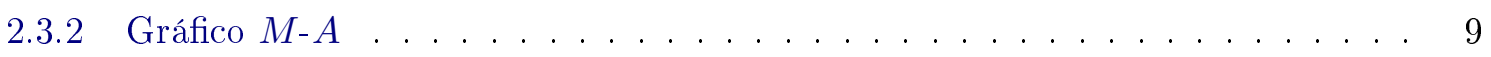

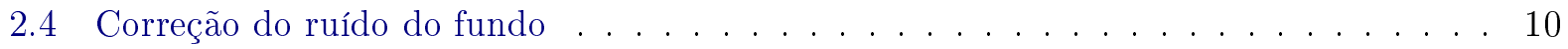

2.4 .1 Efeitos da subtração do fundo . . . . . . . . . . . . . . . . 11

2.4.2 Correção usando o modelo de convolução normal-exponencial . . . . . . . . . 12

2.5 Normalização . . . . . . . . . . . . . . . . . . . . . . . 15

2.5.1 Normalização de dados dependentes da intensidade . . . . . . . . . . . . . 15

2.6 Análise da expressão diferencial . . . . . . . . . . . . . . . . . . . . . . 16

3 Expressões gênicas com erros de medida $\quad 19$

3.1 Representação das expressões gênicas pelas médias . . . . . . . . . . . . . . . . . . 19

3.2 Representação das expressões gênicas por intervalos . . . . . . . . . . . . . . . . 20

3.3 Estimação da média e da variância por expansão de Taylor . . . . . . . . . . . . . . . 24

3.3 .1 Estimação de $\mathbb{E}\left(f\left(R_{i}, G_{i}\right)\right): \ldots \ldots \ldots \ldots \ldots$

3.3 .2 Estimação de $\operatorname{Var}\left(f\left(R_{i}, G_{i}\right)\right): \ldots \ldots \ldots \ldots \ldots$

3.3 .3 Estimação de $\mathbb{E}\left(M_{i}\right)$ e $\operatorname{Var}\left(M_{i}\right) \ldots \ldots \ldots \ldots \ldots \ldots \ldots$

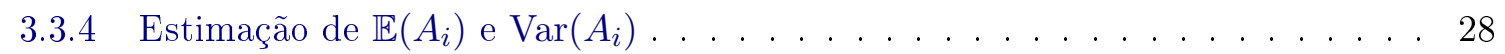

3.4 Consideração das imprecisões nas medidas com correção de fundo . . . . . . . . . . . 29

4 Lowess para dados de expressões gênicas $\quad 31$

4.1 Conceitos preliminares . . . . . . . . . . . . . . . . . . . . . . 31

4.1 .1 Por que regressão local? . . . . . . . . . . . . . . . . 32

4.1 .2 O modelo local . . . . . . . . . . . . . . . . . . . . . . 32

4.1 .3 A vizinhança de suavização . . . . . . . . . . . . . . . . . . 34 
4.2 Adaptações para dados heteroscedásticos . . . . . . . . . . . . . . . . . . . 35

4.2.1 Detecção de heteroscedasticidade . . . . . . . . . . . . . . . . . 35

4.2.2 Resolução por mínimos quadrados residuais ponderados . . . . . . . . . . . . 36

4.2.3 Algoritmo iterativo para robustez à outliers . . . . . . . . . . . . . . . . . . 38

4.3 Estimativa da variância da variável resposta . . . . . . . . . . . . . . . . . . . 40

4.3.1 Variância não homogênea . . . . . . . . . . . . . . . . . . . 40

4.3.2 Variância homogênea . . . . . . . . . . . . . . . . . . . . . 41

4.4 Medidas de qualidade do modelo . . . . . . . . . . . . . . . . . . . . . . . . . 42

4.4.1 Erro quadrático médio . . . . . . . . . . . . . . . . . . . . . 42

4.4 Viés ................................ 42

4.4 Variância . . . . . . . . . . . . . . . . . . . . . . . . 43

4.4.4 Avaliando o viés e a variância da estimativa graficamente . . . . . . . . . . 43

4.5 Efeitos dos parâmetros na superfície de suavização . . . . . . . . . . . . . . . . . . 44

4.5.1 O efeito do grau do polinômio . . . . . . . . . . . . . . . . . . . . 44

4.5.2 O efeito da largura da banda . . . . . . . . . . . . . . . . . . . 46

4.6 Critérios de avaliação da qualidade do modelo . . . . . . . . . . . . . . . . . . . 49

4.6.1 Caracterização global do modelo: graus de liberdade do ajuste . . . . . . . . . 49

4.6.2 Erro quadrático médio de predição . . . . . . . . . . . . . . . . 50

4.6.3 Erro quadrático médio da estimativa . . . . . . . . . . . . . . . . . 51

5 Normalização das expressões gênicas com erros de medida 53

5.1 Algoritmos de seleção dos parâmetros do lowess para aplicação em larga escala 53

5.1 .1 Minimização do erro quadrático médio de predição . . . . . . . . . . . . . . 54

5.1 .2 Minimização do erro quadrático da estimativa . . . . . . . . . . . . . . 54

5.1.3 M-plot: ferramenta de visualização do erro quadrático médio . . . . . . . . 55

5.1 .4 Método de seleção proposto . . . . . . . . . . . . . . . . 56

5.2 Estimação do erro do lowess por intervalo de confiança . . . . . . . . . . . . . . . . 57

5.2.1 Processo de determinação das amostras bootstrap . . . . . . . . . . . . 61

5.3 Normalização usando valores esperados de $M$ e $A$. . . . . . . . . . . . . . . . 63

5.4 Normalização considerando dados intervalares . . . . . . . . . . . . . . . . 65

6 Genes diferencialmente expressos considerando erros de medida 71

6.1 Determinação de genes diferencialmente expressos com dados intervalares . . . . . . 71

6.1.1 O modelo linear misto ........................ . . 72

6.1.2 O modelo com erros homoscedásticos . . . . . . . . . . . . . . . . 73

6.1.3 Testes de Hipóteses para efeitos fixos . . . . . . . . . . . . . . . . 76

6.1.4 O modelo com erros heteroscedásticos . . . . . . . . . . . . . . . . . 77

7 Aplicação em dados reais de expressões gênicas 83

7.1 Base de dados . . . . . . . . . . . . . . . . . . . . . . 84

7.2 Pré-processamento dos dados . . . . . . . . . . . . . . . . . . . 85

7.3 Determinação dos genes diferencialmente expressos . . . . . . . . . . . . . . . . 89

7.4 Comparação entre as variantes da base de dados . . . . . . . . . . . . . . . . . . 95

7.5 Genes diferencialmente expressos concordando com a literatura . . . . . . . . . . 125 
7.6 Genes diferencialmente expressos das vias do câncer . . . . . . . . . . . . 125

8 Conclusão

A Resoluções e verificações

A.1 Resolução do problema de mínimos quadrados ponderados para a estimação de $\hat{\beta}$. . 137

A.2 Decomposição viés-variância do erro quadrático médio do estimador . . . . . . . . 138

A.3 Estimação da variância das observações $Y_{i}$ quando ela é constante . . . . . . . . . 139

A.4 Determinação do critério VCG . . . . . . . . . . . . . . . . . . . 140

A.5 Verificação do não enviesamento da estimativa Cp . . . . . . . . . . . . . . . . 141

A.6 Verificação do não enviesamento da estimativa HRCp . . . . . . . . . . . . . . . . . . 142

B Estimação dos parâmetros por máxima verossimilhança 143

$\begin{array}{ll}\text { C Breve introdução à tecnologia Agilent } & 151\end{array}$

$\begin{array}{ll}\text { Referências Bibliográficas } & 153\end{array}$ 


\section{Capítulo 1}

\section{Introdução}

A partir do estudo das expressões dos genes, podemos compreender o funcionamento das células e abordar questões específicas sobre diferentes fenótipos.

A tecnologia de microarranjos, que provocou um grande impacto nas pesquisas do final da década de 90 (Hughes et al. (2000)) e ainda é muito utilizada para o estudo das expressões gênicas, permite analisarmos, simultaneamente, expressões de milhares de genes.

No entanto, mesmo sendo uma ferramenta muito utilizada em pesquisas biomédicas, os microarranjos ainda geram respostas muito ruidosas e, por isso, a confiabilidade das análises é afetada.

Neste trabalho, nos focaremos em estudar os métodos de análise de dados de microarranjos de dois canais, mostraremos algumas formas de utilizar as imprecisões das medidas nas análises e veremos o impacto dessas abordagens nos resultados.

A tecnologia de microarranjos de dois canais permite compararmos os níveis das expressões gênicas de duas amostras de células diferentes. Nesse caso, cada tipo de amostra de DNA é identificado com um fluoróforo diferente, permitindo que ambas as amostras sejam hibridizadas simultaneamente na lâmina de microarranjos. Em seguida, é feito uma digitalização especial da lâmina, obtendo-se imagens com as intensidades de fluorescência de cada corante.

É durante o processamento dessas imagens que ocorre a principal fonte de variação que estamos interessados neste estudo. A análise das imagens é feita com a intenção de obter, para cada amostra, os valores representativos das expressões dos fragmentos genéticos impressos na lâmina de microarranjos.

A expressão de um fragmento genético é assumida ser proporcional à intensidade de fluorescência do corante na região da lâmina onde ele foi impresso. No entanto, em cada região, são obtidas as intensidades de vários píxeis e essas intensidades podem ser muito distintas. Isso se deve às imprecisões no sistema de medição, incluindo limitação na definição das imagens, configurações da digitalização, imprecisões dos algoritmos de segmentação e comportamentos inesperados durante a hibridização.

É por esse motivo, que muitos programas de análise dessas imagens não nos fornecem apenas um valor para a expressão de cada gene, mas sim estatísticas das intensidades de cada conjunto de píxeis de cada canal, como média, mediana, moda e variância. Além disso, são obtidas medidas que avaliam a qualidade e confiabilidade do local, como sua área, perímetro e circularidade.

Diante desse quadro, podemos nos questionar se há alguma forma de incorporar essas informações na representação das expressões gênicas ou nas análises.

A estimação das medidas de expressões gênicas mais popular é a desenvolvida por Brown et al. (2001), em que utiliza-se a razão da média das intensidades do canal da amostra de teste, pela média das intensidades do canal da amostra de controle. Essa medida, que usualmente é utilizada após uma transformação logarítmica, permite um controle nos experimentos com várias lâminas, já que a amostra controle é utilizada em todas as lâminas e a expressão em estudo será sempre relativa à mesma expressão de controle.

No trabalho de Brown et al. (2001), a correção do sinal pela remoção do fundo também é considerada, mas, novamente, a partir de uma medida de tendência central, como a média das 
intensidades do fundo. Ou seja, essa abordagem descarta as informações de imprecisão das medidas.

O uso da mediana para representar os sinais de cada canal também é bastante comum, já que essa medida é mais robusta a possíveis píxeis outliers. No entanto, é mais uma abordagem que despreza os erros da medição.

Como é mostrado na seção 1.1.1, poucos trabalhos tentam obter um valor que represente as expressões utilizando as demais estatísticas obtidas durante o processamento das imagens.

Em uma abordagem conhecida como modelagem do ruído ou propagação das incertezas, também encontramos, embora poucos, trabalhos que levam em consideração a variabilidade de cada canal. Como veremos na seção 1.1.2, geralmente nesses trabalhos há a suposição de que as intensidades de cada canal seguem uma distribuição de probabilidade em que a variância é composta de um termo aditivo, para a influência do fundo, por exemplo, e um fator multiplicativo para modelagem dos demais erros sistemáticos. Embora seja uma abordagem interessante, essas modelagens têm sido pouco utilizadas, já que aumenta consideravelmente a complexidade das análises.

Neste trabalho, mostramos como podemos levar em consideração os erros das medidas nas análises de dados de microarranjos de dois canais, como uma extensão dos métodos convencionais de análise de dados gênicos. Isso permite aplicarmos as propostas aqui sugeridas utilizando ferramentas já bastante difundidas na comunidade científica.

Com base na representação convencional da expressão gênica, que é medida de expressão relativa proposta por Brown et al. (2001), propomos algumas representações da expressão gênica que levam em consideração as imprecisões dos sinais. Determinamos tanto uma estimativa da média da expressão gênica que considera as variâncias dos píxeis em cada canal, como também propomos uma representação das expressões por dados intervalares, indicando medidas de expressões gênicas com erro.

Além disso, mostramos como podemos minimizar e estimar os erros acumulados durante os métodos de pré-processamento, em especial, a normalização com o bem conhecido método lowess, e assim adicioná-los ao erro de medição.

Finalmente, mostramos como determinar os genes diferencialmente expressos a partir das expressões gênicas médias e dos erros estimados e avaliamos o impacto em relação aos métodos convencionais.

\subsection{Trabalhos relacionados}

A medida de expressão relativa, isto é, a razão entre as medidas das intensidades dos sinais de cada canal (ou o seu logaritmo), é muito utilizada para a representação das expressões gênicas nas análises. No entanto, como comentam os autores Newton et al. (2001), uma série de fatores pode afetar a acurácia com que essas razões representam a expressão relativa verdadeira. Um dos fatores é que os sinais muito baixos são muito ruidosos e, assim, tornam as estimativas das razões altamente variáveis.

Com essa grande imprecisão das medidas das intensidades de fluorescência associadas a cada local genético, muitos estudos foram feitos na tentativa de encontrar o valor que represente a expressão gênica adequadamente, como os que serão apresentados na seção 1.1.1.

Além desses erros, que consideramos como erros de medição, temos os erros sistemáticos e os aleatórios. O pré-processamento dos dados, que inclui a remoção do fundo e a normalização (Yang et al. (2000) e Quackenbush (2002)), é realizado exatamente para reduzir os efeitos dos erros sistemáticos nas análises das expressões gênicas. No entanto, nem todo erro consegue ser removido, inflando as estimativas dos erros aleatórios. Por isso, alguns estudos foram focados na modelagem da propagação das incertezas, ou seja, na modelagem dos erros aleatórios. Mostramos alguns desses modelos na seção 1.1.2. 


\subsubsection{Representações da expressão gênica}

No estudo de Nunez-Garcia et al. (2004), foi questionado o uso da mediana em relação às outras medidas de tendência central, tais como a média e a moda. Segundo eles, a intensidade mediana não é a medida mais apropriada em muitos casos, dentre eles quando o local genético se apresenta na imagem digitalizada na forma de "donut". Esse é um caso em que a moda é a medida mais próxima da intensidade esperada. Eles também comentam que devido às variabilidades sistemáticas, geralmente temos que a distribuição dos píxeis não é normal. Ela costuma ser, no entanto, assimétrica e com cauda esquerda mais pesada. Assim, temos um deslocamento maior para a média e para a mediana, enquanto a moda é mais estável.

Uma abordagem que vai contra a ideia de utilizar a razão entre os sinais de cada canal para representar as expressões gênicas é a sugerida por Tran et al. (2002). Eles argumentam que as intensidades associadas a genes raramente expressos são geralmente perdidas nos tratamentos convencionais de pré-processamento, como a tomada da razão entre as intensidades dos canais, a correção do fundo e a transformação logarítmica. Assim, eles defendem o uso de uma simples correlação entre a média e a mediana das intensidades, argumentando que as medidas de baixa intensidade não são perdidas e a não acurácia dos sinais é eliminada.

Outra proposta mais complexa é a de Bakewell e Wit (2005). Considerando a média, a variância e o número de píxeis dos canais, Bakewell e Wit (2005) estimam as expressões dos locais genéticos por um método de máxima verossimilhança. Eles argumentam que esse método é mais eficiente que o estimador convencional justamente por não usar apenas a média das intensidades, mas também as variâncias.

Um trabalho mais recente é o de Chan e Chang (2009). Os autores desenvolveram um algoritmo chamado META que pondera as razões entre as intensidades de cada canal com o inverso da variância do local, criando, assim, um estimador mais robusto para as expressões gênicas. Além disso, eles propõem uma métrica para avaliar a qualidade do local.

\subsubsection{Modelagem da propagação das incertezas}

A modelagem dos erros propagados tem por objetivo explicar melhor os efeitos nos erros aleatórios, que são as flutuações nos dados deixadas após as correções dos erros sistemáticos.

Se alguma variabilidade importante nos dados não for considerada no modelo, então os erros aleatórios, que deveriam apenas representar a variabilidade natural dos dados, serão estimados de forma inflada. Não é possível prever o valor exato desses erros, mas a variância dos erros aleatórios pode ser utilizada nas análises para tornar os testes estatísticos mais confiáveis.

Os testes de hipóteses realizados nas análises da expressão gênica diferencial são altamente influenciados pela estimativa da variância de cada grupo de dados (expressões de amostras com fenótipos diferentes) e, assim, devemos obtê-la de forma confiável.

A intensidade da variância em medidas de microarranjos é dependente das intensidades, fenômeno já discutido pelos autores Tu et al. (2002). Muitos modelos de erro foram desenvolvidos para descrever a variância da medida das expressões gênicas (Chen et al. (1997) e Li e Wong (2001)). O que percebe-se nesses modelos é que a variância tende a ser maior em altas intensidades.

Há dois tipos de abordagem para modelar a variância do erro dependente das intensidades. Uma, puramente obtida pelos dados, é dada pela superfície de regressão que descreve a relação entre as intensidades e a variância, que pode ser obtida por lowess. Exemplo de estudo que utiliza essa técnica é o de Jain et al. (2003). A outra abordagem é por modelagem clássica dos erros, que faz uso do conhecimento de uma causa real do erro. Os artigos de Rocke e Durbin (2001), Theilhaber et al. (2001) e Dror (2001) mostram exemplos desses modelos de erros. O modelo de erro Rosetta, desenvolvido por Weng et al. (2006), também foi construído de forma a capturar o comportamento previsível da variância dos erros em relação às intensidades para dados de microarranjos de dois canais. Nesse modelo, o erro da intensidade é estimado e usado para estabilizar a estimação da variância. 


\subsection{Organização do trabalho}

No capítulo 2, vemos com mais detalhes como são geralmente obtidas as medidas representativas das expressões gênicas e mostramos os principais pré-processamentos realizados no sinal. Discutimos com cuidado a transformação logarítmica, a correção para remoção da influência do fundo e a normalização para correção do viés causado pela dependência que os corantes têm das intensidades. Concluímos com uma breve descrição sobre a análise convencional feita para a determinação dos genes diferencialmente expressos.

No capítulo 3, mostramos como pode ser feita a estimação das médias das expressões gênicas considerando uma medida de tendência central e as medidas de variância e covariância das intensidades de cada canal, todas disponibilizadas pelos programas de análise das imagens dos microarranjos. Além disso, mostramos como a correção por subtração da intensidade média do fundo influencia a nossa estimativa e, assim, discutimos o uso de um método mais elaborado, o normexp, para a correção do fundo.

Também mostramos como obter uma estimativa da variância das expressões gênicas após as transformações nos dados. Esse medida pode ser usada, em um primeiro momento, como critério de qualidade dos dados. Discutimos também como utilizá-la, assumindo a normalidade da distribuição dos logaritmos das expressões gênicas relativas, para determinarmos os erros das medidas e construirmos as representações intervalares dos dados.

Já no capítulo 4, fazemos um estudo detalhado do método de regressão polinomial local robusto, conhecido por lowess.

As medidas das expressões gênicas, independente da forma com que foram estimadas, apresentam muitos ruídos provenientes de variabilidades sistemáticas e, por isso, precisamos realizar algumas transformações nos dados a fim de obtermos a efetiva expressão de um gene.

Uma das maiores fontes de variação sistemática é a dependência que os corantes têm da intensidade do local. Para corrigirmos esse efeito nos dados, realizamos um processo de normalização intra-lâmina, em que uma estimativa desse viés, obtida geralmente pelo método lowess, é subtraída das medidas.

Mostramos nesse capítulo como cada parâmetro do lowess influencia na estimação da superfície de suavização e revisamos os critérios que avaliam a qualidade do modelo. Uma estimação inadequada do viés do corante pode acarretar em correções inapropriadas dos sinais, adicionando mais ruídos ou até mesmo causando perda de informações.

Por isso, no capítulo 5, propomos um algoritmo de seleção dos parâmetros do lowess para que, de forma automatizada, o processo de normalização de cada lâmina seja realizado adequadamente, reduzindo a quantidade de ruído proveniente do método.

No capítulo 5, também mostramos como combinar as imprecisões originais das medidas com as provenientes da estimação do lowess e como realizar o processo de normalização tanto com as expressões representadas pelas suas médias como por intervalos.

No capítulo 6, discorremos sobre o modelo de regressão linear misto e mostramos como utilizá-lo para a análise dos genes diferencialmente expressos quando há erros na medida.

Finalmente, no capítulo 7 utilizamos uma base de dados de experimentos de microarranjos da plataforma Agilent para compararmos os métodos propostos com os convencionais e para analisarmos o efeito de incluir os erros das medidas tanto nos pré-processamentos como na determinação dos genes diferencialmente expressos. 


\section{Capítulo 2}

\section{Análise de expressões gênicas}

Neste capítulo, descreveremos alguns conceitos básicos sobre expressão gênica e microarranjos, além de descrever como são realizadas as análises convencionais das expressões gênicas obtidas em um experimento com microarranjos de dois canais e quais os principais problemas relacionados.

Expressão gênica é o processo no qual a informação do gene é usada para a síntese de produtos funcionais. Quando o gene está em atividade, ocorre a fabricação de produtos que usam a sua informação, como proteínas ou moléculas de RNAs (ácidos ribonucleicos). Inicialmente, a informação do gene que está na molécula de DNA (ácido desoxirribonucleico) é copiada, base por base, formando o RNA mensageiro (RNAm). Esse processo é conhecido como transcrição. Em seguida, o RNAm leva a informação do núcleo (quando em organismos maiores) até o citoplasma da célula, onde ocorrerá o processo de tradução. Nesse processo, os ribossomos decodificam o RNAm criando uma cadeia de aminoácidos específica, que, mais tarde, formará uma proteína ativa.

As quantidades de proteínas geradas a partir dos genes determinam tanto a morfologia como a funcionalidade da célula. Pequenas alterações nos níveis das expressões gênicas podem determinar mudanças grandes no organismo e até mesmo provocar uma doença como um câncer (Devereux et al. (1998)).

Por isso, tecnologias que permitem a comparação dos níveis das expressões gênicas entre diferentes amostras de células despertam tanto interesse da comunidade científica.

A necessidade de analisar simultaneamente níveis de expressões de muitos genes impulsionou o aparecimento de várias tecnologias, dentre elas, os microarranjos. Com seu surgimento, foi possível a análise de expressões de milhares de genes simultaneamente, proporcionando grandes avanços científicos, especialmente no campo da biologia molecular.

\subsection{Tecnologia de microarranjos}

Os microarranjos são pequenos arranjos de moléculas de DNA dispostos sobre uma lâmina, geralmente um substrato de vidro ou plástico. Em cada arranjo, há milhares de locais genéticos organizados em forma de matriz. Esses locais genéticos são alguns picomols de uma sequência específica do DNA impressos na lâmina, que podem ser, por exemplo, uma pequena parte de um gene. Dependendo da tecnologia de fabricação das lâminas, essas moléculas podem ser fragmentos de DNA, DNA complementares (cDNA) ou oligonucleotídeos.

Os arranjos são fabricados de acordo com o experimento a ser feito. Durante a fabricação da lâmina, sequências de DNA são impressas em cada local a fim de representar os genes que serão estudados e também outras cadeias arbitrárias que servem para ampliar as análises dos dados. Neste trabalho, denotamos essas regiões por locais genéticos.

Durante o experimento, as lâminas são misturadas a uma solução que contém cadeias simples de DNA da amostra a ser estudada, algumas complementares às sequências impressas na lâmina. Essas cadeias podem ser obtidas, por exemplo, por transcrição reversa dos RNAm presentes na amostra. Com isso, as cadeias que possuem uma sequência complementar depositada no substrato 
dos arranjos são hibridizadas. Quando há uma grande quantidade de cadeias hibridizadas em um local, dizemos que o gene a ele associado está muito ativo ou muito expresso.

Essa técnica permite, portanto, estudarmos os níveis das expressões de cada fragmento genético impresso na lâmina. Nesse tipo de estudo, as cadeias de DNA da amostra são identificadas com um corante fluorescente. Assim, é possível medir, a partir da intensidade de fluorescência de cada local, a quantidade de RNAm proveniente do gene representado.

Esse processo pode ser realizado para várias amostras de DNA, identificando cada uma delas com um corante diferente. Nesse caso, a solução com todas as amostras é usada para a lavagem da lâmina de microarranjos iniciando um processo de hibridização competitivo. Experimentos desse tipo são conhecidos como de multicanais.

Um experimento bastante comum e que será estudado neste trabalho é o experimento de dois canais, feito quando estamos interessados em comparar a expressão dos genes entre dois grupos, por exemplo, uma amostra de tecido tumoral e outra de tecido saudável. Nesse caso, é comum identificarmos a amostra do tecido de referência com o corante Cy3 (verde) e a amostra que estamos interessados em estudar com o corante Cy5 (vermelho). No entanto, outros corantes também podem ser utilizados.

Por causa das propriedades de fluorescência desses corantes, é possível fazer uma digitalização das lâminas usando fontes de luzes apropriadas e obter uma imagem com as intensidades das fluorescências para cada canal.

Durante o processamento dessas imagens, são identificados os locais de cada fragmento genético e são obtidas estatísticas das intensidades dos píxeis de cada local. Como essas intensidades podem ser relacionadas à quantidade de RNAm presente na amostra, temos que as medidas obtidas para um dado local descrevem a expressão do fragmento genético correspondente.

\subsection{Variações indesejadas nas medidas das expressões gênicas}

Por causa da variabilidade de cada processo realizado durante um experimento com microarranjos, os valores obtidos para as expressões gênicas tendem a ser bastante ruidosos.

Ao final do processamento das imagens obtidas após a digitalização da lâmina, o valor associado a cada local deveria representar precisamente a quantidade de RNAm presente na solução que hibridizou a lâmina neste local. No entanto, como essas variabilidades não podem ser controladas e muitas delas não são nem lineares (Yang et al. (2002)), não podemos fazer uma associação direta entre os valores obtidos e as expressões dos genes que estamos interessados.

Além disso, os altos custos dos experimentos tornam inviável a realização de um número grande de réplicas do experimento para que esses erros sejam absorvidos nos modelos estatísticos.

É por isso que existem tantos esforços na tentativa de criar um método que modele adequadamente essas variações experimentais e, assim, permita a remoção dos artefatos dos dados. Métodos que apresentam esse objetivo se enquadram num processo conhecido como normalização, que veremos em mais detalhes na seção 2.5. Ele é essencial para tornar os dados comparáveis na análise das expressões gênicas, principalmente quando precisamos combinar dados de diferentes lâminas.

\subsubsection{Imprecisão do sistema de medição}

Além das variações experimentais comentadas anteriormente, uma questão de grande importância mas que nem sempre é levada em consideração nas análises é a imprecisão do sistema de medição das intensidades dos locais genéticos.

Assim, por um lado, temos as variações experimentais que distorcem o valor verdadeiro da expressão do gene. Mas, por outro lado, esse valor, mesmo que distorcido, não pode ser capturado com precisão pelos sistemas de imageamento. O que temos são estatísticas dos conjuntos de píxeis considerados associados a cada um dos locais genéticos. E essas devem ser utilizadas para descrever a expressão de cada fragmento genético. 
Exemplos dessas medidas são média, mediana e variância. Além disso, geralmente são obtidas as medidas de correlação entre os canais para cada conjunto de píxeis.

No entanto, por causa de imprecisões nos processos de análise das imagens, essas medidas podem não estar associadas a somente a região correspondente de cada fragmento genético. Em especial, o processo de segmentação, no qual é feita a identificação da posição e da extensão dos conjuntos de píxeis de cada local genético e a classificação dos píxeis de cada um deles como sinal, fundo ou ruído, ainda é bastante impreciso.

Como os locais genéticos da lâmina são dispostos, em geral, em forma de matriz, parece simples implementar um algoritmo computacional que encontra a localização dos fragmentos genéticos de forma precisa. No entanto, temos uma grande variabilidade na fabricação das lâminas.

As dimensões e espaçamentos dos locais de cada arranjo variam. Também, pode ocorrer falta de alinhamento desses locais e variações no posicionamento de cada microarranjo da lâmina. Os locais da lâmina também não possuem nem um formato regular e nem possuem o mesmo tamanho.

Além das características da lâmina, também há questões relacionadas com a própria hibridização. Como pode ocorrer hibridização de sequências de DNA em regiões inesperadas da lâmina, alguns píxeis podem ser associados a partículas de sujeira e até mesmo contaminação nos locais genéticos.

Assim, além do real local do fragmento genético poder estar bem distante do estimado pela análise da imagem e da região estimada não ter o contorno exato de cada local, ainda é possível que a medida seja bastante diferente do que deveria ser. Isso afeta diretamente a confiabilidade dos dados das expressões gênicas.

Ainda não temos um modelo de análise definitivo para corrigirmos todos esses problemas. Assim, neste trabalho, propomos melhorar a medida da expressão gênica deixando de representá-la por apenas uma medida de tendência central das intensidades de cada canal, passando a representá-la também a partir das demais estatísticas disponibilizadas pelos algoritmos de análise das imagens.

Uma medida estatística de grande interesse e que geralmente é descartada no modelo da expressão genética é a variância dos píxeis de cada canal. Assim, se modelarmos as expressões utilizando essa medida de variabilidade, poderemos alcançar uma representação mais fiel da intensidade do sinal de cada canal, para cada local genético. Apresentamos no capítulo 3 como isso pode ser feito.

\subsection{Medidas de expressão gênica}

Como já foi discutido, em experimentos com dois canais, são obtidas duas imagens após a digitalização da lâmina de microarranjos. Uma com as intensidades do corante utilizado na amostra de teste e outra com as intensidades associadas à amostra de referência. No processamento de cada uma dessas imagens, a localização de cada fragmento genético depositado na lâmina é estimado e são obtidas estatísticas que descrevem o conjunto de píxeis associado a esse local.

Podemos, então, considerar a resposta de cada canal como uma variável aleatória. Como geralmente o fluoróforo Cy5, de cor vermelha, identifica a amostra de teste, e o fluoróforo Cy3, de cor verde, identifica a amostra de referência, nos referiremos às intensidade desses canais, para um dado local genético $i$, respectivamente pelas variáveis aleatórias $R_{i}$ e $G_{i}$.

As estatísticas disponibilizadas pelos programas de análise das imagens são, portanto, estimativas de estatísticas dessas variáveis aleatórias. Assim, temos disponíveis estimativas como a média amostral de cada canal, $\bar{R}_{i}$ e $\bar{G}_{i}$, e variância amostral de cada canal, $\hat{\operatorname{Var}}\left(R_{i}\right)$ e $\hat{\operatorname{Var}}\left(G_{i}\right)$.

Veremos nesta seção como utilizar essas estatísticas para obter um valor que representa a expressão de cada local genético.

\subsubsection{Representação das expressões gênicas}

Em experimentos com dois canais, costuma-se utilizar as medidas de expressões gênicas relativas para representar a expressão de cada fragmento genético disponível na lâmina de microarranjos. Assim, sendo $R_{i}$ a variável que representa as intensidades de fluorescência do local genético $i$ no 
canal da amostra de teste e $G_{i}$ a variável que representa as intensidades de fluorescência da amostra de referência, temos que a expressão relativa é dada por $R_{i} / G_{i}$.

Devido a vários fatores, é recomendável por Wu e P. Xing (2008), Dudoit et al. (2002) e Drăghici (2012), aplicar a transformação logarítmica nessas medidas relativas, geralmente de base dois.

Uma das razões para essa transformação ser feita é que os valores ficam mais fáceis de interpretar, além de mais significativos do ponto de vista biológico, já que mudanças que afetam as intensidades pequenas podem ser comparadas às mudanças que ocorrem ao redor das intensidades altas.

Também temos uma maior estabilidade numérica, já que podemos realizar os cálculos utilizando subtração, ou seja, temos que

$$
\log _{2}\left(\frac{R_{i}}{G_{i}}\right)=\log _{2}\left(R_{i}\right)-\log _{2}\left(G_{i}\right)
$$

Outra razão é que a transformação logarítmica reduz a variabilidade da amostra e modifica a distribuição dos dados tornando-a mais simétrica e próxima da normal. Isso possibilita o uso de muitos métodos de análise de dados que fazem a suposição de normalidade e homoscedasticidade, como a análise de variância.

Para a determinação de uma superfície de ajuste no método de normalização das lâminas de microarranjos, a suposição de normalidade pode ser relaxada utilizando um método de regressão robusta, como o lowess. Apresentamos em detalhes a teoria e propriedades desse método no capítulo 4.

Na figura 2.1, esboçamos, para uma das lâminas de microarranjos, que contém 45015 locais genéticos, as médias de $R_{i}, \bar{R}_{i}$, pelas médias de $G_{i}, \bar{G}_{i}$, com $i=1, \ldots, 45015$, antes e depois da transformação logarítmica. Assim, é possível ver como essa transformação reduz a variabilidade nas medidas.

(a) Antes da transformação logaritmica 45010 pontos

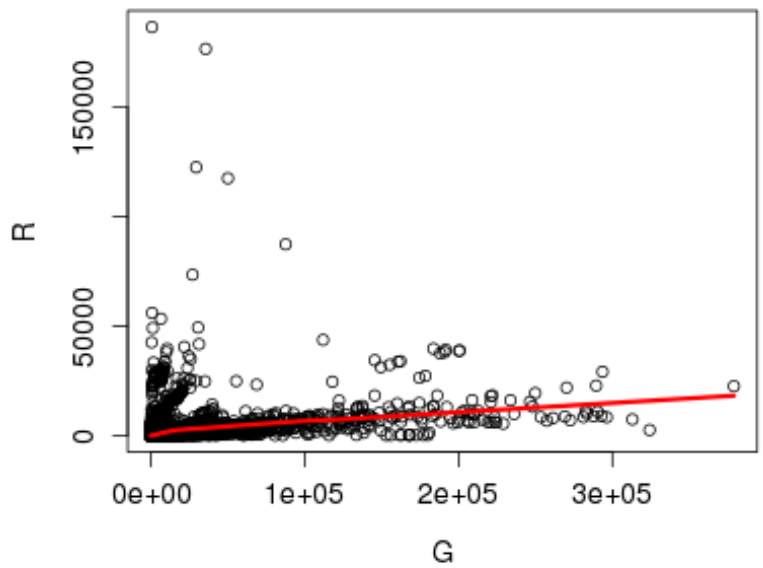

(b) Após a transformação logarítimica 45010 pontos

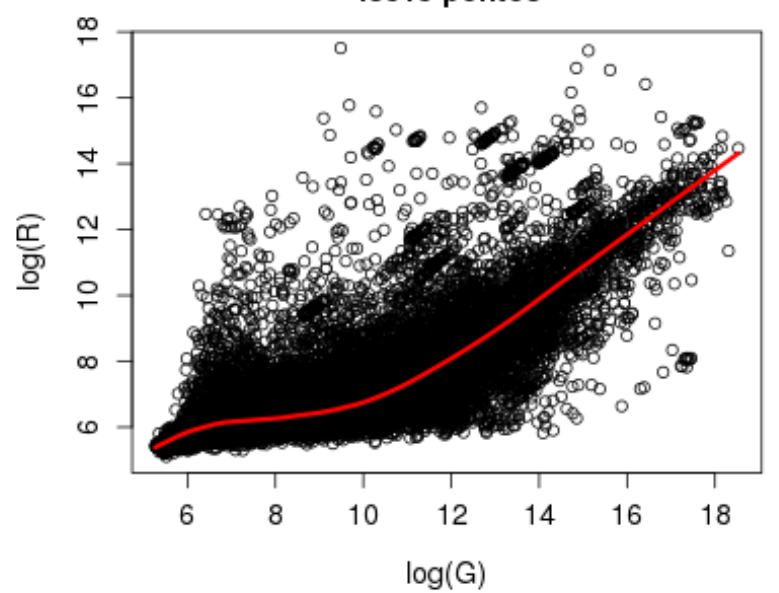

Figura 2.1: No gráfico à esquerda, é possivel ver que a dispersão das observaçôes $G_{i}$ é maior que a das observaçôes $R_{i}$. Essa heteroscedasticidade é bastante reduzida com a transformação logarítmica, como vemos no gráfico à direita. Essa lâmina, de identificação 251485069614_1_4, faz parte da base de dados utilizada em nossa aplicação, melhor descrita no capítulo $\%$.

Com essas transformações, passamos, então, a descrever a expressão do fragmento genético de um dado local $i$, por uma nova variável aleatória, $M_{i}$ :

$$
M_{i} \doteq \log _{2}\left(R_{i}\right)-\log _{2}\left(G_{i}\right) .
$$

Assim, $M_{i}$ descreve a expressão relativa do local genético $i$ em escala logarítmica.

É nessa transformação que, convencionalmente, ocorre um simplificação excessiva nas variáveis 
aleatórias $R_{i}$ e $G_{i}$. Apesar de estarem disponíveis diversas estatísticas que descrevem as variáveis $R_{i}$ e $G_{i}$, elas passam a ser representadas simplesmente por uma medida de tendência central, como a média ou mediana. E, nesse caso, a expressão gênica de um local $i$ é comumente representada por:

$$
\hat{M}_{i} \doteq \log _{2}\left(\bar{R}_{i}\right)-\log _{2}\left(\bar{G}_{i}\right)
$$

Devemos observar que as médias amostrais $\bar{R}_{i}$ e $\bar{G}_{i}$ devem ser sempre positivas, já que o logaritmo não é definido para valores não positivos. Assim, qualquer processo de correção dessas medidas, como a remoção do efeito do fundo, deve manter as medidas ainda positivas. Quando isso não ocorre para a resposta corrigida de algum canal, uma abordagem comum é descartar essa medida, o que pode não ser interessante.

Outra medida importante utilizada nas análises é a intensidade média da expressão gênica. Para um dado local $i$, temos que essa medida é descrita pela variável aleatória $A_{i}$, que é determinada pela média das intensidades de cada canal, mas em escala logarítmica, ou seja:

$$
A_{i} \doteq \frac{\log _{2}\left(R_{i}\right)+\log _{2}\left(G_{i}\right)}{2}
$$

Novamente, quando utilizamos apenas uma medida de tendência central das variáveis $R_{i}$ e $G_{i}$ para obter o valor de $A_{i}$, fazemos uma simplificação excessiva na representação dessa medida. No caso particular de utilizarmos as médias de $R_{i}$ e $G_{i}$, passamos a utilizar nas análises a seguinte estimativa:

$$
\hat{A}_{i} \doteq \frac{\log _{2}\left(\bar{R}_{i}\right)+\log _{2}\left(\bar{G}_{i}\right)}{2}
$$

No capítulo 3 , discutimos como podemos obter uma representação da variável $M_{i}$ considerando as imprecisões das variáveis $R_{i}$ e $G_{i}$.

\subsubsection{Gráfico $M-A$}

As variáveis $M_{i}$ e $A_{i}$ podem ser definidas também como as coordenadas do vetor resultante na transformação feita sobre o par de variáveis $\left(G_{i}, R_{i}\right)$ :

$$
\left(G_{i}, R_{i}\right) \longmapsto\left(A_{i}, M_{i}\right) .
$$

Essa transformação é definida pela aplicação do logaritmo nos vetores $\left(G_{i}, R_{i}\right)$, seguida de uma rotação de $\pi / 4$ radianos no sentido horário e uma mudança de escala:

$$
\left(\begin{array}{cc}
\frac{\sqrt{2}}{2} & 0 \\
0 & \sqrt{2}
\end{array}\right)\left(\begin{array}{cc}
\cos (\pi / 4) & \sin (\pi / 4) \\
-\sin (\pi / 4) & \cos (\pi / 4)
\end{array}\right)\left(\begin{array}{c}
\log _{2} G_{i} \\
\log _{2} R_{i}
\end{array}\right)=\left(\begin{array}{c}
\left(\log _{2} R_{i}+\log _{2} G_{i}\right) / 2 \\
\log _{2} R_{i}-\log _{2} G_{i}
\end{array}\right) \doteq\left(\begin{array}{c}
A_{i} \\
M_{i}
\end{array}\right)
$$

Uma forma de observar as expressões gênicas é por gráficos que esboçam $\log _{2}\left(R_{i}\right)$ por $\log _{2}\left(G_{i}\right)$.

No entanto, como a transformação (2.6) pode ser vista como uma mudança no sistema de coordenadas, é equivalente à visualização por gráficos que esboçam $M_{i}$ por $A_{i}$.

Podemos observar essa transformação geométrica na figura 2.2. Os gráficos foram gerados a partir das médias de $R_{i}$ e $G_{i}$ de uma lâmina de microarranjos com 45015 locais genéticos $(i=$ $1, \ldots, 45015)$.

Esse gráfico, conhecido como gráfico $M$ - $A$, é uma aplicação do conhecido gráfico Bland-Altman (Martin Bland e Altman (1986)) em estatística médica (gráfico de diferenças), pois ele ilustra a diferença entre as medidas, isto é, $\log _{2} R_{i}-\log _{2} G_{i}$, em relação à média delas, isto é, $\left(\log _{2} R_{i}+\right.$ $\left.\log _{2} G_{i}\right) / 2$.

O seu uso é aconselhado para identificarmos mais facilmente artefatos e dependências em relação às intensidades. A rotação e mudança de escala permite melhor visibilidade da diferença dada por 
(a) Após a transformação logarítimica 45010 pontos

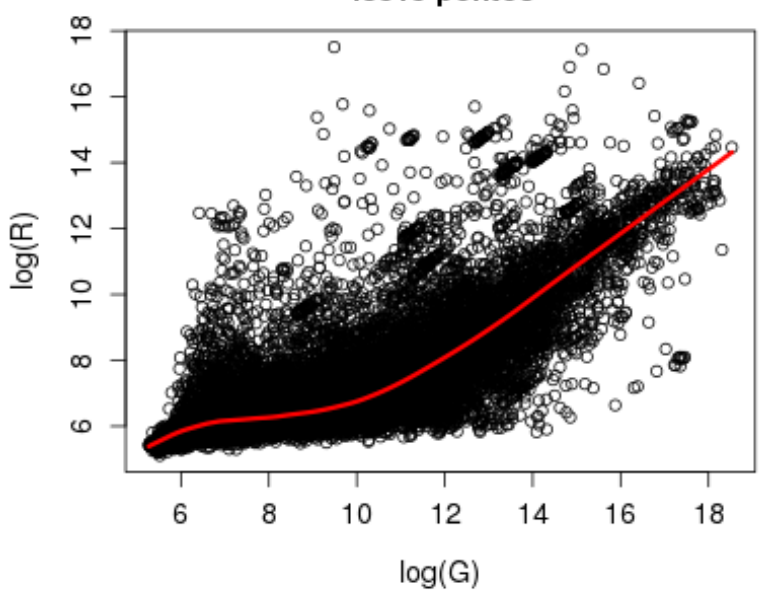

(b) Após transformação M-A 45010 pontos

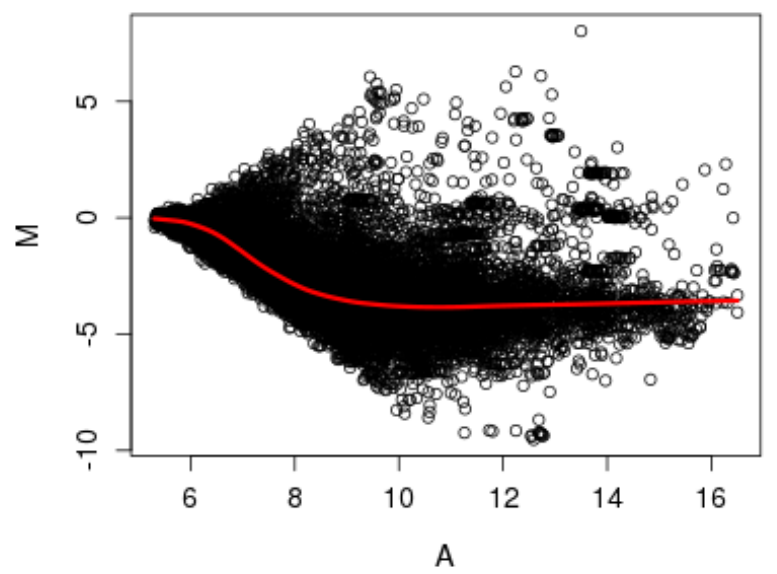

Figura 2.2: Na figura, podemos visualizar o efeito da transformação geométrica que define o gráfico $M$-A. Os vetores $\left(\log _{2} G_{i}, \log _{2} R_{i}\right)$, no gráfico à esquerda, sofreram uma mudança de escala e uma rotação de $\pi / 4$ radianos em sentido horário, resultando nos vetores $\left(A_{i}, M_{i}\right)$, à direita. Essa lâmina, de identificação 251485069614_1_4, faz parte da base de dados utilizada em nossa aplicação, melhor descrita no capitulo 7.

$M$ e dá ênfase aos outliers, eliminando as falsas noções de concordância que podem ocorrer no gráfico de $\log _{2} R_{i}$ por $\log _{2} G_{i}$.

As nomenclaturas $M$ e $A$ foram inspiradas nas palavras em inglês $\boldsymbol{M}$ inus e $\boldsymbol{A} d d$ por serem, respectivamente, uma subtração e uma soma dos logaritmos das intensidades.

Assim, para as análises das expressões gênicas, usaremos os pares de variáveis $\left(A_{i}, M_{i}\right)$.

No caso de utilizarmos uma medida de tendência central das variáveis $G_{i}$ e $R_{i}$ para representálas, a transformação (2.5) é dada por:

$$
\left(\bar{G}_{i}, \bar{R}_{i}\right) \longmapsto\left(\hat{A}_{i}, \hat{M}_{i}\right)
$$

em que $\hat{A}_{i}$ e $\hat{M}_{i}$ são as medidas já definidas, respectivamente, em (2.4) e (2.2).

\subsection{Correção do ruído do fundo}

Durante o processamento das imagens, estatísticas do fundo são calculadas a partir das intensidades dos píxeis que estão ao redor de cada local genético.

Como discutido na seção 2.2, há muitos ruídos nas medidas de expressões gênicas. Um deles está associado à interferência da intensidade do fundo. É comum que a intensidade observada para o local seja uma composição entre a fluorescência do fundo e a fluorescência da amostra de RNAm hibridizada. Nesse caso, para obtermos um valor proporcional apenas à quantidade de RNAm, é necessário fazer uma correção no sinal de cada canal utilizando as estatísticas disponíveis sobre o sinal do fundo.

Essa correção deve ser feita nas medidas das intensidades de cada canal e deve ser feita antes de qualquer transformação discutida na seção 2.3.1. Dessa forma, o método de correção utilizado não deve interferir na determinação das medidas $M_{i}$ e $A_{i}$.

Como discutido em Brown et al. (2001), o método mais comum de correção desse efeito é a subtração de uma das medidas de tendência central (média, mediana ou moda) das intensidades do fundo, que são disponibilizadas pelos programas de análise das imagens dos microarranjos.

Nesse caso, consideremos $B g R_{i}$ e $B g G_{i}$ sendo as variáveis aleatórias que caracterizam, respectivamente, os fundos dos canais $R_{i}$ e $G_{i}$. Denotaremos ainda as medidas de tendência central de interesse (usualmente a mediana) por, respectivamente, $\overline{B g R_{i}}$ e $\overline{B g G_{i}}$.

Assim, aplicamos a seguinte transformação para a remoção do efeito do fundo: 


$$
\left(G_{i}, R_{i}\right) \mapsto\left(G_{i}-\overline{B g G}_{i}, R_{i}-\overline{B g R}_{i}\right), \quad \text { para } i=1, \ldots n .
$$

A partir dessa correção, as transformações nos dados podem ser feitas como descrito na seção 2.3.1.

\subsubsection{Efeitos da subtração do fundo}

A correção do sinal feita pela subtração do fundo é bastante polêmica. Em textos mais antigos ou mais gerais sobre análise de dados de microarranjos, como os de Chen et al. (1997) e Hegde et al. (2000), é comum encontrarmos diretrizes apontando que a subtração direta das intensidades dos fundos deve ser feita, pois torna as intensidades dos locais mais próximas dos valores que representam a quantidade de RNAm hibridizados, ou seja, reduz o viés das medidas de $M_{i}$.

Porém, como comenta Scharpf et al. (2007) e Kooperberg et al. (2002), essa correção aumenta a variabilidade das observações de $M_{i}$.

Também, como comenta Drăghici (2012), ao fazermos a suposição de que o sinal real é obtido por uma simples subtração da intensidade do fundo, estamos desconsiderando que as propriedades de interação entre os RNAm das amostras, os genes impressos e a própria lâmina influenciam as intensidades.

Outro problema dessa correção é que ela pode causar perda de informações. Em geral, as intensidades dos fundos são baixas em relação às intensidades dos canais, mas pode ocorrer do valor da intensidade média do fundo ser maior que o valor da intensidade média do local. Nesse caso, teríamos um sinal negativo após a correção. Como o domínio da transformação logarítmica são os reais estritamente positivos, precisamos descartar esses dados. Como comentam ainda Brown et al. (2001), o método de subtração do fundo não é preciso e faz com que certa de 1 a $5 \%$ dos locais genéticos de uma lâmina de microarranjos comum tenha intensidades negativas sem sentido.

Na figura 2.3, podemos observar um exemplo de dados de microarranjos em que há a necessidade de uma correção do sinal pela remoção do fundo, pois há locais em que a intensidade é alta devido a uma influência alta do fundo. No entanto, constatamos também que a simples subtração da média do fundo não é um método bom, pois há locais em que a intensidade do fundo é maior que a intensidade do sinal.
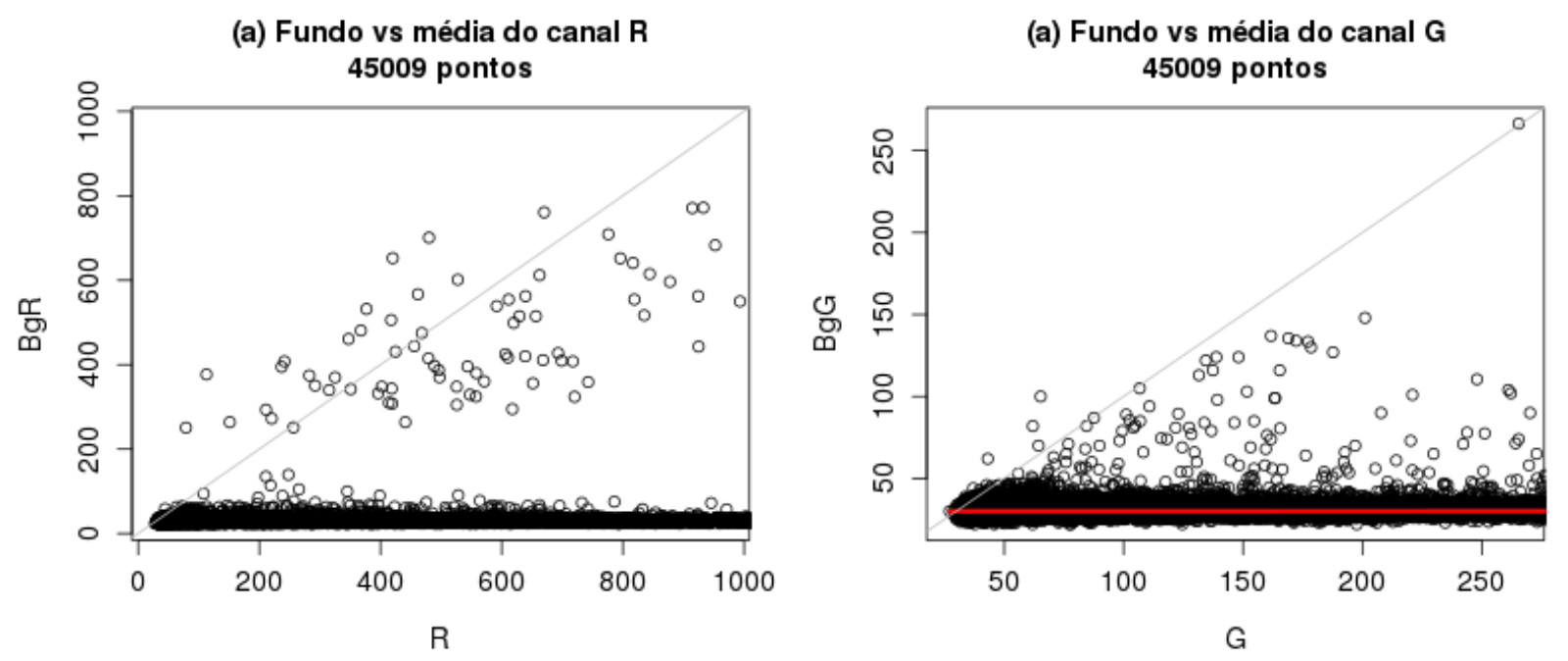

Figura 2.3: Nesse experimento, alguns locais possuem a intensidade média do canal menor que a intensidade média do fundo. Nesse caso, a correção pela subtração do fundo fará com que esses locais tenham uma intensidade média negativa e não poderão ser utilizados na análise. Essa lâmina, de identificação 251485069395_1_1, faz parte da base de dados utilizada em nossa aplicação, melhor descrita no capitulo 7.

É possível encontrar na literatura métodos mais cuidadosos que uma simples subtração do fundo, 
como o método de Kooperberg et al. (2002).

No entanto, atualmente temos opiniões, como a de Scharpf et al. (2007), de que é questionável o uso das intensidades do fundo para a correção do sinal. Em seu artigo, Scharpf et al. (2007) usa as correlações entre as intensidades dos locais e as intensidades dos fundos para dizer se devemos ou não fazer a subtração do fundo. Além disso, ele mostra como podemos observar o balanço viés-variância por simulações.

Com isso, durante esse processo do tratamento do sinal, é importante avaliar com cuidado as medidas das intensidades do fundo para que não sejam feitas correções inapropriadas no sinal.

\subsubsection{Correção usando o modelo de convolução normal-exponencial}

Vimos que, após a análise das imagens obtidas em um experimento de microarranjo de dois canais, temos estatísticas que descrevem as variáveis $R_{i}$ e $G_{i}$ correspondentes às intensidades dos sinais do local $i$ para, respectivamente, o canal da amostra de teste e o canal da amostra de controle.

Além disso, temos também as estatísticas das intensidades dos fundos para um dado local genético $i$, que denotamos por $B g R_{i}$ (associado ao canal da amostra de teste) e por $B g G_{i}$ (associado ao canal da amostra de controle).

Para a remoção das intensidades dos fundos nos sinais de cada canal, Silver et al. (2009) desenvolveram o modelo, conhecido como normexp, que faz as seguintes suposições:

$$
\begin{aligned}
& R_{i}=B g R_{i}+B_{R_{i}}+S_{R_{i}} \\
& G_{i}=B g G_{i}+B_{G_{i}}+S_{G_{i}} .
\end{aligned}
$$

em que $S_{R_{i}}$ e $S_{G_{i}}$ são as verdadeiras expressões dos sinais (sem o efeito do fundo) e $B_{R_{i}}$ e $B_{G_{i}}$ são as intensidades ambientais residuais não explicadas por, respectivamente, $B g R_{i}$ e $B g G_{i}$.

No modelo, os autores assumem que $S_{R_{i}}$ é distribuído exponencialmente com média $\alpha_{R_{i}}$, enquanto que $B_{R_{i}}$ é normalmente distribuído com média $\mu_{R_{i}}$ e variância $\sigma_{R_{i}}^{2}$. Analogamente para o canal da amostra de referência, assumem que $S_{G_{i}}$ é distribuídos exponencialmente com média $a_{G_{i}}$, enquanto que $B_{G_{i}}$ é normalmente distribuído com média $\mu_{G_{i}}$ e variância $\sigma_{G_{i}}^{2}$. Todas as variáveis são assumidas serem independentes.

Como as expressões para as intensidades do canal da amostra de teste e do canal da amostra controle são similares, descreveremos a abordagem apenas para a expressão da amostra de teste, isto é, para $R_{i}$.

Seja $X_{R_{i}}=R_{i}-B g R_{i}$ a intensidade com o sinal do fundo subtraído. Dessa forma, das suposições vistas em (2.7), temos que:

$$
X_{R_{i}}=B_{R_{i}}+S_{R_{i}}
$$

Dado que $S_{R_{i}}$ é distribuída exponencialmente e, assim, sua função de densidade de probabilidade para valores positivos $(s>0)$ é

$$
f_{S_{R_{i}}}\left(s ; \alpha_{R_{i}}\right)=\frac{1}{\alpha_{R_{i}}} e^{-s / \alpha_{R_{i}}},
$$

e dado que $B_{R_{i}}$ é distribuída normalmente, ou seja, com função de densidade de probabilidade, para todo $b$ e $\sigma_{R_{i}}>0$, igual a

$$
f_{B_{R_{i}}}\left(b ; \mu_{R_{i}}, \sigma_{R_{i}}\right)=\frac{1}{\sqrt{2 \pi \sigma_{R_{i}}^{2}}} e^{-\left(b-\mu_{R_{i}}\right)^{2} / 2 \sigma_{R_{i}}^{2}} .
$$

temos que, para $s>0$, a densidade conjunta de $B_{R_{i}}$ e $S_{R_{i}}$, sob independência, é dada pelo produto de suas funções densidades individuais:

$$
f_{B_{R_{i}}, S_{R_{i}}}\left(b, s ; \mu_{R_{i}}, \sigma_{R_{i}}, \alpha_{R_{i}}\right)=\frac{1}{\alpha_{R_{i}}} e^{-s / \alpha_{R_{i}}} \frac{1}{\sqrt{2 \pi \sigma_{R_{i}}^{2}}} e^{-\left(b-\mu_{R_{i}}\right)^{2} / 2 \sigma_{R_{i}}^{2}} .
$$


Podemos multiplicar a primeira exponencial e dividir a segunda exponencial por

$$
e^{\frac{1}{\alpha}\left(-x+s+\mu+\sigma^{2} /(2 \alpha)\right)} \text {. }
$$

Considerando a expressão (2.8) para $X_{R_{i}}$, que nos permite reescrever $b$ como $x-s$, e rearranjando os termos das exponenciais, conseguimos a seguinte densidade conjunta de $X_{R_{i}}$ e $S_{R_{i}}$, para $s>0$ :

$$
f_{X_{R_{i}}, S_{R_{i}}}\left(x, s ; \mu_{R_{i}}, \sigma_{R_{i}}, \alpha_{R_{i}}\right)=\frac{1}{\alpha_{R_{i}}} e^{\left(\frac{\sigma_{R_{i}}^{2}}{2 \alpha_{R_{i}}^{2}}-\frac{x-\mu_{R_{i}}}{\alpha_{R_{i}}}\right)} \frac{1}{\sqrt{2 \pi \sigma_{R_{i}}^{2}}} e^{-\frac{\left(s-x+\mu_{R_{i}}+\sigma^{2} / \alpha\right)^{2}}{2 \sigma_{R_{i}}^{2}}} .
$$

Ou ainda, denotando a função densidade de probabilidade normal por $\phi$, temos:

$$
f_{X_{R_{i}}, S_{R_{i}}}\left(x, s ; \mu_{R_{i}}, \sigma_{R_{i}}, \alpha_{R_{i}}\right)=\frac{1}{\alpha_{R_{i}}} e^{\left(\frac{\sigma_{R_{i}}^{2}}{2 \alpha_{R_{i}}^{2}}-\frac{x-\mu_{R_{i}}}{\alpha_{R_{i}}}\right)} \phi\left(s ; \mu_{S . X}, \sigma_{R_{i}}^{2}\right),
$$

em que $s>0$ e $\mu_{S . X}=x-\mu_{R_{i}}-\sigma_{R_{i}}^{2} / \alpha_{R_{i}}$.

Para determinarmos a densidade marginal de $X_{R_{i}}$, basta integrarmos em $s$ :

$$
f_{X_{R_{i}}}\left(x ; \mu_{R_{i}}, \sigma_{R_{i}}, \alpha_{R_{i}}\right)=\frac{1}{\alpha_{R_{i}}} e^{\left(\frac{\sigma_{R_{i}}^{2}}{2 \alpha_{R_{i}}^{2}}-\frac{x-\mu_{R_{i}}}{\alpha_{R_{i}}}\right)}\left(1-\Phi\left(0 ; \mu_{S . X}, \sigma_{R_{i}}^{2}\right)\right),
$$

em que $\Phi$ é a função de distribuição gaussiana.

Dividindo a densidade conjunta pela densidade marginal, temos a densidade condicional de $S_{R_{i}}$ dado $X_{R_{i}}$. Assim, para $s>0$, temos

$$
f_{S_{R_{i}} \mid X_{R_{i}}}\left(s \mid x ; \mu_{R_{i}}, \sigma_{R_{i}}, \alpha_{R_{i}}\right)=\frac{\phi\left(s ; \mu_{S . X}, \sigma_{R_{i}}^{2}\right)}{1-\Phi\left(0 ; \mu_{S . X}, \sigma_{R_{i}}^{2}\right)} .
$$

Como podemos conferir em Barr e Sherrill (1999), uma variável $Y \sim N\left(\mu, \sigma^{2}\right)$, com valores $a \leq y \leq \infty$, tem função densidade de probabilidade truncada gaussiana, dada por

$$
f(y ; \mu, \sigma, a, b)=\frac{\frac{1}{\sigma} \phi\left(y ; \mu, \sigma^{2}\right)}{1-\Phi\left(a ; \mu, \sigma^{2}\right)}
$$

e valor esperado igual a

$$
\mathrm{E}(Y \mid Y>a)=\mu+\sigma \frac{\phi\left(a ; \mu, \sigma^{2}\right)}{1-\Phi\left(a ; \mu, \sigma^{2}\right)} .
$$

Com isso, podemos ver que a função (2.9), a menos de um fator multiplicativo igual a $\sigma$, é uma distribuição gaussiana de média $\mu_{S . X}$ e variância $\sigma_{R_{i}}^{2}$, truncada no intervalo $(0, \infty)$.

Assim, o valor esperado de $S_{R_{i}} \mid X_{R_{i}}$ é

$$
\mathrm{E}\left(S_{R_{i}} \mid X_{R_{i}}=x\right)=\mu_{S . X}+\frac{\sigma^{2} \phi\left(0 ; \mu_{S . X}, \sigma_{R_{i}}^{2}\right)}{1-\Phi\left(0 ; \mu_{S . X}, \sigma_{R_{i}}^{2}\right)} .
$$

A partir da equação (2.10), podemos obter, para um dado sinal com o fundo subtraído, que denotamos por $X_{R_{i}}$, o valor esperado para o sinal verdadeiro (sem interferência do fundo), que denotamos por $S_{R_{i}}$.

O sinal obtido pela subtração direta do fundo, $X_{R_{i}}$, pode ser obtido pela diferença entre as medidas de tendência central do sinal medido (por exemplo, $\bar{R}_{i}$ ) e do sinal do fundo (por exemplo, $\overline{B g R}_{i}$ ). Essas medidas são geralmente disponibilizadas pelo programa que analisa as imagens dos microarranjos.

A correção do fundo deve ser realizada para cada arranjo e para cada canal, resultando nas estimativas estritamente positivas $\hat{S}_{R_{i}}$, para o canal da amostra de teste, e $\hat{S}_{G_{i}}$, para o canal da 
amostra de referência. Assim, a correção que remove a influência do fundo é dada pela transformação:

$$
\left(G_{i}, R_{i}\right) \mapsto\left(S_{G_{i}}, S_{R_{i}}\right),
$$

As medidas $G_{i}$ e $R_{i}$ corrigidas podem ser utilizadas para estimar $M_{i}$ e $A_{i}$ com as transformação vistas na seção 2.3.1.

Para isso, precisamos determinar os parâmetros desconhecidos $\mu_{R_{i}}, \sigma_{R_{i}}^{2}$ e $\alpha_{R_{i}}$. Como podemos ver em Silver et al. (2009) os parâmetros podem ser estimados por máxima verossimilhança usando estimativas ponto de sela para valores iniciais.

Usando a aproximação ponto de sela, Ritchie et al. (2007) mostraram que o método normexp acompanhado de um deslocamento foi o que resultou em menor taxa de falsos positivos quando comparado a diversos outros métodos de correção de fundo.

Além disso, Rocke e Durbin (2003) e Ritchie et al. (2007) também mostraram que deslocar as intensidades corrigidas por um valor pequeno positivo $k$, ou seja, aplicar a correção para a remoção do fundo como

$$
\left(G_{i}, R_{i}\right) \mapsto\left(S_{G_{i}}+k, S_{R_{i}}+k\right),
$$

ajuda a estabilizar a variância das medidas $M_{i}$, já que desloca as intensidades para valores distantes de zero.

Nesse estudo, os autores escolheram o valor $k=50 \mathrm{com}$ base em conhecimento prévio de dados experimentais de microarranjos de cDNA.

A redução da variabilidade das medidas $M_{i}$ vem do fato dos valores de $R_{i}$ e $G_{i}$ ficarem, após o deslocamento de $k$, distantes do zero e, portanto, a razão entre essas medidas também.

Esse resultado torna-se também bastante atraente a métodos que esperam que as intensidade dos canais $R_{i}$ e $G_{i}$ não sejam muito baixas, como os que apresentamos no capítulo 3 .

Nas figuras 2.4 e 2.5, mostramos um exemplo de como a remoção das intensidades dos fundos a partir do método normexp afeta as intensidades dos sinais. Nesse exemplo, utilizamos as estimativas das médias de $G_{i}$ e de $R_{i}$ fornecidas pelo programa de análise das imagens dos microarranjos. Para os sinais observados do fundo, utilizamos as medianas, também já disponíveis.

(a) M-A plot antes da correção do fundo 45010 pontos

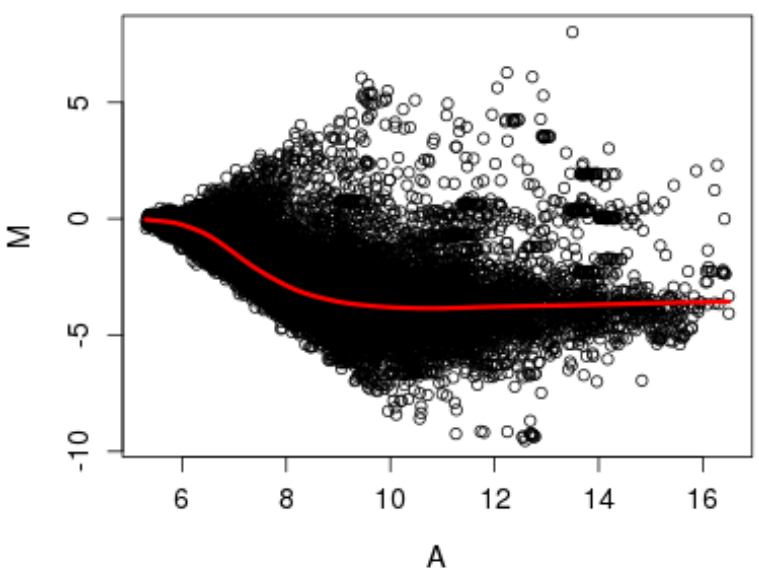

(b) M-A plot após correção do fundo com normexp - 45010 pontos

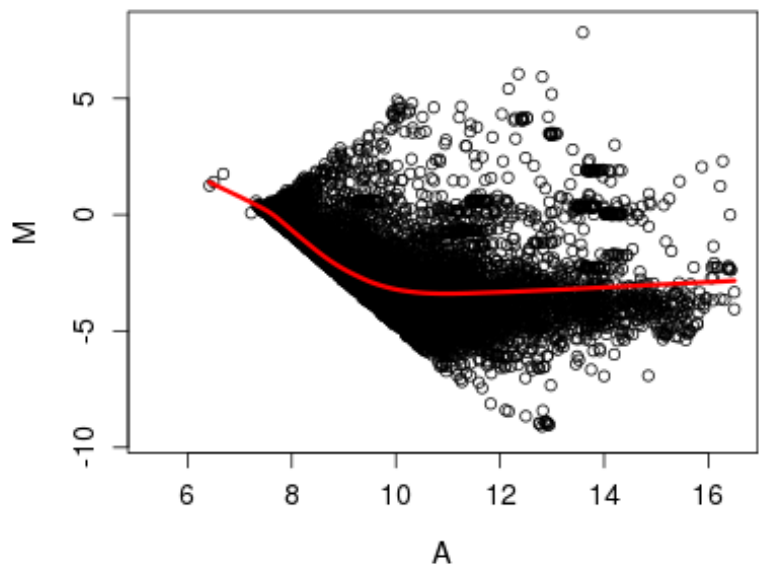

Figura 2.4: Gráfico $M-A$ antes (a) e depois (b) da remoção das intensidades dos fundos utilizando o método normexp. Lâmina de microarranjos com identificação 251485069614_1_4, onde foi hibridizada uma amostra de estômago com metaplasia grau II. 
(a) Valores de $M$ antes da correção do fundo 45010 pontos

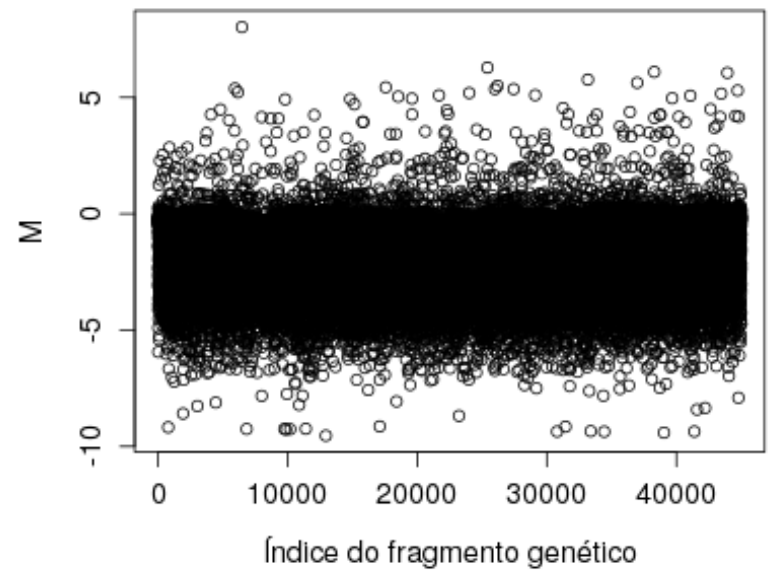

(b) Valores de $M$ após correção do fundo com normexp - 45010 pontos

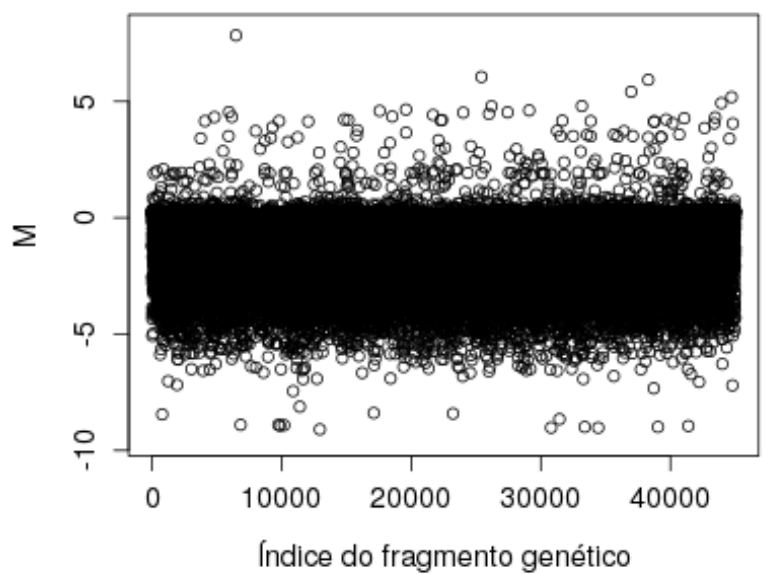

Figura 2.5: Gráfico dos valores de $M i$ em relação aos índices dos fragmentos genéticos representados da lâmina de microarranjos 251485069614_1_4 antes (a) e depois (b) da remoção das intensidades dos fundos utilizando o método normexp.

\subsection{Normalização}

Controlar os efeitos dos erros sistemáticos mantendo ainda a variação biológica devido a grupo é uma tarefa crítica para conseguirmos bons resultados na análise dos dados de microarranjos.

Uma das maiores fontes de variação sistemática é a dependência que os corantes têm da intensidade. É feita a suposição de que os logaritmos das intensidades relativas, $M_{i}$, são independentes da média dos logaritmos das intensidades de cada canal, $A_{i}$. E que qualquer dependência que apareça entre esses dados não é resultado de um efeito do gene, mas sim de uma variação sistemática que deve ser removida.

No artigo de Yang et al. (2000), é reportado que, até mesmo em experimentos com duas amostras idênticas de RNAm, identificadas com corantes diferentes e hibridizadas na mesma lâmina, as médias das intensidades dos corantes não são iguais. Inclusive, é comum que as intensidades da amostra identificada com $\mathrm{Cy} 3$ (corante verde) sejam mais altas que as intensidades da amostra quando é identificada com Cy5 (corante vermelho).

Isso corrobora com a hipótese de que o viés nas medidas $M_{i}$ é um efeito do corante e não de algum gene. Mas, esse viés pode ser resultado de fatores que vão desde características particulares do corante, como eficiência de incorporação, sensibilidade à luz e ao calor e meia-vida relativa do corante, até variabilidades do processo, como configurações do digitalizador.

Como esse viés nas medidas $M_{i}$ impossibilita a comparação dos níveis das expressões gênicas entre lâminas diferentes é necessário removê-lo.

As transformações que vimos nas seções anteriores podem ser úteis para estabilizar as variâncias e minimizar o efeito do local, mas não reduzem os efeitos provocados por essas características dos corantes nos dados.

Com o propósito de minimizar esses efeitos e balancear as intensidades dos canais $R_{i}$ e $G_{i}$, vários métodos foram propostos em um processo conhecido como normalização.

\subsubsection{Normalização de dados dependentes da intensidade}

Ao observarmos as medidas das expressões gênicas de uma lâmina no gráfico $M$ - $A$, é comum que exista uma tendência das observações $M_{i}$ em relação às observações $A_{i}$. Nesse caso, temos que as medidas das intensidades relativas são dependentes da intensidade média do local e, assim, podemos estimar uma função $f$ tal que $M_{i} \approx f\left(A_{i}\right)$. 
Para tornarmos essas medidas independentes e, assim, recuperar os valores dos níveis de expressão sem esse efeito, podemos subtrair de cada observação $M_{i}$ o valor de uma estimativa da função $f$ no ponto $A_{i}$.

Esse processo é um dos métodos de normalização intra-lâmina de experimentos de dois canais e pode ser descrito pela seguinte transformação:

$$
\left(A_{i}, M_{i}\right) \longmapsto\left(A_{i}^{*}, M_{i}^{*}\right)=\left(A_{i}, M_{i}-f\left(A_{i}\right)\right) .
$$

Para estimarmos a função $f$, é comum o uso da regressão polinomial local robusta conhecida como lowess. Esse método é discutido em detalhes no capítulo 4.

Assim, o processo de normalização é feito substituindo os valores dos níveis de expressão observados pelo resíduo da regressão que determina a função $f$.

Segundo Yang et al. (2000), para utilizarmos o lowess, precisamos que o par de amostras hibridizadas em cada arranjo deve ter poucos genes diferencialmente expressos ou que as médias dos níveis de expressão dos genes subexpressos e superexpressos sejam normalmente distribuídas. Com isso, ao final da normalização, a média dos valores normalizados de uma lâmina deve estar próxima de zero.

\subsection{Análise da expressão diferencial}

Um dos interesses da análise de microarranjos é identificar quais são os fragmentos genéticos, dentre os representados na lâmina, que apresentam níveis de expressão significantemente alterados entre as amostras em estudo. Esses genes são denominados genes diferencialmente expressos.

Nesta seção, faremos apenas uma descrição breve do método mais simples de determinação dos genes diferencialmente expressos, que é por ajuste de um modelo linear para dados sem erro e homoscedásticos. No capítulo 6 descrevemos uma abordagem que permite incluirmos os erros das medidas, além de modelar uma possível heteroscedasticidade nos dados.

Apesar das bibliotecas para programas computacionais permitirem o uso de extensões do método básico nesta análise (Smyth (2005)), as funções, em sua forma padrão, em geral descrevem um ajuste linear simples. Assim, consideramos essa abordagem como convencional e a utilizamos em nossa aplicação no capítulo 7 para efeito de comparação com o método trabalhado no capítulo 6 .

A determinação dos genes diferencialmente expressos pode ser feita em experimentos que incluem amostras de várias grupos. Assim, é possível determinar em qual condição um gene tem uma expressão maior (superexpresso) ou uma expressão menor (subexpresso) em relação às demais condições em estudo.

Genes diferencialmente expressos em grupos diferentes são importantes, pois podem explicar a variação entre esses fenótipos e alavancar um estudo a nível biológico para a criação de novos tratamentos.

Geralmente, o experimento inclui várias lâminas para estudo de um mesmo grupo. Assim, conseguimos, para cada condição de interesse, uma amostra de expressões de cada um dos genes.

Como comentamos, na abordagem convencional para a determinação dos genes diferencialmente expressos ajustamos, para cada gene, um modelo linear sobre os valores de expressão. Assim, obtemos a expressão média de cada condição experimental e o problema passa a ser um simples teste de comparação das médias. Uma análise de variância (ANOVA) clássica pode ser utilizada para resolver esse problema.

Para ilustrarmos melhor a metodologia, consideremos um experimento com $K$ fenótipos em estudo e que, para cada condição experimental $k=1, \ldots, K$, temos um conjunto de $n_{k}$ lâminas de microarranjos. Temos, então, para um dado gene $i$, os seguintes vetores de expressões:

$$
\left(M_{i}^{*}\right)^{(k)}=\left(\left(M_{i_{1}}^{*}\right)^{(k)},\left(M_{i_{2}}^{*}\right)^{(k)}, \ldots,\left(M_{i_{n_{k}}}^{*}\right)^{(k)}\right), \quad k=1, \ldots, K .
$$

Os componentes $\left(M_{i_{l}}^{*}\right)^{(k)}, l=1, \ldots, n_{k}$, de cada vetor $k=1, \ldots, K$, são expressões do gene $i$ obtidas após o processo de normalização de cada lâmina $l$. 
Para obtermos a expressão média do gene $i$ em cada condição $k$, fazemos um ajuste de um modelo linear sobre as observações de cada vetor $\left(M_{i}^{*}\right)^{(k)}$. Assim, assumimos que as expressões podem ser modeladas da seguinte forma:

$$
\left(M_{i_{l}}^{*}\right)^{(k)}=\mu_{i}+\tau_{i}^{(k)}+\varepsilon_{i_{l}}^{(k)}, \quad l=1, \ldots, n_{k} ; \quad k=1, \ldots, K,
$$

em que $\mu_{i}$ é a média das expressões do gene $i$ independente da condição da amostra; $\tau_{i}^{(k)}$ é efeito da expressão do gene $i$ pertencer à condição $k$ e $\varepsilon_{i_{l}}^{(k)}$ é o fator residual da $l$-ésima expressão do gene $i$ na condição $k$. Os fatores residuais, que descrevem a natureza aleatória dos dados, são supostamente normais e com variância $\sigma^{2}$ desconhecida.

Equivalentemente, podemos escrever esse modelo em notação matricial:

$$
M_{i}^{*}=X \beta_{i}+\varepsilon_{i},
$$

em que $M_{i}^{*}$ é o vetor com as expressões do gene $i$ normalizadas, para todas as $K$ condições experimentais; $X$ é a matriz de delineamento do experimento, especificando os grupos das amostras de cada expressão observada; $\beta_{i}=\left(\mu_{i}, \tau_{i}^{(1)}, \ldots, \tau_{i}^{(K)}\right)$ é o vetor dos coeficientes que deverão ser estimados e $\varepsilon_{i}$ é o vetor dos valores residuais.

Nesse caso, o modelo tem como efeito fixo o grupo da amostra e, assim, é possível testar se, para esse determinado gene $i$, os coeficientes estimados para cada fator desse efeito fixo é significativo.

Podemos construir uma matriz $C$ de contrastes, cujas linhas determinam as restrições lineares (testes) de interesse. Assim, podemos testar a seguinte hipótese:

$$
H_{0}: C \beta_{i}=b,
$$

em que $b$ é uma constante para ajuste da hipótese.

Essas restrições são combinações lineares dos coeficientes de cada grupo. Então, para testarmos, por exemplo, se o gene $i$ é diferencialmente expresso nas condições $k=1$ e $k=2$, basta construirmos uma restrição que teste se os coeficientes associados a essas condições são iguais. Isto é, construímos a seguinte hipótese:

$$
H_{0}: \beta_{i}^{(1)}-\beta_{i}^{(2)}=0 .
$$

Para uma matriz $C$ que agrupa, em suas linhas, $c$ restrições de interesse, podemos avaliar as hipóteses nulas pelo seguinte teste estatístico:

$$
F_{0}=\frac{\left(C \hat{\beta}_{i}-b\right)^{t}\left[\hat{\sigma}^{2} C\left(X^{t} X\right)^{-1} C^{t}\right]^{-1}\left(C \hat{\beta}_{i}-b\right)}{c},
$$

em que $\hat{\beta}_{i}=\left(\hat{\mu}_{i}, \hat{\beta}_{i}^{(1)}, \ldots, \hat{\beta}_{i}^{(K)}\right)$ é o vetor com as estimativas dos coeficientes do modelo.

Como $\left(C \hat{\beta}_{i}-b\right)$ mede quanto os coeficientes observados $\left(C \hat{\beta}_{i}\right)$ diferem da hipótese $\left(C \beta_{i}\right)$, se a hipótese nula for verdadeira, então essa diferença deve ser $0 \mathrm{e}$, consequentemente, o teste $F_{0}$ também. Qualquer desvio do 0 seria devido à amostragem ou a um efeito aleatório. Assim, $\left(C \beta_{i}-b\right)^{t}$ e $\left(C \beta_{i}-b\right)$ representam o quadrado desses desvios. O termo central, $\left[\hat{\sigma}^{2} C\left(X^{t} X\right)^{-1} C^{t}\right]^{-1}$ normaliza esses desvios para uma escala unitária, já que é exatamente a variância desses desvios:

$$
\operatorname{Var}\left(C \hat{\beta}_{i}-b\right)=C \operatorname{Var}(\hat{\beta}) C^{t}=\sigma^{2} C\left(X^{t} X\right)^{-1} C^{t} .
$$

Obtido o valor da estatística de teste $F_{0}$, precisamos ver se ele é maior que o resultante por uma variação aleatória.

Isso pode ser feito obtendo o p-valor do teste, ou seja, a probabilidade, sob a hipótese nula, de observar uma estatística tão extrema quanto a que obtivemos.

Nesse caso, assumimos que a distribuição de $F_{0}$, sob a hipótese nula, é uma distribuição $F$ com graus de liberdade $c$ e $N-(K+1)$, em que $N=\sum_{k} n_{k}$ é o número de observações, $K$ é o número de variáveis independentes e $c$ é o número de restrições. 
Se o p-valor do teste pertencer à região crítica para alguma das restrições de interesse, então podemos rejeitar a hipótese nula e dizer que o gene está associado à variação do grupo descrita pelo contraste.

Como desejamos fazer esse teste para milhares de genes, temos um problema de múltiplos testes e devemos fazer uma correção nos p-valores. Isso porque, se utilizarmos, por exemplo, um corte de 0,05 para o p-valor na determinação da região crítica (onde rejeitamos a hipótese nula do teste), esperamos que $5 \%$ dos genes encontrados sejam determinados como diferencialmente expressos por acaso. Assim, se fizermos, por exemplo, 10.000 testes separados, esperamos que 500 deles sejam falsos positivos, o que geralmente é muito.

Uma alternativa é fazer a correção dos p-valores controlando a taxa de falsos positivos (FDR - do inglês, false discovery rate), ou seja, controlando a proporção de falsos positivos no conjunto dos genes para os quais a hipótese nula (7.1) foi rejeitada (Benjamini e Hochberg (1995)). 


\section{Capítulo 3}

\section{Expressões gênicas com erros de medida}

\subsection{Representação das expressões gênicas pelas médias}

Vimos na seção 2.3, que as variáveis $M_{i}(2.1)$ e $A_{i}$ (2.3) representam, respectivamente, a expressão gênica relativa e a média das intensidades do $i$-ésimo local genético de uma lâmina de microarranjos, ambas em escalas logarítmicas.

Essas medidas são obtidas a partir das variáveis que representam as intensidades dos canais $R_{i}$ e $G_{i}$. Para não carregarmos mais a notação, assumiremos, a partir deste capítulo, que as variáveis $G_{i}$ e $R_{i}$ já sofreram a correção para a remoção do fundo. Além disso, assumiremos que essa correção não afetou as medidas de variabilidade (covariância e variância) dessas variáveis.

Comentamos também, na seção 2.3, que é muito comum estimar a média das variáveis $M_{i}$ e $A_{i}$ (média dos píxeis de cada local genético) utilizando apenas uma medida de tendência central das intensidades de cada canal, por exemplo, a média amostral do canal da amostra de teste, $\bar{R}_{i}$, e a média amostra do canal da amostra de referência, $\bar{G}_{i}$. Essa abordagem descarta as imprecisões das intensidades dos píxeis de cada canal, que são descritas pelas suas variâncias.

Em particular, quando utilizamos a média das intensidades de cada canal, o que estamos calculando ao obter $\hat{M}_{i}(2.2)$ e $\hat{A}_{i}$ (2.4) é uma aproximação das médias, respectivamente, das variáveis $M_{i}$ e $A_{i}$. Como será melhor discutido nas seções 3.3.3 e 3.3.4, essas aproximações correspondem às médias da expansão de Taylor dessas variáveis em apenas um termo.

Dessa forma, uma extensão natural, que será mostrada neste trabalho, é obter uma aproximação da média da função dessas variáveis a partir de uma expansão que inclui mais termos. Particularmente, adotaremos neste trabalho, as expansões de segunda ordem de Taylor de $M_{i}$ e de $A_{i}$. Essa estimação é uma aplicação do Método Delta Multivariado (Casella e Berger (1990) e Leite e Singer (1990)), que permite aproximar a média e a variância de funções de variáveis aleatórias. Detalhes dessa estimação são mostrados nas seções 3.3 .3 e 3.3.4, onde também é possível observar que os novos termos da expansão são expressões que dependem da variância e da covariância de $R_{i}$ e de $G_{i}$ e, portanto, levamos em consideração a dispersão dessas variáveis.

Assim, a primeira proposta deste trabalho para incluir os erros das medidas nas análises é representar as expressões gênicas por uma estimativa melhorada das médias de $M_{i}$ e $A_{i}$.

Essas novas estimativas para as médias das variáveis $A_{i}$ e $M_{i}$, serão denotadas, respectivamente, por $\bar{M}_{i}$ e $\bar{A}_{i}$.

Na figura 3.1, mostramos um exemplo de gráfico $M-A$ de uma lâmina de microarranjos, com valores das médias de $M_{i}$ e $A_{i}$ obtidos com os estimadores convencionais, $\hat{M}_{i}$ e $\hat{A}_{i}$, e com os novos estimadores, que consideram as imprecisões das medidas, $\bar{M}_{i}$ e $\bar{A}_{i}$. Na figura 3.2 podemos observar as diferenças entre as medidas em relação ao índice do fragmento genético.

Na figura 3.3, vemos como os estimadores afetam individualmente as médias de $A_{i}$ e $M_{i}$ da mesma lâmina de exemplo que usamos na figura 3.1.

Mais um exemplo de como os novos estimadores para as médias de $M_{i}$ e de $A_{i}$, respectivamente, $\bar{M}_{i}$ e $\bar{A}_{i}$, se comportam em relação aos estimadores convencionais, $\hat{M}_{i}$ e $\hat{A}_{i}$, pode ser observado nas figuras $3.4,3.5$ e 3.6 . 
(a) M-A plot usando estimadores convencionais para a média - $\mathbf{4 5 0 1 0}$ pontos

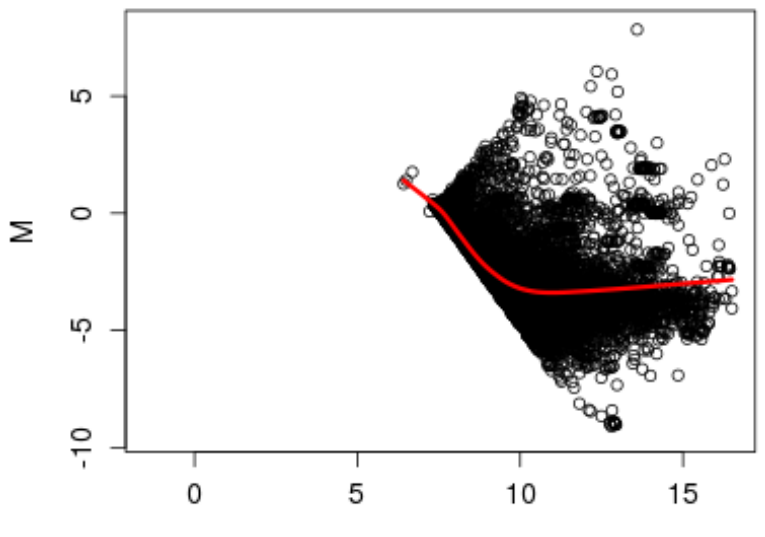

A (b) M-A plot usando novos estimadores para a média - $\mathbf{4 5 0 1 0}$ pontos

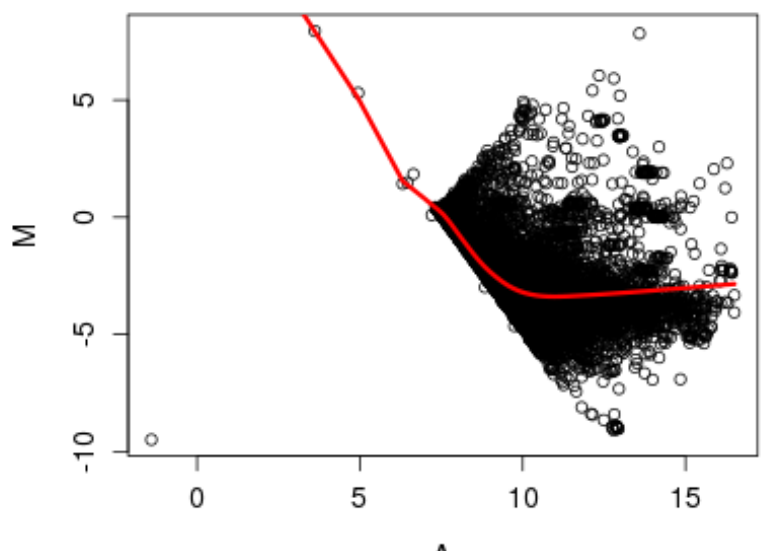

A

Figura 3.1: Gráficos $M-A$ com (a) médias obtidas pelos estimadores $\hat{A}_{i}$ e $\hat{M}_{i}$, que descartam a imprecisão das medidas, e com (b) médias obtidas pelos estimadores $\bar{A}_{i}$ e $\bar{M}_{i}$, que consideram as imprecisões das medidas. Lâmina de microarranjos com identificação 251485069614_1_4, onde foi hibridizada uma amostra de estômago com metaplasia grau II.

(a) Valores de $\mathrm{M}$ usando estimadores convencionais para a média - $\mathbf{4 5 0 1 0}$ pontos

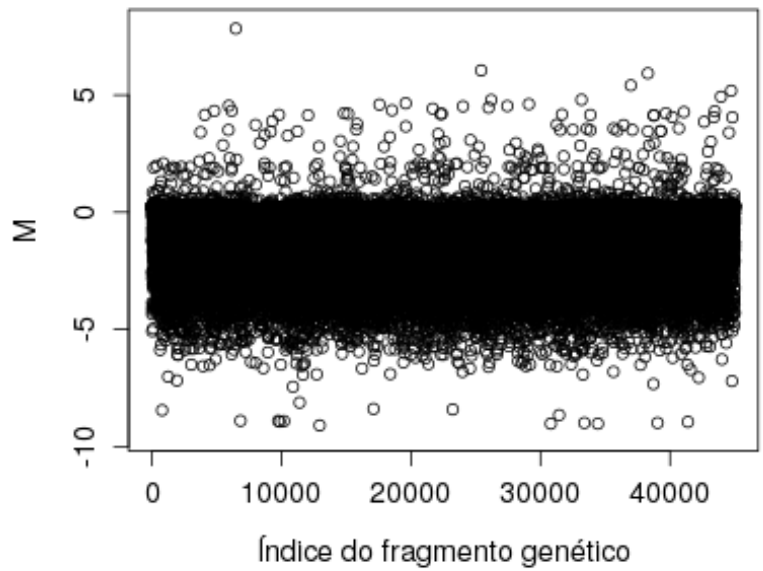

(b) Valores de $\mathrm{M}$ usando novos estimadores para a média - $\mathbf{4 5 0 1 0}$ pontos

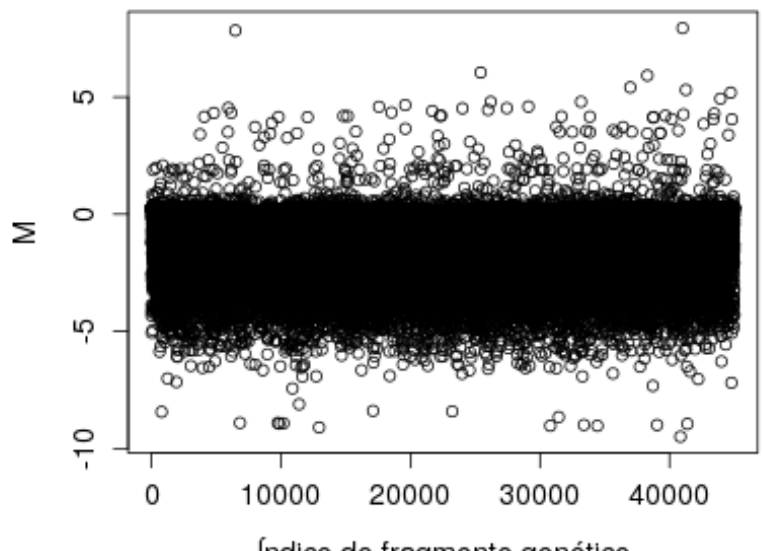

Indice do fragmento genético

Figura 3.2: Gráficos, em relação ao indices dos fragmentos genético, dos valores das médias de $M$ (a) obtidas pelo estimador $\hat{M}_{i}$, que descarta a imprecisão das medidas, e (b) obtidas pelo estimador $\bar{M}_{i}$, que considera as imprecisões das medidas. Lâmina de microarranjos com identificação 251485069614_1_4, onde foi hibridizada uma amostra de estômago com metaplasia grau II.

\subsection{Representação das expressões gênicas por intervalos}

$\mathrm{Na}$ estimação da média mais refinada das variáveis $M_{i}$ e $A_{i}$, já utilizamos as informações de variabilidade dos píxeis de cada canal. No entanto, podemos ainda utilizar essa variabilidade para construir não uma medida pontual da expressão gênica, mas sim uma medida intervalar. Dessa forma, representamos as expressões gênicas como medidas com erro.

Utilizando novamente as expansões de Taylor de $M_{i}$ e $A_{i}$, podemos obter as estimativas das variâncias e, assim, dos desvios padrões, que denotaremos por $\hat{\sigma}\left(M_{i}\right)$ e $\hat{\sigma}\left(A_{i}\right)$.

Com isso e fazendo a suposição de que a variável $M_{i}$ segue uma distribuição normal, podemos obter o intervalo que contém a média de $M_{i}$, com um nível de confiança $\alpha$, da seguinte maneira: 
(a) Diferença entre estimadores de E[Ai] 45010 pontos

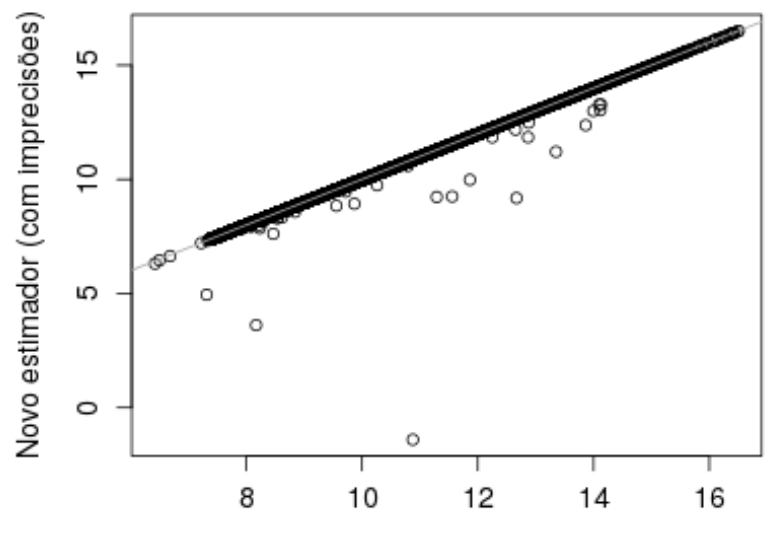

Estimador convencional (b) Diferença entre estimadores de $\mathrm{E}[\mathrm{Mi}]$ 45010 pontos

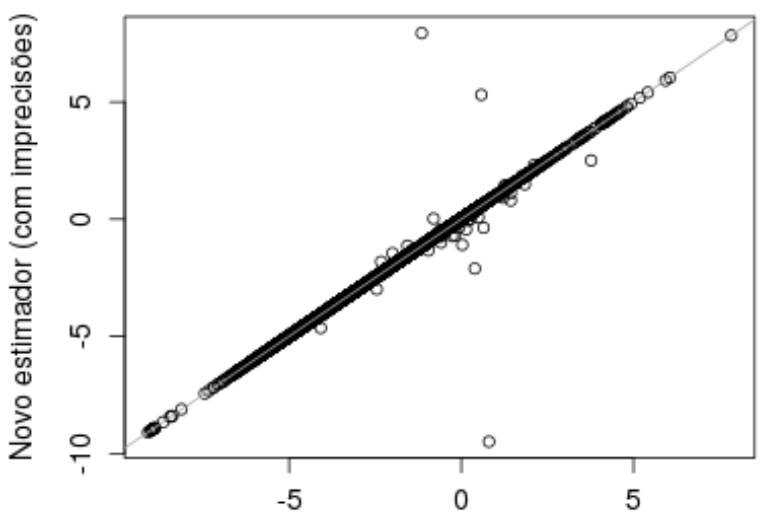

Estimador convencional

Figura 3.3: Gráficos mostrando a relação entre os dois estimadores vistos para as médias de $A_{i}$, em (a), e de $M_{i}$, em (b). Lâmina de microarranjos com identificação 251485069614_1_4, onde foi hibridizada uma amostra de estômago com metaplasia grau II.

(a) M-A plot usando estimadores convencionais para a média - $\mathbf{4 5 0 1 5}$ pontos

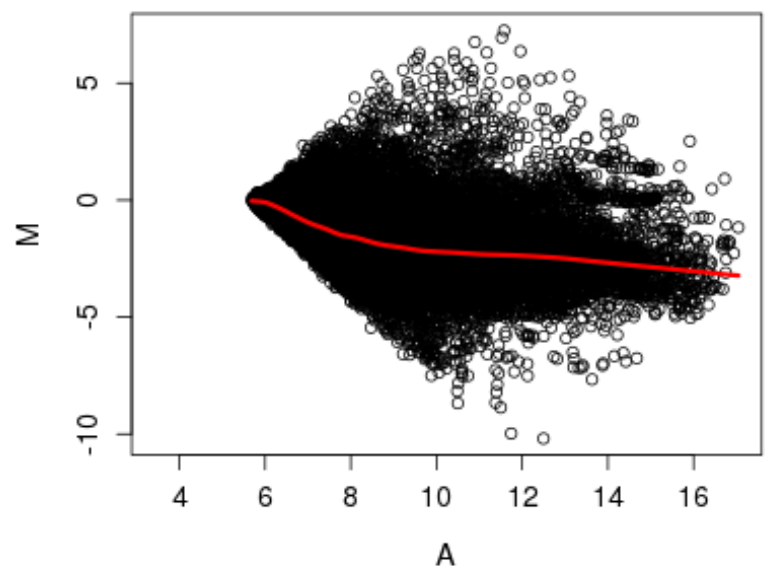

(b) M-A plot usando novos estimadores para a média - $\mathbf{4 5 0 1 5}$ pontos

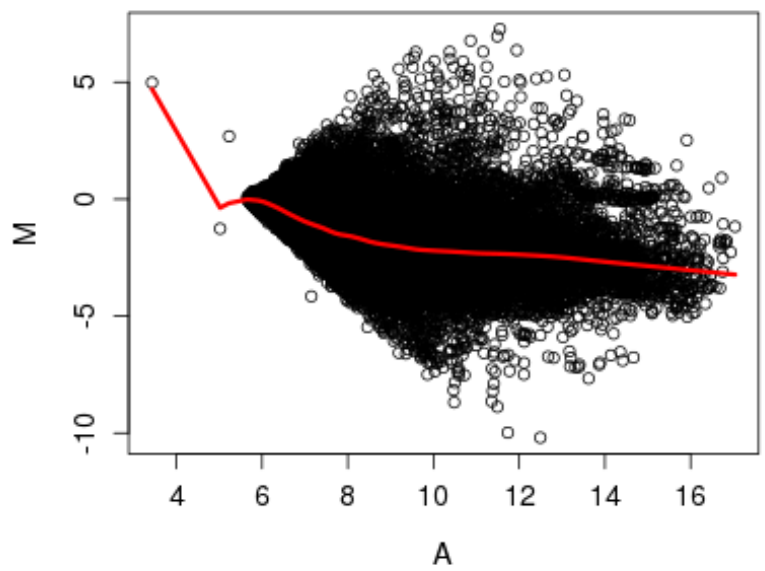

Figura 3.4: Gráficos $M-A$ com (a) médias obtidas pelos estimadores $\hat{A}_{i}$ e $\hat{M}_{i}$, que descartam a imprecisão das medidas, e com (b) médias obtidas pelos estimadores $\bar{A}_{i}$ e $\bar{M}_{i}$, que consideram as imprecisões das medidas. Lâmina de microarranjos com identificação 251485069514_1_2, onde foi hibridizada uma amostra de estômago com metaplasia grau II.

$$
I_{M_{i}} \doteq\left(\bar{M}_{i}-c \hat{\sigma}\left(M_{i}\right), \bar{M}_{i}+c \hat{\sigma}\left(M_{i}\right)\right)
$$

em que $c$ é o quantil da distribuição normal correspondente ao nível de confiança $\alpha$ desejado. Assim, para uma confiança de $95 \%$, basta usarmos $c=1,96$.

Podemos fazer o mesmo para a variável $A_{i}$. Assim, o intervalo que contém a média de $A_{i}$, com uma confiança determinada pelo quantil $c$ da distribuição normal, é:

$$
I_{A_{i}} \doteq\left(\bar{A}_{i}-c \hat{\sigma}\left(A_{i}\right), \bar{A}_{i}+c \hat{\sigma}\left(A_{i}\right)\right)
$$

Mostraremos, nas seções 3.3.3 e 3.3.4, como podemos obter estimativas para $\operatorname{Var}\left(M_{i}\right)$ e a $\operatorname{Var}\left(A_{i}\right)$, que denotamos por $\hat{\sigma}^{2}\left(M_{i}\right)$ e $\hat{\sigma}^{2}\left(A_{i}\right)$. Tomando as raízes quadradas desses estimadores, teremos os estimadores dos desvios padrões necessários para determinarmos esses intervalos. 
(a) Valores de $M$ usando estimadores convencionais para a média - $\mathbf{4 5 0 1 5}$ pontos

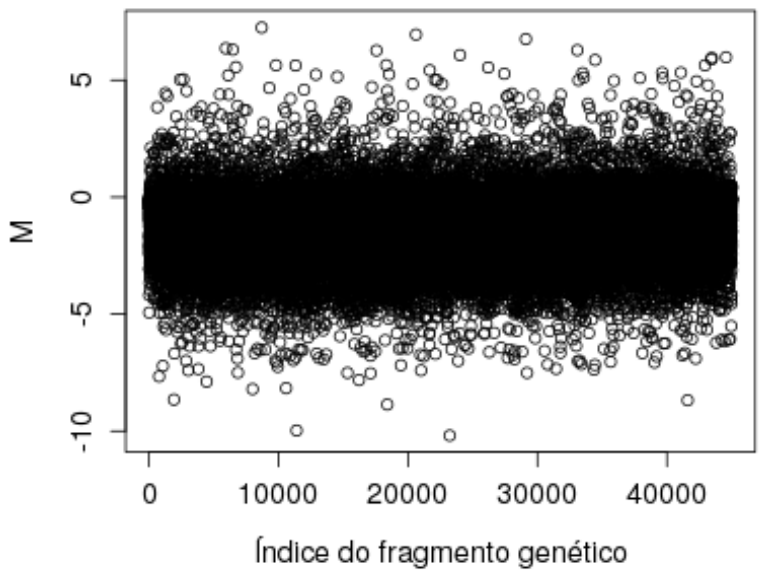

(b) Valores de $M$ usando novos estimadores para a média - 45015 pontos

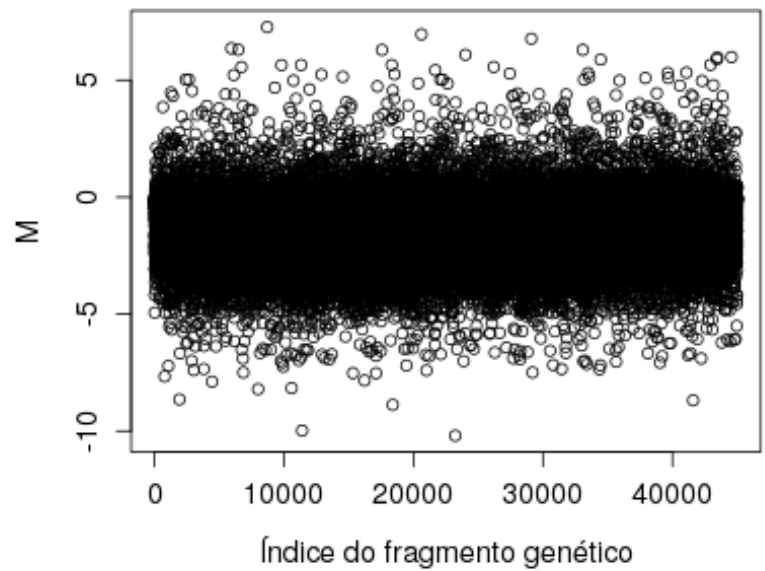

Figura 3.5: Gráficos, em relação ao indices dos fragmentos genético, dos valores das médias de $M$ (a) obtidas pelo estimador $\hat{M}_{i}$, que descarta a imprecisão das medidas, e (b) obtidas pelo estimador $\bar{M}_{i}$, que considera as imprecisões das medidas. Lâmina de microarranjos com identificação 251485069514_1_2, onde foi hibridizada uma amostra de estômago com metaplasia grau II.

(a) Diferença entre estimadores de $\mathrm{E}[\mathrm{Ai}]$ 45015 pontos

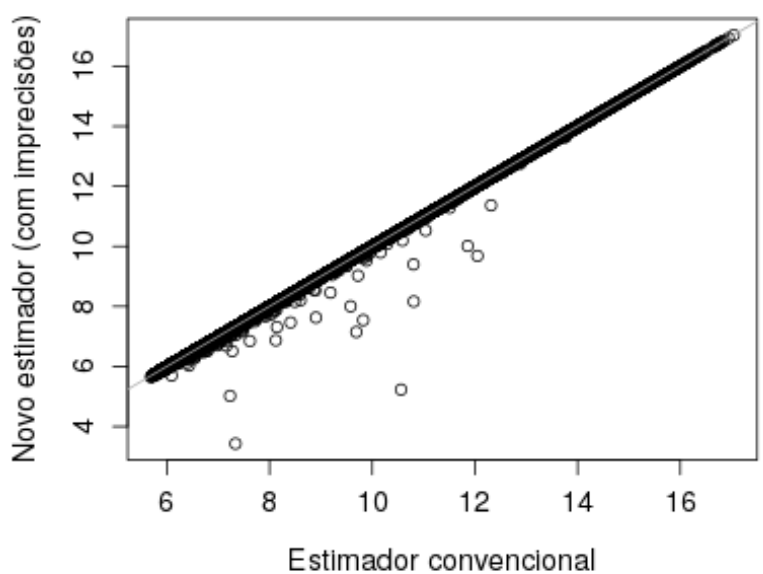

(b) Diferença entre estimadores de $\mathrm{E}[\mathrm{Mi}]$ 45015 pontos

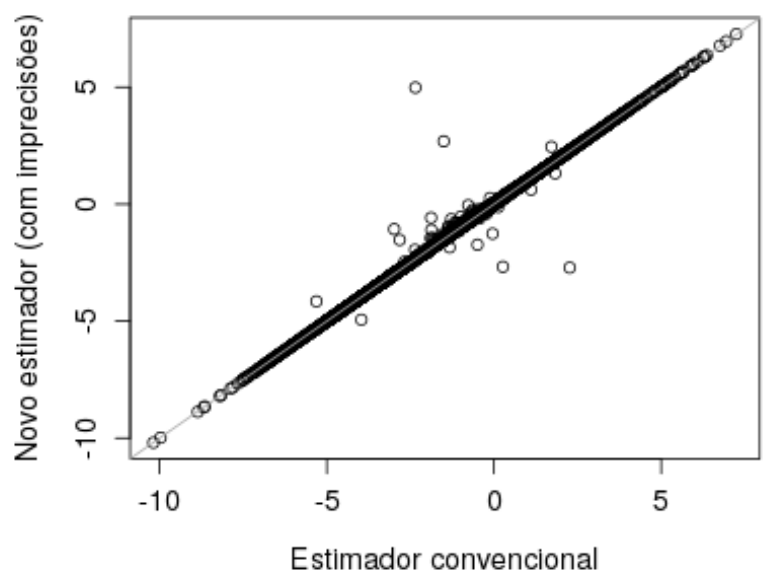

Figura 3.6: Gráficos mostrando a relação entre os dois estimadores vistos para as médias de $A_{i}$, em (a), e de $M_{i}$, em (b). Lâmina de microarranjos com identificação 251485069514_1_2, onde foi hibridizada uma amostra de estômago com metaplasia grau II.

Na figura 3.7, podemos observar um exemplo de gráfico $M$ - $A$, onde está ressaltado o intervalo que inclui as médias de $M_{i}$ com uma confiança de $95 \%$. É possível ver que as imprecisões das medidas são maiores quando a intensidade média é baixa. Isso pode ser observado também pelos gráficos da figura 3.8

Com os dados dessa mesma lâmina de microarranjos, ilustramos na figura 3.9 o gráfico dos tamanhos dos intervalos de confiança, tanto para as médias de $A_{i}$, quanto para as médias $M_{i}$, em relação aos índices dos fragmentos genéticos. Podemos observar que, para essa lâmina, a imprecisão da medida parece também estar relacionada com a localização do fragmento genético.

Os intervalos de confiança nos mostram quais são os fragmentos genéticos cujas medidas possuem maior imprecisão e como essas imprecisões podem estar associadas com a localização na lâmina e com as intensidades médias das medidas.

Podemos ver outros exemplos desses gráficos que ressaltam os intervalos de confiança, obtidos 


\section{M-A plot usando novos estimadores para a média - 45010 pontos}

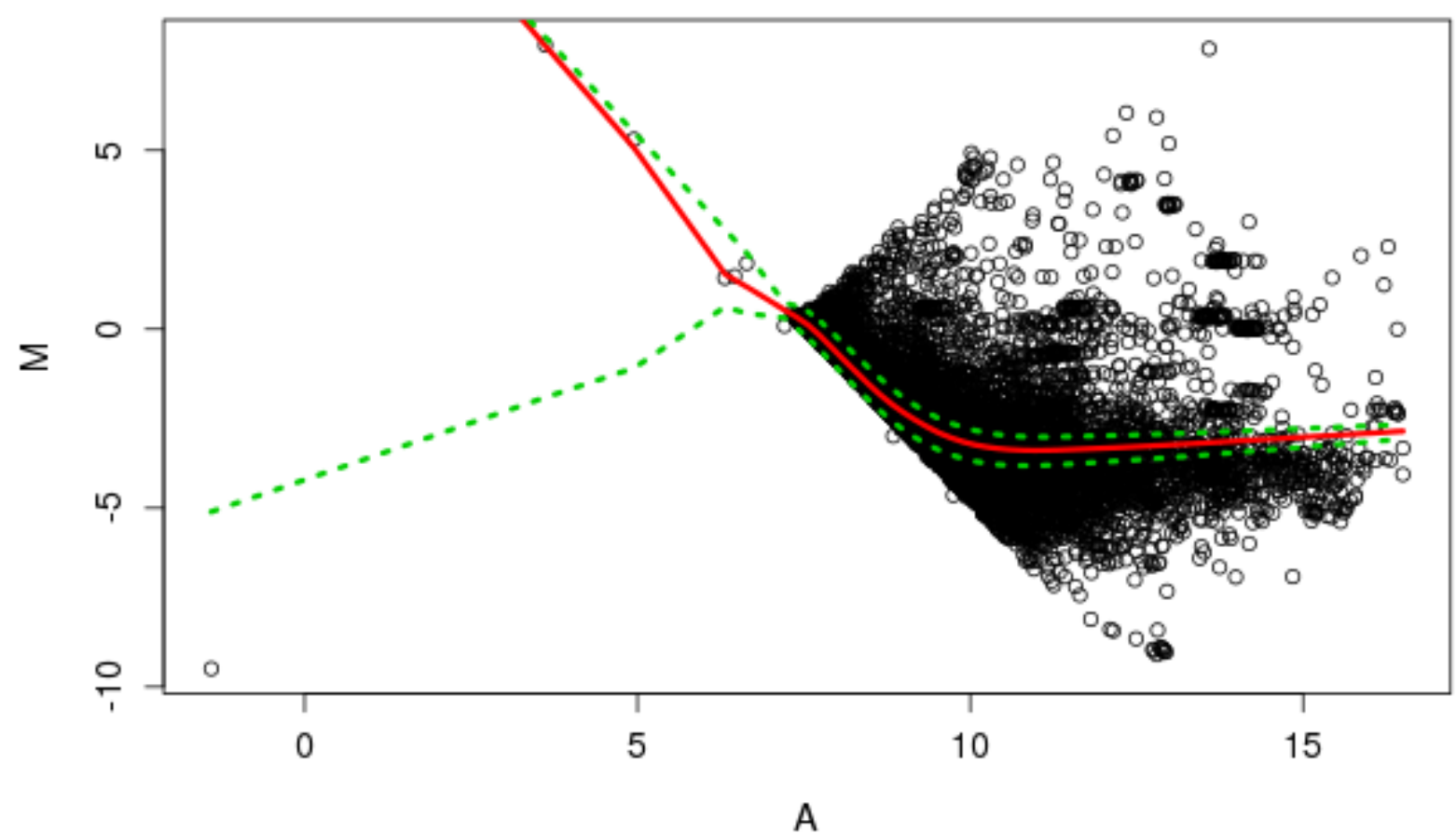

Figura 3.7: Gráfico $M-A$ ressaltando o intervalo que inclui as médias de $M_{i}$ com uma confiança de $95 \%$. Lâmina de microarranjos com identificação 251485069614_1_4, onde foi hibridizada uma amostra de estômago com metaplasia grau II.

(a) Tamanhos dos I.C para a média de Mi em relação a Mi - 45010 pontos

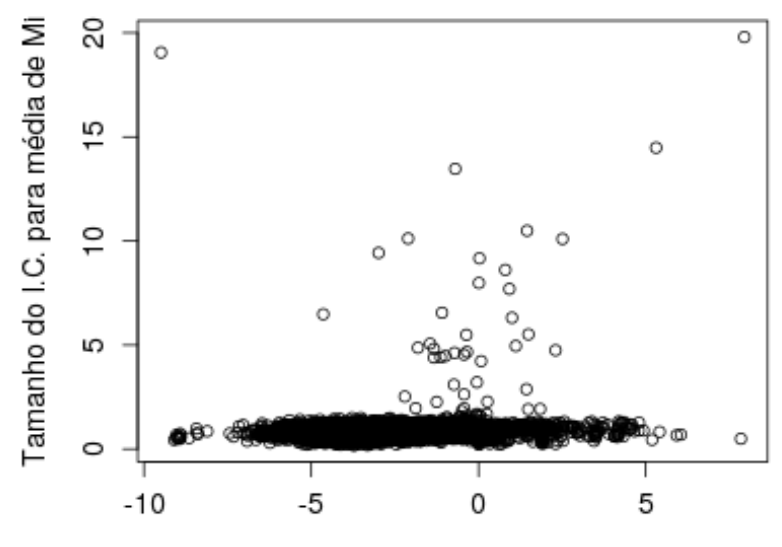

Média estimada de Mi (com imprecisőes) (a) Tamanhos dos I.C para a média de Ai em relação a $\mathrm{Ai}$ - 45010 pontos

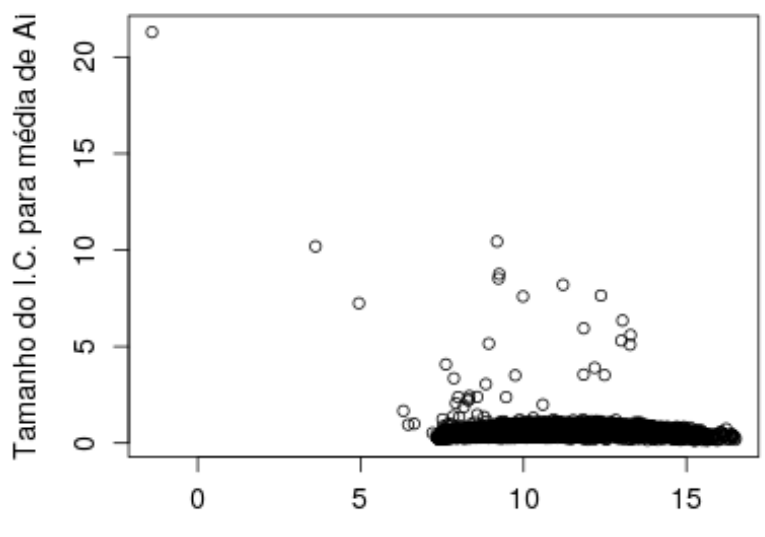

Média estimada de $\mathrm{Al}$ (com imprecisőes)

Figura 3.8: Tamanho do intervalo de confiança em relação à média estimada para $M_{i}$ (a) e para $A_{i}$ (b). Lâmina de microarranjos com identificação 251485069614_1_4, onde foi hibridizada uma amostra de estômago com metaplasia grau II.

com dados de uma outra lâmina de microarranjos, nas figuras 3.10, 3.11 e 3.12. 
(a) Tamanhos dos intervalos de confiança para a média de $\mathrm{Mi} \mathbf{- 4 5 0 1 0}$ pontos

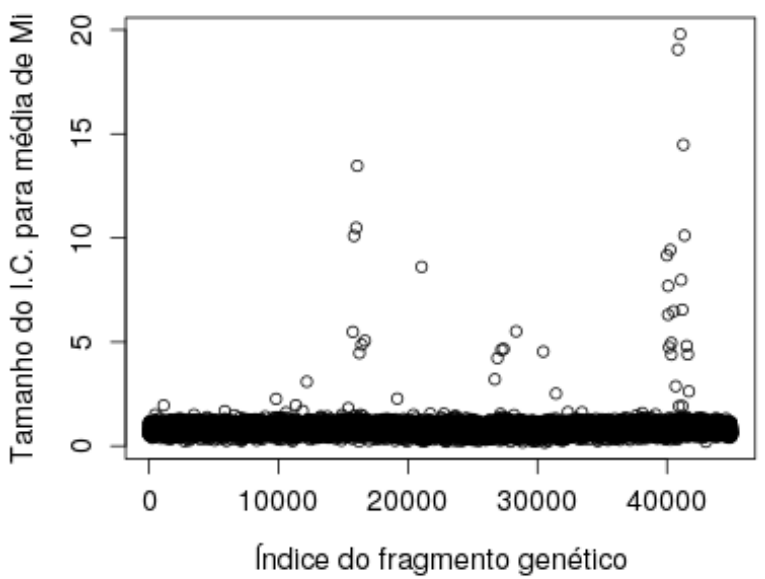

(b) Tamanhos dos intervalos de confiança para a média de $\mathrm{Ai}-\mathbf{4 5 0 1 0}$ pontos

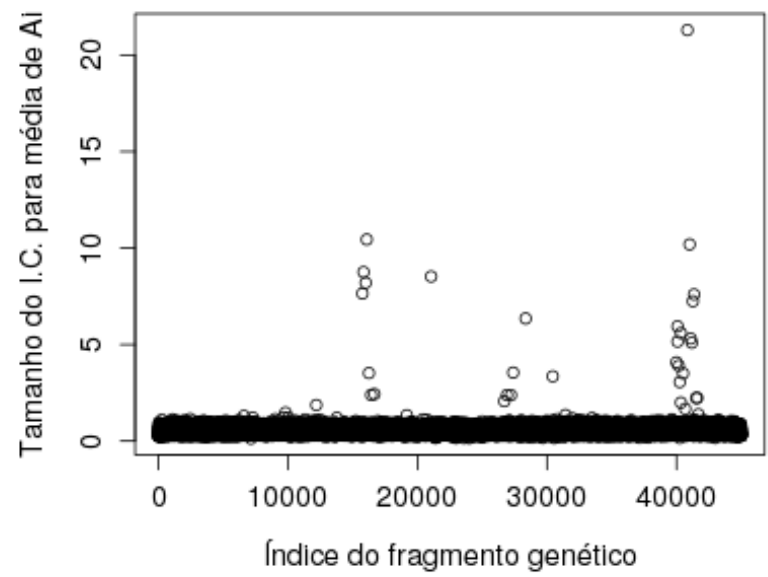

Figura 3.9: Tamanhos dos intervalos de confiança, tanto para as médias de $A_{i}(a)$, quanto para as médias de $M_{i}$ (b), em relação aos indices dos fragmentos genéticos representados nessa lâmina de microarranjos. Lâmina de microarranjos com identificação 251485069614_1_4, onde foi hibridizada uma amostra de estômago com metaplasia grau II.

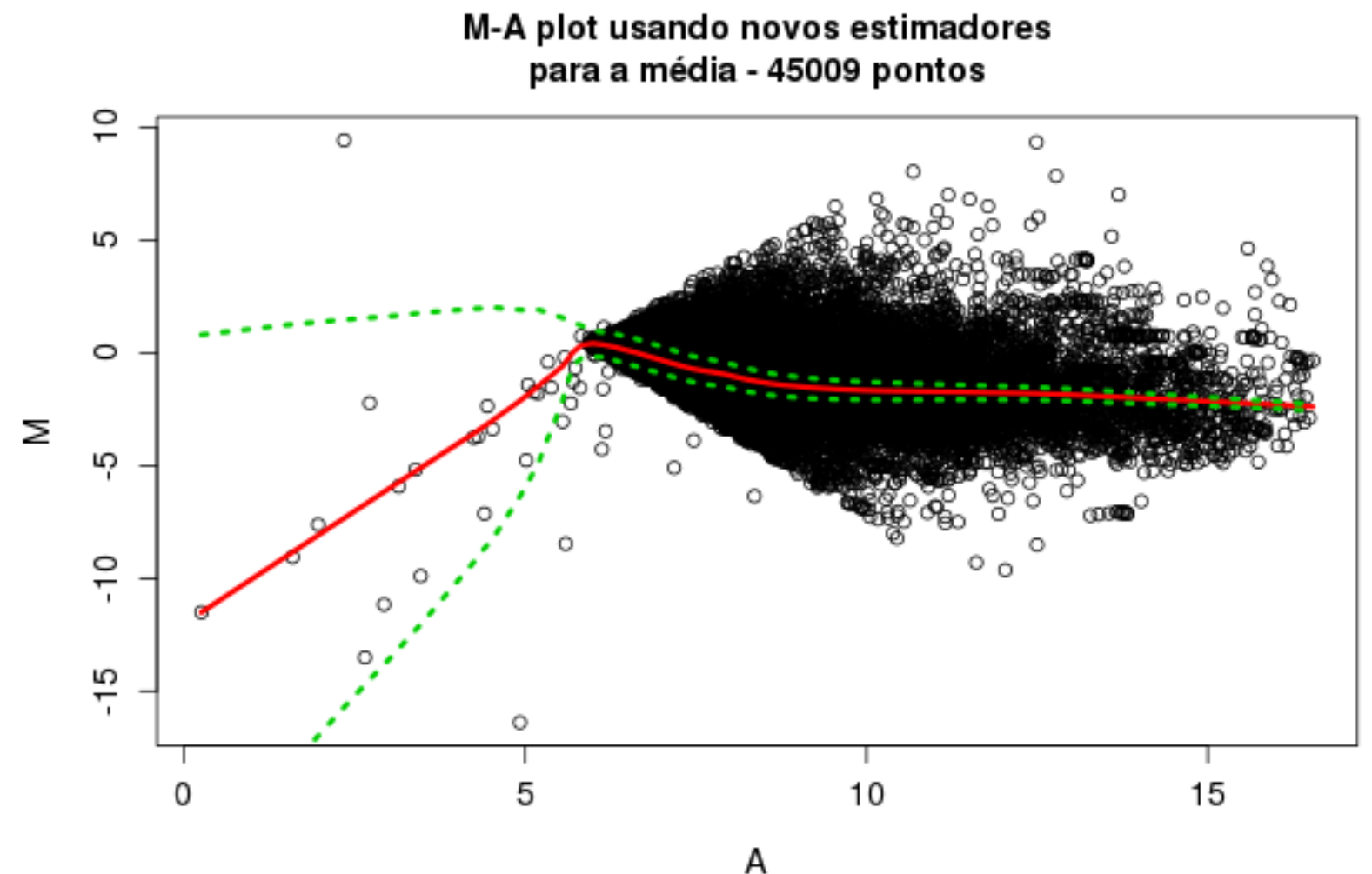

Figura 3.10: Gráfico $M-A$ ressaltando o intervalo que inclui as médias de $M_{i}$ com uma confiança de 95\%. Lâmina de microarranjos com identificação 251485069395_1_1, onde foi hibridizada uma amostra de estômago saudável.

\subsection{Estimação da média e da variância por expansão de Taylor}

Das definições das variáveis $M_{i}(2.1)$ e $A_{i}(2.3)$, vemos que elas são funções das variáveis $R_{i}$ e $G_{i}$.

Assim, podemos obter estatísticas dessas variáveis a partir da expansão de Taylor das funções 
(a) Tamanhos dos I.C para a média de Mi em relação a $\mathrm{Mi}-\mathbf{4 5 0 0 9}$ pontos

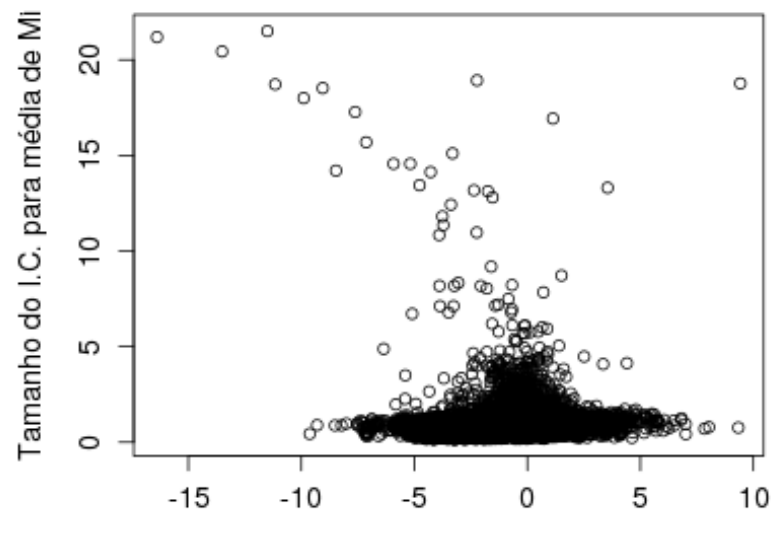

Média estimada de Mi (com imprecisōes) (a) Tamanhos dos I.C para a média de Ai em relação a $\mathrm{Ai}$ - 45009 pontos

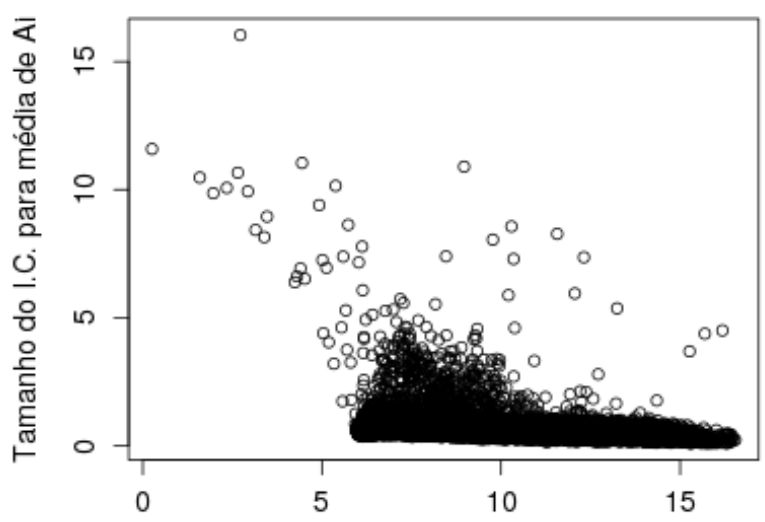

Média estimada de $\mathrm{Al}$ (com imprecisőes)

Figura 3.11: Tamanho do intervalo de confiança em relação à média estimada para $M_{i}$ (a) e para $A_{i}$ (b). Lâmina de microarranjos com identificação 251485069395_1_1, onde foi hibridizada uma amostra de estômago saudável.

(a) Tamanhos dos intervalos de confiança para a média de $\mathrm{Mi}-45009$ pontos

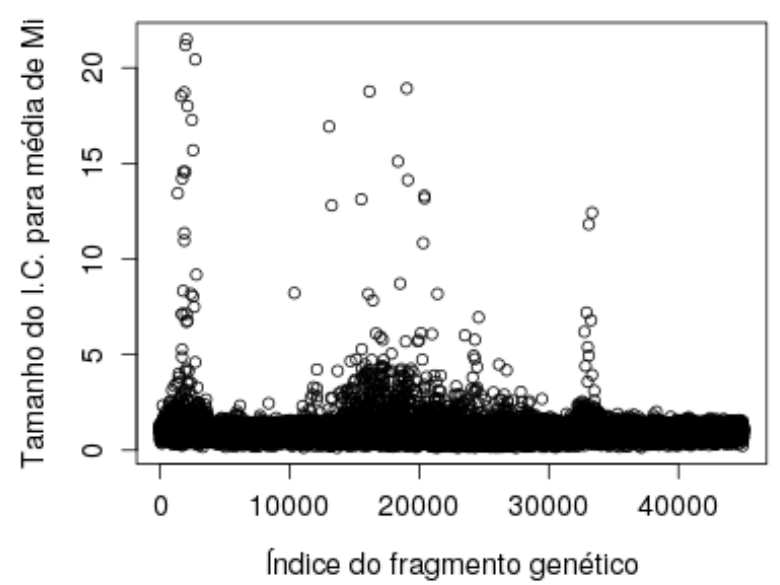

(b) Tamanhos dos intervalos de confiança para a média de $\mathrm{Ai}-\mathbf{4 5 0 0 9}$ pontos

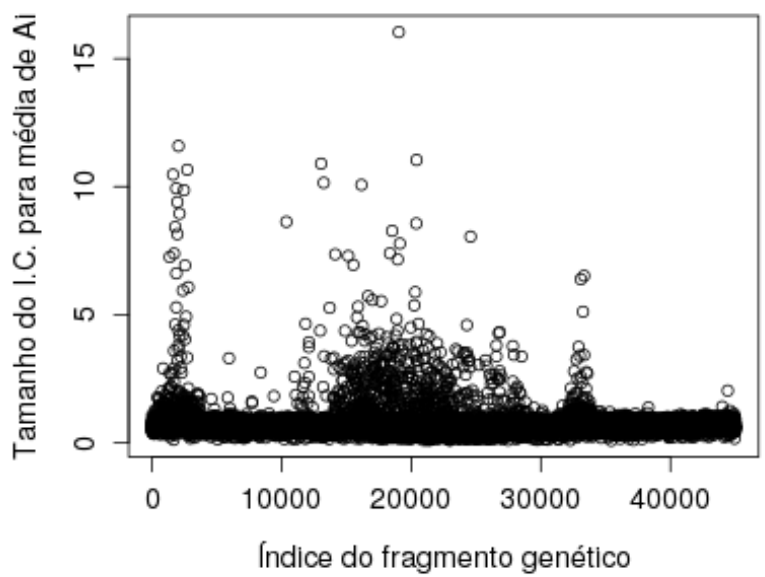

Figura 3.12: Tamanhos dos intervalos de confiança, tanto para as médias de $A_{i}$ (a), quanto para as médias de $M_{i}(b)$, em relação aos indices dos fragmentos genéticos representados nessa lâmina de microarranjos. Lâmina de microarranjos com identificação 251485069395_1_1, onde foi hibridizada uma amostra de estômago saudável.

que as definem.

Como estamos interessados na esperança e na variância das variáveis $M_{i}$ e $A_{i}$, precisamos obter as expressões que determinam as aproximações dessas estatísticas para uma variável determinada por uma função de duas variáveis, $f\left(R_{i}, G_{i}\right)$. Faremos isso a partir da expansão de Taylor de segunda ordem de $f$.

Sendo $f\left(R_{i}, G_{i}\right)$, uma função de duas variáveis aleatórias, $R_{i}$ e $G_{i}$, a expansão de Taylor de segunda ordem de $f$ ao redor do ponto $\left(\mathbb{E}\left(R_{i}\right), \mathbb{E}\left(G_{i}\right)\right)$ é dada por: 


$$
\begin{aligned}
f\left(R_{i}, G_{i}\right) \approx f\left(\mathbb{E}\left(R_{i}\right), \mathbb{E}\left(G_{i}\right)\right)+\frac{\partial f}{\partial R_{i}}\left(\mathbb{E}\left(R_{i}\right), \mathbb{E}\left(G_{i}\right)\right)\left(R_{i}-\mathbb{E}\left(R_{i}\right)\right)+\frac{\partial f}{\partial G_{i}}\left(\mathbb{E}\left(R_{i}\right), \mathbb{E}\left(G_{i}\right)\right)\left(G_{i}-\mathbb{E}\left(G_{i}\right)\right)+ \\
\frac{1}{2}\left(\frac{\partial^{2} f}{\partial R_{i}^{2}}\left(\mathbb{E}\left(R_{i}\right), \mathbb{E}\left(G_{i}\right)\right)\left(R_{i}-\mathbb{E}\left(R_{i}\right)\right)^{2}+2 \frac{\partial^{2} f}{\partial R_{i} \partial G_{i}}\left(\mathbb{E}\left(R_{i}\right), \mathbb{E}\left(G_{i}\right)\right)\right. \\
{\left.\left[\left(R_{i}-\mathbb{E}\left(R_{i}\right)\right)\left(G_{i}-\mathbb{E}\left(G_{i}\right)\right)\right]+\frac{\partial^{2} f}{\partial G_{i}^{2}}\left(\mathbb{E}\left(R_{i}\right), \mathbb{E}\left(G_{i}\right)\right)\left(G_{i}-\mathbb{E}\left(G_{i}\right)\right)^{2}\right) . }
\end{aligned}
$$

\subsubsection{Estimação de $\mathbb{E}\left(f\left(R_{i}, G_{i}\right)\right)$ :}

Podemos obter uma aproximação de segunda ordem de $\mathbb{E}\left(f\left(R_{i}, G_{i}\right)\right)$ calculando a esperança dos termos da expansão segunda ordem de Taylor de $f$, obtidos em (3.3).

Pela linearidade da esperança, basta aplicá-la nos termos dessa expansão:

$$
\begin{aligned}
\left.\mathbb{E}\left(f\left(R_{i}, G_{i}\right)\right) \approx \mathbb{E}\left[f\left(\mathbb{E}\left(R_{i}\right), \mathbb{E}\left(G_{i}\right)\right)\right)\right]+\frac{\partial f}{\partial R_{i}}\left(\mathbb{E}\left(R_{i}\right), \mathbb{E}\left(G_{i}\right)\right) \mathbb{E}\left(R_{i}-\mathbb{E}\left(R_{i}\right)\right)+ \\
\frac{\partial f}{\partial G_{i}}\left(\mathbb{E}\left(R_{i}\right), \mathbb{E}\left(G_{i}\right)\right) \mathbb{E}\left(G_{i}-\mathbb{E}\left(G_{i}\right)\right)+\frac{1}{2}\left(\frac{\partial^{2} f}{\partial R_{i}^{2}}\left(\mathbb{E}\left(R_{i}\right), \mathbb{E}\left(G_{i}\right)\right) \mathbb{E}\left[\left(R_{i}-\mathbb{E}\left(R_{i}\right)\right)^{2}\right]+\right. \\
2 \frac{\partial^{2} f}{\partial R_{i} \partial G_{i}}\left(\mathbb{E}\left(R_{i}\right), \mathbb{E}\left(G_{i}\right)\right) \mathbb{E}\left[\left(R_{i}-\mathbb{E}\left(R_{i}\right)\right)\left(G_{i}-\mathbb{E}\left(G_{i}\right)\right)\right]+ \\
\left.\frac{\partial^{2} f}{\partial G_{i}^{2}}\left(\mathbb{E}\left(R_{i}\right), \mathbb{E}\left(G_{i}\right)\right) \mathbb{E}\left[\left(G_{i}-\mathbb{E}\left(G_{i}\right)\right)^{2}\right]\right) .
\end{aligned}
$$

Lembrando que

$$
\begin{aligned}
& \operatorname{Var}\left(R_{i}\right)=\mathbb{E}\left[\left(R_{i}-\mathbb{E}\left(R_{i}\right)\right)^{2}\right] \\
& \operatorname{Var}\left(G_{i}\right)=\mathbb{E}\left[\left(G_{i}-\mathbb{E}\left(G_{i}\right)\right)^{2}\right] \\
& \operatorname{Cov}\left(R_{i}, G_{i}\right)=\mathbb{E}\left[\left(R_{i}-\mathbb{E}\left(R_{i}\right)\right)\left(G_{i}-\mathbb{E}\left(G_{i}\right)\right)\right],
\end{aligned}
$$

conseguimos simplificar a expressão, resultando na seguinte aproximação da esperança de $f$ :

$$
\begin{aligned}
\mathbb{E}\left(f\left(R_{i}, G_{i}\right)\right) \approx f\left(\mathbb{E}\left(R_{i}\right), \mathbb{E}\left(G_{i}\right)\right)+\frac{1}{2}\left(\frac{\partial^{2} f}{\partial R_{i}^{2}}\left(\mathbb{E}\left(R_{i}\right), \mathbb{E}\left(G_{i}\right)\right) \operatorname{Var}\left(R_{i}\right)+\right. \\
\left.2 \frac{\partial^{2} f}{\partial R_{i} \partial G_{i}}\left(\mathbb{E}\left(R_{i}\right), \mathbb{E}\left(G_{i}\right)\right) \operatorname{Cov}\left(R_{i}, G_{i}\right)+\frac{\partial^{2} f}{\partial G_{i}^{2}}\left(\mathbb{E}\left(R_{i}\right), \mathbb{E}\left(G_{i}\right)\right) \operatorname{Var}\left(G_{i}\right)\right) .
\end{aligned}
$$

\subsubsection{Estimação de $\operatorname{Var}\left(f\left(R_{i}, G_{i}\right)\right)$ :}

Uma estimativa de $\operatorname{Var}\left(f\left(R_{i}, G_{i}\right)\right)$ pode ser dada a partir da expansão de Taylor de primeira ordem da variância de $f\left(R_{i}, G_{i}\right)$. Não usaremos o termo de segunda ordem pois aparecerão estatísticas que geralmente são desconhecidas como, por exemplo, $\operatorname{Var}\left(R_{i}^{2}\right)$.

Assim, temos: 


$$
\begin{aligned}
\operatorname{Var}\left(f\left(R_{i}, G_{i}\right)\right) \approx \operatorname{Var}( & f\left(\mathbb{E}\left(R_{i}\right), \mathbb{E}\left(G_{i}\right)\right)+\left(\frac{\partial f}{\partial R_{i}}\left(\mathbb{E}\left(R_{i}\right), \mathbb{E}\left(G_{i}\right)\right)\right)^{2} \operatorname{Var}\left(R_{i}-\mathbb{E}\left(R_{i}\right)\right)+ \\
& \left(\frac{\partial f}{\partial G_{i}}\left(\mathbb{E}\left(R_{i}\right), \mathbb{E}\left(G_{i}\right)\right)\right)^{2} \operatorname{Var}\left(G_{i}-\mathbb{E}\left(G_{i}\right)\right)+ \\
& 2\left(\frac{\partial f}{\partial R_{i}}\left(\mathbb{E}\left(R_{i}\right), \mathbb{E}\left(G_{i}\right)\right)\right)\left(\frac{\partial f}{\partial G_{i}}\left(\mathbb{E}\left(R_{i}\right), \mathbb{E}\left(G_{i}\right)\right)\right) \operatorname{Cov}\left(R_{i}, G_{i}\right) .
\end{aligned}
$$

Simplificando um pouco mais a expressão, obtemos a seguinte aproximação da variância de $f$ :

$$
\begin{array}{r}
\operatorname{Var}\left(f\left(R_{i}, G_{i}\right)\right) \approx\left(\frac{\partial f}{\partial R_{i}}\left(\mathbb{E}\left(R_{i}\right), \mathbb{E}\left(G_{i}\right)\right)\right)^{2} \operatorname{Var}\left(R_{i}\right)+\left(\frac{\partial f}{\partial G_{i}}\left(\mathbb{E}\left(R_{i}\right), \mathbb{E}\left(G_{i}\right)\right)\right)^{2} \operatorname{Var}\left(G_{i}\right)+ \\
2\left(\frac{\partial f}{\partial R_{i}}\left(\mathbb{E}\left(R_{i}\right), \mathbb{E}\left(G_{i}\right)\right)\right)\left(\frac{\partial f}{\partial G_{i}}\left(\mathbb{E}\left(R_{i}\right), \mathbb{E}\left(G_{i}\right)\right)\right) \operatorname{Cov}\left(R_{i}, G_{i}\right) .
\end{array}
$$

\subsubsection{Estimação de $\mathbb{E}\left(M_{i}\right)$ e $\operatorname{Var}\left(M_{i}\right)$}

Podemos aproximar $\mathbb{E}\left(M_{i}\right)=\mathbb{E}\left(\log _{2}\left(R_{i}\right)-\log _{2}\left(G_{i}\right)\right)$, obtendo a esperança de uma expansão de segunda ordem de Taylor da função

$$
f\left(R_{i}, G_{i}\right) \doteq \log _{2}\left(R_{i}\right)-\log _{2}\left(G_{i}\right)
$$

ao redor do ponto $\left(\mathbb{E}\left(R_{i}\right), \mathbb{E}\left(G_{i}\right)\right)$.

Para isso, podemos utilizar o resultado obtido na equação (3.4), que nos fornece uma expressão para essa aproximação da esperança, dada uma função $f$ de duas variáveis.

Precisamos, então, calcular as derivadas de primeira e segunda ordem da função $f$, em relação às duas variáveis, $R_{i}$ e $G_{i}$.

Os resultados são mostrados a seguir:

$$
\begin{aligned}
& \frac{\partial f}{\partial R_{i}}=\frac{1}{R_{i} \ln (2)} ; \quad \frac{\partial f}{\partial G_{i}}=-\frac{1}{G_{i} \ln (2)} ; \\
& \frac{\partial^{2} f}{\partial R_{i}^{2}}=-\frac{1}{R_{i}^{2} \ln (2)} ; \quad \frac{\partial^{2} f}{\partial G_{i}^{2}}=\frac{1}{G_{i}^{2} \ln (2)} ; \quad \frac{\partial^{2} f}{\partial R_{i} \partial G_{i}}=0 .
\end{aligned}
$$

Substituindo os valores dessas derivadas na equação (3.4), temos:

$$
\begin{aligned}
\mathbb{E}\left(M_{i}\right) & =\mathbb{E}\left(\log _{2}\left(R_{i}\right)-\log _{2}\left(G_{i}\right)\right) \\
& \approx \log _{2}\left(\mathbb{E}\left(R_{i}\right)\right)-\log _{2}\left(\mathbb{E}\left(G_{i}\right)\right)+\frac{1}{2}\left(-\frac{\operatorname{Var}\left(R_{i}\right)}{\ln (2) \mathbb{E}^{2}\left(R_{i}\right)}+\frac{\operatorname{Var}\left(G_{i}\right)}{\ln (2) \mathbb{E}^{2}\left(G_{i}\right)}\right) \\
& =\log _{2}\left(\mathbb{E}\left(R_{i}\right)\right)-\log _{2}\left(\mathbb{E}\left(G_{i}\right)\right)+\frac{1}{2 \ln (2)}\left(-\frac{\operatorname{Var}\left(R_{i}\right)}{\mathbb{E}^{2}\left(R_{i}\right)}+\frac{\operatorname{Var}\left(G_{i}\right)}{\mathbb{E}^{2}\left(G_{i}\right)}\right) .
\end{aligned}
$$

Podemos utilizar as médias amostrais $\bar{R}_{i}$ e $\bar{G}_{i}$ e as variâncias amostrais, $\hat{\operatorname{Var}}\left(R_{i}\right)$ e $\hat{\operatorname{Var}}\left(G_{i}\right)$, das intensidades dos píxeis, respectivamente, do canal da amostra de teste e do canal a amostra de referência, todas disponibilizadas pelo programa de análise das imagens dos microarranjos.

Com essas estatísticas, concluímos o estimador da esperança de $M_{i}$, que é dado por

$$
\bar{M}_{i} \doteq \log _{2}\left(\bar{R}_{i}\right)-\log _{2}\left(\bar{G}_{i}\right)+\frac{1}{2 \ln (2)}\left(-\frac{\hat{\operatorname{Var}}\left(R_{i}\right)}{\bar{R}_{i}^{2}}+\frac{\hat{\operatorname{Var}}\left(G_{i}\right)}{\bar{G}_{i}^{2}}\right),
$$

assumindo que $\bar{R}_{i}$ e $\bar{G}_{i}$ sejam diferentes de zero.

Podemos observar, com isso, que 


$$
\bar{M}_{i}=\hat{M}_{i}+\frac{1}{2 \ln (2)}\left(-\frac{\hat{\operatorname{Var}}\left(R_{i}\right)}{\bar{R}_{i}^{2}}+\frac{\hat{\operatorname{Var}}\left(G_{i}\right)}{\bar{G}_{i}^{2}}\right) .
$$

Ou seja, a abordagem original, que define $\hat{M}_{i}$, é uma aproximação de $\mathbb{E}\left(M_{i}\right)$ obtida a partir do primeiro termo da expansão de Taylor de $f$ apenas, que é o valor da função $f$ no ponto $\left(\mathbb{E}\left(R_{i}\right), \mathbb{E}\left(G_{i}\right)\right)$. Nessa abordagem, medidas de mesma intensidade média, mas com variância diferente, são representadas pelo mesmo valor. Já com a aproximação dada por $\bar{M}_{i}$, que não descarta a informação de que alguns dados são mais imprecisos que outros, essas medidas seriam diferenciadas.

Além disso, observando a expressão $\bar{M}_{i}$, vemos que a diferença entre os estimadores de $\mathbb{E}\left(M_{i}\right)$ aumenta conforme a diferença entre os seguintes termos aumenta:

$$
\frac{\hat{\operatorname{Var}}\left(R_{i}\right)}{\bar{R}_{i}^{2}} \text { e } \frac{\hat{\operatorname{Var}}\left(G_{i}\right)}{\bar{G}_{i}^{2}}
$$

A partir do resultado obtido na equação (3.5) e usando novamente os valores das derivadas calculados em (3.6), podemos obter uma aproximação $\operatorname{Var}\left(M_{i}\right)$.

Como $M_{i}$ é descrito pela função $f\left(R_{i}, G_{i}\right)=\log _{2}\left(R_{i}\right)-\log _{2}\left(G_{i}\right)$, essa estimativa será obtida a partir da expansão de Taylor de primeira ordem da função $f$ ao redor do ponto $\left(\mathbb{E}\left(R_{i}\right), \mathbb{E}\left(G_{i}\right)\right)$.

Assim, substituindo os valores das derivadas na equação (3.5), obtemos:

$$
\begin{aligned}
\operatorname{Var}\left(M_{i}\right)=\operatorname{Var}\left(\log _{2}\left(\frac{R_{i}}{G_{i}}\right)\right) & \approx\left(\frac{1}{\ln (2) \mathbb{E}\left(R_{i}\right)}\right)^{2} \operatorname{Var}\left(R_{i}\right)+\left(-\frac{1}{\ln (2) \mathbb{E}\left(G_{i}\right)}\right)^{2} \operatorname{Var}\left(G_{i}\right)+ \\
& =\frac{1}{\ln ^{2}(2)}\left(\frac{1}{\ln (2) \mathbb{E}\left(R_{i}\right)}\right)\left(-\frac{1}{\ln (2) \mathbb{E}\left(G_{i}\right)}\right) \operatorname{Cov}\left(R_{i}, G_{i}\right) \\
\mathbb{E}^{2}\left(R_{i}\right) & \left.\frac{\operatorname{Var}\left(G_{i}\right)}{\mathbb{E}^{2}\left(G_{i}\right)}-2 \frac{\operatorname{Cov}\left(R_{i}, G_{i}\right)}{\mathbb{E}\left(R_{i}\right) \mathbb{E}\left(G_{i}\right)}\right)
\end{aligned}
$$

Usando novamente as estatísticas já disponibilizadas pelo programa de análise das imagens dos microarranjos e assumindo que $\bar{R}_{i}$ e $\bar{G}_{i}$ são diferentes de zero, definimos a estimativa:

$$
\hat{\operatorname{Var}}\left(M_{i}\right)=\hat{\sigma}^{2}\left(M_{i}\right) \doteq \frac{1}{\ln ^{2}(2)}\left(\frac{\hat{\operatorname{Var}}\left(R_{i}\right)}{\bar{R}_{i}^{2}}+\frac{\hat{\operatorname{Var}}\left(G_{i}\right)}{\bar{G}_{i}^{2}}-2 \frac{\hat{\operatorname{Cov}}\left(R_{i}, G_{i}\right)}{\bar{R}_{i} \bar{G}_{i}}\right) .
$$

\subsubsection{Estimação de $\mathbb{E}\left(A_{i}\right)$ e $\operatorname{Var}\left(A_{i}\right)$}

De forma semelhante à estimação de $\mathbb{E}\left(M_{i}\right)$ e de $\operatorname{Var}\left(M_{i}\right)$, vista na seção 3.3.3, podemos aproximar $\mathbb{E}\left(A_{i}\right)$ e $\operatorname{Var}\left(A_{i}\right)$ utilizando agora para representar a variável $A_{i}$ a função

$$
f\left(R_{i}, G_{i}\right) \doteq \frac{\log _{2}\left(R_{i}\right)+\log _{2}\left(G_{i}\right)}{2} .
$$

Assim, para utilizarmos a expressão da esperança aproximada obtida na equação (3.4), precisamos obter as derivadas de primeira e segunda ordem da função $f$.

Com essas derivadas obtidas,

$$
\begin{aligned}
& \frac{\partial f}{\partial R_{i}}=\frac{1}{2 \ln (2) R_{i}} ; \quad \frac{\partial f}{\partial G_{i}}=\frac{1}{2 \ln (2) G_{i}} ; \\
& \frac{\partial^{2} f}{\partial R_{i}^{2}}=-\frac{1}{2 \ln (2) R_{i}^{2}} ; \quad \frac{\partial^{2} f}{\partial G_{i}^{2}}=-\frac{1}{2 \ln (2) G_{i}^{2}} ; \quad \frac{\partial^{2} f}{\partial R_{i} \partial G_{i}}=0,
\end{aligned}
$$

determinamos a seguinte estimativa de $\mathbb{E}\left(A_{i}\right)$ : 


$$
\begin{aligned}
\mathbb{E}\left(A_{i}\right) & \approx \frac{1}{2}\left(\log _{2}\left(\mathbb{E}\left(R_{i}\right)\right)+\log _{2}\left(\mathbb{E}\left(G_{i}\right)\right)\right)+\frac{1}{2}\left(-\frac{\operatorname{Var}\left(R_{i}\right)}{2 \ln (2) \mathbb{E}^{2}\left(R_{i}\right)}-\frac{\operatorname{Var}\left(G_{i}\right)}{2 \ln (2) \mathbb{E}^{2}\left(G_{i}\right)}\right) \\
& =\frac{1}{2}\left(\log _{2}\left(\mathbb{E}\left(R_{i}\right)\right)+\log _{2}\left(\mathbb{E}\left(G_{i}\right)\right)\right)-\frac{1}{4 \ln (2)}\left(\frac{\operatorname{Var}\left(R_{i}\right)}{\mathbb{E}^{2}\left(R_{i}\right)}+\frac{\operatorname{Var}\left(G_{i}\right)}{\mathbb{E}^{2}\left(G_{i}\right)}\right) .
\end{aligned}
$$

A partir das estatísticas disponíveis pelo programa de análise das imagens de microarranjos e assumindo que $\bar{R}_{i}$ e $\bar{G}_{i}$ são diferentes de zero, definimos o estimador para a esperança de $A_{i}$ :

$$
\bar{A}_{i} \doteq \frac{1}{2}\left(\log _{2}\left(\bar{R}_{i}\right)+\log _{2}\left(\bar{G}_{i}\right)\right)-\frac{1}{4 \ln (2)}\left(\frac{\hat{\operatorname{Var}}\left(R_{i}\right)}{\bar{R}_{i}^{2}}+\frac{\hat{\operatorname{Var}}\left(G_{i}\right)}{\bar{G}_{i}^{2}}\right) .
$$

Novamente, vemos que a medida $\hat{A}_{i}$ é uma aproximação de $\mathbb{E}\left(A_{i}\right)$ dada apenas pelo valor da função $f$ no ponto $\left(\mathbb{E}\left(R_{i}\right), \mathbb{E}\left(G_{i}\right)\right)$. A medida que estamos sugerindo, $\bar{A}_{i}$, é uma aproximação melhor, já que é determinada tanto pelos termos de primeira quanto os de segunda ordem da expansão de Taylor. Ou seja, temos que

$$
\bar{A}_{i}=\hat{A}_{i}-\frac{1}{4 \ln (2)}\left(\frac{\hat{\operatorname{Var}}\left(R_{i}\right)}{\bar{R}_{i}^{2}}+\frac{\hat{\operatorname{Var}}\left(G_{i}\right)}{\bar{G}_{i}^{2}}\right) .
$$

Observando a expressão de $\bar{A}_{i}$, vemos que ocorrerá diferença entre as estimativas $\hat{A}_{i}$ e $\bar{A}_{i}$ de $\mathbb{E}\left(A_{i}\right)$, se a seguinte soma não for nula:

$$
\frac{\hat{\operatorname{Var}}\left(R_{i}\right)}{\bar{R}_{i}^{2}}+\frac{\hat{\operatorname{Var}}\left(G_{i}\right)}{\bar{G}_{i}^{2}}
$$

Como temos apenas valores positivos nessas razões, qualquer variância nas medidas fará com que haja uma diferença nos estimadores.

A estimativa da $\operatorname{Var}\left(A_{i}\right)$ pode ser obtida utilizando a expressão (3.5) com a função $f$ que descreve $A_{i}$. Teremos, com ela, uma aproximação da variância obtida a partir da expansão de Taylor de primeira ordem da função $f$ ao redor do ponto $\left(\mathbb{E}\left(R_{i}\right), \mathbb{E}\left(G_{i}\right)\right)$.

Utilizando novamente os valores das derivadas calculados em (3.9), obtemos a seguinte aproximação de $\operatorname{Var}\left(A_{i}\right)$ :

$$
\begin{aligned}
\operatorname{Var}\left(A_{i}\right) & \approx\left(\frac{1}{2 \ln (2) \mathbb{E}\left(R_{i}\right)}\right)^{2} \operatorname{Var}\left(R_{i}\right)+\left(\frac{1}{2 \ln (2) \mathbb{E}\left(G_{i}\right)}\right)^{2} \operatorname{Var}\left(G_{i}\right)+ \\
& =\frac{1}{4 \ln ^{2}(2)}\left(\frac{1}{2 \ln (2) \mathbb{E}\left(R_{i}\right)}\right)\left(\frac{1}{2 \ln (2) \mathbb{E}\left(G_{i}\right)}\right) \operatorname{Cov}\left(R_{i}, G_{i}\right) \\
\mathbb{E}^{2}\left(R_{i}\right) & \left.\frac{\operatorname{Var}\left(G_{i}\right)}{\mathbb{E}^{2}\left(G_{i}\right)}+2 \frac{\operatorname{Cov}\left(R_{i}, G_{i}\right)}{\mathbb{E}\left(R_{i}\right) \mathbb{E}\left(G_{i}\right)}\right) .
\end{aligned}
$$

Novamente, a partir das estatísticas disponibilizadas pelo programa de análise das imagens dos microarranjos e assumindo que $\bar{R}_{i}$ e $\bar{G}_{i}$ são diferentes de zero, podemos definir o estimador da variância de $A_{i}$ por:

$$
\hat{\operatorname{Var}}\left(A_{i}\right)=\hat{\sigma}^{2}\left(A_{i}\right) \doteq \frac{1}{4 \ln ^{2}(2)}\left(\frac{\hat{\operatorname{Var}}\left(R_{i}\right)}{\bar{R}_{i}^{2}}+\frac{\hat{\operatorname{Var}}\left(G_{i}\right)}{\bar{G}_{i}^{2}}+2 \frac{\hat{\operatorname{Cov}}\left(R_{i}, G_{i}\right)}{\bar{R}_{i} \bar{G}_{i}}\right)
$$

\subsection{Consideração das imprecisões nas medidas com correção de fundo}

Como vimos, nos novos estimadores tanto da média como da variância das variáveis $A_{i}$ e $M_{i}$, aparecem pelo menos algum dos seguintes termos: 


$$
\frac{\hat{\operatorname{Var}}\left(R_{i}\right)}{\bar{R}_{i}^{2}} ; \quad \frac{\hat{\operatorname{Var}}\left(G_{i}\right)}{\bar{G}_{i}^{2}} \quad \text { e } \frac{\hat{\operatorname{Cov}}\left(R_{i}, G_{i}\right)}{\bar{R}_{i} \bar{G}_{i}} .
$$

Durante a estimação, para que não ocorra divisão por zero, é esperado que as variáveis não possuam média próxima de zero.

No entanto, como os métodos de correção do fundo procuram remover o efeito causado pelas intensidades ao redor dos locais genéticos, os valores corrigidos para $\bar{R}_{i}$ e $\bar{G}_{i}$, denotados por $\bar{R}_{c_{i}}$ e $\bar{G}_{c_{i}}$, podem ficar muito próximos do zero.

Nos modelos mais comuns de correção do fundo, é suposto que o sinal verdadeiro é obtido pelo sinal observado subtraído por alguma constante estimada.

O método mais simples, por exemplo, consiste de simplesmente subtrair uma medida de tendência central da variável que descreve as intensidades dos fundos.

Já o método normexp, que vimos ser o melhor método para correção do fundo em microarranjos de dois canais segundo Ritchie et al. (2007), também supõe que o sinal verdadeiro é dado a partir da subtração do sinal observado por uma constante associada ao fundo. Porém, essa constante não é apenas a média das intensidades observadas dos fundos. Ela inclui uma quantidade estimada referente às intensidades ambientes não explicadas pelas intensidades já observadas.

Assumindo, assim, que a correção é feita pela subtração de alguma constante, podemos fazer a suposição de que a variância do sinal corrigido é a mesma que a do sinal original. Ou seja, a correção do fundo apenas provocou um deslocamento da média da distribuição das variáveis $R_{i}$ e $G_{i}$.

Para que não tenhamos problemas com os valores de intensidade muito próximos do zero após a correção do fundo, podemos utilizar o recurso de deslocamento (offset) utilizado no método de correção do fundo por normexp e descrito na seção 2.4.2.

Esse deslocamento é feito para todos os locais genéticos e, como já comentamos, torna os valores $A_{i}$ sempre positivos e mais afastados do zero. Além disso, o deslocamento também reduz a variabilidade entre as medidas $M_{i}$ de uma lâmina de microarranjos. Como apontado também na seção 2.4.2, um valor de deslocamento comumente utilizado na literatura é $k=50$. 


\section{Capítulo 4}

\section{Lowess para dados de expressões gênicas}

Como vimos na seção 2.5.1, o método mais comum para a estimação do viés causado por fatores sistemáticos, dentre eles a diferença nas características dos corante usados na identificação das amostras simultaneamente hibridizadas nas lâminas de microarranjos, é o lowess. Com essa estimativa, podemos reduzir o viés em um processo conhecido como normalização intra-lâmina. $\mathrm{O}$ processo da correção do viés, incluindo a aplicação do lowess em cada lâmina do experimento de microarranjos, será visto em detalhes no capítulo 5 .

Devido a algumas características particulares dos dados de expressões gênicas, o método lowess, em sua forma padrão, pode não nos fornecer a melhor estimativa da superfície de regressão.

Neste capítulo, analisaremos essas características dos dados e mostraremos tanto os cuidados que devem ser tomados na escolha dos parâmetros do lowess como algumas adaptações que devem ser feitas para que a estimação da superfície de regressão seja adequada.

O lowess é um método de regressão polinomial local ponderada robusto à outliers. Assim, na seção 4.1, iniciaremos um estudo sobre o método, apresentando os conceitos que fundamentam a regressão polinomial local.

Em seguida, na seção 4.2, veremos como é feita a adaptação do método quando temos dados heteroscedásticos (a variância das expressões dos genes de uma mesma lâmina não é constante), umas das principais características dos dados de expressões gênicas.

O uso de regressão ponderada é o artifício clássico utilizado quando os dados são heteroscedásticos. Porém, na estimação da superfície de lowess, em sua forma padrão, a ponderação dos resíduos do modelo local é feita apenas para determinar a vizinhança de suavização, assumindo que os erros são homoscedásticos. Como essa suposição não é válida para muitos dados de expressões gênicas, apresentamos o modelo que considera essa variabilidade, permitindo uma estimação mais honesta da superfície de suavização. Mostramos ainda na seção 4.2 como são ajustados esses pesos de forma a tornar o método robusto à outliers.

Para concluir este capítulo, mostramos na seção 4.4 algumas propriedades estatísticas do modelo e analisamos, na seção 4.5, como cada parâmetro influencia na qualidade da estimação da superfície de regressão.

Este capítulo nos fornece a base teórica necessária para a aplicação do método lowess durante o processo de normalização e para o entendimento do algoritmo de seleção dos parâmetros que propomos no capítulo 5 .

\subsection{Conceitos preliminares}

Os conceitos apresentados nesta seção são importantes para uma compreensão básica da regressão local. A partir deles, poderemos facilmente entender os conceitos do método lowess e, assim, utilizá-los de forma rigorosa no processo de normalização. 


\subsubsection{Por que regressão local?}

Muitas vezes, temos interesse em saber como uma variável depende de uma ou mais variáveis. Os métodos de suavização tentam construir uma relação funcional entre as diferentes medidas.

O método de regressão local é interessante pois nos permite estimar superfícies de regressão sem a necessidade de escolher uma classe paramétrica.

Consideremos $X: \Omega_{x} \mapsto \mathbb{R}^{p}$ um vetor de variáveis aleatórias independentes e suponhamos que $Y: \Omega_{y} \mapsto \mathbb{R}$ é uma variável aleatória que depende de $X$.

Podemos, então, fazer $n$ observações de $Y$, juntamente com as respectivas observações de $X=$ $\left(X_{1}, \ldots, X_{p}\right)$, e formar a seguinte base de dados:

$$
\left\{Y_{i}, X_{i 1}, \ldots, X_{i p}\right\}_{i=1}^{n},
$$

em que $X_{i}=\left(X_{i 1}, \ldots, X_{i p}\right)$ é o $i$-ésimo vetor de observações das variáveis preditoras e $Y_{i}$ é a variável resposta correspondente.

Uma técnica clássica é a regressão linear, onde consideramos que os dados são gerados a partir do modelo

$$
Y=\mu(X)+\varepsilon=\beta_{0}+\beta_{1} X_{1}+\beta_{2} X_{2}+\ldots+\beta_{p} X_{p}+\varepsilon,
$$

em que $\varepsilon$ é um erro aleatório não observável e $\beta_{0}, \beta_{1}, \ldots, \beta_{p}$ são coeficientes constantes.

Esses coeficientes são estimados de forma com que as observações da base de dados satisfaçam o modelo, ou seja:

$$
Y_{i}=\beta_{0}+\beta_{1} X_{i 1}+\beta_{2} X_{i 2}+\ldots+\beta_{p} X_{i p}+\varepsilon_{i}, \quad i=1, \ldots, n .
$$

Nesse caso, os dados que não podem ser explicados por uma função afim são considerados ruídos. A resposta média é dada, nesse caso, da seguinte forma:

$$
\mathbb{E}\left(Y \mid X=x=\left(x_{1}, \ldots, x_{p}\right)\right)=\mu(x)=\beta_{0}+\beta_{1} x_{1}+\beta_{2} x_{2}+\ldots+\beta_{p} x_{p} .
$$

Portanto, se a interação entre as variáveis tiver um comportamento não linear ou bastante peculiar, a regressão linear produzirá uma estimativa com um grande viés.

Para resolvermos esse problema, uma alternativa é aumentar o número de parâmetros da regressão polinomial, ou seja, aumentar o grau do polinômio a ser ajustado. No entanto, polinômios não são adequados para ajustar superfícies com diferentes graus de suavização em diferentes pontos, além de serem muito sensíveis a outliers. Em Fan e Gijbels (1996), podemos ver vários exemplos nos quais polinômios de grau até quatro falham em ajustar os pontos de forma visualmente satisfatória e os polinômios de grau maior são numericamente instáveis.

O que poderíamos fazer é, então, ajustar funções mais complexas, como o que ocorre nos métodos de regressão por splines e por séries ortogonais. Poderíamos também, em vez de tentar resolver um único problema paramétrico difícil, usar uma abordagem local.

Nesse caso, para cada ponto que queremos conhecer sua superfície de suavização, ajustamos em sua vizinhança um função simples, como um polinômio de grau baixo. Com isso, não precisamos mais escolher antecipadamente a família paramétrica da função $\mu(x)$ e passamos a apenas supor que na vizinhança do ponto de interesse a função é suave. Isso permite estimarmos qualquer função suave, o que abrange uma classe muito maior em relação à classe de funções paramétricas. Esse método é conhecido como regressão polinomial local.

\subsubsection{O modelo local}

No método de regressão polinomial local, precisamos aplicar o método para cada ponto que quisermos conhecer sua superfície de suavização. Assim, a função $\mu(x)$ não é determinada globalmente por uma família paramétrica, como ocorre no modelo de regressão paramétrico, mas sim pelas vizinhanças e pela família paramétrica da superfície ajustada localmente. 
Descrevendo o método de regressão local mais formalmente, temos que a superfície que descreve um dado ponto $x_{0}$ é dada por:

$$
Y_{i}=\mu_{x_{0}}\left(X_{i}\right)+\sigma\left(X_{i}\right) \varepsilon_{i}, \quad \forall X_{i} \in \mathcal{V}_{x_{0}}
$$

em que:

- $\mathcal{V}_{x_{0}}$ é vizinhança de $x_{0}$;

- $\mu_{x_{0}}$ é uma função que associa valores da vizinhança $\mathcal{V}_{x_{0}}$ a valores reais, definida por: $\mu_{x_{0}}(x)=$ $\mathbb{E}(Y \mid X=x)$

- $\varepsilon_{i}$ representa o erro aleatório ou a variabilidade das fontes que não estão inclusas em $X_{i}$; e

- $\sigma\left(X_{i}\right)$ é uma função das variáveis independentes $X_{i}$ que permite a modelagem da heteroscedasticidade dos erros.

Assim, $\mu_{x_{0}}(x)$ é a função média da variável $Y$ apenas para valores de $X$ que pertencem à $\mathcal{V}_{x_{0}}$. Por isso, enfatizamos a dependência de $x_{0}$ na determinação dos parâmetros desse polinômio.

Nesse modelo, fazemos a suposição de que os erros são independentes, com média 0 e, para simplificação dos cálculos, $\operatorname{Var}\left(\varepsilon_{i}\right)=1$.

Com isso, temos que

$$
\operatorname{Var}\left(Y \mid X=X_{i}\right)=\operatorname{Var}\left(\sigma\left(X_{i}\right) \varepsilon_{i}\right)=\sigma^{2}\left(X_{i}\right) \operatorname{Var}\left(\varepsilon_{i}\right)=\sigma^{2}\left(X_{i}\right) .
$$

Não são feitas suposições globais sobre a função $\mu$, apenas supomos que ele é aproximável localmente por um polinômio.

De forma mais precisa, se quisermos que $\mu_{x_{0}}$ seja estimada por um polinômio de ordem $q$ em uma vizinhança de raio $h\left(x_{0}\right)$, definimos

$$
\mathcal{V}_{x_{0}} \doteq B_{h\left(x_{0}\right)}\left(x_{0}\right)
$$

isto é, a bola aberta de raio $h\left(x_{0}\right)$ centrada em $x_{0}$, e supomos que $\mu_{x_{0}} \in C^{q+1}\left(B_{h\left(x_{0}\right)}\left(x_{0}\right)\right)$, isto é, estamos supondo que a derivada $q+1$ existe e é contínua.

Com isso, podemos determinar a expansão de Taylor de $\mu_{x_{0}}(x)$ em torno de $x_{0}$,

$$
\mu_{x_{0}}(x)=\sum_{|\alpha| \leq q} \frac{\partial^{\alpha} \mu_{x_{0}}\left(x_{0}\right)}{\alpha !}\left(x-x_{0}\right)^{\alpha}+R_{q+1}\left(x, x_{0}\right), \quad x \in B_{h\left(x_{0}\right)}\left(x_{0}\right),
$$

que está representada usando uma notação com multi-índice de dimensão $p$, ou seja,

- $\alpha=\left(\alpha_{1}, \ldots, \alpha_{p}\right) \in \mathbb{Z}_{+}^{p}$;

- $|\alpha|=\alpha_{1}+\ldots+\alpha_{p}$;

- $\alpha !=\alpha_{1} ! \ldots \alpha_{p} !$; e, finalmente, se $x=\left(x_{1}, \ldots, x_{p}\right) \in \mathbb{R}^{p}$, então:

- $x^{\alpha}=x_{1}^{\alpha_{1}} \ldots x_{p}^{\alpha_{p}} ; \mathrm{e}$

- $\partial^{\alpha}=\partial_{x_{1}}^{\alpha_{1}} \ldots \partial_{x_{p}}^{\alpha_{p}}=\frac{\partial^{|\alpha|}}{\partial_{x_{1}}^{\alpha_{1} \ldots} \partial_{x_{p}}^{\alpha_{p}}}$.

Portanto, podemos estimar $\mu_{x_{0}}$ pelo polinômio de Taylor de grau $q$ :

$$
\mu_{x_{0}}(x) \approx \sum_{|\alpha| \leq q} \beta_{\alpha}\left(x_{0}\right)\left(x-x_{0}\right)^{\alpha}, \quad x \in B_{h\left(x_{0}\right)}\left(x_{0}\right)
$$


em que $\beta_{\alpha}\left(x_{0}\right)$ é o coeficiente do polinômio de Taylor de ordem $q$ em $x_{0}$, associado a um dado multi-índice $\alpha$.

No entanto, no conceito de regressão local, $\mu_{x_{0}}(x)$ é estimado apenas para conhecermos o valor da superfície de suavização no ponto $x_{0}$. Assim, precisamos conhecer apenas da estimativa de $\mu_{x_{0}}\left(x_{0}\right)$, que é dada por:

$$
\hat{\mu}_{x_{0}}\left(x_{0}\right)=\sum_{|\alpha| \leq q} \hat{\beta}_{\alpha}\left(x_{0}\right)\left(x_{0}-x_{0}\right)^{\alpha}=\hat{\beta}_{(0, \ldots, 0)}\left(x_{0}\right) .
$$

Podemos determinar o vetor das estimativas dos coeficientes de Taylor, que denotamos por $\left(\hat{\beta}_{\alpha}\right)_{|\alpha| \leq q}\left(x_{0}\right)$, solucionando o problema de mínimos quadrados residuais ponderados.

O uso de pesos no problema de mínimos quadrados permite tanto a determinação da vizinhança de suavização, o que torna a abordagem local, como também permite que a regressão seja feita em observações com variância não constante. A escolha adequada desses pesos será vista com mais detalhes nas próximas seções.

Nesse caso, teremos que $\hat{\beta}_{(0, \ldots, 0)}\left(x_{0}\right)$ é uma combinação linear das observações $Y_{i}$, cujos coeficientes compõem um vetor $l\left(x_{0}\right)$, conhecido como diagrama de pesos. Assim, como apenas esse vetor é dependente de $x_{0}$, podemos escrever a função de suavização global por:

$$
\hat{\mu}(x)=\hat{\beta}_{(0, \ldots, 0)}(x)=\sum_{i=1}^{n} \pi_{i}(l(x)) Y_{i},
$$

em que $\pi_{i}$ é a função projeção na coordenada $i$.

\subsubsection{A vizinhança de suavização}

Um parâmetro crítico na determinação da superfície de suavização associada a um dado ponto $x_{0}$ é o raio da sua vizinhança, mais conhecido como largura da banda (do inglês, bandwidth).

A partir desse parâmetro, determinamos quais observações $X_{i}$ são vizinhas a $x_{0}$ e, portanto, serão utilizadas na estimativa do polinômio local.

Como a vizinhança de $x_{0}$, de largura de banda $h\left(x_{0}\right)$, é definida por $B_{h\left(x_{0}\right)}\left(x_{0}\right)$, temos que o conjunto das observações pertencentes à vizinhança é:

$$
\left\{X_{i}: d\left(X_{i}, x_{0}\right)<h\left(x_{0}\right), \forall i=1, \ldots, n\right\} .
$$

Utilizaremos apenas essas observações para estimarmos a média condicional de $Y$ quando $X$ está restrito à $B_{h\left(x_{0}\right)}\left(x_{0}\right)$.

Portanto, para a escolha da vizinhança, precisamos definir uma função distância $d: \mathbb{R}^{p} \times \mathbb{R}^{p} \rightarrow \mathbb{R}$.

Em problemas de apenas uma dimensão, costumamos definir $d(u, v)=|u-v|$. Mas, em problemas multidimensionais, é possível que as variáveis independentes tenham sido medidas em diferentes escalas. Por isso, devemos primeiro padronizá-las, o que pode ser feito dividindo a observação pelo seu desvio padrão. Depois, podemos aplicar a função distância, que pode ser, por exemplo, a norma euclidiana padronizada. Nesse caso, obtemos a seguinte métrica adaptada:

$$
d(u, v)=\sqrt{\sum_{j=1}^{p}\left(\frac{u_{j}-v_{j}}{\sigma_{j}}\right)^{2}},
$$

em que $\sigma_{j}$ é o parâmetro de escala, dado pelo desvio padrão da variável da $j$-ésima dimensão.

Para muitos problemas, o ideal é termos uma largura de banda adaptativa, ou seja, termos um largura para cada ponto. Assim, para cada ponto $x_{0}$, representamos por $h\left(x_{0}\right)$ a largura de banda ótima. Essa é a melhor abordagem para modelar as características locais. No entanto, na prática, é difícil escolher tal função. 
Por outro lado, poderíamos definir a largura de banda por uma função constante, isto é, $h(x)=h$. Mas essa também não é uma boa abordagem. Se as observações $X_{i}$ seguirem uma distribuição não uniforme, devido à esparsidade dos dados, é possível determinarmos vizinhanças vazias. Isso ocorreria frequentemente em problemas de alta dimensão e nas estimativas associadas a pontos perto das fronteiras ou das regiões das caudas.

A alternativa simples que resolve esse problema da esparsidade é definir a função pelos vizinhos mais próximos (nearest neighbour bandwidth).

Nessa abordagem, $h(x)$ é definida por um parâmetro de suavização $\alpha \in] 0,1]$, de forma que, para $k=\lfloor n \alpha\rfloor$, temos:

$$
h(x) \doteq k \text {-ésima menor distância entre } x \text { e } X_{i}, \quad \text { com } i=1, \ldots, n .
$$

Com essa definição, o parâmetro $\alpha$ determina a porcentagem de pontos da amostra que pertencerá à vizinhança de suavização. Assim, temos uma função de largura de banda adaptativa, mas com a quantidade de observações pertencentes à vizinhança constante.

\subsection{Adaptações para dados heteroscedásticos}

\subsubsection{Detecção de heteroscedasticidade}

Uma das características dos dados de expressões gênicas é a heteroscedasticidade, ou seja, a variância das expressões relativas dos genes (variável $M$ ) de uma mesma lâmina não é constante ao longo da variável independente (variável $A$ ).

Essa característica fica bastante evidente quando esboçamos as medidas de expressões gênicas no gráfico $M$ - $A$, visto na seção 2.3.2. Mesmo após a aplicação de métodos para a remoção do fundo, é comum vermos esses gráficos com os dados dispostos em forma de "leque", ou seja, com uma variabilidade crescente em relação às intensidades de expressões médias. Também é comum vermos dados com uma variabilidade maior para os valores medianos da variável $A$. Alguns exemplos desse gráfico podem ser vistos nas figuras 2.2 e 2.4.

Outra forma de analisarmos graficamente a heteroscedasticidade é esboçando os resíduos absolutos não padronizados, $\left|\hat{\varepsilon}_{i}\right|$, pelos valores ajustados, $\hat{\mu}\left(X_{i}\right)$, ou pelas variáveis preditoras $X_{i}$. No primeiro caso, podemos verificar se a variância dos resíduos é dependente de $\hat{\mu}\left(X_{i}\right)$. No segundo caso, verificamos a dependência da variância em relação a uma ou mais variáveis preditoras. Se os resíduos apresentarem algum padrão especial, ou seja, se não estiverem aleatoriamente distribuídos ao redor do zero, então dizemos que há heteroscedasticidade. Podemos observar um exemplo de dados de expressões gênicas com variância não constante na figura 4.1.

Há alguns testes estatísticos que podem ser feitos para confirmar essa condição nos dados. Quando, por exemplo, os resíduos aumentam, ou diminuem, consistentemente conforme os valores de variável preditora aumentam, podemos fazer o teste Goldfeld-Quandt (Goldfeld e Quandt (1965)). Já quando há uma pequena variância nas observações centrais e uma grande variância nas extremidades, podemos utilizar o teste Glejser (Glejser (1969)). Mais detalhes sobre esses testes podem ser vistos em Berry e Feldman (1985).

No modelo escolhido para a suavização local, dado na equação (4.1), consideramos a possibilidade dos erros não possuírem uma variância constante. Fizemos isso, permitindo que essa variância seja modelada em função das variáveis independentes $X_{i}$, ou seja,

$$
\operatorname{Var}(Y \mid X=x)=\sigma^{2}\left(X_{i}\right) \operatorname{Var}\left(\varepsilon_{i}\right)=\sigma^{2}\left(X_{i}\right) .
$$

Se a heteroscedasticidade não for verificada em nenhum dos gráficos, então podemos considerar um modelo de regressão com erros homoscedásticos, isto é, com $\sigma^{2}\left(X_{i}\right)$ constante. Essa variância pode ser estimada pela equação (4.7).

Quando ocorre heteroscedasticidade, podemos estimar a função de variância a partir da equação dada em (4.6). Nesse caso, se a variância for estimada com a equação (4.7), que supõe homosce- 
dasticidade, as estimativas dos coeficientes da regressão serão maiores do que deveriam, além de, possivelmente, enviesadas.
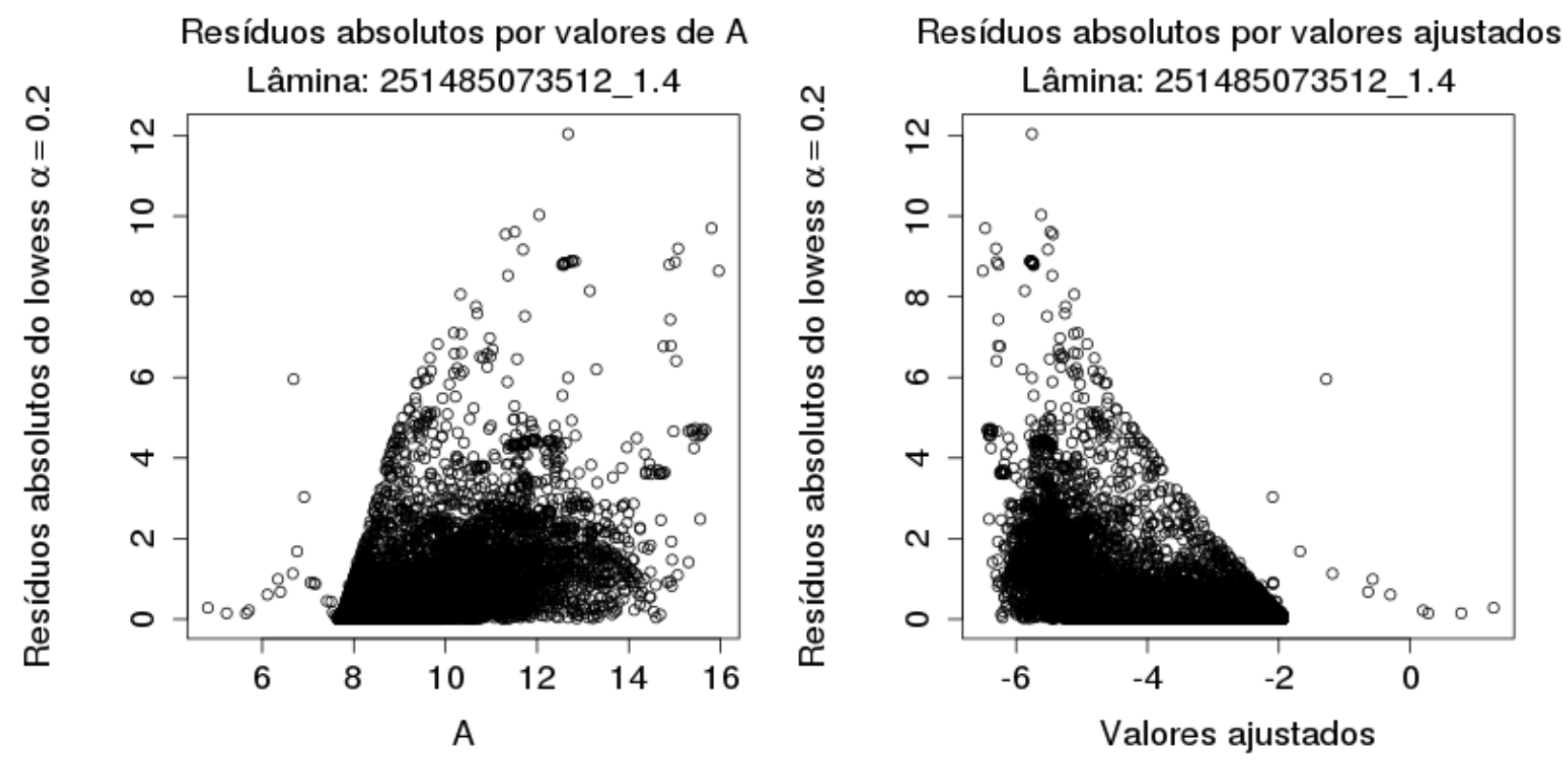

Figura 4.1: Gráfico de diagnóstico da variância das observações $M_{i}$. Vemos que tanto em relação às observações da variável preditora, $A_{i}$, como em relação aos valores ajustados, a variância de $M_{i}$ não é constante, já que os resíduos absolutos não estão aleatoriamente distribuídos.

\subsubsection{Resolução por mínimos quadrados residuais ponderados}

O uso de mínimos quadrados residuais ponderados é necessário, a princípio, para que a abordagem da regressão seja local. Para estimarmos a superfície associada a um dado ponto $x_{0}$, precisamos determinar a vizinhança de suavização. Isso é feito atribuindo um peso maior às observações mais próximas de $x_{O}$ e um peso nulo para aquelas que não devem pertencer à vizinhança.

No entanto, podemos atribuir também mais um conjunto de pesos que penaliza as observações com maior variância no caso dessas não possuírem variância constante. Assim, a solução de mínimos quadrados ponderados nos permite, diferentemente da solução de mínimos quadrados ordinários, encontrar os coeficientes da superfície de suavização das observações $Y_{i}$ mesmo se os erros residuais forem heteroscedásticos e correlacionados.

Como os dados de microarranjos costumam não satisfazer a suposição de homoscedasticidade, o uso desse método torna-se adequado no pré-processamento das medidas de expressão gênica relativas.

Para estimarmos a superfície associada a um dado ponto $x_{0}$, precisaremos determinar, além do grau $q$ do polinômio e da vizinhança do ponto $x_{0}$, uma função $K$ que atribui um peso às observações da vizinhança.

Em geral, queremos que quanto mais próxima uma observação estiver de $x_{0}$, maior é a sua influência no formato da superfície estimada. Isso pode ser alcançado atribuindo um peso maior a essas observações na função objetivo do problema de minimização.

Além disso, como queremos que apenas observações dentro da vizinhança de $x_{0}$ sejam consideradas na estimativa, podemos escolher uma função peso $K$, também conhecida por função Kernel, que atribui peso nulo às observações que distam $h\left(x_{0}\right)$ ou mais de $x_{0}$. Dessa forma, sendo $K$ uma função não negativa e unimodal, podemos definir o peso da observação $X_{i}$ como:

$$
\varphi_{i}=K\left(\frac{d\left(X_{i}, x_{0}\right)}{h\left(x_{0}\right)}\right)
$$


Do modelo de regressão, dado pela equação (4.1), temos que os resíduos são dados por:

$$
\varepsilon_{i}=\frac{Y_{i}-\mu_{x_{0}}\left(X_{i}\right)}{\sigma\left(X_{i}\right)}
$$

Assim, a soma dos resíduos quadrados é dada por:

$$
\sum_{i=1}^{n}\left(\frac{Y_{i}-\mu_{x_{0}}\left(X_{i}\right)}{\sigma\left(X_{i}\right)}\right)^{2}=\sum_{i=1}^{n} \frac{1}{\sigma^{2}\left(X_{i}\right)}\left(Y_{i}-\mu_{x_{0}}\left(X_{i}\right)\right)^{2} .
$$

Com isso, o problema a ser minimizado é:

$$
\sum_{i=1}^{n} \frac{1}{\sigma^{2}\left(X_{i}\right)} \varphi_{i}\left(Y_{i}-\mu_{x_{0}}\left(X_{i}\right)\right)^{2} I\left(\frac{d\left(X_{i}, x_{0}\right)}{h\left(x_{0}\right)} \leq 1\right),
$$

em que a função indicadora $I$ permite que apenas observações $X_{i}$ com distância de no máximo $h\left(x_{0}\right)$ em relação a $x_{0}$ sejam avaliadas no problema.

Devemos observar que no caso homoscedástico, em que temos

$$
\sigma^{2}\left(X_{i}\right)=\sigma^{2} \quad \forall i=1, \ldots n,
$$

e, portanto, temos uma variância de $Y_{i}$ constante,

$$
\operatorname{Var}\left(Y_{i}\right)=\operatorname{Var}\left(\sigma \varepsilon_{i}\right)=\sigma^{2} \operatorname{Var}\left(\varepsilon_{i}\right)=\sigma^{2},
$$

podemos tirar a constante $\sigma^{2}$ do problema de otimização, já que ela não afeta o resultado. Já quando os erros são heteroscedásticos, lembrando que $\operatorname{Var}\left(Y_{i}\right)=\sigma^{2}\left(X_{i}\right)$, temos que o inverso da variância de $Y_{i}$ tem o papel de penalizar as observações com maior variância.

Em vez de usarmos a função indicadora na equação (4.3), podemos alcançar o mesmo objetivo de restrição da vizinhança definindo a função $K(4.2)$, que define os pesos $\varphi_{i}$, por uma função que tenha um suporte compacto contido em $[0,1]$. Dessa forma, a função se encarregará de eliminar as observações não pertencentes à vizinhança atribuindo a elas peso nulo. Nesse caso, podemos simplificar o problema (4.3) para:

$$
\sum_{i=1}^{n} \frac{\varphi_{i}}{\sigma^{2}\left(X_{i}\right)}\left(Y_{i}-\mu_{x_{0}}\left(X_{i}\right)\right)^{2}
$$

A escolha de uma função $K$ com suporte compacto não é obrigatória. Apenas é necessário que ela tenha um decrescimento rápido o suficiente para eliminar o impacto causado por pontos bem distantes de $x_{0}$. No entanto, para simplificarmos o problema, é comum a escolha de uma função $K$ contínua, definida nos reais positivos, com pico em 0 e suporte em $[0,1]$. A escolha mais comum é a função tricubo:

$$
K(u)= \begin{cases}\left(1-|u|^{3}\right)^{3}, & \text { se } 0 \leq u<1 \\ 0, & u \geq 1 .\end{cases}
$$

Como vimos na seção 4.1.2, para determinar $\hat{\mu}_{x_{0}}(x)$ precisamos estimar os coeficientes do polinômio de Taylor de ordem $q$ associado ao nosso ponto de interesse $x_{0}$.

Sendo $\beta \doteq\left(\beta_{\alpha}\right)_{|\alpha| \leq q}$ o vetor desses coeficientes ordenados lexigraficamente, podemos estimá-lo fazendo a minimização da soma ponderada dos quadrados dos resíduos.

Caso os valores de $\sigma\left(X_{i}\right)$, que representam a variância de $Y_{i}$, sejam desconhecidos, é possível utilizar estimativas desses valores. Veremos na seção 4.3 como essa estimação pode ser feita.

A solução desse problema será dada por:

$$
\hat{\beta}\left(x_{0}\right) \doteq\left(\hat{\beta}_{\alpha}\right)_{|\alpha| \leq q}\left(x_{0}\right)=\underset{\beta}{\arg \min } J_{x_{0}}(\beta),
$$


em que a função objetivo $J_{x_{0}}$ é definida por:

$$
J_{x_{0}}(\beta)=\sum_{i=1}^{n} \frac{\varphi_{i}}{\sigma^{2}\left(X_{i}\right)}\left(Y_{i}-\sum_{|\alpha| \leq q} \beta_{\alpha}\left(X_{i}-x_{0}\right)^{\alpha}\right)^{2} .
$$

Podemos ver na seção A.1, que a estimativa local $\hat{\mu}_{x_{0}}$ determinada pela solução do problema de mínimos quadrados ponderados é dada por:

$$
\hat{\mu}_{x_{0}}\left(x_{0}\right)=\hat{\beta}_{(0, \ldots, 0)}\left(x_{0}\right)=\sum_{i=1}^{n} \pi_{i}\left(l\left(x_{0}\right)\right) Y_{i},
$$

em que $\pi_{i}$ é a função projeção na coordenada $i$.

Assim, para qualquer ponto de interesse $x_{0}$, existe um diagrama de pesos $l\left(x_{0}\right) \in R^{n}$ tal que a estimativa no ponto $x_{0}$ é uma combinação linear das observações $Y_{i}$. Além disso, podemos ver também na seção A.1, que ele é expresso por:

$$
l\left(x_{0}\right)^{t} \doteq e_{1}^{t}\left(A^{t} V W A\right)^{-1} A^{t} V W,
$$

em que os valores das matrizes $A$ e $W$ são dependentes do ponto $x_{0}$ e, com a suposição de que os erros são independentes, a matriz $V$ é diagonal e corresponde à inversa da matriz de variância-covariância das observações $Y_{i}$.

Concluímos que, como a dependência de $x_{0}$ está apenas na determinação do diagrama de pesos, podemos escrever a estimativa da função de suavização, para qualquer ponto $x$, da seguinte forma:

$$
\hat{\mu}(x)=\hat{\beta}_{(0, \ldots, 0)}(x)=\sum_{i=1}^{n} \pi_{i}(l(x)) Y_{i} .
$$

\subsubsection{Algoritmo iterativo para robustez à outliers}

O método lowess é uma extensão do método de regressão polinomial local ponderada, agregando um algoritmo que determina pesos $\delta_{i}, i=1, \ldots, n$, que serão multiplicados aos pesos $\frac{\varphi_{i}}{\sigma^{2}\left(X_{i}\right)}$ no problema de mínimos quadrados ponderados de forma a diminuir a influência dos outliers.

Esses pesos são determinados a partir de um algoritmo constituído de um laço que, a cada iteração, estima a superfície de suavização e avalia o tamanho dos resíduos resultantes. Se algum resíduo for grande, o valor do peso associado à essa observação será reduzido.

Mais especificamente, com pode ser visto em Cleveland (1979), se o resíduo for menor que 6 vezes o valor da mediana de todos os resíduos, o peso será ajustado de acordo com a função biquadrada. Se ele for maior, a observação associada será desconsiderada na determinação da estimativa.

Com isso, precisamos de mais um parâmetro para estimar a função $\mu$ em um dado ponto $x_{0}$ : o número $t$ de iterações necessárias para a estimação dos pesos de robustez. Segundo Cleveland (1979), um valor de $t=3$ é adequado para a maioria das situações.

Assim, em cada iteração $k$ do laço do algoritmo, é determinado um conjunto de pesos $\delta_{i}^{(k)}$.

Uma vez que os pesos $\delta_{i}^{(t)}$ foram determinados na t-ésima iteração, definimos $\delta_{i} \doteq \delta_{i}^{(t)}$ e o ajuste local associado ao ponto $x_{0}$ é determinado como antes, mas com pesos $\frac{\delta_{i} \varphi_{i}}{\sigma^{2}\left(X_{i}\right)}$. Ou seja,

$$
\hat{\beta}\left(x_{0}\right) \doteq\left(\hat{\beta}_{\alpha}\right)_{|\alpha| \leq q}\left(x_{0}\right)=\underset{\beta}{\arg \min } J_{x_{0}}(\beta), \forall i=1, \ldots, n,
$$

em que a função objetivo $J_{x_{0}}$ é agora dada por:

$$
J_{x_{0}}(\beta) \approx \sum_{i=1}^{n} \frac{\delta_{i} \varphi_{i}}{\sigma^{2}\left(X_{i}\right)}\left(Y_{i}-\sum_{|\alpha| \leq q} \beta_{\alpha}\left(X_{i}-x_{0}\right)^{\alpha}\right)^{2} .
$$

Como resultado, teremos um diagrama de pesos $l\left(x_{0}, t\right)$, tal que: 


$$
\hat{\mu}_{x_{0}}\left(x_{0}\right)=\sum_{i=1}^{n} \pi_{i}\left(l\left(x_{0}, t\right)\right) Y_{i} .
$$

Se usarmos o mesmo número de iterações para a estimação da superfície em qualquer ponto, podemos deixar implícito o parâmetro $t$ e, assim, a função de suavização, para qualquer ponto $x$ é dada por:

$$
\hat{\mu}(x)=\sum_{i=1}^{n} \pi_{i}(l(x)) Y_{i}
$$

\section{Determinação dos pesos de robustez}

Como vimos, no método lowess, as observações serão ponderadas pelo inverso da variância de $Y_{i}, \frac{1}{\sigma^{2}\left(X_{i}\right)}$, pelos valores $\varphi_{i}$, definidos pela função $W$ e por $\delta_{i}$, os pesos obtidos na $t$-ésima iteração do algoritmo de robustez, isto é, $\delta_{i} \doteq \delta_{i}^{(t)}$.

Em cada iteração $k$ desse algoritmo, com $k=1, \ldots, t$, um conjunto de pesos $\left\{\delta_{i}^{(k)}\right\}_{i=1}^{n}$ é determinado.

Para isso, precisamos das estimativas dos coeficientes $\beta^{(k)}\left(X_{i}\right) \doteq\left(\hat{\beta}_{\alpha}^{(k)}\right)_{|\alpha| \leq q}\left(X_{i}\right)$ do polinômio local de grau $q$, a ser ajustado ao redor de cada observação $X_{i}, i=1, \ldots, n$.

Assim, para cada estimativa $\hat{\mu}^{(k)}\left(X_{i}\right), \operatorname{com} i=1, \ldots, n$, estimamos os seus coeficientes usando a solução do problema:

$$
\hat{\beta}^{(k)}\left(X_{i}\right) \doteq\left(\hat{\beta}_{\alpha}^{(k)}\right)_{|\alpha| \leq q}=\underset{\beta^{(k)}\left(X_{i}\right)}{\arg \min } J_{X_{i}}^{(k)}(\beta), \forall i=1, \ldots, n,
$$

em que a função objetivo $J_{X_{i}}^{(k)}$ é dada por:

$$
J_{X_{i}}^{(k)}\left(\beta^{(k)}\left(X_{i}\right)\right) \doteq \sum_{i=j}^{n} \delta_{i}^{(k)} \frac{\varphi_{i}}{\sigma^{2}\left(X_{i}\right)}\left(Y_{i}-\sum_{|\alpha| \leq q} \beta_{\alpha}^{(k)}\left(X_{i}\right)\left(X_{j}-X_{i}\right)^{\alpha}\right)^{2},
$$

com

$$
\begin{aligned}
\varphi_{i} & =K\left(\frac{d\left(X_{j}, X_{i}\right)}{h\left(X_{i}\right)}\right) ; \mathrm{e} \\
\delta_{i}^{(k)} & = \begin{cases}1, & \text { se } k=0 ; \\
B\left(\frac{\hat{\varepsilon}_{i}^{(k-1)}}{6 \operatorname{Mediana}\left(\left|\hat{\varepsilon}^{(k-1)}\right|\right)}\right), & \text { se } k \geq 1 .\end{cases}
\end{aligned}
$$

Para a definição de $\delta_{i}^{(k)}$, usamos as seguintes notações:

$$
\begin{aligned}
& B(u)= \begin{cases}\left(1-u^{2}\right)^{2}, & \text { se } 0 \leq u<1 ; \\
0, & u \geq 1,\end{cases} \\
& \hat{\varepsilon}_{i}^{(k-1)}=\left(Y_{i}-\hat{\mu}_{X_{i}}^{(k-1)}\left(X_{i}\right)\right), \text { para } i=1, \ldots, n ; \text { e } \\
& \left|\hat{\varepsilon}^{(k-1)}\right|=\left(\left|\hat{\varepsilon}_{1}^{(k-1)}\right|, \ldots,\left|\hat{\varepsilon}_{n}^{(k-1)}\right|\right), \text { para } k \geq 1 .
\end{aligned}
$$

Assim, ao final da $t$-ésima iteração, teremos o conjunto de pesos de robustez $\left\{\delta_{i}^{(t)}\right\}_{i=1}^{n}$ e a matriz de predição da base de dados $L$, cuja $i$-ésima linha é dada pelo diagrama de pesos $l\left(X_{i}, t\right)$. 


\section{A relação entre loess e lowess}

Lowess e loess são ambos métodos de regressão polinomial local ponderada e aparecem muitas vezes associados na literatura, gerando assim algumas confusões e discussões sobre suas definições.

A característica principal que difere ambos os métodos é que apenas o lowess agrega um algoritmo que aumenta a robustez em relação aos outliers.

Lowess (do inglês, LOcal WEighted RegreSSion) foi como ficou conhecido o método de regressão local robusto sugerido por Cleveland (1979). Com o método lowess, ajustamos localmente um polinômio de grau genérico e univariado, e, assim, estimamos a média de observações independentes. No entanto, a principal diferença em relação aos demais métodos de regressão polinomial local é o uso de um algoritmo para aumentar a robustez à outliers. Com eles, os pesos das observações no problema de mínimos quadrados ponderados são ajustados de acordo com os resíduos resultantes.

O método loess, de Cleveland e Devlin (1988), estende o método lowess permitindo que o modelo local seja multivariado. Exceto pelo algoritmo que aumenta a robustez aos outliers, são estabelecidas as mesmas especificações do lowess. Os coeficientes do modelo local no método loess também são obtidos minimizando os quadrados dos resíduos ponderados, logo podemos encontrar superfícies que ajustam observações com erros residuais heteroscedásticos.

Tanto no método lowess como no loess são sugeridas a função tricubo para aumentar o peso das observações mais próximas e a especificação da função de vizinhança por vizinhos mais próximos.

Uma curiosidade é que o nome loess, além de ter sido inspirado no nome em inglês do método, LOcal regrESSion, tem um significado a mais. Em geologia, loess (do alemão Löss, solto) é um solo amarelado formado por sedimentos finos como argila, areia e limo, depositados pelo vento. Eles são comuns em vales de rios. Assim, em uma seção transversal do planeta Terra, onde poderíamos observar as diferentes camadas do solo, o depósito de loess apareceria como uma camada fina e curva ao longo da seção, semelhante à curva de regressão estimada pelo método.

Na figura 4.2 vemos como os pesos de robustez modificam a estimativa da superfície de suavização. A superfície obtida pelo método lowess é muito mais estável na presença de outliers.

\subsection{Estimativa da variância da variável resposta}

\subsubsection{Variância não homogênea}

Como vimos na seção 4.2.1, é possível que as observações $Y_{i}$ não sejam homoscedásticas.

Nesse caso, se a função $\sigma^{2}(x)=\operatorname{Var}(Y \mid X=x)$ for conhecida, vimos que podemos modificar o critério de mínimos quadrados, dado em (4.4), adicionando como peso o inverso dessa variância. Nesse caso, o diagrama de pesos resultante do problema de minimização é dado por:

$$
l\left(x_{0}\right)^{t} \doteq e_{1}^{t}\left(A^{t} V W A\right)^{-1} A^{t} V W,
$$

em que $V$ é uma matriz diagonal cuja $i$-ésima entrada é igual a $1 / \sigma^{2}\left(X_{i}\right)$.

No entanto, caso a variância condicional de $Y$ não seja conhecida, devemos estimá-la. Como fizemos a suposição de que a variância dos erros é uma função das variáveis independentes, uma alternativa fácil de implementar é a sugerida por Loader (1999). Nesse caso, estimaremos a variância localmente. Assim, a estimativa da variância condicional de $Y$, para um dado ponto $x_{0}$, é dada por:

$$
\hat{\operatorname{Var}}\left(Y \mid X=x_{0}\right)=\hat{\sigma}^{2}\left(x_{0}\right)=\frac{\sum_{i=1}^{n} \varphi_{i}\left(Y_{i}-\widetilde{\mu}_{x_{0}}\left(X_{i}\right)\right)^{2}}{\operatorname{tr}(W)-\operatorname{tr}\left(\left(A^{t} W A\right)^{-1}\left(A^{t} W^{2} A\right)\right)},
$$

em que o numerador é a soma dos resíduos quadrados resultantes de uma suavização com vizinhança bem pequena e o denominador são os graus de liberdade residuais dessa estimativa.

Para a determinação da estimativa $\widetilde{\mu}_{x_{0}}(x)$ e dos graus de liberdade residuais, Loader (1999) sugere utilizarmos localmente um polinômio quadrático com um parâmetro de suavização $\alpha=0,1$. Além disso, como essa estimativa costuma apresentar muito ruído, a autora sugere melhorá-la com uma suavização local gama. 


\section{Gráfico M-A - Lowess vs Loess}

Lâmina: 251485069395_1.1

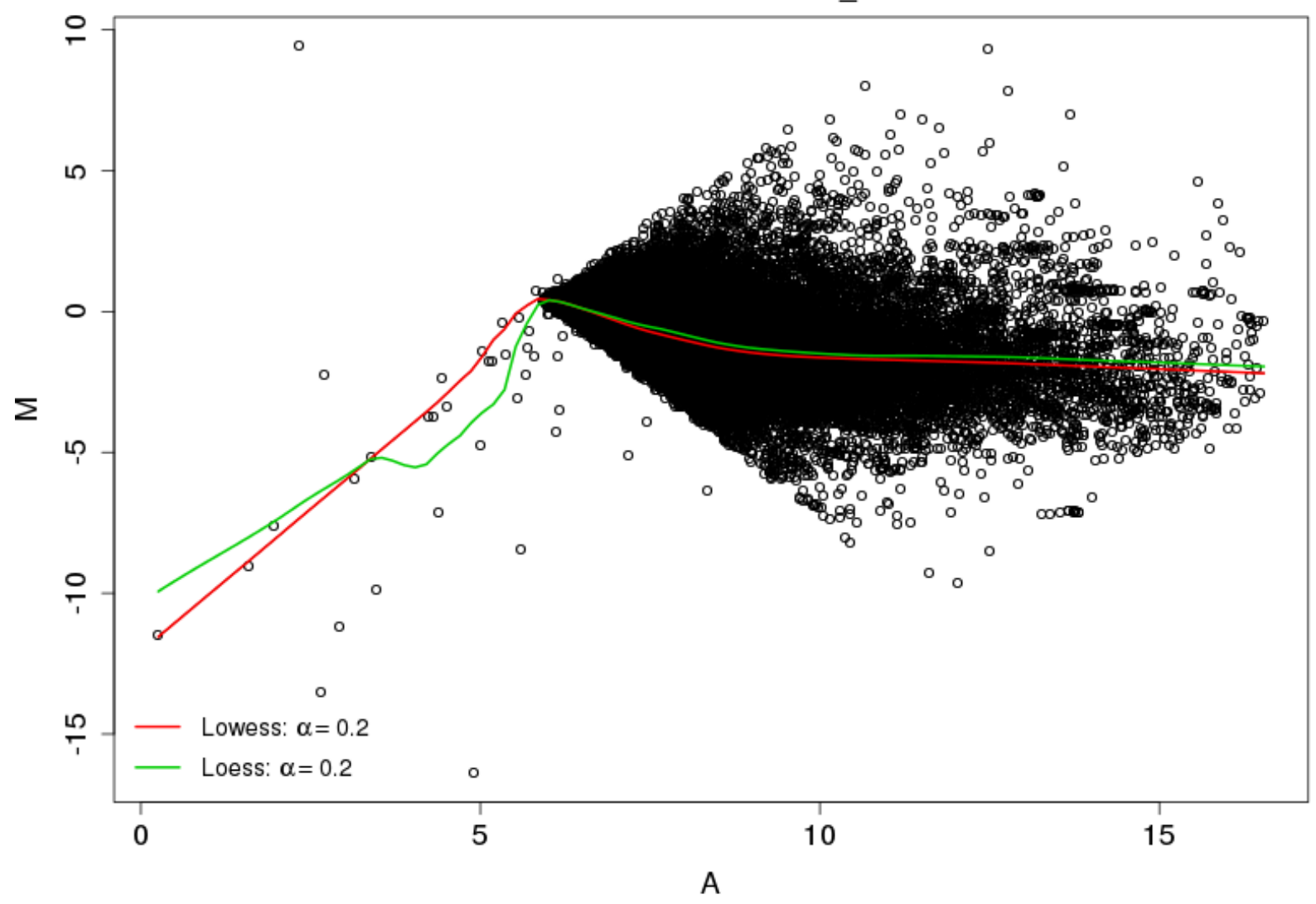

Figura 4.2: Neste gráfico, podemos ver a diferença entre as curvas estimadas, uma usando por loess e outra usando lowess. Claramente vemos que a estimativa com loess é mais sensivel aos outliers. Como os demais parâmetros foram fixados, podemos ver que o efeito é causado pelos pesos de robustez determinados no algoritmo do lowess.

\subsubsection{Variância homogênea}

Caso a variância das observações seja constante, igual $\sigma^{2}$, podemos utilizar a estimativa de $\operatorname{Var}\left(Y_{i}\right)=\sigma^{2}$ sugerida por Cleveland e Devlin (1988).

O problema de mínimos quadrados, dado em (4.4), pode, nesse caso, ser modelado sem a ponderação devida à variância. No entanto, como uma constante não altera a solução do problema de otimização, ele pode ser formulado como antes.

Ela é obtida também assumindo que a estimativa $\hat{\mu}\left(X_{i}\right)$ é não enviesada. Com isso, temos:

$$
\hat{\operatorname{Var}}\left(Y_{i}\right)=\hat{\sigma}^{2} \doteq \frac{1}{n+\nu_{2}-2 \nu_{1}}\left[\sum_{i=1}^{n}\left(Y_{i}-\hat{\mu}\left(X_{i}\right)\right)^{2}\right] .
$$

Os detalhes da estimação dessa variância podem ser vistos na seção A.3.

Por causa dessa suposição de não enviesamento da estimativa $\hat{\mu}\left(X_{i}\right)$, é recomendável, em métodos de seleção de parâmetros, implementar essa estimativa utilizando um ajuste particular, calculado com os parâmetros de suavização que proporcionam o menor viés em questão. 


\subsection{Medidas de qualidade do modelo}

\subsubsection{Erro quadrático médio}

Uma medida bastante utilizada para avaliar a qualidade do modelo é o erro quadrático médio do estimador, definido por:

$$
\mathbb{E}\left((\mu(x)-\hat{\mu}(x))^{2}\right) .
$$

Com a decomposição viés-variância do erro quadrático médio entre $\mu$ e $\hat{\mu}$, que pode ser vista no apêndice A.2, temos que:

$$
\mathbb{E}\left((\mu(x)-\hat{\mu}(x))^{2}\right)=\operatorname{Vies}^{2}(\hat{\mu})+\operatorname{Var}(\hat{\mu}) .
$$

Essa decomposição é interessante pois nos permite avaliar a qualidade do modelo apenas observando o comportamento da variância e do viés. Assim, se quisermos verificar qual combinação de parâmetros nos fornece um modelo mais adequado em relação ao erro quadrático médio, basta compararmos o viés e a variância das estimativas resultantes.

Para facilitar alguns cálculos, determinaremos as expressões para o viés e para a variância da estimativa $\hat{\mu}(x)$, em função da sua solução por mínimos quadrados ponderados, isto é, utilizando que

$$
\hat{\mu}(x)=\sum_{i=1}^{n} \pi_{i}(l(x)) Y_{i},
$$

como determinamos na equação (4.5).

\subsubsection{Viés}

O viés do modelo é dado por:

$$
\operatorname{Vies}(\hat{\mu}(x)) \doteq \mathbb{E}(\hat{\mu}(x))-\mu(x) .
$$

Dessa forma, para encontrarmos uma expressão para o viés, precisamos primeiro determinar a esperança do modelo. Assim, temos que:

$$
\begin{aligned}
\mathbb{E}(\hat{\mu}(x)) & =\mathbb{E}\left(\sum_{i=1}^{n} \pi_{i}(l(x)) Y_{i}\right) \\
& =\sum_{i=1}^{n} \pi_{i}(l(x)) \mathbb{E}\left(Y_{i}\right) \\
& =\sum_{i=1}^{n} \pi_{i}(l(x)) \mu\left(X_{i}\right) .
\end{aligned}
$$

Para o resultado dado na última linha, precisamos lembrar da teoria de regressão, onde temos que $\mu(x)=E(Y \mid X=x)$.

Portanto,

$$
\begin{aligned}
\operatorname{Vies}(\hat{\mu}(x)) & =\mathbb{E}(\hat{\mu}(x))-\mu(x) \\
& =\sum_{i=1}^{n} \pi_{i}(l(x)) \mu\left(X_{i}\right)-\mu(x) .
\end{aligned}
$$

Infelizmente, como essa expressão depende da função média desconhecida $\mu(x)$, ela não é muito útil para estudarmos seu comportamento para diferentes combinações de parâmetros. No entanto, na seção 4.5.2, comentaremos sobre a expansão assintótica dessa expressão determinada 
por Ruppert e Wand (1994) e mostraremos como ela pode nos dar as informações que precisamos para entender o comportamento do viés.

\subsubsection{Variância}

Assumindo que as observações $Y_{i}$ são independentes, a variância da estimativa $\hat{\mu}(x)$ pode ser obtida como a seguir:

$$
\begin{aligned}
\operatorname{Var}(\hat{\mu}(x)) & =\operatorname{Var}\left(\sum_{i=1}^{n} \pi_{i}\left(l\left(x_{0}\right)\right) Y_{i}\right) \\
& =\sum_{i=1}^{n} \operatorname{Var}\left(\pi_{i}(l(x)) Y_{i}\right) \\
& =\sum_{i=1}^{n} \pi_{i}(l(x))^{2} \operatorname{Var}\left(Y_{i}\right) \\
& =\sum_{i=1}^{n} \pi_{i}(l(x))^{2} \sigma^{2}\left(X_{i}\right) .
\end{aligned}
$$

Na seção 4.5.2 veremos que também foi determinada uma expansão assintótica da variância e a usaremos para entender o seu comportamento conforme alteramos os parâmetros que determinam a estimativa $\hat{\mu}(x)$.

\subsubsection{Avaliando o viés e a variância da estimativa graficamente}

Podemos dizer se a superfície de regressão tem pouco viés se, no gráfico das observações independentes $X_{i}$ pelas observações dependentes $Y_{i}$, a curva está bem ajustada aos dados.

Porém, se a superfície de regressão ajustada captura até as características dos dados que são consideradas ruídos, esse super ajuste resultará em pouco viés, mas virá acompanhado de muita variância.

Quando o oposto ocorre, ou seja, quando a superfície não captura as características importantes do comportamento, dizemos que ela tem muito viés, porém a variância costuma ser pequena.

Outra maneira de observar se o viés da superfície de regressão ajustada é pequeno é a partir do gráfico dos resíduos $\hat{\varepsilon}_{i}$, por cada variável independente de $X_{i}$.

Se a estimativa $\hat{\mu}\left(X_{i}\right)$ for não enviesada, então

$$
\mathbb{E}\left(\hat{\mu}\left(X_{i}\right)\right)=\mu\left(X_{i}\right)=\mathbb{E}\left(Y_{i}\right) .
$$

Com isso,

$$
\begin{aligned}
\mathbb{E}\left(\hat{\varepsilon}_{i}\right) & =\mathbb{E}\left(Y_{i}-\hat{\mu}\left(X_{i}\right)\right) \\
& =\mathbb{E}\left(Y_{i}\right)-\mu\left(X_{i}\right) \\
& =\mathbb{E}\left(Y_{i}\right)-\mathbb{E}\left(Y_{i}\right) \\
& =0 .
\end{aligned}
$$

Assim, se os resíduos ficarem centrados no zero e não houver dependência, então a estimativa da superfície de suavização tem pouco viés.

Apesar dos recursos gráficos terem sua limitação, eles podem ser interessantes para diagnosticarmos se a estimação, para uma certa combinação de parâmetros, foi dada com um bom balanço entre viés e variância.

Na figura 4.3, mostramos esses gráficos para dados de expressões gênicas obtidas em uma lâmina de microarranjos. Podemos observar diferentes comportamentos do viés e da variância para o ajuste dos dados de uma lâmina de microarranjos. Quando o parâmetro $\alpha$, que determina a porcentagem de observações pertencentes à vizinhança de suavização, é muito pequeno, temos uma estimativa 
com pouco viés, mas com grande variância. Exatamente o oposto ocorre quando escolhemos um valor grande para $\alpha$.

A limitação do recurso gráfico fica evidente na presença de dados heteroscedásticos, como ocorre no exemplo dessa figura. Como o comportamento dos dados não é muito nítido, fica complicado visualizar qual estimativa descreve adequadamente o comportamento dos dados. Com isso, mostrase necessário um método de seleção dos parâmetros por algum critério de qualidade, como veremos na seção 4.6 .

\subsection{Efeitos dos parâmetros na superfície de suavização}

Como vimos, nos métodos lowess e loess já temos predefinidas a função peso, dada pela função tricubo, e a especificação da função de largura da banda, dada por vizinhos mais próximo. Por isso, nesta seção, avaliaremos apenas os parâmetros que ainda precisamos escolher: o parâmetro de suavização $\alpha$, que determina a porcentagem de observações pertencentes à vizinhança, e o grau do polinômio a ser ajustado.

Esses dois parâmetros são os mais críticos para a qualidade do modelo, pois ambos afetam o nível de viés e de variância do modelo. A função peso afeta pouco o balanço viés-variância, tendo um maior efeito no visual da superfície ajustada.

Para uma dada vizinhança, o ajuste local de um polinômio de grau alto possui um viés menor que um ajuste feito com um polinômio de grau baixo. No entanto, o aumento do grau do polinômio introduz uma parametrização adicional, resultando em uma grande variabilidade dos parâmetros estimados e, consequentemente, em uma estimativa numericamente instável.

Com o parâmetro de suavização $\alpha$, ocorre o contrário. Se ele for muito pequeno, a quantidade de observações a ser considerada na estimativa será insuficiente, resultando em um ajuste muito ruidoso, ou seja, com grande variância. No entanto, se ele for muito grande, um polinômio simples pode não se adaptar bem a todas as observações da vizinhança, distorcendo ou ignorando características importantes. Nesse último caso, teremos um ajuste com um grande viés.

Com isso, podemos ver que os efeitos do grau do polinômio e do parâmetro $\alpha$ ficam confundidos. Por exemplo, com $\alpha$ fixado, a estimativa local quadrática é mais variável que a estimativa local dada por uma reta, mas esse aumento da variância pode ser compensado com um valor maior de $\alpha$.

\subsubsection{O efeito do grau do polinômio}

A ideia da regressão local é reduzir a complexidade das funções estimadas. Assim, devemos escolher um polinômio simples, ou seja, de grau baixo, para o modelo local.

Como vimos, ao aumentarmos o grau do polinômio, diminuímos o viés, mas aumentamos a variância da estimativa. Assim, é difícil escolher o grau do polinômio local.

Uma interessante discussão sobre os graus de polinômios é feita em Loader (1999). Segundo a autora, o uso de polinômios constantes, isto é, de grau zero, é muito suscetível a viés e raramente é adequado. Já as retas são mais adequadas nas fronteiras. Polinômios de grau dois podem ser mais adequados por reduzirem o viés, embora possam ser um problema especialmente nas fronteiras. Polinômios de grau três ou maior raramente melhoram a estimativa.

No entanto, o aumento da variância não é constante com o aumento do grau do polinômio. A variância assintótica somente aumenta se o grau aumentar de um valor ímpar para um valor par. Assim, ela aumenta se mudarmos o grau de um para dois, mas não há perda se aumentarmos de zero para um. Assim, é fortemente sugerido por Fan e Gijbels (1996) e Ruppert e Wand (1994), que apenas polinômios de ordem ímpar sejam considerados, já que o ganho no viés não é associado a uma perda na variância.

Com isso, uma boa alternativa é nos concentrarmos na seleção do valor do parâmetro de suavização $\alpha$, que determina a largura de banda, e fixarmos o grau do polinômio em um.

Podemos observar o comportamento das estimativas ao variarmos os graus do polinômio na figura 4.4, onde foi usado o loess, e na figura 4.5, com lowess. Confirmando a discussão anterior, 


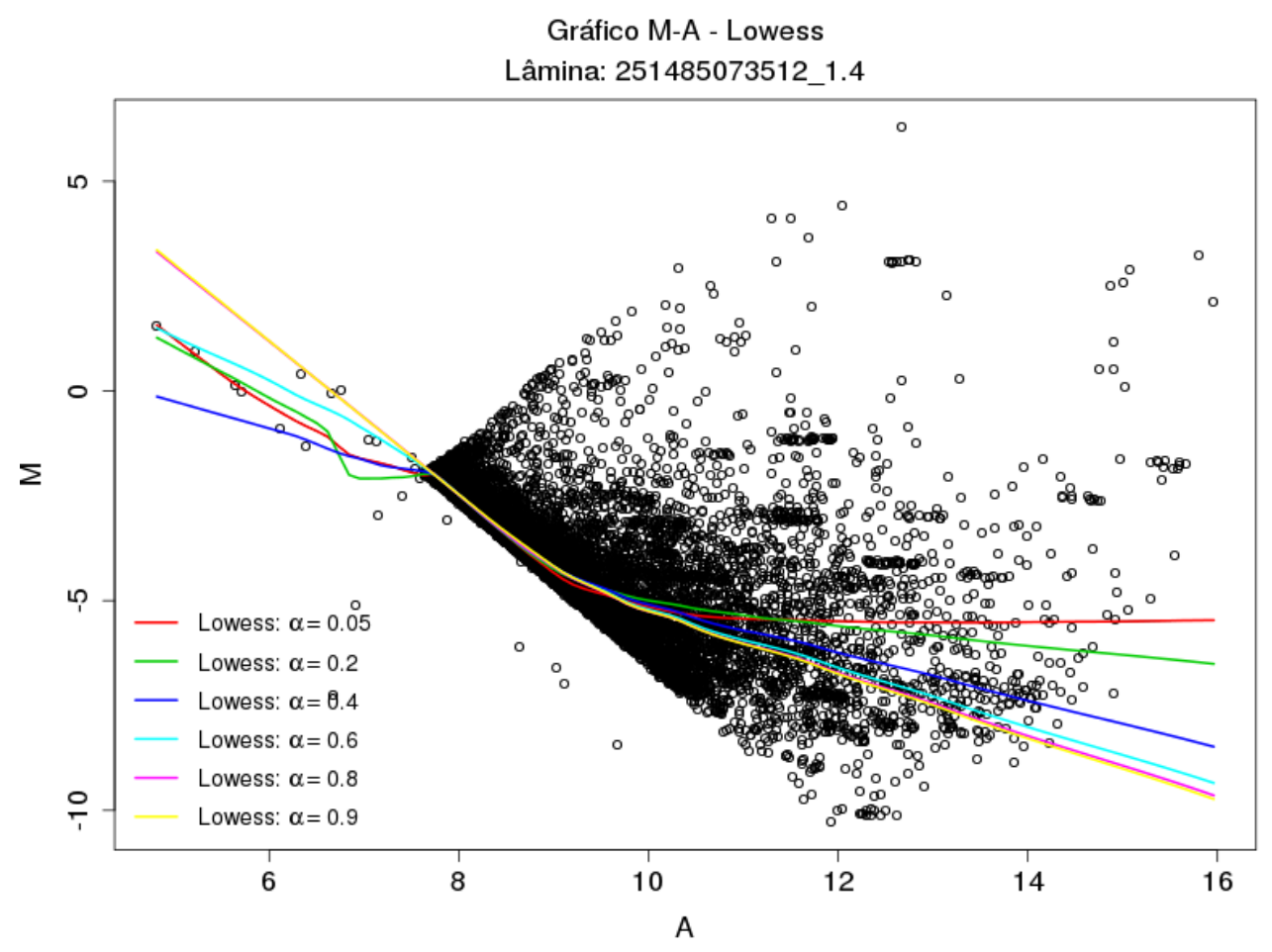

(a) Gráfico $M-A$ com as curvas de regressão obtidas para diferentes valores de $\alpha$.
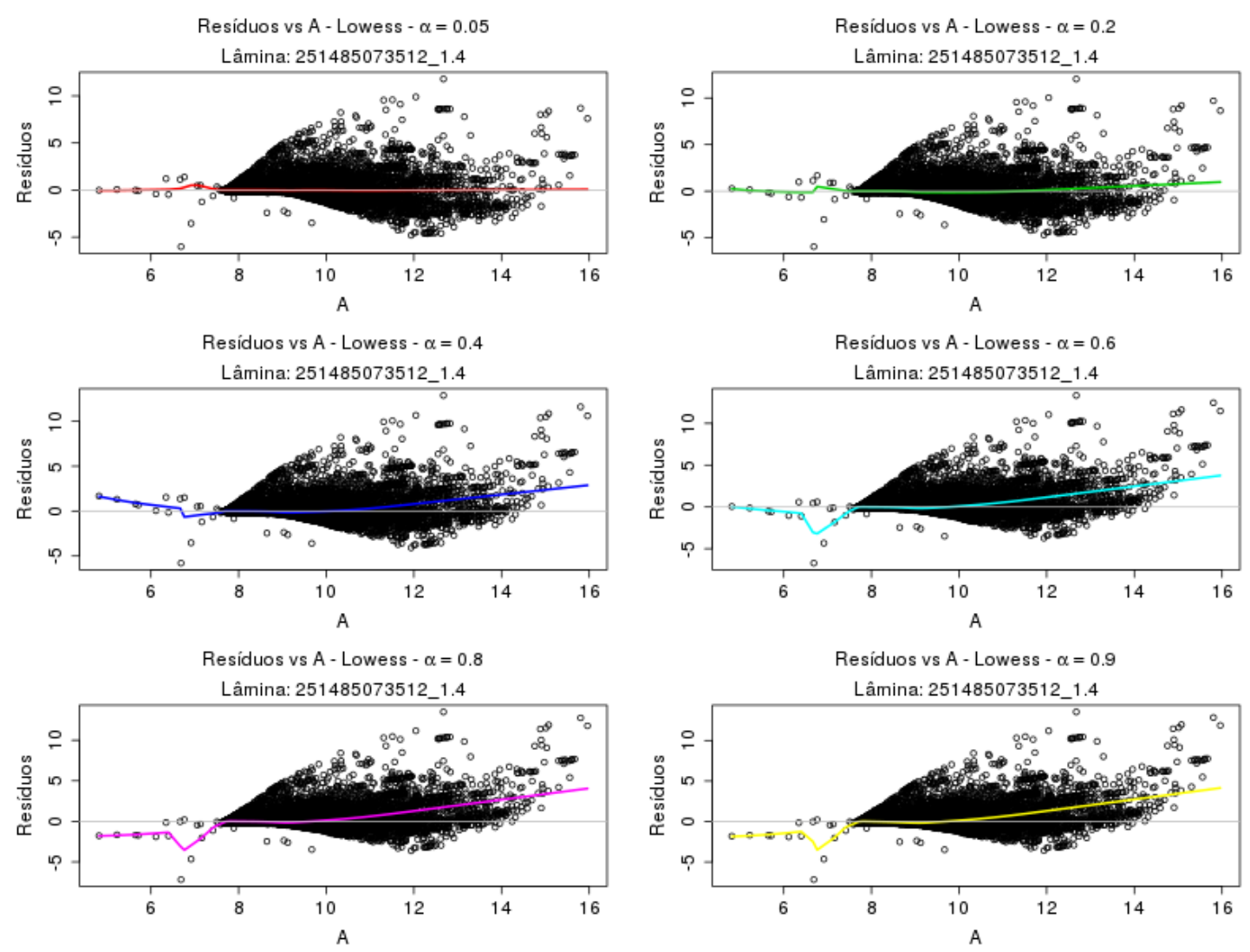

(b) Resíduos dos ajustes realizados com diferentes valores de $\alpha$.

Figura 4.3: $O$ gráfico $M-A$ com as curvas de suavização dos dados para diferentes valores de parâmetros de suavização (a) e os gráficos dos resíduos (b) desses diferentes ajustes permitem analisar o balanço viésvariância. 
a reta é muito mais adequada para o ajuste nas fronteiras. A robustez do lowess permite uma estimativa estável na fronteira com o polinômio de grau dois, mas, com grau três, as estimativas obtidas com ambos os métodos claramente não foram adequadas.

Gráfico M-A - Loess

Lâmina: 251485069395_1.1

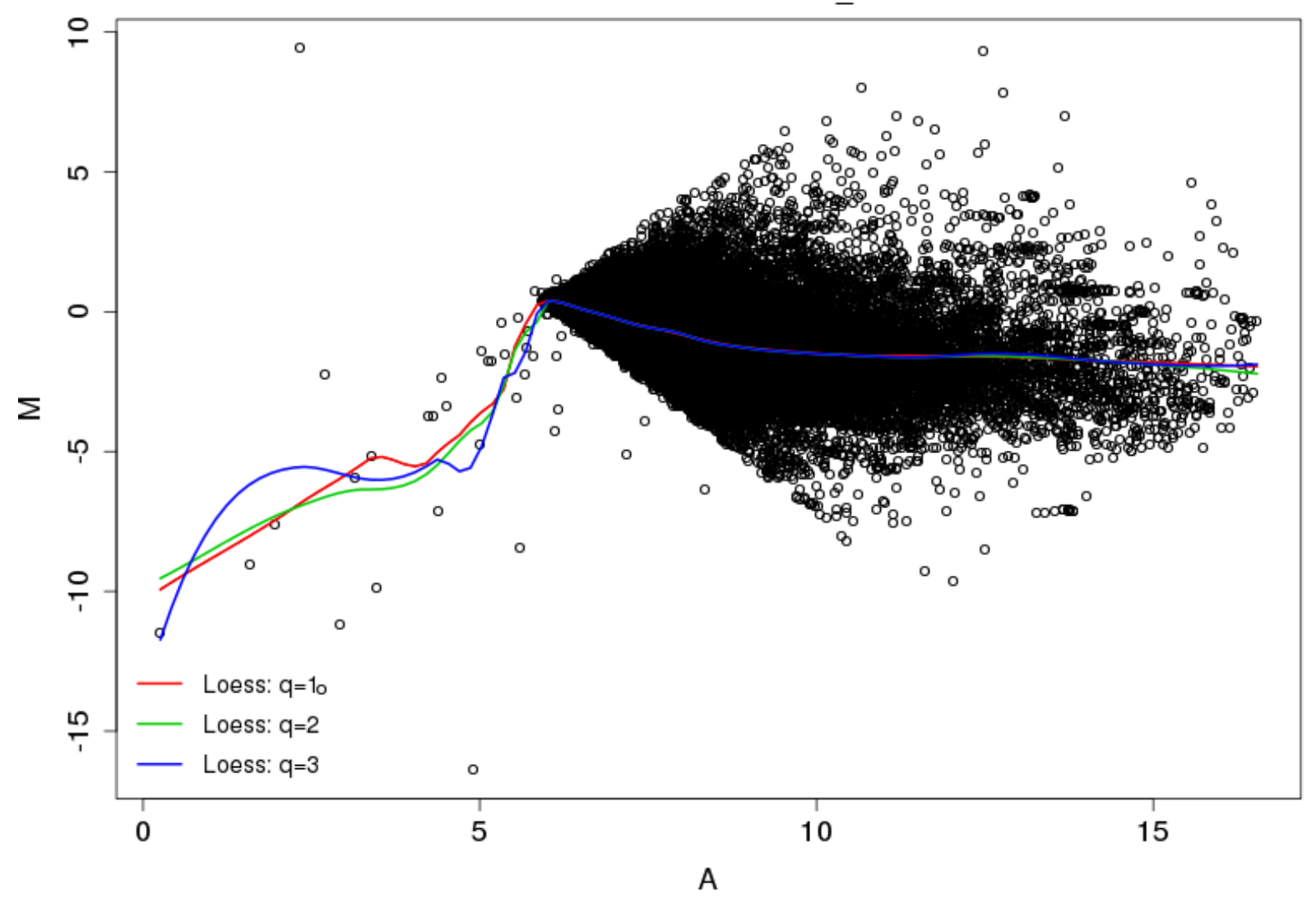

Figura 4.4: Podemos observar, neste gráfico, o efeito do grau do polinômio local. As estimativas foram obtidas com o método loess e parâmetro de suavização a fixado em 0,2. Com polinômios de graus dois e três, as estimativas foram bem mais instáveis nas fronteiras que quando estimadas com polinômio de grau um.

\subsubsection{O efeito da largura da banda}

A largura de banda, determinada pela função $h(x)$, tem um efeito crítico no nível de suavização da estimativa $\hat{\mu}(x)$.

Quando $h(x)=0$, teremos uma estimativa que é, essencialmente, a interpolação dos dados. Por outro lado, se $h(x)=\infty$, o método de regressão local será equivalente ao método de regressão clássico, onde o ajuste é feito globalmente, isto é, abrangendo todas as observações. Com isso, vemos que a complexidade do modelo é efetivamente controlada pela largura da banda.

No entanto, para definir a função $h(x)$ de forma adequada, precisamos utilizar os dados para concluir se determinada especificação de função pode ou não ser descartada, o que é muito difícil.

Como vimos na seção 4.1.3, uma boa alternativa é usar a especificação dos vizinhos mais próximos. No entanto, essa definição ainda depende do parâmetro de suavização $\alpha$, que determina a porcentagem de pontos pertencentes à vizinhança de suavização. Logo, herdamos os mesmos problemas na determinação do valor do parâmetro $\alpha$.

Quando a função nos dá valores muito grandes de largura de banda, temos uma suavização muito forte, sendo claro que a escolha não foi adequada. Mas, se a função nos dá larguras de banda muito pequenas, é difícil julgar se as características adicionais encontradas no modelo são mesmo 
Gráfico M-A - Lowess

Lâmina: 251485069395_1.1

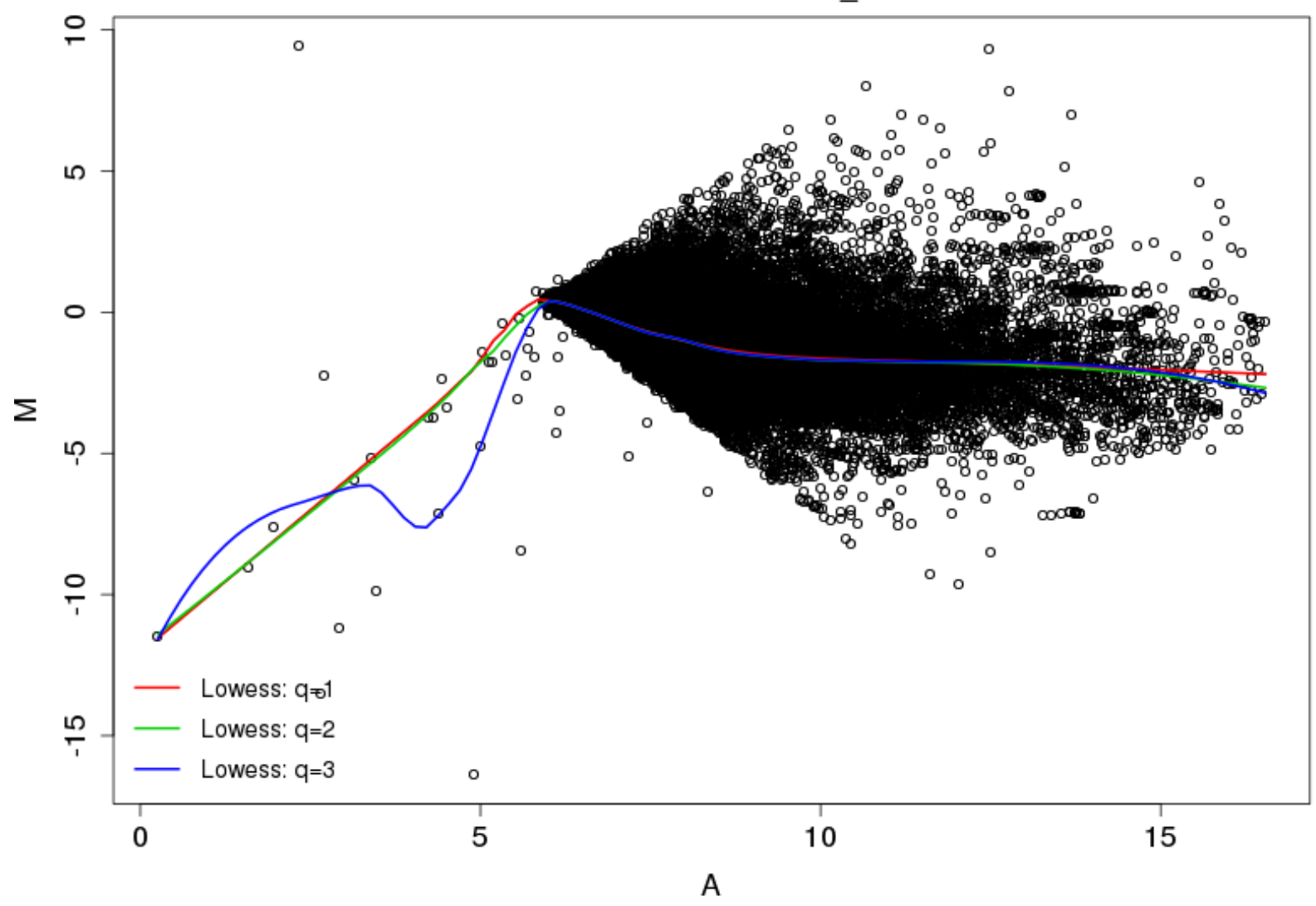

Figura 4.5: O efeito do grau de polinômio local com o método lowess pode ser observados nessas estimativas. Com o parâmetro de suavização $\alpha$ fixado em 0,2 , apenas a estimativa obtida com polinômios cúbicos locais foi instável na fronteira.

reais ou se são apenas ruídos aleatórios nos dados. Em um primeiro momento, ficamos induzidos a dizer que são ruídos aleatórios, já que na natureza nada é perfeito, mas é impossível concluir se isso é verdade a partir do gráfico.

Nas figuras 4.6 e 4.7 podemos ver como as estimativas mudam quando variamos o valor do parâmetro de suavização $\alpha$.

Idealmente, o que precisamos é de uma estimativa com pouco viés e pouca variância. Por isso, precisamos entender como o viés e a variância são afetados com a largura de banda.

Na seção 4.4.2, vimos que o viés da estimativa $\hat{\mu}(x)$ não pode ser obtido diretamente, pois depende da função $\mu(x)$ que é desconhecida.

Por isso, Fan e Gijbels (1992) estabeleceram algumas propriedades assintóticas para o viés e a variância condicional da estimativa $\hat{\mu}(x)$. No entanto, seus resultados são limitados ao caso univariado.

Os resultados para o caso multivariado foram dados por Ruppert e Wand (1994). Eles encontraram uma expansão assintótica para essa expressão do viés usando uma expansão de Taylor de baixa ordem da função $\mu$ e fazendo uma aproximação da soma por integrais.

Uma versão simplificada dessa expansão para o viés, mostrada por Loader (2012), é:

$$
\operatorname{Vies}(\hat{\mu}(x)) \approx \mu^{\prime \prime}(x) h^{2} \frac{\int v^{2} K(v) d v}{2 \int K(v) d v}
$$

onde os termos dependentes da função peso $K$ correspondem à uma aproximação por integrais da somatória dos termos de Taylor de $\mu$ e também do diagrama de pesos dos ajustes em cada 
Gráfico M-A - Loess

Lâmina: 251485069395_1.1

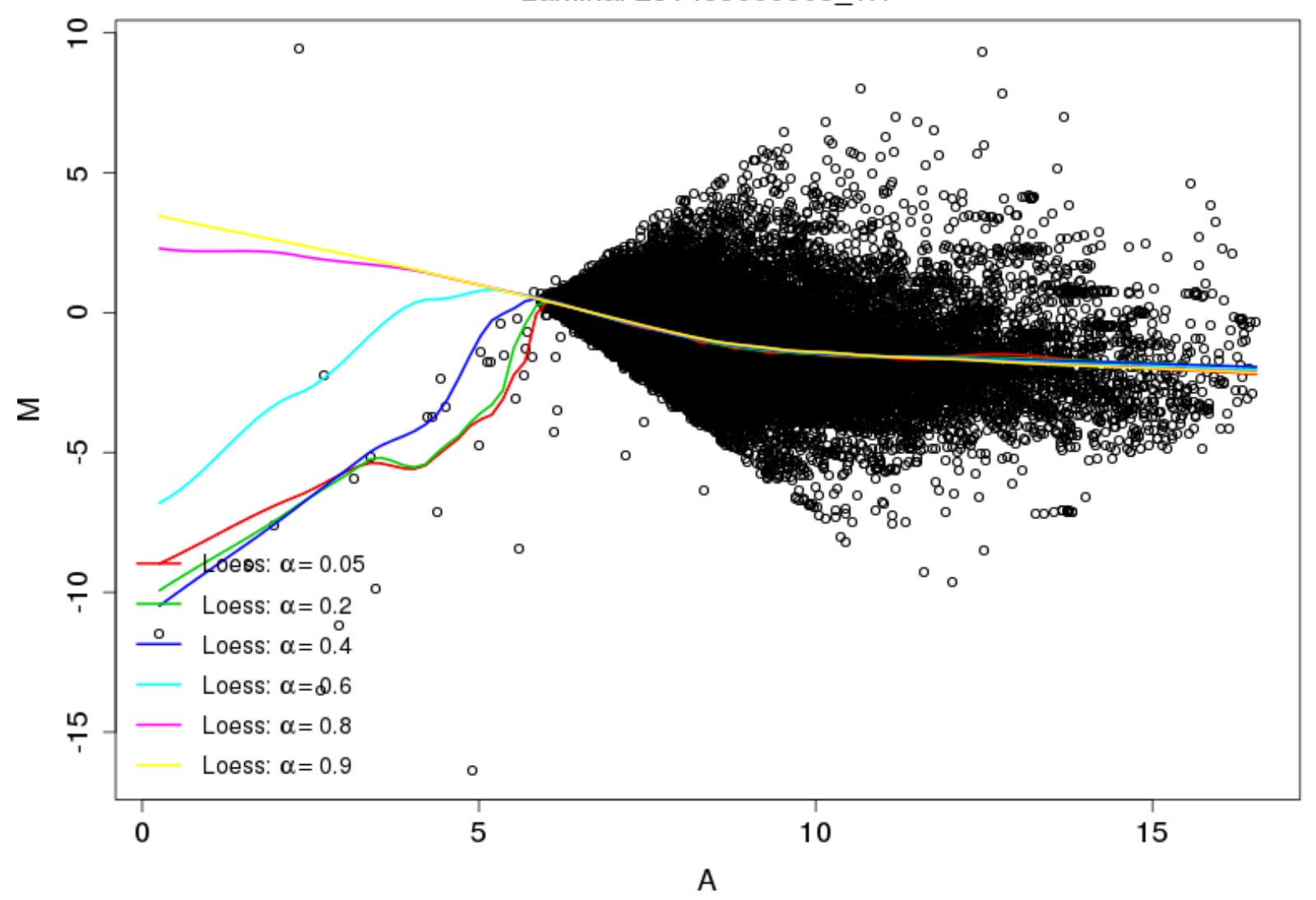

Figura 4.6: Podemos observar que, com o método loess, as estimativas determinadas com valores de $\alpha$ menores que 0,6 foram muito ruidosas. Assim, aparentemente, utilizar vizinhanças que incluem $60 \%$ ou menos das observações não é adequado. Por outro lado, a estimativa com $100 \%$ das observações não se ajusta bem aos dados. As demais estimativas parecem ser adequadas, mas é difícil de julgar a partir do gráfico.

observação $X_{i}$.

Apesar da dependência de $\mu^{\prime \prime}(x)$, que é desconhecida, com essa expressão é possível ver facilmente que o viés cresce quadraticamente com a largura de banda $h$.

Além disso, podemos observar que, se a segunda derivada da média real for grande, isto é, se o gráfico da função tem uma curvatura elevada, então uma estimativa obtida com largura de banda grande não será muito precisa, ou seja, ela terá um viés grande.

No mesmo artigo, Ruppert e Wand (1994) também determinaram uma aproximação assintótica para a variância, aproximando as somas por integrais.

A versão simplificada da expansão da variância, que assume homoscedasticidade, também mostrada por Loader (2012), é:

$$
\operatorname{Var}(\hat{\mu}(x)) \approx \frac{\sigma^{2}}{n h f(x)} \frac{\int K(v)^{2} d v}{\left(\int K(v) d v\right)^{2}},
$$

onde $f(x)$ é a função densidade da qual foram amostrados todas variáveis independentes $X_{i}, n$ é o tamanho da amostra e $h$ é a largura da banda.

Nessa expressão, podemos interpretar o termo $1 /(n h f(x))$ como o inverso do tamanho da amostra usada no ajuste local. Assim, esperamos que a variância aumente conforme essa amostra diminui. Consequentemente, podemos ver que a variância diminui com a largura de banda. Portanto, essas análises validam a nossa intuição.

Para escolhermos uma estimativa com pouco viés e pouca variância, é necessário fazermos um 
Gráfico M-A - Lowess

Lâmina: 251485069395_1.1

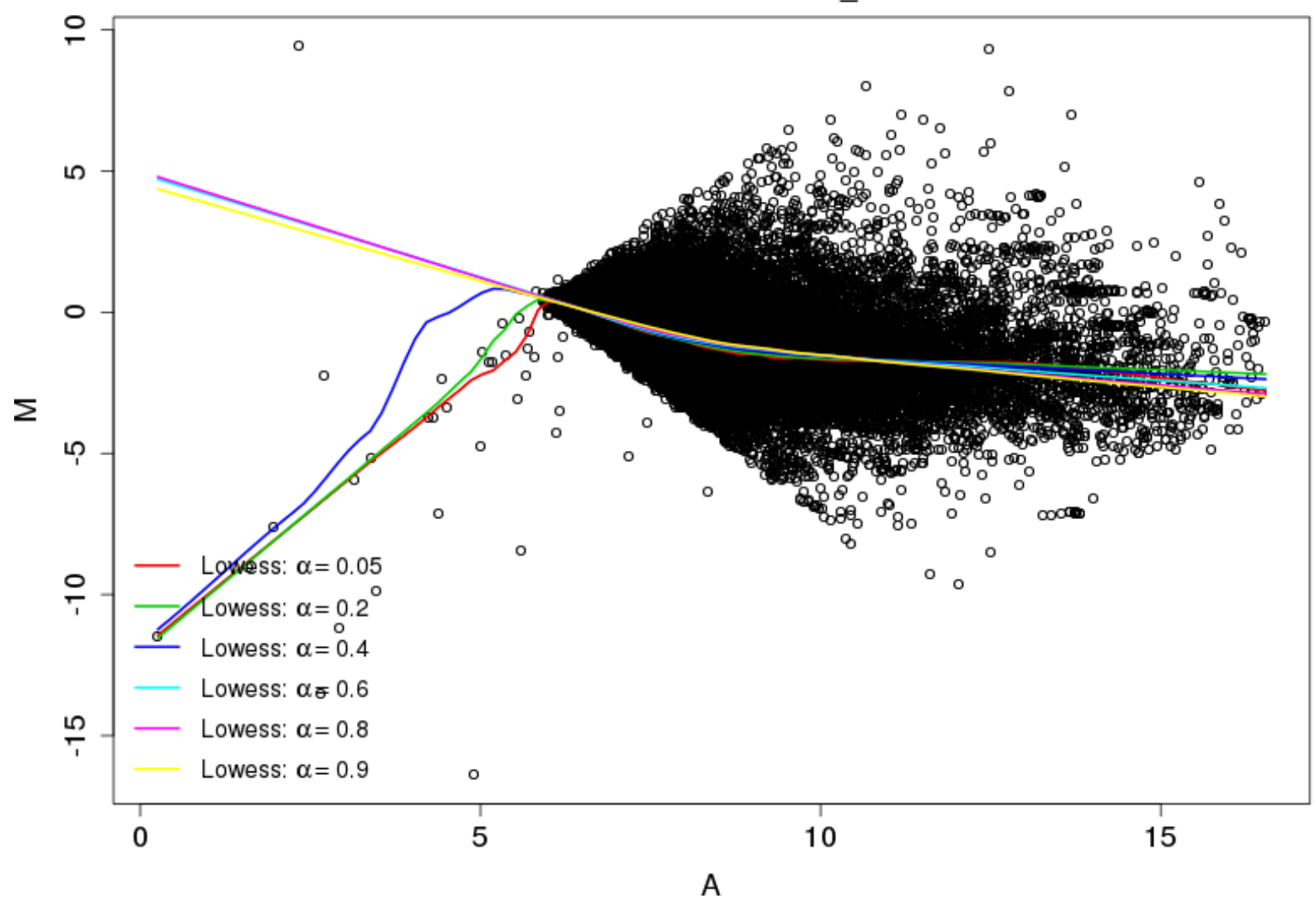

Figura 4.7: Com o método lowess, o valor do parâmetro é menos crítico. Podemos ver que a estimativa determinada com $60 \%$ das observações não sofreu tanta influência dos outliers quanto a observada na figura 4.6. Novamente, apenas observando o gráfico é difícil de julgar se as demais estimativas são adequadas.

balanço entre essas duas medidas. Uma forma de avaliarmos a qualidade do modelo é pelo erro quadrático médio, já que ele é uma medida que incorpora tanto a variância quanto o viés.

Usando a decomposição viés-variância vista no apêndice A.2, temos que a expressão assintóticas do erro quadrático médio é dada por:

$$
\mathbb{E}\left((\mu(x)-\hat{\mu}(x))^{2}\right) \approx \mu^{\prime \prime}(x)^{2} h^{4} \frac{\int v^{2} K(v) d v}{2 \int K(v) d v}+\frac{\sigma^{2}}{n h f(x)} \frac{\int K(v)^{2} d v}{\left(\int K(v) d v\right)^{2}} .
$$

Com essa expressão, podemos ter uma ideia melhor de como deve ser feito o balanço entre viés e variância para reduzir o erro quadrático médio.

\subsection{Critérios de avaliação da qualidade do modelo}

Nesta seção, mostraremos algumas definições e critérios importantes para avaliar a qualidade do ajuste obtido pelo lowess e, como veremos na seção 5.1, que podem ser usados na construção de um método de seleção de parâmetros adequados.

\subsubsection{Caracterização global do modelo: graus de liberdade do ajuste}

Apesar da superfície de suavização ter sido determinada localmente, é interessante ter uma medida que caracteriza a complexidade do modelo de forma global. Os graus de liberdade do modelo de regressão observado de forma global podem satisfazer essa necessidade. É importante salientar que esses graus de liberdade são diferentes dos graus de liberdade residuais. 
O seu uso é bastante utilizado em seleção de modelos, pois permite uma comparação justa de estimativas obtidas por diferentes combinações de parâmetros, mas usando a mesma base de dados. Fornecendo um critério global para a caracterização da função de suavização, podemos comparar, por exemplo, modelos determinados usando diferentes graus do polinômio ou diferentes larguras de banda. Esse é o princípio utilizado pela ferramenta gráfica $M$-plot, que será vista em detalhes na seção 5.1.3.

A definição de graus de liberdade do ajuste global, segundo Ye (1998) é a soma da sensitividade dos valores ajustados com respeito aos valores de resposta observados.

Dessa forma, em modelos de regressão lineares, isto é, em que o mapeamento das observações aos valores ajustados é feito por uma matriz de predição $L$, os graus de liberdade podem ser obtidos por características dessa matriz.

Em métodos de regressão que não são baseados nas projeções dos mínimos quadrados ordinários, como é o caso das regressões por mínimos quadrados generalizadas, que incluem as regressões por mínimos quadrados ponderados, a matriz de predição $L$ não é mais um operador de projeção ortogonal. A matriz de predição do lowess, por exemplo, muitas vezes não é nem simétrica e nem idempotente.

Assim, as somas dos quadrados não são mais uma distribuição proporcional à $\chi^{2}$ e a definição de graus de liberdade convencional a partir da dimensão do domínio dos vetores aleatórios deixa de ser útil.

A partir da definição de graus de liberdade do ajuste de Ye (1998), foram definidas algumas expressões para a obtenção dos graus de liberdade que são apropriadas para muitos métodos de regressão. Essas expressões ficaram conhecidas como graus de liberdade efetivos e algumas delas são:

$$
\begin{aligned}
& \nu_{1} \doteq \operatorname{tr}(L) ; \mathrm{e} \\
& \nu_{2} \doteq \operatorname{tr}\left(L^{t} L\right) .
\end{aligned}
$$

No método de mínimos quadrados ordinários, as definições (4.10) e (4.11) são equivalentes, já que a matriz $L$ é idempotente. Além disso, os graus de liberdade para o ajuste obtidos dessa forma são os mesmo obtidos da forma usual.

\subsubsection{Erro quadrático médio de predição}

Um dos possíveis critérios de avaliação da estimativa de suavização é o erro quadrático médio de predição, dado por:

$$
\operatorname{EQMP}(\hat{\mu})=\mathbb{E}\left(Y_{\text {novo }}-\hat{Y}_{\text {novo }}\right)^{2}=\mathbb{E}\left(Y_{\text {novo }}-\hat{\mu}\left(x_{\text {novo }}\right)\right)^{2} .
$$

Com esse critério, podemos medir a adequação do modelo quanto à predição de uma nova observação, denotada por $Y_{\text {novo }}$.

Podemos estimar esse critério usando validação cruzada, descrita por:

$$
\mathrm{VC}(\hat{\mu})=\frac{1}{n} \sum_{i=1}^{n}\left(Y_{i}-\hat{\mu}_{-i}\left(X_{i}\right)\right)^{2},
$$

em que $\hat{\mu}_{-i}\left(X_{i}\right)$ é a estimativa de $\mu\left(X_{i}\right)$ calculada usando todos os pontos da base exceto $X_{i}$.

Como esse cálculo é muito custoso computacionalmente, é possível utilizar uma estimativa de $\operatorname{VC}(\hat{\mu})$, conhecida como critério de validação cruzada generalizada:

$$
\operatorname{VCG}(\hat{\mu})=\frac{n}{\left(n-\nu_{1}\right)^{2}} \sum_{i=1}^{n}\left(Y_{i}-\hat{\mu}\left(X_{i}\right)\right)^{2},
$$

em que $\nu_{1}$ são os graus de liberdade da curva ajustada, como vimos em (4.10). 
Essa estimativa só é válida quando temos que $\pi_{i}\left(l\left(X_{i}\right)\right)<1, \forall i=1, \ldots, n$, isto é, quando toda entrada da diagonal da matriz de predição $L$ for menor que um. No caso em que os erros são homoscedásticos, isso é verdade sempre que fizermos uma suavização maior que simplesmente a interpolação dos dados, como pode ser conferido em Loader (1999)

Podemos compreender como essa aproximação foi determinada no apêndice A.4.

\subsubsection{Erro quadrático médio da estimativa}

Enquanto o critério VCG nos fornece uma medida de qualidade avaliando o erro da predição, o erro quadrático médio da estimativa do ajuste, dado por

$$
\mathbb{E}\left[(\mu(x)-\hat{\mu}(x))^{2}\right],
$$

nos permite medir o quão próximo da média real está a estimativa do ajuste.

Dependendo se a função de variância das observações $Y_{i}$ é ou não constante, escolhemos um critério diferente para avaliar o erro quadrático média da estimativa da superfície de suavização.

\section{Erro quadrático médio da estimativa com erros homoscedásticos}

No caso dos erros do modelos possuírem a mesma variância e, assim, a variância das observações $Y_{i}$ ser constante igual a $\sigma^{2}$, usamos o critério $C p$ de Cleveland e Devlin (1988).

A versão normalizada do erro quadrático nesse caso é dada pela seguinte função de risco:

$$
\mathrm{R}(\mu, \hat{\mu})=\frac{1}{\sigma^{2}} \sum_{i=1}^{n} \mathbb{E}\left[\left(\hat{\mu}\left(X_{i}\right)-\mu\left(X_{i}\right)\right)^{2}\right] .
$$

Como essa função depende da função média desconhecida $\mu$, não podemos avaliá-la diretamente. Por isso, um critério que foi inicialmente desenvolvido por Mallows (1973) para regressões paramétricas, foi estendido por Cleveland e Devlin (1988) para regressão local, fornecendo, assim, uma estimativa não enviesada de $\mathrm{R}(\mu, \hat{\mu})$, isto é,

$$
\mathbb{E}(\mathrm{Cp}(\hat{\mu}))=\mathbb{E}(\mathrm{R}(\hat{\mu}, \mu)) .
$$

Esse critério é dado por:

$$
\mathrm{Cp}(\hat{\mu})=\frac{1}{\sigma^{2}} \sum_{i=1}^{n}\left(Y_{i}-\hat{\mu}\left(X_{i}\right)\right)^{2}-n+2 \nu_{1}
$$

O nome $\mathrm{Cp}$ foi herdado da estimativa original de seleção de modelos $\mathrm{Cp}$, de Mallows.

Para calcular o valor de $\mathrm{Cp}$, podemos utilizar a estimativa de $\sigma^{2}$ vista em (4.7). No entanto, para compararmos diversos modelos usando essa estatística, devemos, para todos os modelos, usar a mesma estimativa $\sigma^{2}$. Além disso, ela deve ser calculada com os parâmetros da estimativa de menor viés, por exemplo, o menor valor de $\alpha$ em consideração.

Como esse critério é não enviesado, podemos comparar $\mathbb{E}(\mathrm{Cp}(\hat{\mu}))$ e $\mathbb{E}(\mathrm{R}(\hat{\mu}, \mu))$ e entender como ele foi desenvolvido. Essa verificação pode ser vista no apêndice A.5.

\section{Erro quadrático médio da estimativa com erros heteroscedásticos}

Para o caso da regressão ser modelada sobre observações com diferentes variâncias, Liu e Okui (2013) definiram o critério HRCp, que também é uma extensão do método Cp de Mallows (1973) para regressões paramétricas. O nome HRCp vem do inglês, Heteroskedasticity-Robust Cp.

Esse critério fornece uma estimativa da medida de qualidade de $\hat{\mu}$ dada pela seguinte função de risco: 


$$
\mathrm{R}(\mu, \hat{\mu})=\sum_{i=1}^{n} \mathbb{E}\left[\left(\hat{\mu}\left(X_{i}\right)-\mu\left(X_{i}\right)\right)^{2}\right] .
$$

O critério é definido da seguinte forma:

$$
\operatorname{HRCp}(\hat{\mu})=\hat{\mathrm{R}}(\mu, \hat{\mu})=\sum_{i=1}^{n}\left(Y_{i}-\hat{\mu}\left(X_{i}\right)\right)^{2}+2 \operatorname{tr}(\Sigma \mathrm{L}),
$$

em que L é a matriz de predição da regressão que determina $\hat{\mu}$ e $\Sigma$ é a matriz de variância-covariância dos erros $\varepsilon_{i}$. Assumindo que os erros são não correlacionados, a matriz $\Sigma$ é diagonal $n \times n$ onde cada entrada $\Sigma_{i i}$ é dada por $\operatorname{Var}\left(Y_{i}\right)$.

Temos que o critério HRCp é, a mesmo de uma constante, um estimador não enviesado de $R(\mu, \hat{m u})$. Ou seja, temos que

$$
\mathbb{E}(\operatorname{HRCp}(\hat{\mu}))=\mathbb{E}(\mathrm{R}(\hat{\mu}, \mu))+\sum_{i=1}^{n} \sigma^{2}\left(X_{i}\right) .
$$

Essa verificação pode ser vista no apêndice A.6.

Para o caso em que não são conhecidos os valores de $\operatorname{Var}\left(Y_{i}\right)$, pode-se utilizar as estimativas dadas pela equação (4.6). 


\section{Capítulo 5}

\section{Normalização das expressões gênicas com erros de medida}

O último método de pré-processamento que devemos aplicar nos dados de expressões gênicas é a normalização. Como vimos na seção 2.5, o objetivo da normalização é remover o viés ou tendência dos dados proveniente possivelmente da dependência que o corante utilizado nas amostras hibridizadas têm das intensidades médias.

É comum observarmos um viés crescente, porém não linear, nas intensidades medidas para as expressões gênicas de cada local genético. Isto é, conforme a intensidade média do local genético aumenta, a distância entre a intensidade medida e a intensidade correspondente apenas à hibridização também aumenta. Assim, esse viés, que é a estimativa da suavização do lowess sobre as medidas $M$ e $A$, deve ser removido dos dados com o objetivo de tornarmos as observações mais próximas da real medida da expressão dos genes.

Esse processo deve ser realizado em cada uma das lâminas de microarranjos do experimento. Por isso, esse método é conhecido por normalização intra-lâmina.

Em um experimento de microarranjos é comum termos dezenas ou até centenas de lâminas hibridizadas. Assim, torna-se inviável a seleção por ferramentas visuais dos parâmetros mais adequados na determinação da estimativa de lowess para cada uma das lâminas.

Na seção 5.1, mostraremos algoritmos que determinam, para cada lâmina, a combinação de parâmetros para o método lowess que resulta na melhor estimativa de suavização segundo um critério de qualidade bem definido. Também proporemos um método de seleção dos parâmetros que leva em consideração às características dos dados gênicos. Dessa forma, garantimos que a quantidade de ruído que será acumulado aos dados ao final do processo de normalização seja mínima.

Na seção 5.2, veremos como estimar o erro acumulado durante o processo de normalização e, assim, ajustar os erros das medidas nos dados de expressões gênicas representados por intervalos.

Finalmente, nas seções 5.3 e 5.4, mostramos como é realizada a normalização tanto quando as expressões gênicas são representadas pelas suas médias como quando representadas por intervalos que descrevem os erros das medidas.

\subsection{Algoritmos de seleção dos parâmetros do lowess para aplicação em larga escala}

Na seção 4.6, mostramos alguns critérios que estimam tanto o erro quadrático médio da estimativa como o erro quadrático médio de predição.

Esses critérios nos fornecem uma medida de qualidade do modelo, para uma dada escolha de parâmetros. Quanto menor for essa medida, mais adequado está o modelo. Assim, aplicar um algoritmo de minimização desses critérios é a forma mais natural de selecionarmos adequadamente os parâmetros do lowess.

Como vimos na seção 4.5, a escolha dos valores do parâmetro de suavização $\alpha$, que determina 
a largura de banda quando esta é especificada por vizinhos mais próximos, e do grau do polinômio $q$ é crítica. Assim, precisamos de um método para selecionar esses parâmetros de forma a obtermos uma estimativa adequada.

Na seção 4.5.1, vimos que devemos escolher polinômio de grau baixo para simplificarmos as estimativas e, também, vimos que ajustar uma reta localmente é a forma mais estável quando há dados esparsos, como é o caso dos dados provenientes de microarranjos, especialmente nas regiões de menos e maior intensidade média. Assim, neste trabalho, fixaremos o grau do polinômio em um e, assim, nos concentrarmos apenas na escolha do parâmetro de suavização $\alpha$.

Uma forma automática de selecionar os parâmetros é minimizar algum dos critérios estudados da seção 4.6. No entanto, veremos que esse método de seleção de parâmetros não é o melhor, pois descarta algumas propriedades intrínsecas da curva determinada por esses critérios.

Nesta seção, veremos com mais detalhes os processos de minimização desses critérios e mostraremos algumas ferramentas gráficas que são usadas para uma análise exploratória das características dessas curvas. Por fim, proporemos um método automatizado que leva em consideração tanto um critério de qualidade, como VCG (Validação Cruzada Generalizada, definido em (4.13)), Cp (definido em (4.14)) ou HRCp (Heteroskedasticity-Robust Cp, definido em (4.15)), além das características que são geralmente apenas exploradas graficamente.

\subsubsection{Minimização do erro quadrático médio de predição}

Ao minimizarmos o erro quadrático médio de predição, visto na seção 4.6.2, em relação a um vetor de parâmetros, obtemos os parâmetros que nos fornecem a estimativa mais adequada para predição.

Como estamos interessados apenas no valor do parâmetro de suavização $\alpha$, faremos a minimização apenas em relação a esse parâmetro.

A estimativa VCG nos fornece uma medida com custo computacional baixo em relação ao critério de validação cruzada (VC, definida em (4.12)). Assim, para a minimização, determinaremos a medida VCG para cada estimativa dada por um valor de $\alpha$ diferente.

Nesse caso, se quisermos avaliar as estimativas determinadas por $l$ valores diferentes, $\left\{\alpha_{1}, \ldots, \alpha_{l}\right\}$, teremos a seguinte família de estimativas:

$$
\mathcal{F}=\left\{\hat{\mu}_{\alpha_{k}} ; \alpha_{k} \in\left\{\alpha_{1}, \alpha_{2}, \ldots, \alpha_{l}\right\}\right\} .
$$

A solução do problema será, então, dada por:

$$
\alpha^{*} \doteq \underset{\alpha_{k}}{\arg \min } \operatorname{VCG}\left(\hat{\mu}_{\alpha_{k}}\right), \quad \text { tal que } \hat{\mu}_{\alpha_{k}} \in \mathcal{F}
$$

\subsubsection{Minimização do erro quadrático da estimativa}

Outra forma de escolher o valor do parâmetro $\alpha$ é minimizando o erro quadrático entre $\mu$ e $\hat{\mu}_{\alpha}$, para diferentes valores de $\alpha$, visto na seção 4.6.3. Com isso, determinaremos a estimativa que mais se aproxima da média verdadeira $\mu$.

Para isso, podemos calcular a estimativa $\mathrm{Cp}$, ou HRCp no caso das observações da variável resposta $Y$ serem heteroscedásticas, para uma família de ajustes e selecionar o valor de $\alpha$ que nos fornece a estimativa de melhor valor.

Na implementação do critério Cp, é necessária uma estimativa de $\sigma^{2}$. Para isso, podemos usar a estimativa expressa na equação (4.7). No entanto, ela somente é não enviesada se o viés da estimativa $\hat{\mu}$ for tão pequeno que pode ser ignorado. Assim, seguiremos a recomendação de Cleveland e Devlin (1988) de usar a estimativa determinada pela combinação de parâmetros que produz, dentre as combinações em avaliação, o menor viés.

Já na implementação do critério HRCp, podemos utilizar as estimativas de $\operatorname{Var}\left(Y_{i}\right)$ dadas pela equação (4.6). 
Devemos utilizar as mesmas estimativas de $\operatorname{Var}\left(Y_{i}\right)$ para o cálculo do critério de todos os modelos em avaliação.

Assim, com a família de estimativas

$$
\mathcal{F}=\left\{\hat{\mu}_{\alpha_{k}} ; \alpha_{k} \in\left\{\alpha_{1}, \alpha_{2}, \ldots, \alpha_{l}\right\}\right\},
$$

o valor do melhor parâmetro $\alpha$ quando os dados são homoscedásticos é dado por:

$$
\alpha^{*} \doteq \underset{\alpha_{k}}{\arg \min } \operatorname{Cp}\left(\hat{\mu}_{\alpha_{k}}\right), \quad \text { tal que } \hat{\mu}_{\alpha_{k}} \in \mathcal{F} .
$$

Quando os dados forem heteroscedáticos, devemos optar pelo critério HRCp, que é robusto a essa característica. Nesse caso, o valor do melhor parâmetro $\alpha$ é dado por:

$$
\alpha^{*} \doteq \underset{\alpha_{k}}{\arg \min } \operatorname{HRCp}\left(\hat{\mu}_{\alpha_{k}}\right), \quad \text { tal que } \hat{\mu}_{\alpha_{k}} \in \mathcal{F}
$$

\subsubsection{M-plot: ferramenta de visualização do erro quadrático médio}

O $M$-plot é um método gráfico que mostra a contribuição do viés e da variância na determinação do erro quadrático médio, para diferentes combinações de parâmetros de suavização.

Vimos na seção 4.5, que o tamanho da vizinhança e o grau do polinômio influenciam no viés e na variância das estimativas das superfícies de suavização. No entanto, observando apenas as estimativas dos erros quadráticos médios, é difícil ver como a variância e o viés são afetados individualmente quando alteramos o valor desses parâmetros.

Saber como é dado esse efeito de forma separada, pode ser interessante em várias situações. Dependendo da aplicação, pode ser preferível ter um viés muito pequeno, permitindo uma compensação com um aumento da variabilidade. Esse é o caso de quando a seleção de parâmetros é feita para uma regressão que será utilizada apenas como ferramenta gráfica exploratória, já que nossos olhos podem ignorar certos ruídos e queremos detectar todas característica estruturais da superfície de regressão.

Também pode ocorrer de ser preferível um ajuste com menor variância, mesmo que isso cause um aumento do viés. Esse seria o caso quando o tamanho da amostra é pequeno ou quando queremos modelos mais simples, que capturem apenas as características mais salientes.

O M-plot permite tal análise esboçando o gráfico do erro quadrático médio pelo número de graus de liberdade efetivos do ajuste quando visto de forma global. A definição para os graus de liberdade efetivos para o ajuste foi mostrada na seção 4.6.1.

Lembrando que os graus de liberdade do ajuste representam a complexidade do modelo, temos que, quanto menor a largura de banda, maior a complexidade do modelo e, portanto, maior será o número de graus de liberdade do ajuste. Com isso, a variância é uma função crescente com o número de graus de liberdade e o viés é uma função decrescente.

Analisando o crescimento, ou decrescimento, das estimativas do erro quadrático médio em relação ao número de graus de liberdade, podemos, portanto, entender como está sendo feita a compensação entre o viés e a variância.

Além disso, uma característica importante da curva do erro quadrático médio, que já foi apontada por Cleveland e Devlin (1988) e Loader (1999), é seu achatamento perto do número de graus de liberdade que a minimiza. Ou seja, há um intervalo de valores para o parâmetro $\alpha$ que resultam em estimativas com um erro quadrático médio parecido, mas com um número de graus de liberdade diferente. Assim, podemos escolher propriedades diferentes de viés e de variância para a estimativa, sem alterar significativamente o erro quadrático médio.

Dessa forma, utilizar o $M$-plot para os valores dos critérios de qualidade das estimativas de interesse nos permite analisar tanto a compensação entre viés e variância como também informações sobre a variabilidade da amostra. O critério pode ser, por exemplo, algum dos vistos na seção 4.6, incluindo VCG, Cp e HRCp. Uma seleção de parâmetros dada a partir de análises desse tipo pode, certamente, resultar em estimativas mais apropriadas para uma aplicação específica. 
Autores, como Mallows (1973), Cleveland e Devlin (1988) e Loader (1999), concordam que fazer uma escolha de parâmetros apenas minimizando uma função de estimativa do erro quadrático médio é um procedimento medíocre, já que ignora informações intrínsecas do viés e da variância.

Por isso, na próxima seção propomos um método que incorpora a característica de achatamento da curva do erro quadrático médio e, pensando em aplicações como a de normalização de lâminas de microarranjos, selecionamos o parâmetro com baixo erro, mas que nos fornece um modelo mais simples.

\subsubsection{Método de seleção proposto}

Em normalização de lâminas de microarranjos, usamos o método de regressão local para estimar o viés causado pela dependência que o corante tem das intensidades.

No entanto, em artigos sobre normalização de microarranjos, comumente vemos sugestões simples para a escolha dos parâmetros de suavização, sem uma discussão detalhada.

Por exemplo, Yang et al. (2000) dizem que a normalização é geralmente feita utilizando $\alpha$ igual a $20 \%$ para todas as lâminas. Dudoit et al. (2002) comentam que em seus experimentos utilizam valores de $\alpha$ entre 20 e 40\%. Smyth e Speed (2003) dizem que os ajustes são feitos sobre uma vizinhança com $40 \%$ das observações. Nesses três artigos, o ajuste local é feito com um polinômio de grau um.

Já Drăghici (2012) recomenda utilizar grau do polinômio um, no método lowess, e grau no máximo dois, no loess, para evitar super ajuste. Além disso, ele comenta que valores de $\alpha$ entre 0,05 e 0,5 são bons na maioria dos experimentos.

No entanto, com o estudo que fizemos neste trabalho, vemos que essas escolhas são resultado de simulações ou são feitas empiricamente.

O ideal seria uma estimativa que capturasse apenas o efeito do corante, pois ele será removido na normalização das lâminas de microarranjos. Porém esse efeito está confundido com o efeito do gene. Assumindo que tendências nos dados não são provocados pelas diferenças de expressão entre os genes, uma superfície de suavização simples e que capture apenas os comportamentos mais salientes parece ser mais adequada.

A partir disso, fica claro que sem um critério, é difícil escolher um parâmetro que determina uma estimativa boa.

Uma seleção de parâmetros adequada seria minimizar o critério $\mathrm{Cp}$, como vimos na seção 5.1.2. Ou ainda, como geralmente os dados das expressões gênicas obtidas em uma lâmina de microarranjos apresentam heteroscedasticidade, podemos fazer a minimização do critério HRCp. Para detectar a presença de heteroscedasticidade, podemos observar os gráficos de diagnóstico sugeridos na seção 4.2.1.

No entanto, muitas vezes os dados de microarranjos possuem uma grande variabilidade e uma seleção a partir de um simples problema de minimização pode gerar estimativas com muitos ruídos, capturando características que provavelmente não são reais.

Como queremos descrever um fenômeno natural, esperamos que a estimativa da superfície de suavização seja simples, o que seria equivalente a exigir um valor baixo para o número de graus de liberdade efetivos do ajuste. Por isso, é interessante observarmos se há algum parâmetro $\alpha$ que determina uma estimativa de suavização adequada, mas com variabilidade baixa, mesmo que, para isso, seja necessário aumentar o viés.

Assim, propomos utilizar uma extensão do método visto na seção 5.1.2, selecionando o parâmetro com mais parcimônia, levando em consideração a característica de achatamento da curva do erro quadrático médio. Nessa proposta, selecionaremos o parâmetro que pertence à região de achatamento, mas que resulta em uma estimativa mais simples, com menor número graus de liberdade.

Para detectarmos o achatamento, verificaremos se a derivada da curva do erro quadrático médio é pequena. Para isso, procuraremos sequências de três pontos perto do mínimo tais que a diferença no erro quadrático médio é relativamente pequena ao variar o número de graus de liberdade. Todos os pontos dessas sequências determinam a região de achatamento. Basta, então, escolher aquele que possui o menor número de graus de liberdade do ajuste. 
Essa discussão pode ser formalizada com o seguinte problema de otimização discreta:

Sejam:

$$
\begin{aligned}
& \mathcal{F}=\left\{\hat{\mu}_{\alpha_{k}} ; \alpha_{k} \in\left\{\alpha_{1}, \alpha_{2}, \ldots, \alpha_{l}\right\}, \alpha_{k+1}<\alpha_{k}, \text { para } k=1, \ldots, l-1\right\} ; \\
& \alpha_{\text {min }}=\underset{\alpha_{k}}{\arg \min } \operatorname{HRCp}\left(\hat{\mu}_{\alpha_{k}}\right), \quad \text { tal que } \hat{\mu}_{\alpha_{k}} \in \mathcal{F} ; \\
& \alpha_{\text {max }}=\underset{\alpha_{k}}{\arg \max } \operatorname{HRCp}\left(\hat{\mu}_{\alpha_{k}}\right), \quad \text { tal que } \hat{\mu}_{\alpha_{k}} \in \mathcal{F} ; \text { e } \\
& \Delta_{E Q M}=0,05\left(\operatorname{HRCp}\left(\hat{\mu}_{\alpha_{\text {max }}}\right)-\operatorname{HRCp}\left(\hat{\mu}_{\alpha_{\text {min }}}\right)\right) .
\end{aligned}
$$

Então, se o seguinte problema tiver solução, selecionaremos o seguinte valor para $\alpha$ :

$$
\begin{aligned}
& \alpha^{*} \doteq \underset{\alpha_{k}}{\arg \min } \nu_{1}\left(\hat{\mu}_{\alpha_{k}}\right) \\
& \quad \text { sujeito a: } \\
& \hat{\mu}_{\alpha_{k}} \in \mathcal{F} ; \\
& \quad \operatorname{HRCp}\left(\hat{\mu}_{\alpha_{k}}\right) \leq \operatorname{HRCp}\left(\hat{\mu}_{\alpha_{m i n}}\right)+\Delta_{E Q M}, \text { para } k=1,2 ; \\
& \quad \operatorname{HRCp}\left(\hat{\mu}_{\alpha_{k-2}}\right) \leq \operatorname{HRCp}\left(\hat{\mu}_{\alpha_{m i n}}\right)+\Delta_{E Q M}, \text { para } k=3, \ldots, l ; \\
& \left|\operatorname{HRCp}\left(\hat{\mu}_{\alpha_{k}}\right)-\operatorname{HRCp}\left(\hat{\mu}_{\alpha_{k-1}}\right)\right|<\Delta_{E Q M}, \text { para } k=2, \ldots, l ; \text { e } \\
& \quad\left|\operatorname{HRCp}\left(\hat{\mu}_{\alpha_{k}}\right)-\operatorname{HRCp}\left(\hat{\mu}_{\alpha_{k-2}}\right)\right|<\Delta_{E Q M}, \text { para } k=3, \ldots, l
\end{aligned}
$$

Caso contrário, selecionaremos como o melhor parâmetro a solução do problema de minimização:

$$
\alpha^{*} \doteq \underset{\alpha_{k}}{\arg \min } \operatorname{HRCp}\left(\hat{\mu}_{\alpha_{k}}\right), \quad \text { tal que } \hat{\mu}_{\alpha_{k}} \in \mathcal{F}
$$

Nas figuras 5.1 e 5.2, podemos ver o achatamento da curva do erro quadrático médio e como o método proposto, utilizando os critérios Cp, GCV e HRCp, seleciona o valor do parâmetro levando essa característica em consideração.

Na figura 5.4, podemos ver no gráfico $M-A$ as curvas obtidas pela método lowess utilizando diferentes valores estimados para o parâmetro de suavização. Foram ilustradas as curvas estimadas com $\alpha^{*}=0,85$, obtido utilizando o critério HRCp, e $\alpha^{*}=0,3$, obtido utilizando tanto o critério Cp como o critério GCV. Também ilustramos a curva obtida com o valor convencional $\alpha=0,2$.

Podemos observar nesse exemplo que pontos que possuem uma variância grande são penalizados no critério HRCp e, assim, têm menor influência na escolha do valor mais adequado do parâmetro de suavização utilizando esse critério. A função variância estimada para esse exemplo pode ser verificada na figura 5.3. A estimativa foi obtida a partir da equação (4.6).

Na figura 5.5, podemos observar a diferença nos valores dos resíduos usando valores para $\alpha$ iguais a 0,2 (convencional) e 0,85 (estimado minimizando o critério HRCp no método proposto na seção 5.1.4.

\subsection{Estimação do erro do lowess por intervalo de confiança}

Na regressão local, a estimativa de suavização resultante pode apresentar comportamentos bem complexos e de suas características são, geralmente, dependentes dos parâmetros usados, em especial, o parâmetro de suavização. Por isso, é possível que os valores dados pelo modelo estimado não sejam reais.

O intervalo de confiança da estimativa de suavização $\hat{\mu}$ nos fornece, com algum nível de confiança, o intervalo que contém a verdadeira média $\mu$. Em outras palavras, definindo o intervalo de confiança aproximado de $\hat{\mu}$ por 


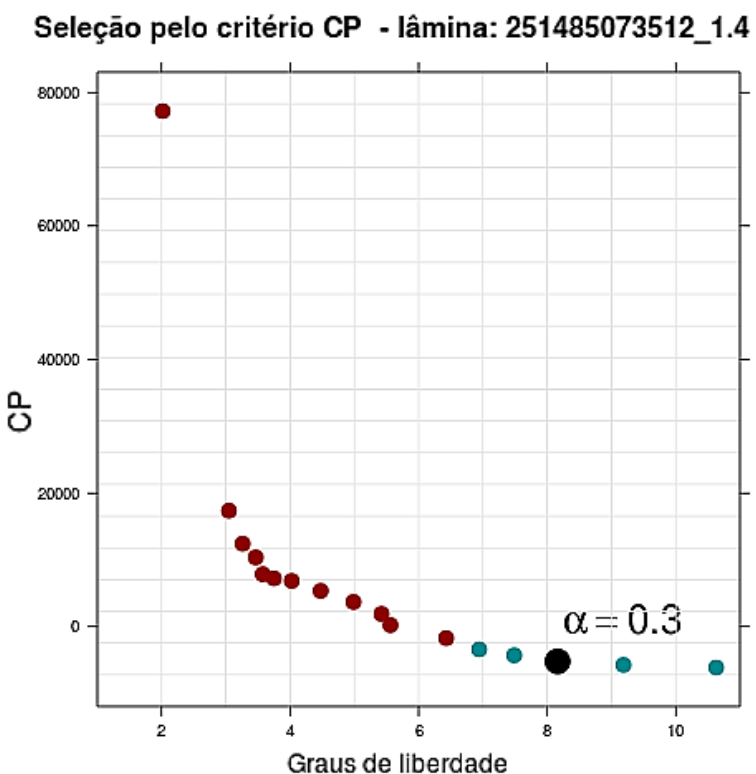

(a) Seleção para o lowess usando o critério Cp: $\alpha^{*}=0,3$.
Seleçāo pelo critério VCG- lâmina: 2514850735121.4

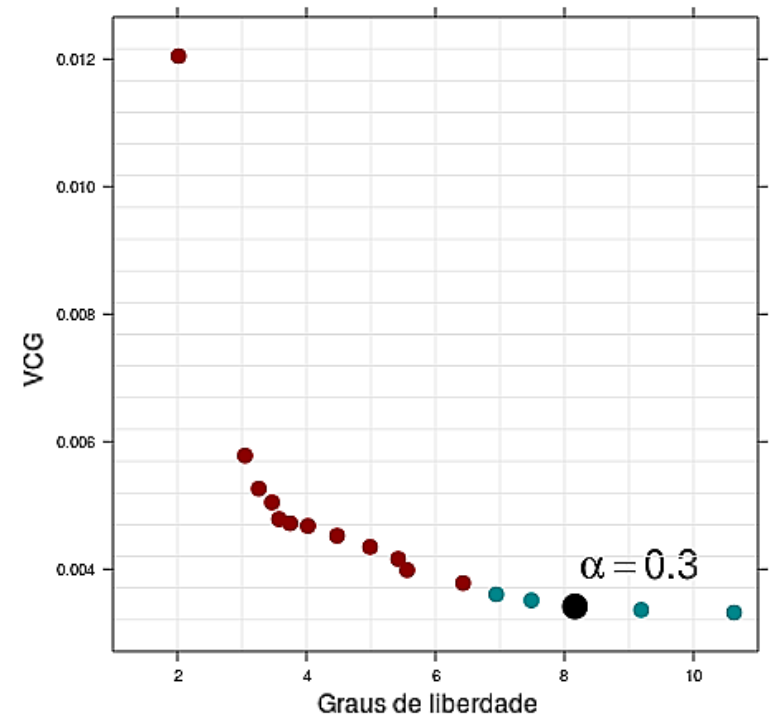

(b) Seleção para o lowess usando o critério GCV: $\alpha^{*}=0,3$.

Figura 5.1: Minimização do critério $C p$ e $G C V$ considerando a região de achatamento, que pode ser observadas nos valores marcados em azul. Foram avaliadas estimativas com o parâmetro $\alpha$ variando de 0,2 a 1. Ou seja, avaliamos estimativas onde o modelo local foi ajustado em vizinhanças que incluem desde $20 \%$ a $100 \%$ das observações.

\section{Seleçāo pelo critério HRCP - lâmina: 251485073512_1.4}

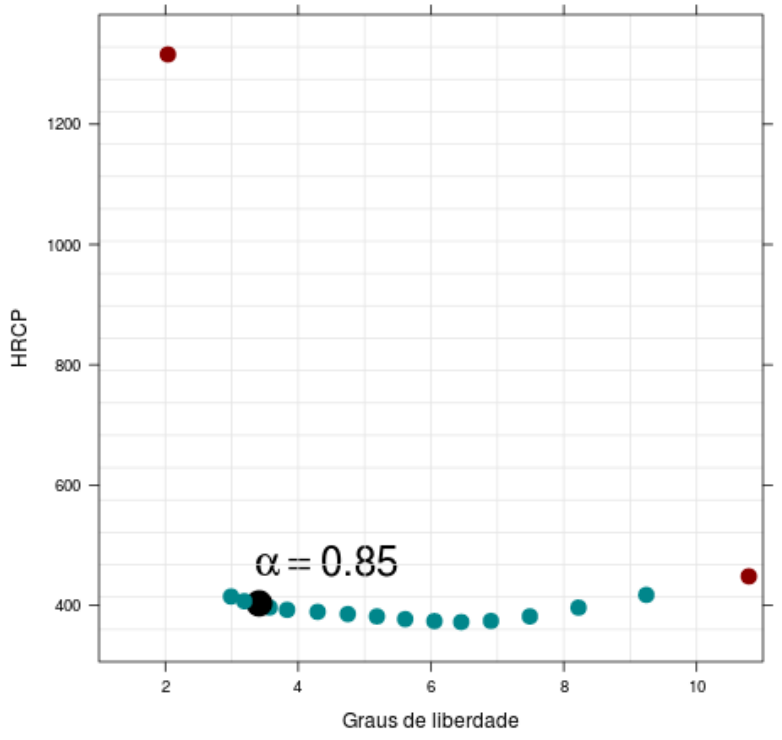

Figura 5.2: Seleção do parâmetro de largura de banda do lowess por minimização do critério HRCp, que é robusto à heteroscedasticidade, e considerando a região de achatamento, que pode ser observadas nos valores marcados em azul. Valor obtido: $\alpha^{*}=0,85$. Foram avaliadas estimativas com o parâmetro $\alpha$ variando de 0,2 a 1 .

$$
C(x) \doteq\left(C_{\text {inf }}(x), C_{\text {sup }}(x)\right),
$$

para um nível de confiança de $1-\alpha$, temos que $\mu(x) \in C(x)$ com probabilidade aproximadamente igual a $1-\alpha$.

Assim, podemos utilizar a função do intervalo de confiança, $C$, em vez da função de regressão 


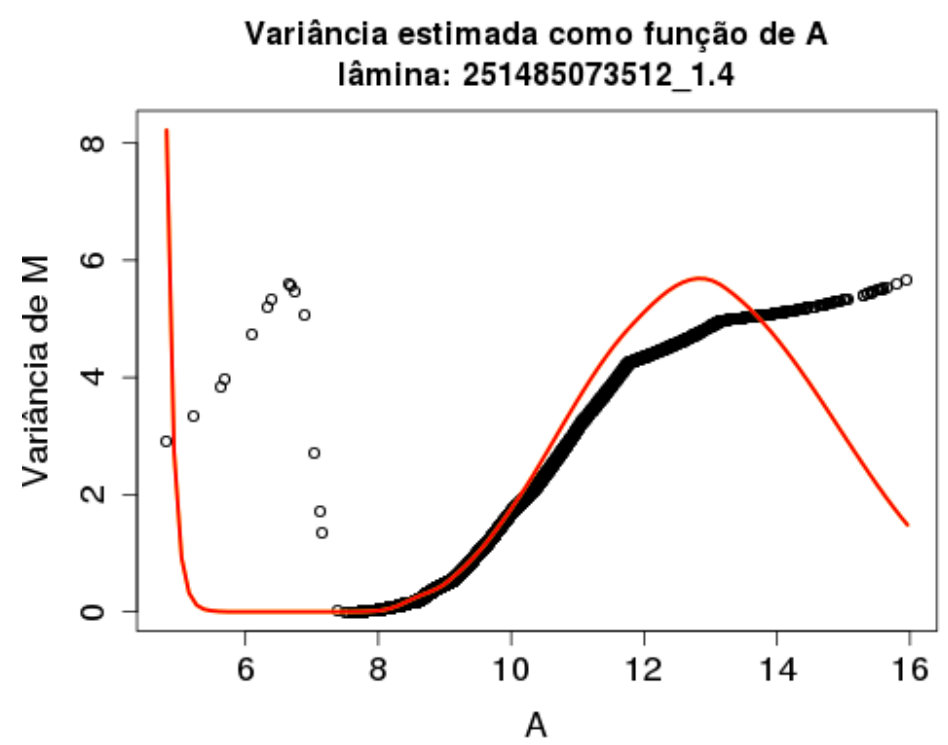

Figura 5.3: Variância estimada da variável dependente $M$ como função da variável independente A, a partir da estimativa dada pela equação (4.6). Em preto, no gráfico, observamos os valores da suavização $\widetilde{\mu}_{x_{0}}(x)$, que utiliza um parâmetro de suavização bem pequeno $(\alpha=0,1)$ e, em vermelho, a função variância resultante após uma suavização local gama.

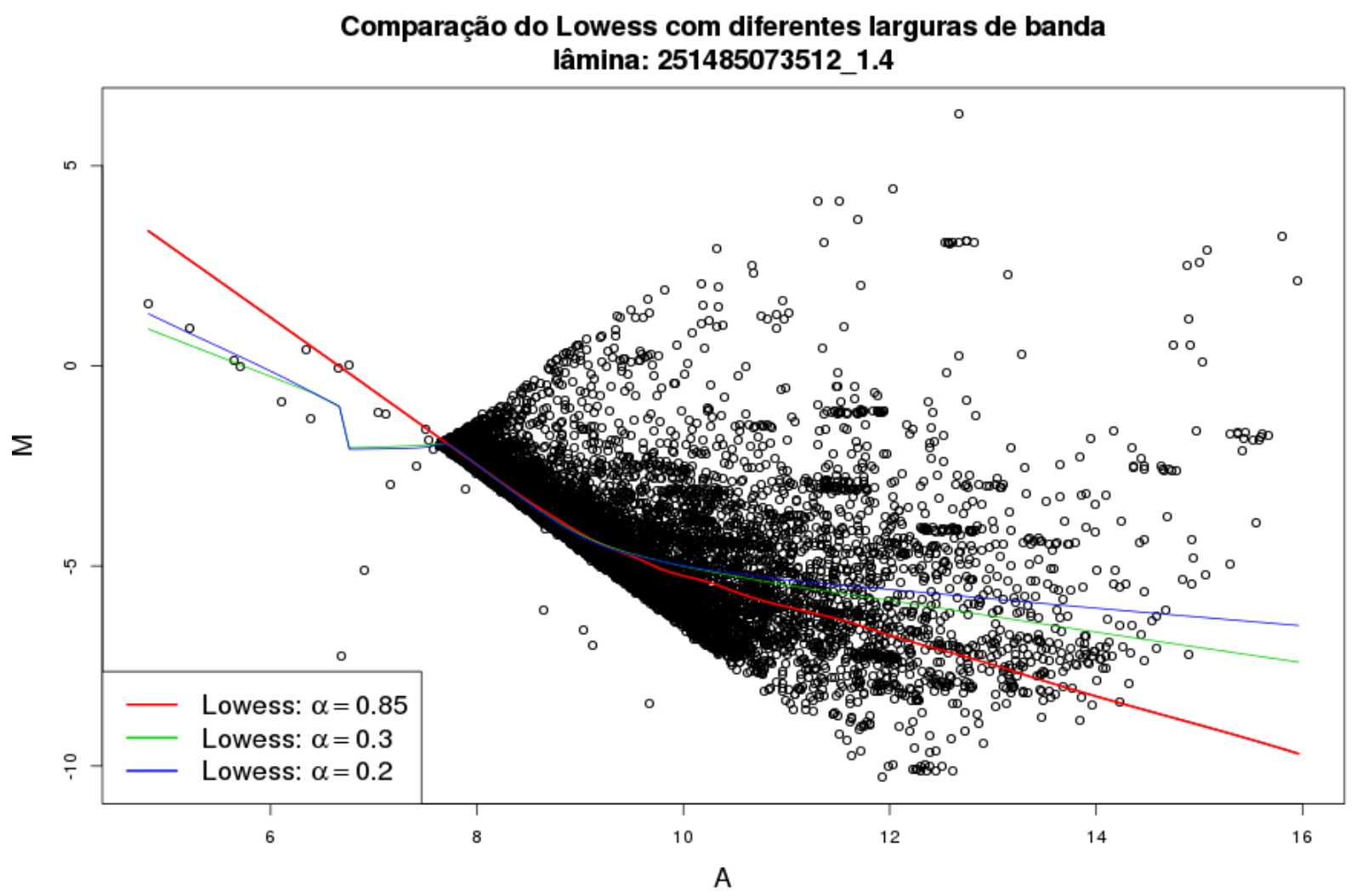

Figura 5.4: Gráfico $M$-A ilustrando as curvas de suavização obtidas com as larguras de banda estimadas pelo método proposto na seção 5.1.4. Utilizando o critério HRCp obtivemos $\alpha^{*}=0,85$ e, com os critérios GCV e Cp, obtivemos $\alpha^{*}=0,3$. Também ilustramos a curva obtida com o valor convencional $\alpha=0,2$.

$\hat{\mu}$ para obtermos as estimativas do viés de cada medida de expressão gênica. Ou seja, podemos utilizar os intervalos $\left(C_{\text {inf }}, C_{\text {sup }}\right)$, que incluem o valor verdadeiro da função $\mu$, em vez dos valores ajustados por $\hat{\mu}$. 


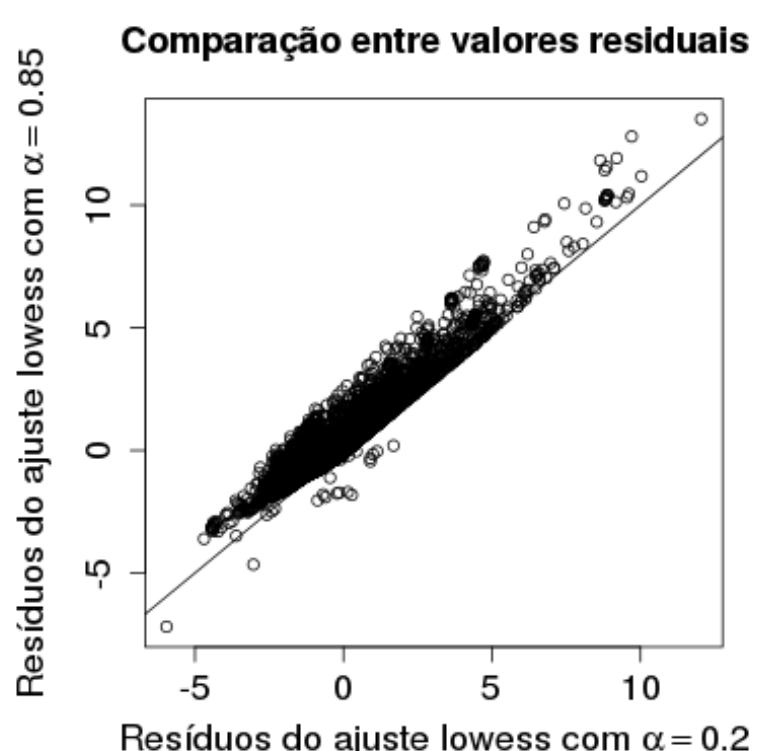

Figura 5.5: Com esse gráfico, podemos observar a diferença entre os resíduos da regressão por lowess com parâmetro de suavização convencional $(\alpha=0,2)$ e os resíduos da regressão, também por lowess, mas utilizando parâmetro de suavização estimado pelo método proposto na seção 5.1.4, com valor igual a 0,85 . Lâmina de microarranjos com identificação 251485073512_1_4.

Essa abordagem nos permite carregarmos o erro da estimação do viés no processo de normalização e nas análises seguintes. Supondo, por exemplo, que as medidas de expressões gênicas são representadas pelos pares de estimativas $\left(\bar{A}_{i}, \bar{M}_{i}\right)$, então os valores ajustados pela superfície de regressão desses pontos, dados por exemplo, por $\hat{(} \mu)\left(\bar{A}_{i}\right)$, podem ser substituídos por $\left(C_{\text {inf }}\left(\bar{A}_{i}\right), C_{\text {sup }}\left(\bar{A}_{i}\right)\right)$ no processo de normalização.

Note que, com isso, ao final da normalização teremos dados representados por intervalos, então é mais interessante utilizá-la quando as medidas de expressões gênicas já estão sendo representadas por intervalos, utilizando, por exemplo, a representação dada pela equação (3.1). Mais detalhes sobre o processo de normalização incluindo o erro da estimação do viés serão mostrados na seção 5.4 .

Para obtermos o intervalo de confiança de $\hat{\mu}$, precisamos conhecer a distribuição amostral desse estimador. Essa distribuição segue da distribuição dos dados, já que a estimativa $\hat{\mu}$ é obtida a partir dos dados. No entanto, não conhecemos exatamente a distribuição do estimador e, assim, precisaremos estimá-lo. Para isso, usaremos uma técnica conhecida como bootstrap (Horowitz (2001)).

Como utilizaremos um método para estimar o intervalo de confiança, o nível de confiabilidade verdadeiro não será exatamente o nível de confiança $1-\alpha$ desejado, mas será uma boa aproximação.

Um bom chute sobre como os dados são gerados é o próprio modelo ajustado aos dados. Assim, podemos simular réplicas desses dados que, por hipótese, têm a mesma distribuição dos dados reais.

A partir dessas novas bases de dados, conhecidas como amostras bootstrap, podemos repetir a estimação de $\mu$ para cada uma delas. Assim, para cada amostra bootstrap $\tilde{B}_{i}$, teremos um estimador de $\mu$ associado, que denotaremos por $\tilde{\mu}$.

Sejam $\tilde{\mu}_{1}, \tilde{\mu}_{2}, \ldots, \tilde{\mu}_{b}$ as estimativas da superfície de suavização $\mu$ obtidas, respectivamente, pelas bases de dados $\tilde{B}_{1}, \tilde{B}_{2}, \ldots, \tilde{B}_{b}$ simuladas a partir da base de dados original $B$.

Estamos interessados no funcional $\mu$ estimado por uma função de teste $f$ quando aplicada à base de dados original $B$. O valor amostral de $\mu$ é, nesses casos, $\hat{\mu}=f(B)$. Assim, temos, ainda que indiretamente, que o próprio estimador $\hat{\mu}$, é uma função de $B$.

A partir das amostrar simuladas, podemos obter os demais valores amostrais desse estimador, ou seja, $\tilde{\mu}_{1}=f\left(\tilde{B}_{1}\right), \tilde{\mu}_{2}=f\left(\tilde{B}_{2}\right), \ldots, \tilde{\mu}_{b}=f\left(\tilde{B}_{b}\right)$.

Assumindo que existe algum valor de $\mu$ para o qual o modelo está correto, podemos então 
estimar o intervalo que contém esse valor com um nível de confiança.

Se $C$ é o intervalo de confiança para $\mu$, com um nível de confiança igual a $1-\alpha$, então nós queremos que:

$$
P(\mu \in C)=1-\alpha .
$$

Denotando o limite inferior de $C$ por $C_{i n f}$ e o limite superior por $C_{\text {sup }}$ e assumindo que o intervalo seja simétrico, temos:

$$
\begin{aligned}
\frac{\alpha}{2} & =P\left(C_{i n f} \geq \mu\right) \\
& =P\left(C_{i n f}-\hat{\mu} \geq \mu-\hat{\mu}\right) \\
& =P\left(\hat{\mu}-\mu \geq \hat{\mu}-C_{i n f}\right) .
\end{aligned}
$$

Analogamente, temos:

$$
\begin{aligned}
\frac{\alpha}{2} & =P\left(\mu \geq C_{\text {sup }}\right) \\
& =P\left(\mu-\hat{\mu} \geq C_{\text {sup }}-\hat{\mu}\right) \\
& =P\left(\hat{\mu}-\mu \leq \hat{\mu}-C_{\text {sup }}\right) .
\end{aligned}
$$

O método bootstrap nos dá justamente a distribuição de $\tilde{\mu}-\hat{\mu}$, que julgamos ser próxima da distribuição de $\hat{\mu}-\mu$. Conhecendo a distribuição de $\tilde{\mu}-\hat{\mu}$ e o valor de $\hat{\mu}$, podemos determinar o intervalo da seguinte forma:

$$
\begin{aligned}
C_{\text {inf }} & =\hat{\mu}-\left(Q_{\tilde{\mu}}\left(1-\frac{\alpha}{2}\right)-\hat{\mu}\right) ; \quad \mathrm{e} \\
C_{\text {sup }} & =\hat{\mu}-\left(Q_{\tilde{\mu}}\left(\frac{\alpha}{2}\right)-\hat{\mu}\right) .
\end{aligned}
$$

em que $Q_{\tilde{\mu}}$ é a função quantílica de $\tilde{\mu}$.

Esse é o intervalo de confiança conhecido como intervalo bootstrap pivotal (Tibshirani (1984)). Ele é simples e com uma acurácia razoável, sendo, assim, uma boa escolha de método para determinarmos o intervalo de confiança.

\subsubsection{Processo de determinação das amostras bootstrap}

Para realizarmos o teste, segundo o princípio do bootstrap, devemos determinar um processo de simulação dos dados.

A distribuição da estatística de teste sob esse processo artificial de simulação dos dados é conhecida como distribuição bootstrap. O p-valor bootstrap pode ser calculado usando a distribuição bootstrap como distribuição nominal.

Com um modelo de regressão, ajustado à base de dados $\left\{\left(X_{i}, y_{i}\right)\right\}_{i=1}^{n}$, temos algumas opções para simular a amostra de bootstrap:

- podemos simular novos valores para as observações independentes $X_{i}$ e, então, obter $y_{i}$ de uma distribuição condicional $y \mid X$ específica;

- podemos sortear novamente, com reposição, os pares $\left(X_{i}, y_{i}\right)$; ou

- podemos manter $X_{i}$ fixos, mas tomar $y_{i}$ igual a $\hat{\mu}\left(X_{i}\right)$ adicionada a um resíduo $\varepsilon_{j}$, em que $j$ é um índice sorteado entre $1, \ldots, n$, ou seja, estamos sorteando os resíduos com reposição.

O primeiro caso é considerado um bootstrapping paramétrico. Nesse caso, o intervalo de confiança resultante tende a ser menor quando comparado aos outros casos. Porém isso se deve a suposição de que tanto a forma da superfície de regressão, como a distribuição dos resíduos é correta.

No segundo caso, estamos gerando amostras a partir da distribuição conjunta de $\left(X_{i}, y_{i}\right)$. Nesse caso, não é necessário assumir que são corretas nem a distribuição dos resíduos está correta e nem a 


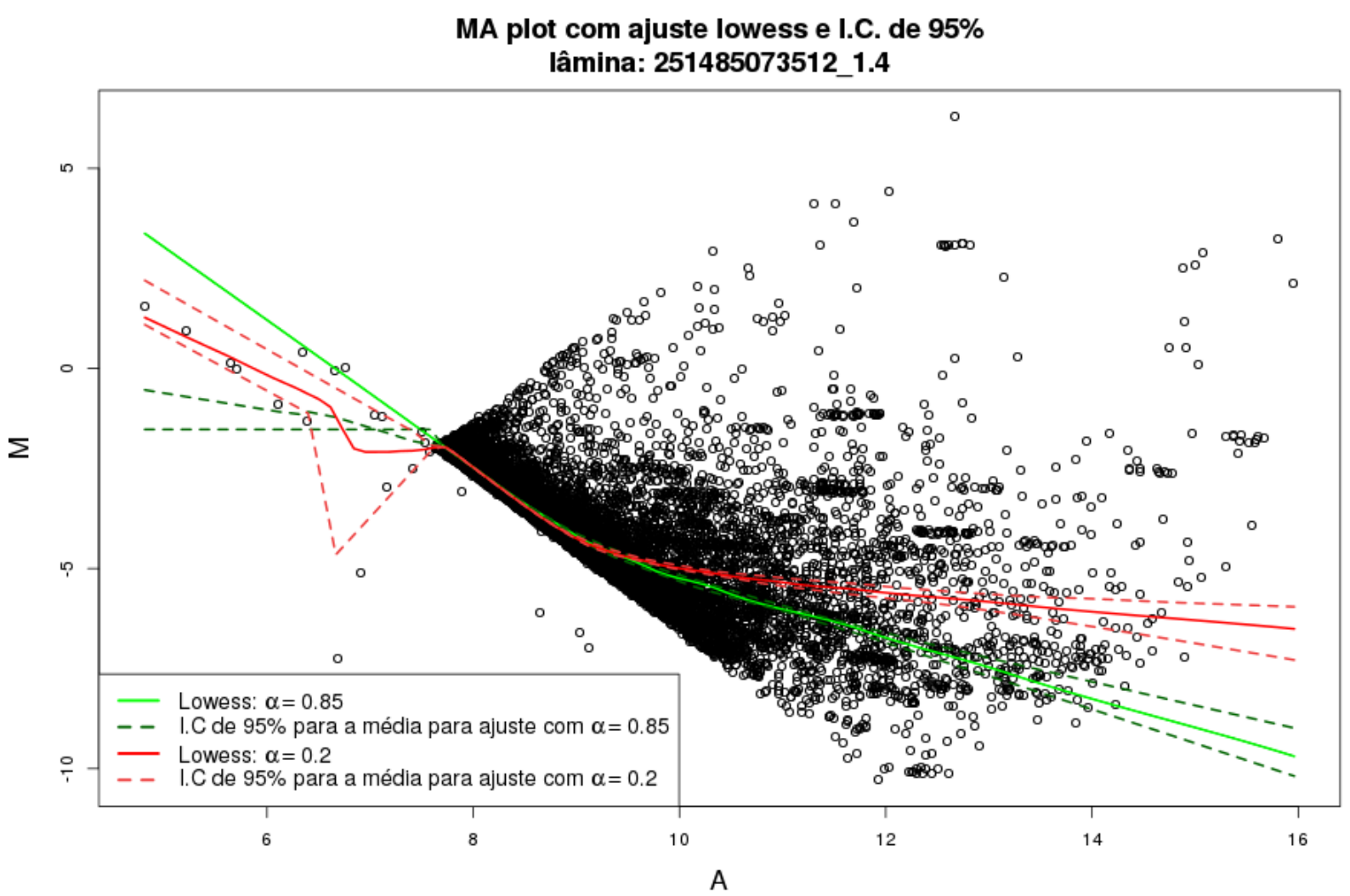

Figura 5.6: Gráfico $M$-A com a curva de suavização obtida por lowess usando parâmetro de suavização convencional $(\alpha=0,2)$ e parâmetro de suavização estimado pelo método proposto na seção 5.1.4, com valor igual a 0,85 , ambas com os respectivos intervalos de confiança de $95 \%$ obtidos usando wild bootstrap.

forma da superfície de regressão. Assume-se apenas que os pares de observações são independentes. É o método de bootstrap mais seguro, porém o intervalo de confiança tende a ser muito largo, fornecendo uma folga grande para a média verdadeira.

Já no último caso, fazemos uma nova amostragem dos resíduos com reposição. Nesse método, há a vantagem de conservar a informação das variáveis explicativas na estimação de $\mu$, já que os regressores são mantidos no valor amostral e a variável resposta é obtida a partir dos valores residuais. Já a distribuição dos resíduos deixa de ser considerada. Se temos confiança de que a forma da superfície de regressão está correta, mas não temos a mesma certeza para a distribuição dos resíduos, então essa é a melhor opção de método de amostragem bootstrap.

Sortear os resíduos como descrevemos assume que a distribuição das flutuações ao redor da superfície de regressão é a mesma para todos os valores de $X_{i}$. Quando isso não é verificado, ou seja, quando ocorre heteroscedasticidade, devemos fazer alguma correção na distribuição dos resíduos.

O método wild bootstrap foi desenvolvido por Liu et al. (1988), utilizando os trabalhos de Wu et al. (1986) e Beran (1988). Ele é um método de amostragem bootstrap para dados heteroscedásticos.

O processo de simulação dos dados para gerar a amostra bootstrap é dado por:

$$
y_{i}^{*}=\hat{\mu}\left(X_{i}\right)+\varepsilon_{i}^{*},
$$

em que

$$
\varepsilon_{i}^{*}=\hat{\varepsilon}_{i} \xi_{i},
$$

$\operatorname{com} \xi_{i}$ seguindo uma distribuição, $F, \operatorname{com} \mathbb{E}\left(\xi_{i}\right)=0$ e $\operatorname{Var}\left(\xi_{i}\right)=1$.

Assim, geramos as amostras bootstrap fixando os valores de $X_{i}$ e obtendo os valores de $y_{i}$ adicionando à estimativa $\hat{\mu}\left(X_{i}\right)$ o resíduo original $\hat{\varepsilon}_{i}$ multiplicado por uma variável amostrada de 
uma distribuição $F$.

A partir dessa nova amostra bootstrap, obtemos a estimativa de regressão $\tilde{\mu}$ sem considerar heteroscedasticidade, ou seja, sem adicionar os inversos das variâncias de cada observação da base de dados no problema de mínimos quadrados.

A distribuição da estatística de teste

$$
\tau=\frac{\hat{\mu}^{*}-\mu}{\sqrt{\hat{\operatorname{Var}}\left(\hat{\mu}^{*}\right)}}
$$

é a distribuição wild bootstrap.

Os autores Flachaire (2001) mostraram por simulações que a distribuição Rademacher

$$
F_{1}: \xi_{i}^{*}= \begin{cases}1 & \text { com probabilidade } 0,5 \\ -1 & \text { com probabilidade } 0,5\end{cases}
$$

para a distribuição de $\xi_{i}^{*}$ sempre oferece resultados melhores que outras distribuições populares como a distribuição de dois pontos, dada por:

$$
F_{2}: \xi_{i}^{*}= \begin{cases}-\frac{\sqrt{5}-1}{2} & \text { com probabilidade } p=\frac{\sqrt{5}+1}{2 \sqrt{5}} \\ \frac{\sqrt{5}-1}{2} & \text { com probabilidade } 1-p .\end{cases}
$$

Assim, quando temos dados heteroscedásticos, podemos obter o intervalo de confiança para a média $\mu$ a partir do estimador da superfície de suavização de lowess, utilizaremos o método wild bootstrap.

\subsection{Normalização usando valores esperados de $M$ e $A$}

Como comentamos no capítulo 3, uma proposta simples para incorporarmos as imprecisões das medidas das expressões gênicas nas análises é utilizar estimativas mais precisas para as médias das variáveis $M_{i}$ e $A_{i}$, que denotamos por $\bar{M}_{i}$ e $\bar{A}_{i}$.

Podemos estimar o viés causado pela dependência do corante estimando a curva de suavização dos pontos $\left\{\left(\bar{A}_{i}, \bar{M}_{i}\right)\right\}_{i=1}^{n}$. Essa estimação é feita geralmente por lowess, pois precisamos de robustez à outliers.

Na seção 5.1, vimos formas de selecionarmos os parâmetros do método lowess. Uma proposta é aproximar a função de suavização por polinômios de grau um em uma vizinhança determinada pelo parâmetro selecionado pelo método visto na seção 5.1.4.

Durante esse processo, obtemos a matriz de predição de lowess $L$ que mapeia todos os pontos $\bar{A}_{i}$ da base, para os seus valores ajustados $\hat{\mu}\left(A_{i}\right)$, com $i=1, \ldots, n$.

Com esses valores ajustados, corrigimos o viés do corante com a seguinte transformação:

$$
\left\{\left(\bar{A}_{i}, \bar{M}_{i}\right)\right\}_{i=1}^{n} \longmapsto\left\{\left(A_{i}^{*}, M_{i}^{*}\right)\right\}_{i=1}^{n} \doteq\left\{\left(\bar{A}_{i}, \bar{M}_{i}-\hat{\mu}\left(\bar{A}_{i}\right)\right)\right\}_{i=1}^{n},
$$

ou seja, definimos que a expressão relativa do $i$-ésimo local genético da lâmina de microarranjos é o resíduo da regressão no ponto $\bar{A}_{i}$, dado por $\bar{M}_{i}-\hat{\mu}\left(\bar{A}_{i}\right)$.

Nas figuras 5.7 e 5.8, podemos observar os dados de uma lâmina após a normalização com lowess utilizando, respectivamente, $\alpha$ estimado pelo método proposto em 5.1 .4 e $\alpha=0,2$. O valores de $M$ no gráfico $M-A$ da lâmina após a normalização são os resíduos da suavização por lowess. Os boxplots mostram a distribuição dos resíduos para valores de $A$ em intervalos de mesmo comprimento.

Vale a pena ressaltar que as curvas de suavização desses gráficos foram obtidas utilizando uma ferramenta gráfica simples. Assim, possuem apenas importância visual, permitindo uma análise gráfica da tendência geral dos resíduos. A média dos resíduos para ambos os casos foi muito próxima de zero. 
Gráfico M-A após normalização com lowess: $\alpha=0.85$

\begin{tabular}{l}
0 \\
0 \\
0 \\
11 \\
0 \\
00 \\
00 \\
0 \\
0 \\
0 \\
\hline \\
0 \\
0 \\
0 \\
0 \\
0 \\
0 \\
0 \\
0 \\
0 \\
0 \\
0 \\
$\frac{0}{0}$ \\
0 \\
$\simeq$
\end{tabular}

lâmina: 251485073512_1.4

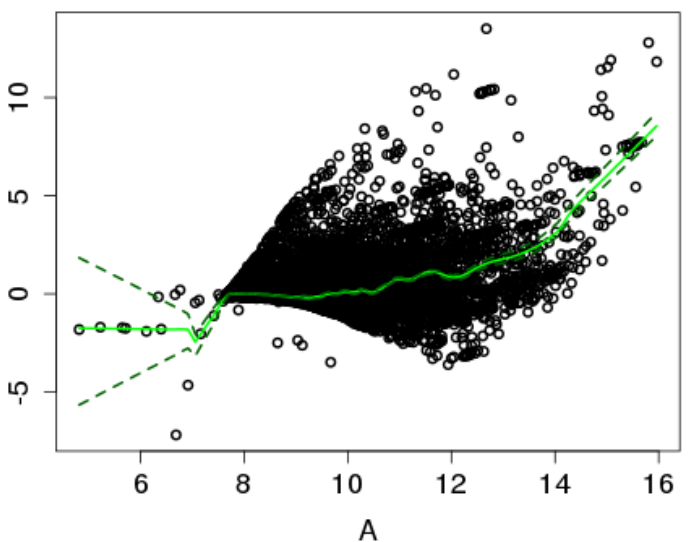

Boxplot dos resíduos por A - Lowess: $\alpha=0.85$

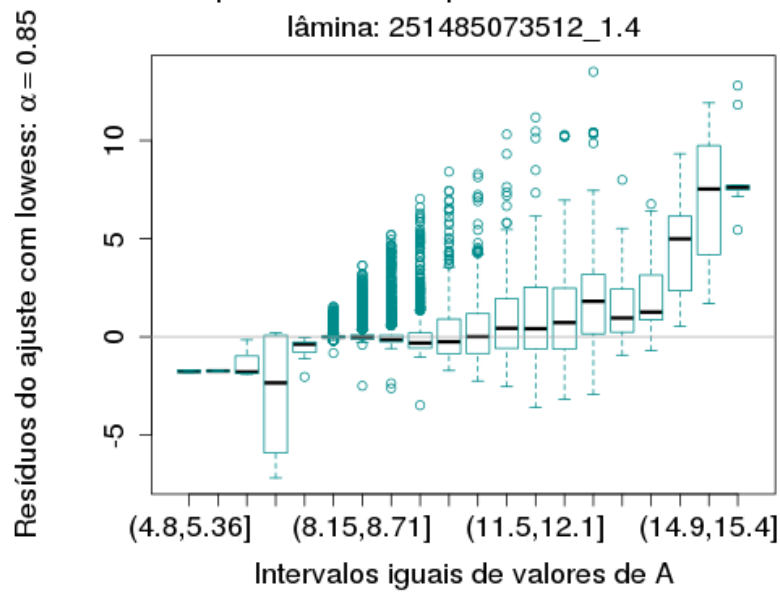

Figura 5.7: Gráfico $M-A$ após a normalização da lâmina usando lowess com valor de $\alpha$ igual a 0,85, e, à direita, boxplot dos valores dos resíduos para valores $A$ em intervalos de tamanhos iguais.

Gráfico M-A após normalização com lowess: $\alpha=0.2$

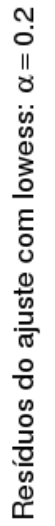

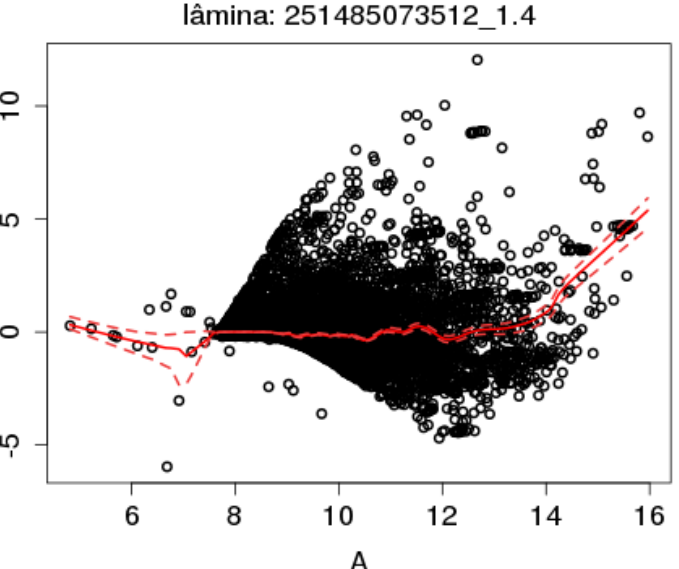

Boxplot dos resíduos por A - Lowess: $\alpha=0.2$

lâmina: $251485073512 \quad 1.4$

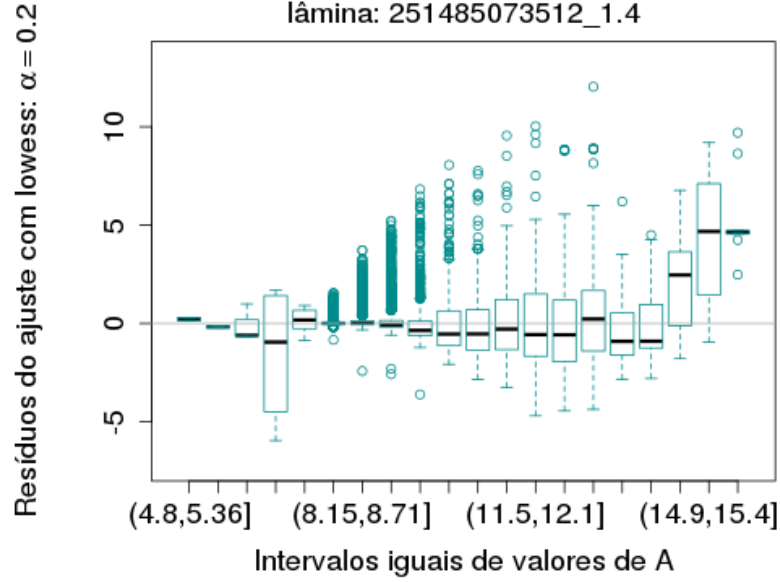

Figura 5.8: Gráfico $M$-A após a normalização da lâmina usando lowess com valor de $\alpha$ igual a 0,2 , e, à direita, boxplot dos valores dos resíduos para valores $A$ em intervalos de tamanhos iguais. 


\subsection{Normalização considerando dados intervalares}

No capítulo 3, vimos que as medidas de variância das intensidades de cada local genético podem, além de melhorar as estimativas das médias de $M_{i}$ e $A_{i}$, também ser usadas para construir intervalos que representam medidas de expressões gênicas com erro.

Assim, o valor da expressão de um local genético deixa de ser representado por uma estimativa de tendência central, como a média, e passa a ser definido por um intervalo de valores normalmente distribuídos e que contém, com uma certa confiança, essa média.

Para definirmos esse intervalo utilizamos os estimadores $\bar{M}_{i}$ e $\bar{A}_{i}$ para as médias, definidos, respectivamente, pelas equações (3.7) e (3.10)). Além disso, a partir dos estimadores da variância dessas medidas, $\hat{\sigma}^{2}\left(M_{i}\right)$ e $\hat{\sigma}^{2}\left(A_{i}\right)$, respectivamente definidos pelas equações (3.8) e (3.11)), obtemos os desvios padrões tomando as suas raízes quadradas.

Com isso, representamos as medidas de expressão dos $n$ locais genéticos por:

$$
\left\{\left(\left(\bar{A}_{i}-\epsilon_{A_{i}}, \bar{A}_{i}+\epsilon_{A_{i}}\right),\left(\bar{M}_{i}-\epsilon_{M_{i}}, \bar{M}_{i}+\epsilon_{M_{i}}\right)\right)\right\}_{i=1}^{n},
$$

em que os erros das medidas $A_{i}$ e $M_{i}$, respectivamente, $\epsilon_{A_{i}}$ e $\epsilon_{M_{i}}$, são definidos, para um quantil $c$ apropriado da distribuição normal, por:

$$
\begin{aligned}
& \epsilon_{A_{i}} \doteq c \hat{\sigma}\left(A_{i}\right) \mathrm{e} \\
& \epsilon_{M_{i}} \doteq c \hat{\sigma}\left(M_{i}\right) .
\end{aligned}
$$

Para a suavização utilizando dados intervalares, podemos utilizar a abordagem sugerida pelos autores de Carvalho et al. (2004).

Nesse método, determinamos duas superfícies de regressão. Uma sobre os pontos médios dos intervalos e outra sobre os tamanhos dos intervalos.

Ou seja, determinamos $\hat{\mu}_{M d}$, que suaviza a base de dados formada pelos pontos médios,

$$
\left\{\left(\bar{A}_{i}, \bar{M}_{i}\right)\right\}_{i=1}^{n},
$$

e $\hat{\mu}_{\epsilon}$, que é determinada sobre a base formada pelos tamanhos dos intervalos,

$$
\left\{\left(2 \epsilon_{A_{i}}, 2 \epsilon_{M_{i}}\right)\right\}_{i=1}^{n}
$$

Com o método lowess, obtemos duas matrizes de predição. Uma que faz o mapeamento dos pontos $\bar{A}_{i}$, para os seus valores ajustados $\hat{\mu}_{M d}\left(A_{i}\right)$, com $i=1, \ldots, n$, e outra que faz o mapeamento dos tamanhos dos intervalos de $A_{i}, 2 \epsilon_{A_{i}}$, para os tamanhos dos intervalos suavizados de $M_{i}, \hat{\mu}_{\epsilon}\left(A_{i}\right)$.

Com isso, podemos realizar o processo de normalização, que é descrito pela transformação em que a sequência de pares de intervalos

$$
\left\{\left(I_{A_{i}}, I_{M_{i}}\right)\right\}_{i=1}^{n}=\left\{\left(\left(\bar{A}_{i}-\epsilon_{A_{i}}, \bar{A}_{i}+\epsilon_{A_{i}}\right),\left(\bar{M}_{i}-\epsilon_{M_{i}}, \bar{M}_{i}+\epsilon_{M_{i}}\right)\right)\right\}_{i=1}^{n}
$$

é levada nos pares de intervalos normalizados $\left\{\left(I_{A_{i}^{*}}, I_{M_{i}^{*}}\right)\right\}_{i=1}^{n}$ definidos como:

$$
\left\{\left(\left(\bar{A}_{i}-\epsilon_{A_{i}}, \bar{A}_{i}+\epsilon_{A_{i}}\right),\left(\bar{M}_{i}-\hat{\mu}_{M d}\left(\bar{A}_{i}\right)-\frac{1}{2} \hat{\mu}_{\epsilon}\left(A_{i}\right), \bar{M}_{i}-\hat{\mu}_{M d}\left(\bar{A}_{i}\right)+\frac{1}{2} \hat{\mu}_{\epsilon}\left(A_{i}\right)\right)\right)\right\}_{i=1}^{n} .
$$

Assim, fazemos uma translação do ponto médio do intervalo de $M_{i}$, mas também modificamos os limites dos intervalos, que serão dados pela estimativa $\hat{\mu}_{\epsilon}$.

A estimativa da curva de suavização $\hat{\mu}_{\epsilon}$ pode ser feita utilizando lowess com parâmetro de suavização estimado pelo método visto na seção 5.1.4. Um exemplo dessa estimação pode ser visto na figura, 5.11. Como os dados são heteroscedásticos, selecionamos o parâmetro de suavização $\alpha$ minimizando o critério HRCp. O gráfico da seleção desse parâmetro pode ser visto na figura 5.9 e a função de variância estimada para a utilização desse critério pode ser vista na figura 5.10. 
Seleçāo pelo critério HRCP - lâmina: 251485073512_1.4

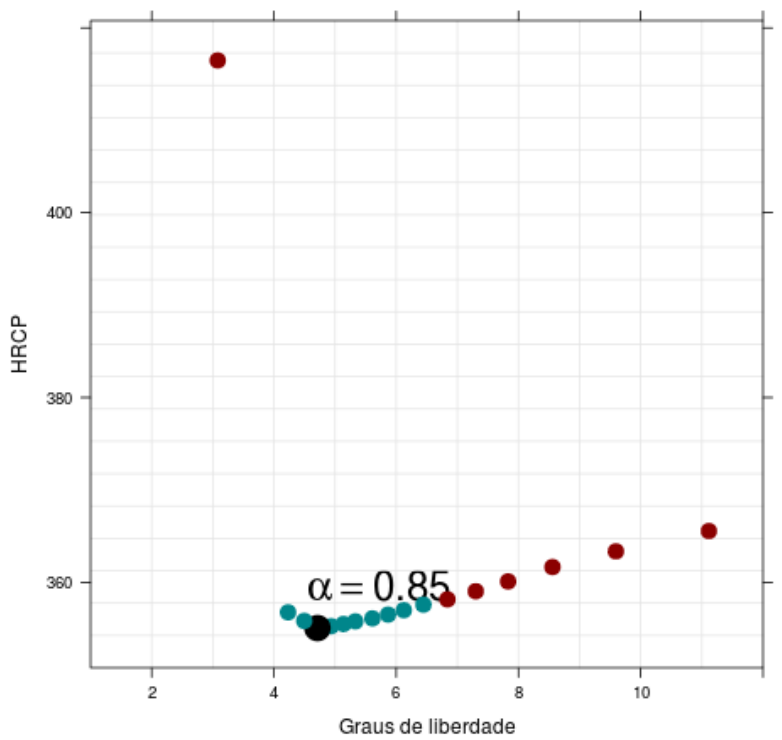

Figura 5.9: Seleção do parâmetro de largura de banda para determinação de $\hat{\mu}_{\epsilon}$, a curva de suavização lowess dos tamanhos dos intervalos. A seleção foi obtida por minimização do critério HRCp, que é robusto à heteroscedasticidade, e considerando a região de achatamento, que pode ser observadas nos valores marcados em azul. Valor obtido: $\alpha^{*}=0,85$. Foram avaliadas estimativas com o parâmetro $\alpha$ variando de 0,2 a 1.

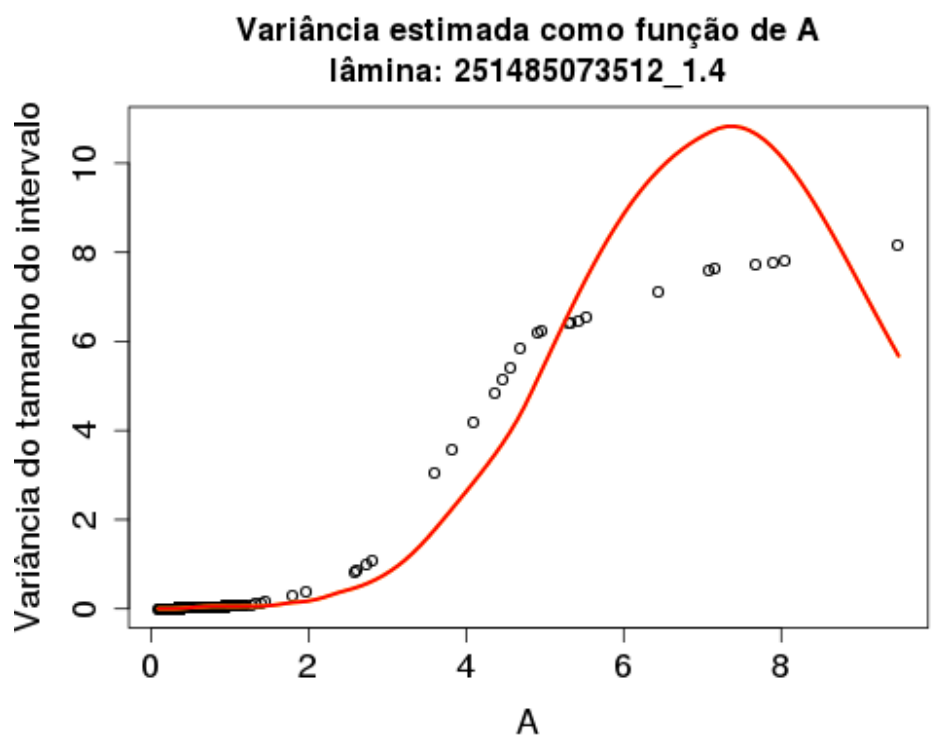

Figura 5.10: Variância estimada do tamanho dos intervalos $I_{M_{i}}$ como função da variável independente A, a partir da estimativa dada pela equação (4.6). Em preto, no gráfico, observamos os valores da suavização $\widetilde{\mu}_{x_{0}}(x)$, que utiliza um parâmetro de suavização bem pequeno $(\alpha=0,1)$ e, em vermelho, a função variância resultante após uma suavização local gama.

Uma das vantagens de trabalharmos com dados intervalares é que podemos corrigir esses dados adicionando as incertezas acumuladas durante os pré-processamentos.

Para considerarmos as incertezas do método de suavização, por exemplo, o lowess, podemos substituir os valores ajustados, $\hat{\mu}_{M d}\left(\bar{A}_{i}\right)$, pelo intervalo de confiança que inclui o valor $\mu_{M d}\left(\bar{A}_{i}\right)$, dado por $\left(C_{\text {inf }_{i}}\left(\bar{A}_{i}\right), C_{\text {sup }_{i}}\left(\bar{A}_{i}\right)\right)$.

Assim, para considerarmos tanto os erros originais das medidas como os obtidos durante a estimação no viés, a normalização definida na equação 5.2 pode ser modificada para: 


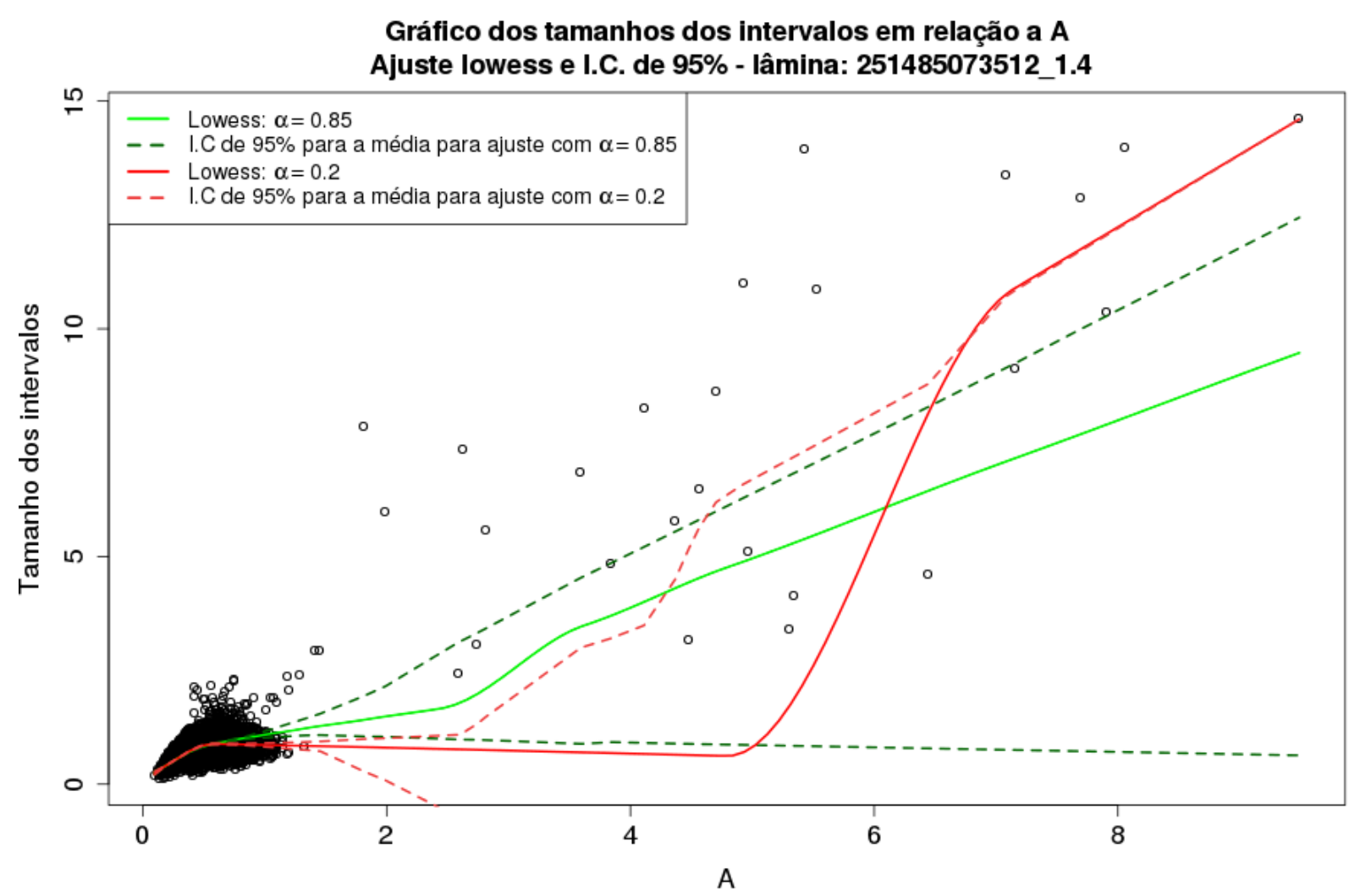

Figura 5.11: Estimativa das curvas de suavização dos tamanhos dos intervalos em relação aos valores das intensidades médias A, utilizando lowess com parâmetro de suavização estimado pelo método visto na seção 5.1 .4 e parâmetro de suavização igual a 0,2 .

$$
\left\{\left(\bar{A}_{i}, \bar{M}_{i}\right)\right\}_{i=1}^{n} \longmapsto\left\{\left(A_{i}^{*}, M_{i}^{*}\right\}_{i=1}^{n} \doteq\left\{\left(\bar{A}_{i},\left(\bar{M}_{i}-C_{\text {sup }}\left(\bar{A}_{i}\right), \bar{M}_{i}-C_{\text {inf }}\left(\bar{A}_{i}\right)\right)\right)\right\}_{i=1}^{n} .\right.
$$

Da equação (5.5), observamos que as medidas $M_{i}$ normalizadas, denotadas por $M_{i}^{*}$, são intervalos. Assim, a análise com esses dados não pode ser feita de forma convencional.

Devemos ainda notar que, como

$$
C_{\text {inf }} \leq C_{\text {sup }} \Leftrightarrow-C_{\text {inf }} \geq-C_{\text {sup }} \Leftrightarrow \bar{M}_{i}-C_{\text {inf }} \geq \bar{M}_{i}-C_{\text {sup }},
$$

tomamos o cuidado de definir os extremos do intervalo $I_{M_{i}^{*}}$ sem deixá-los invertidos.

A normalização das expressões gênicas representadas por intervalos também pode ser adaptada para incluir os erros provenientes do método de estimação do viés. Nesse caso, os pares de intervalos normalizados, $\left\{\left(I_{A_{i}^{*}}, I_{M_{i}^{*}}\right)\right\}_{i=1}^{n}$, definidos em (5.4), passarão a ser obtidos da seguinte forma:

$$
\left\{\left(\left(\bar{A}_{i}-\epsilon_{A_{i}}, \bar{A}_{i}+\epsilon_{A_{i}}\right),\left(\bar{M}_{i}-C_{\text {sup }}\left(\bar{A}_{i}\right)-\frac{1}{2} \hat{\mu}_{\epsilon}\left(A_{i}\right), \bar{M}_{i}-C_{i n f}\left(\bar{A}_{i}\right)+\frac{1}{2} \hat{\mu}_{\epsilon}\left(A_{i}\right)\right)\right)\right\}_{i=1}^{n}
$$

Nas figuras 5.12 e 5.13, podemos ver o resultado da normalização de uma lâmina de microarranjos para uma estimação do viés feita com, respectivamente, lowess e $\alpha=0,85$, estimado pelo método visto na seção 5.1.4, e lowess com $\alpha=0,2$. Nos gráficos, foram esboçadas as curvas do intervalo de confiança de $95 \%$ para as medidas $M_{i}$, do intervalo que representa as medidas com seus erros originais, desses erros suavizados pelo método proposto por de Carvalho et al. (2004) e, por fim, do intervalo com os erros suavizados somados aos erros da estimação do viés, que são dados pelo intervalo de confiança. 
Determinação dos erros da medida após Lowess com $\alpha=0.85$

lâmina: 251485073512_1.4

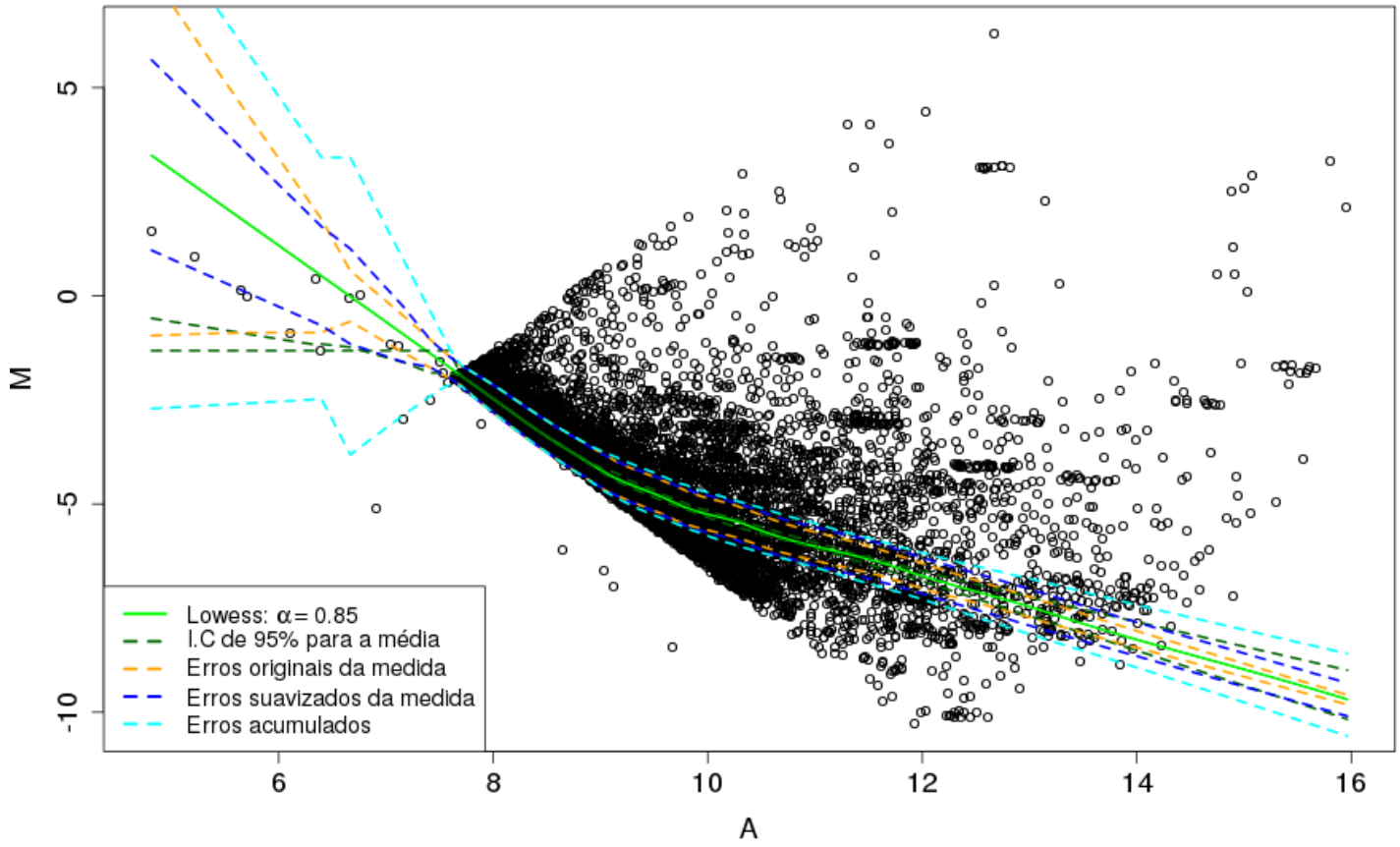

(a) Gráfico $M$ - $A$ antes da normalização.

Medidas e erros normalizados com Lowess: $\alpha=0.85$

lâmina: 251485073512_1.4

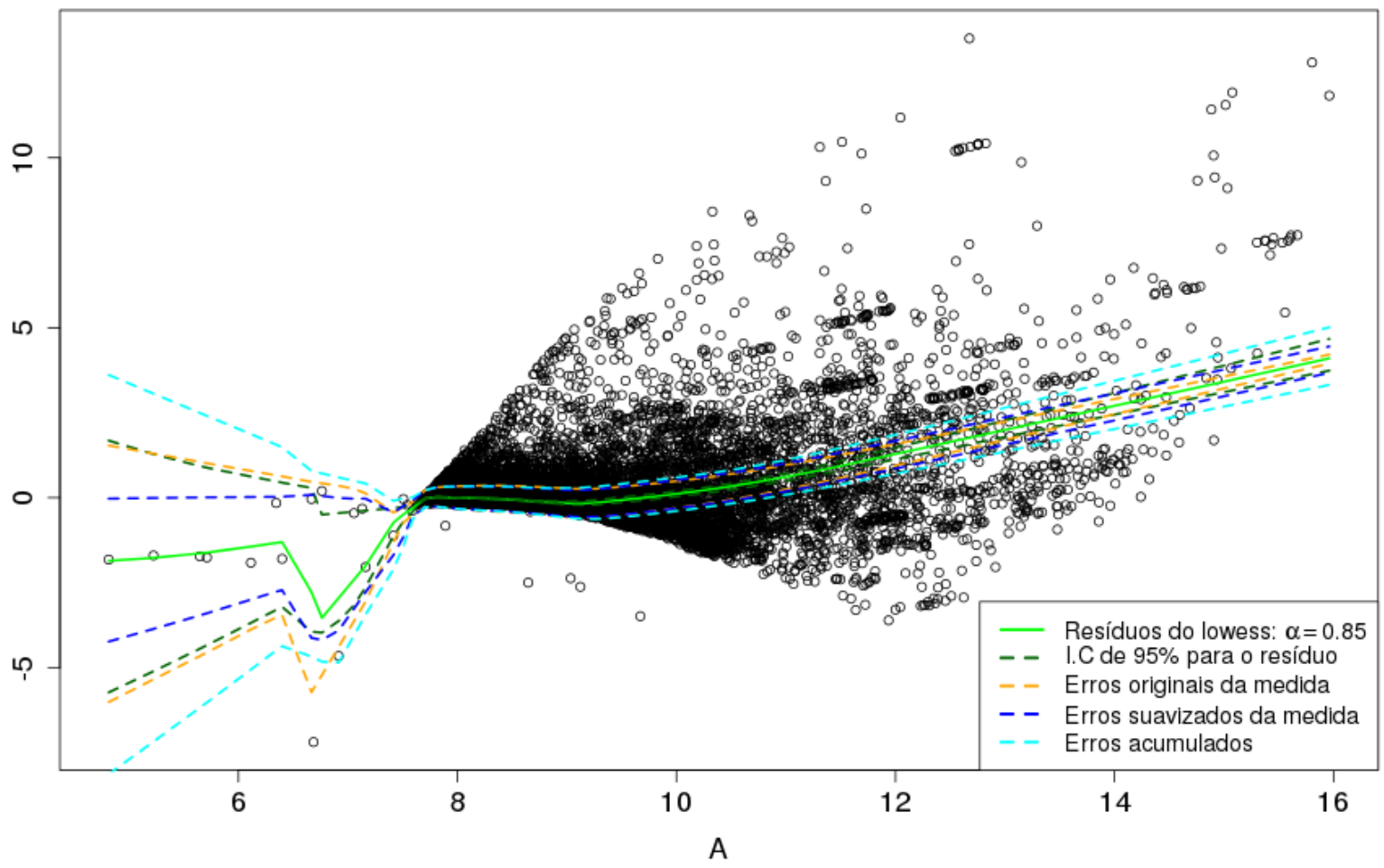

(b) Gráfico $M$-A após a normalização.

Figura 5.12: Gráfico $M$-A antes da normalização (em (a)), e após a normalização (em (b)). No gráfico é mostrada a curva de suavização ajustada por lowess usando parâmetro de suavização igual a 0,85 , estimada pelo método proposto na seção 5.1.4. Também são mostrados o intervalo de confiança de $95 \%$ e os intervalos que representam as medidas com erro antes da suavização, suavizados e com os erros provenientes do método lowess acumulados. 


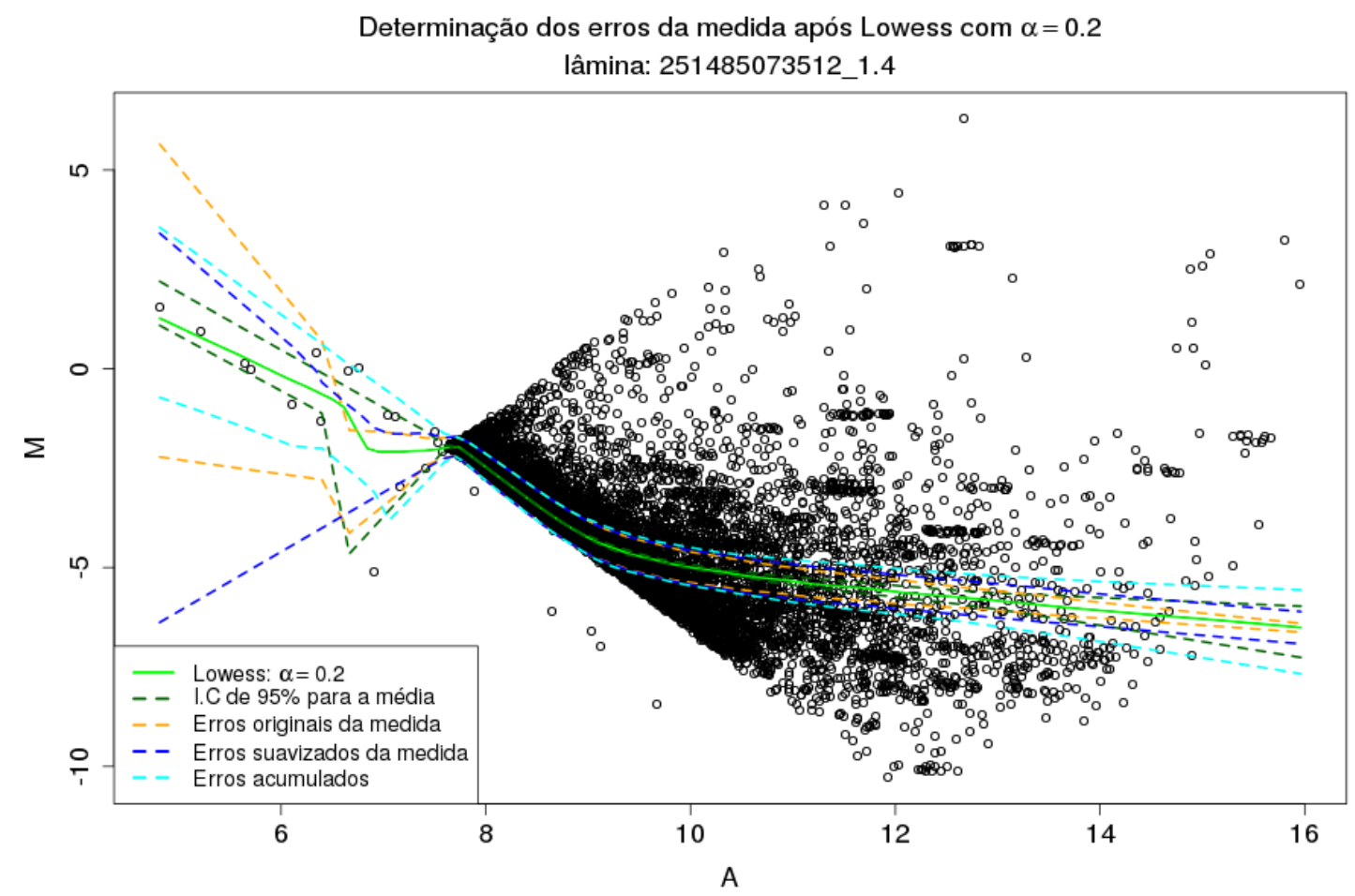

(a) Gráfico $M$-A antes da normalização.

Medidas e erros normalizados com Lowess: $\alpha=0.2$

lâmina: 251485073512_1.4

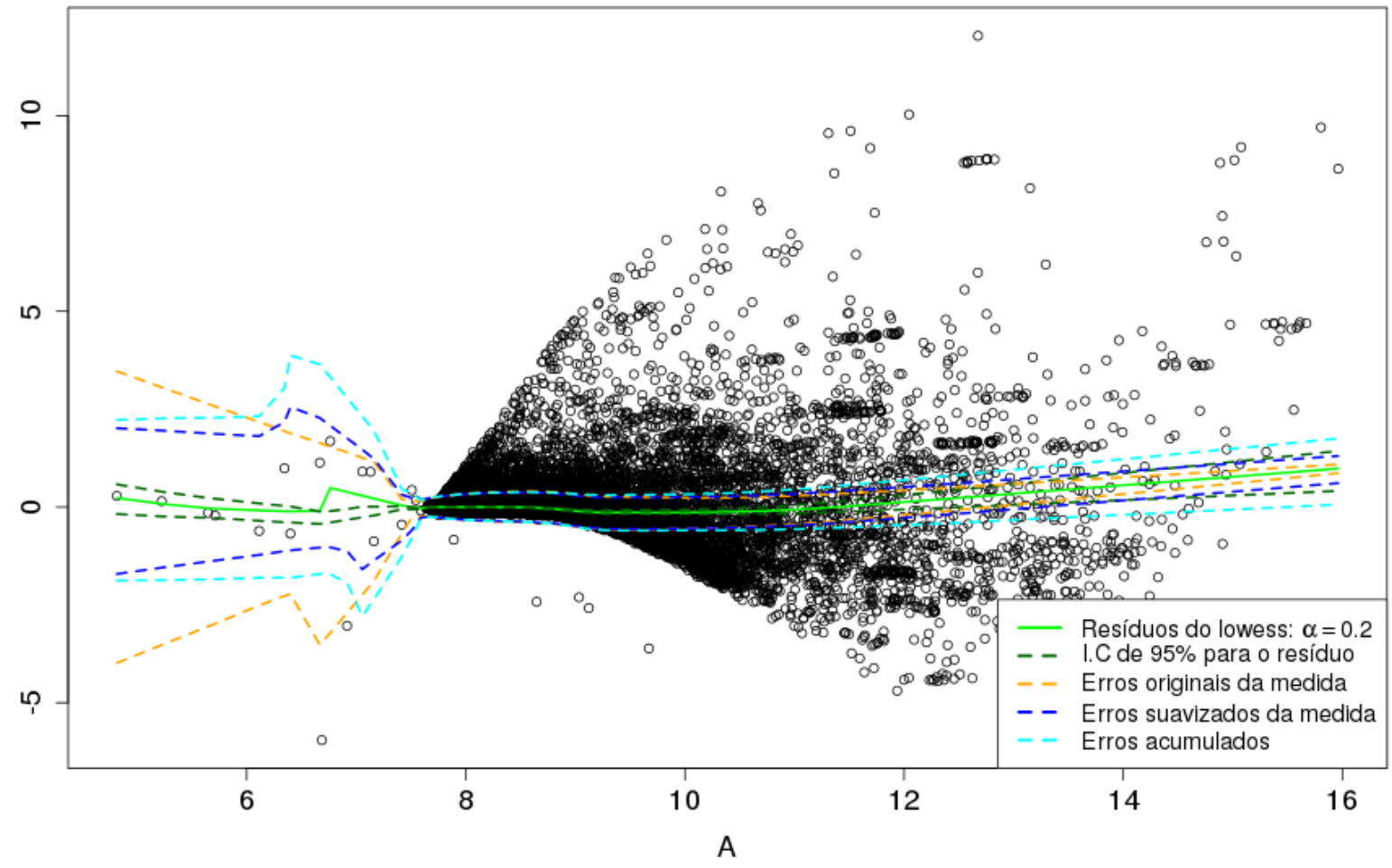

(b) Gráfico $M-A$ após a normalização.

Figura 5.13: Gráfico $M-A$ antes da normalização (em (a)), e após a normalização (em (b)). No gráfico é mostrada a curva de suavização ajustada por lowess usando parâmetro de suavização igual a 0,2. Também são mostrados o intervalo de confiança de $95 \%$ e os intervalos que representam as medidas com erro antes da suavização, suavizados e com os erros provenientes do método lowess acumulados. 


\section{Capítulo 6}

\section{Genes diferencialmente expressos considerando erros de medida}

Como discutimos na seção 2.6, um dos objetivos da análise de dados de um experimento com expressões gênicas é determinar quais são os genes diferencialmente expressos.

$\mathrm{Na}$ abordagem discutida na seção 2.6, ajustamos um modelo linear sobre as expressões de um dado gene $i$, considerando como efeito fixo a condição experimental de cada amostra.

Esse modelo pode ser aplicado quando consideramos apenas uma medida de expressão central do gene $i$, para cada lâmina $l$ do experimento de microarranjos, pois assumimos que essas medidas são independentes. Assim, o método para obtermos os genes diferencialmente expressos quando utilizamos as medidas $\bar{M}_{i l}$ (3.7) (estimativas das médias considerando as imprecisões da medida da expressão do gene $i$ em cada lâmina $l$ ) é o mesmo. Porém, quando descrevemos os erros das medidas $M_{i l}$ por intervalos, não podemos utilizar essa mesma abordagem.

Vale a pena ressaltar aqui a notação que utilizaremos neste capítulo. Nos capítulos anteriores, fixamos uma lâmina $l$ e cada local genético $i$ tinha uma medida de expressão $M_{i}$. Agora, estamos fixando um local genético $i$ e teremos como amostra as expressões desse local genético obtidas em cada uma das $l=1, \ldots, n$ lâminas. Para não carregarmos muito a notação, omitiremos o índice $i$.

Neste capítulo, mostraremos uma abordagem para determinarmos os genes diferencialmente expressos quando suas expressões são representadas por intervalos.

\subsection{Determinação de genes diferencialmente expressos com dados intervalares}

Na seção 3.2, mostramos como representar a medida da expressão gênica em um intervalo que considera os erros de medição. Mas, além desses erros, que são provenientes tanto do processo de digitalização das imagens de cada canal da lâmina quanto do processo de segmentação dos locais genéticos, também temos os erros acumulados durante o processo de normalização.

Vimos, na seção 5.2, como podemos obter uma estimativa do intervalo que contém os erros acumulados durante o processo de normalização com lowess. Assim, para uma dada lâmina $l$, a estimativa dos erros totais da expressão do gene $i$ após a normalização, é descrita pelo intervalo $I_{M_{l}^{*}}$, definido na equação (5.6).

$\mathrm{Na}$ abordagem que apresentaremos neste capítulo, discretizaremos cada intervalo $I_{M_{l}^{*}}, l=$ $1, \ldots, n$. Para isso, em cada lâmina $l$, amostramos $m$ observações de uma variável aleatória com distribuição normal, cujas observações caem, com probabilidade de $99,73 \%$, no intervalo $I_{M_{l}^{*}}$. Pela conhecida regra dos 3-sigmas, definimos essa variável como:

$$
M_{l}^{*} \sim \mathcal{N}\left(I_{M_{l m e d}^{*}} \frac{I_{M_{l m a x}^{*}}-I_{M_{l m e d}^{*}}}{3}\right)
$$

em que $I_{M_{l}^{*} \text { med }}$ é o ponto médio e $I_{M_{l}^{*} \text { max }}$ é o limite superior do intervalo $I_{M_{l}^{*}}$. 
Os valores amostrados da variável $M_{l}^{*}$ e, consequentemente, do intervalo $I_{M_{l}^{*}}$ serão considerados réplicas observadas da medida da expressão normalizada de um dado local genético na lâmina $l$.

Nesse caso em que estamos gerando as réplicas por amostragem aleatória simples, podemos sempre gerar as $m$ réplicas da expressão de cada local genético de cada lâmina e, assim, podemos considerar um experimento balanceado. Além disso, podemos assumir que as expressões de todas as réplicas são de igual importância.

Dessa forma, fixado um local genético, teremos $m n$ observações agrupadas em $n$ lâminas, ou seja, teremos as seguintes observações:

$$
M_{l j}^{*}, \quad \text { para } l=1, \ldots, n ; \quad j=1, \ldots, m .
$$

Esse artifício utilizado simula um experimento conhecido como experimento com medidas repetidas Neter et al. (1996). Assim, além da condição do paciente (considerado um efeito fixo), precisamos considerar no modelo um efeito aleatório, correspondente ao agrupamento das réplicas em lâminas. Nesse caso, denominaremos o fator de agrupamento por lâmina, que terá $n$ níveis e $m$ observações amostradas para cada nível.

Nosso interesse é conhecer apenas o efeito que a condição experimental da amostra, que chamamos de condição do paciente, exerce sobre a média de todas as expressões. As lâminas, que representam pacientes, são uma amostra de toda a população e, assim, não desejamos fazer inferências sobre uma lâmina específica. Por esses motivos que o fator lâmina é colocado no modelo como um efeito aleatório.

Uma observação importante é que poderíamos ter mais fatores de agrupamento, em que lâmina seria o fator de agrupamento mais interno. Nesse caso, teríamos um modelo misto aninhado (Nested Mixed Design) e que pode ser visto com mais detalhes em Neter et al. (1996). Neste trabalho, consideraremos lâmina como o único fator de agrupamento e, por causa das características dos experimentos de microarranjos, temos, para cada lâmina (grupo), observações de apenas um nível do efeito fixo condição do paciente. O modelo que apresentaremos pode ser facilmente adaptado para casos com mais níveis de agrupamento.

Modelos de análise de variância para estudos que incluem tanto fatores fixos como aleatórios são chamados de Modelo III ANOVA com fatores mistos (Neter et al. (1996)).

Nas próximas seções deste capítulo, apresentaremos o modelo linear de efeitos mistos, ou seja, aquele em que tanto os efeitos fixos como os efeitos aleatórios ocorrem linearmente.

\subsubsection{O modelo linear misto}

Os modelos mistos lineares são extensões do modelo linear que levam em consideração os efeitos aleatórios. Esses efeitos podem ser interpretados como um termo de erro adicional, já que leva em conta a correlação entre observações dentro de um mesmo grupo (lâmina).

Para mostrarmos a importância do agrupamento no modelo, consideraremos inicialmente o modelo linear convencional, isto é, sem o agrupamento por lâmina.

Nesse caso, temos

$$
M_{l j k}^{*}=\mu+\tau_{k}+\varepsilon_{l j k}, \quad l=1, \ldots, n, \quad j=1, \ldots, m, \quad k=1, \ldots, K,
$$

em que

$M_{l j k}^{*}$ é a $j$-ésima réplica da expressão normalizada de um dado local genético, observada na $l$-ésima lâmina, com condição experimental $k$;

$\mu$ é uma constante que representa a expressão média entre as lâminas amostradas;

$\tau_{k}$ é o efeito fixo associado a condição do paciente $k$; e

$\varepsilon_{l j k}$ são os erros independentes e com distribuição $\mathcal{N}\left(0, \sigma^{2}\right)$, em que $\sigma^{2}$ é a variância das observações dentro da lâmina. 
Como o efeito de grupo será incorporado aos resíduos, teremos uma estimativa inflada da variabilidade dos resíduos, que deveria ser apenas associada à variabilidade intra-lâmina.

Na figura 6.1, mostramos os resíduos dessa modelagem em relação às lâminas para enfatizar a importância do grupo. Vemos que os resíduos estão dispersos entre -4 e 4, porém fica claro que a dispersão dentro de qualquer uma das lâminas é bem menor. Assim, se o efeito da lâmina for modelado, teremos um ruído muito menor.
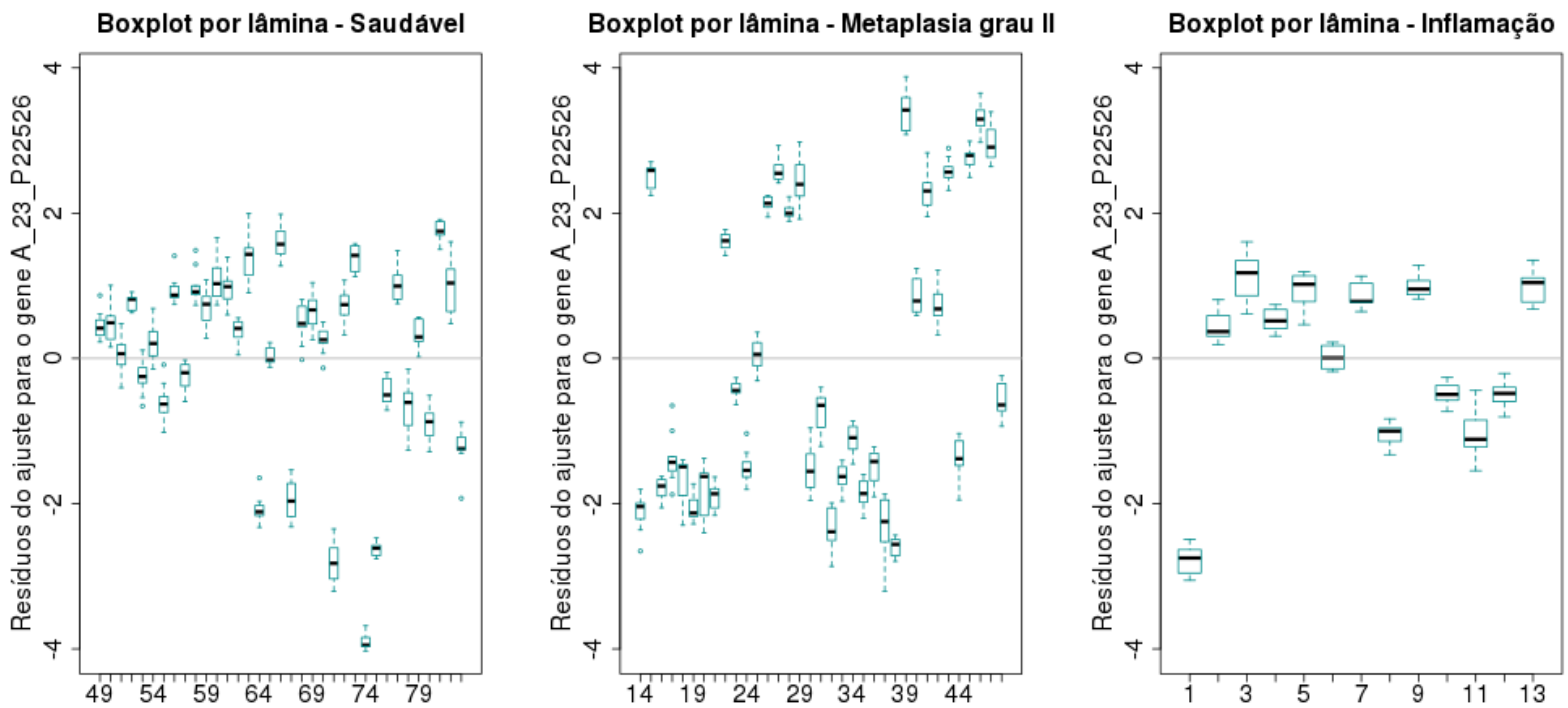

Figura 6.1: Gráfico dos resíduos do ajuste das expressões do gene A_23_P22526 sem considerar o agrupamento por lâmina.

Podemos estender o modelo (6.1), adicionando o fator de agrupamento lâmina como um efeito aleatório. Assim, o efeito de uma observação pertencer a uma lâmina $l$ será capturado pelo modelo a partir da variável $\gamma_{l}$ :

$$
M_{l j k}^{*}=\mu+\tau_{k}+\gamma_{l}+\varepsilon_{l j k}, \quad l=1, \ldots, n, \quad j=1, \ldots, m, \quad k=1, \ldots, K .
$$

O efeito $\gamma_{l}$ pode ser interpretado como o desvio entre a média geral e a média da expressão considerando apenas a lâmina $l$. Além disso, os efeitos $\gamma_{l}$ são independentes e com distribuição $\mathcal{N}\left(0, \sigma_{\gamma}^{2}\right)$, em que $\sigma_{\gamma}^{2}$ é a variância entre lâminas.

Devemos observar que estamos desconsiderando a interação entre a lâmina e a condição do paciente porque, neste experimento, esse efeito não tem um significado que nos interessa.

Ao modelarmos o efeito do grupo (o agrupamento em lâminas), estamos explicando uma variabilidade importante dos dados e, assim, esperamos que os resíduos representem apenas o ruído aleatório. Podemos ver na figura 6.2, que, com essa modelagem, os resíduos ficaram centrados ao redor do zero e com magnitude consideravelmente menor.

Os parâmetros a serem estimados no modelo (6.2) são: $\mu, \tau_{k}, k=1, \ldots, K, \sigma_{\gamma}^{2}$ e $\sigma^{2}$. Os efeitos aleatórios $\gamma_{l}$ são apenas uma outra variação no modelo, logo não precisam ser estimados. No entanto, podemos fazer as predições $\hat{\gamma}_{l}$ a partir dos dados observados.

Veremos na seção ?? que a estimação desses parâmetros pode ser feita por máxima verossimilhança (maximum likelihood - ML) ou por máxima verossimilhança restrita (restricted maximum likelihood - REML).

\subsubsection{O modelo com erros homoscedásticos}

Devemos observar que no modelo (6.2) estamos assumindo que os erros $\varepsilon_{l j k}$ são homoscedásticos, ou seja, apresentam variância constante igual a $\sigma^{2}$. 

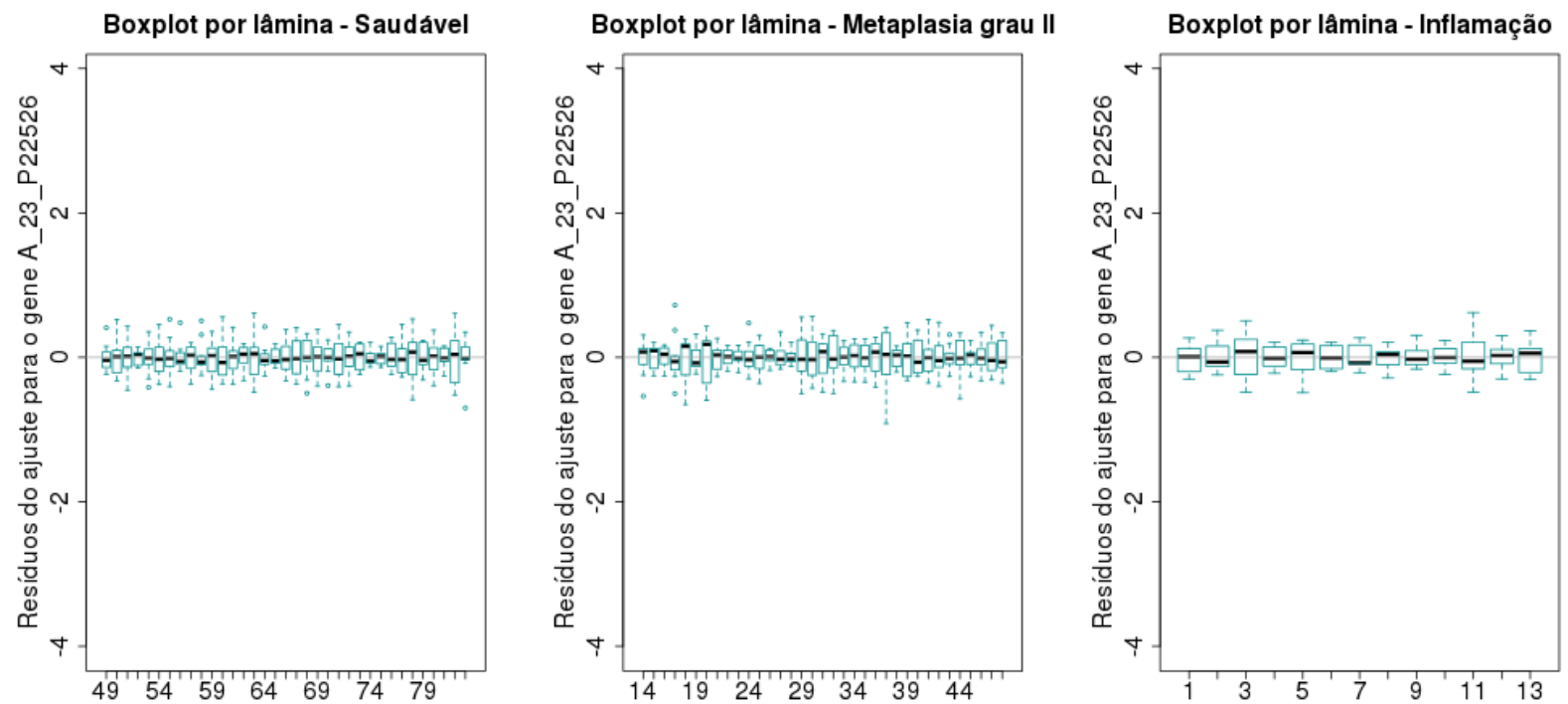

Figura 6.2: Gráfico dos resíduos do ajuste das expressões do gene A_23_P22526 considerando o agrupamento por lâmina.

Supor que a variância intra-lâmina é a mesma para todas as lâminas é o mesmo que assumir que os intervalos que definem as expressões de um dado local genético não são significantemente distintos entre as lâminas. Assim, esse modelo não é o mais adequado para realizarmos a análise dos dados de expressões gênicas com erro de medida.

Apesar disso, como pode ser visto com mais detalhes na seção 6.1.4, vale a pena estudarmos as ferramentas de estimação do modelo básico, pois com uma mudança de variáveis, podemos transformar o modelo com erros heteroscedásticos em um modelo com erros homoscedásticos.

Assim, inicialmente descreveremos o modelo com erros homoscedásticos, mostraremos como estimar os parâmetros do modelo e testar suas significâncias, respectivamente, nas seções ?? e 6.1.3. Finalmente, na seção 6.1.4, mostraremos como modelar a heteroscedasticidade e fazer a mudança de variáveis para conseguirmos adaptar as ferramentas já estudadas para o modelo com erros homoscedásticos.

Outro ponto a se observar é que, quando incorporamos o efeito de grupo $\gamma_{l}$, estamos modelando o desvio da média geral causado pela escolha da lâmina $l$. Assim, como todas as réplicas dentro de uma mesma lâmina são sujeitas ao mesmo efeito, elas são correlacionadas. Como vimos na equação (6.2), a covariância de quaisquer duas observações de um mesmo nível é constante e a mesma em todos os níveis (igual a $\sigma_{\gamma}^{2}$ ). Observações de diferentes grupos foram consideradas independentes.

Diante dessas suposições, temos que a covariância entre quaisquer observações de uma mesma lâmina é $\sigma_{\gamma}^{2}$ e entre observações de lâminas diferentes é 0 . Ou seja:

$$
\begin{aligned}
& \operatorname{cov}\left(M_{l j k}^{*}, M_{l j^{\prime} k}^{*}\right)=\sigma_{\gamma}^{2}, \quad j \neq j^{\prime} \\
& \operatorname{cov}\left(M_{l j k}^{*}, M_{l^{\prime} j^{\prime} k}^{*}\right)=0, \quad l \neq l^{\prime}
\end{aligned}
$$

Além disso, como supomos que os efeitos aleatórios $\gamma_{l}$ e $\varepsilon_{l j k}$ são independentes entre si, temos que a variância das observações $M_{l j k}^{*}$ é uma constante dada pela soma das variâncias de $\gamma_{l}$ e $\varepsilon_{l j k}$. Lembrando que a variância dos erros $\varepsilon_{l j k}$ é $\sigma^{2}$, temos:

$$
\operatorname{Var}\left(M_{l j k}^{*}\right)=\sigma_{\gamma}^{2}+\sigma^{2}, \quad l=1, \ldots, n, \quad j=1, \ldots, m, \quad k=1, \ldots, K .
$$

Consequentemente, a correlação entre as respostas de uma mesma lâmina $l$ é dada por:

$$
\operatorname{corr}\left(M_{l j k}^{*}, M_{l j^{\prime} k}^{*}\right)=\frac{\operatorname{cov}\left(M_{l j k}^{*}, M_{l j^{\prime} k}^{*}\right)}{\operatorname{Var}\left(M_{l j k}^{*}\right)}=\frac{\sigma_{\gamma}^{2}}{\sigma_{\gamma}^{2}+\sigma^{2}}, \quad j \neq j^{\prime} .
$$


Para estudarmos as características do modelo com efeitos mistos, vamos considerar:

1. os vetores de respostas $M_{l}^{*} \in \mathbb{R}^{m}$, das expressões de cada lâmina $l$, para $l=1, \ldots, n$;

2. o vetor dos efeitos fixos $\beta \in \mathbb{R}^{p}$, para $p=K+1$, considerando o intercepto e os $K$ níveis da condição do paciente;

3. o vetor com os efeitos aleatórios $\varepsilon_{l} i n \mathbb{R}^{m}$, com os erros intra-lâmina; e

4. o vetor com os efeitos aleatórios $\gamma_{l} \in \mathbb{R}^{q}$, considerando possíveis $q$ níveis para as réplicas geradas. No caso de nossa aplicação, $q=1$, já que temos apenas uma observação por réplica, mas, por questão de generalização, manteremos essa indexação no modelo.

Dessa forma, podemos reescrever o modelo na forma matricial:

$$
\begin{gathered}
M_{l}^{*}=X_{l} \beta+Z_{l} \gamma_{l}+\varepsilon_{l}, \quad l=1, \ldots, n, \\
\gamma_{l} \sim \mathcal{N}(0, \Phi), \quad \varepsilon_{l} \sim \mathcal{N}\left(0, \sigma^{2} I\right) .
\end{gathered}
$$

A aplicação linear $X_{l}$ é definida pela matriz de contrastes $m \times p$, ou seja, com os identificadores dos efeitos fixos, sendo que as entradas da primeira coluna $\left(X_{l}\right)_{.1}=1$, correspondendo ao intercepto. A aplicação linear $Z_{l}$ é definida pela matriz $m \times q$ com os identificadores dos efeitos aleatórios.

Os parâmetros do modelo a serem estimados são $\beta$, a matriz de covariâncias dos efeitos aleatórios $\Phi$ e a variância $\sigma^{2}$ dos ruídos $\varepsilon_{l}$.

A distribuição dos efeitos aleatórios $\gamma_{l}$ é assumida ser normal, com média 0 e é completamente caracterizada pela matriz de covariâncias $\Phi$.

Como os componentes aleatórios $\gamma_{l}$ e $\varepsilon_{l}$ são independentes, a matriz de covariâncias de $M_{l}^{*}$ é dada pela soma das matrizes de covariância desses componentes:

$$
\begin{aligned}
\operatorname{Cov}\left(M_{l}^{*}\right) & =\operatorname{Cov}\left(Z_{l} \gamma_{l}\right)+\operatorname{Cov}\left(\varepsilon_{l}\right) \\
& =Z_{l} \operatorname{Cov}\left(\gamma_{l}\right) Z_{l}^{t}+\operatorname{Cov}\left(\varepsilon_{l}\right) \\
& =Z_{l} \Phi Z_{l}^{t}+\sigma^{2} I_{m \times m} \\
& =\sigma^{2} \Sigma_{l}, \quad \text { para } \Sigma_{l}=I+Z_{l}^{t} \Phi Z_{l} / \sigma^{2} .
\end{aligned}
$$

Considerando o caso particular de nossa aplicação em que $q=1$ e lembrando que todas as observações dentro da mesma lâmina $l$ sofrem o mesmo efeito $\gamma_{l}$, temos que $Z_{l}$ é definida pelo vetor $1_{m \times 1}$, ou seja, um vetor de tamanho $m$ cujas entradas são todas iguais a 1 . Além disso, a matriz $\Phi$ é uma constante igual $\sigma_{\gamma}^{2}$ para qualquer que seja $l$. Com isso, temos que a matriz de covariâncias de $M_{l}^{*}$ é dada por:

$$
\begin{aligned}
\operatorname{Cov}\left(M_{l}^{*}\right) & =\sigma^{2} \Sigma_{l}, \\
& =\sigma^{2}\left(I_{m \times m}+\frac{\sigma_{\gamma}^{2} 1_{m \times m}}{\sigma^{2}}\right) .
\end{aligned}
$$

em que $I_{m \times m}$ é a matriz identidade de dimensão $m \times m$. Note ainda que $\operatorname{Cov}\left(M_{l}^{*}\right)$ é constante para todo $l$.

Além disso, como as observações de diferentes blocos são independentes, temos que a matriz de covariância do vetor $M^{*}$, com todas as observações $M_{i j k}^{*}$, é da forma bloco diagonal, em que cada bloco $l$ é dado por (6.4). Em outras palavras, temos que:

$$
\operatorname{Cov}\left(M^{*}\right)=I_{l \times l} \otimes \operatorname{Cov}\left(M_{l}^{*}\right)
$$

em que $I_{l \times l}$ é a matriz identidade de dimensão $l \times l$, e $\otimes$ é o produto de Kronecker.

A estimação dos parâmetros do modelo misto pelos métodos de máxima verossimilhança (ML, do inglês, maximum likelihood) e de máxima verossimilhança restrita (REML, do inglês, restricted 
maximum likelihood ) podem ser vistas em detalhes no apêndice B. Ambos são implementados atualmente nos principais pacotes estatísticos do R, como na biblioteca nlme (Pinheiro et al. (2011)), e no SAS (pela função proc mixed - Littell (2006)). Esses métodos são encontrados nos artigos de Patterson e Thompson (1971) e Harville (1977). Outra referência bem completa sobre esses métodos é Pinheiro e Bates (2000).

\subsubsection{Testes de Hipóteses para efeitos fixos}

Diferentemente do método de máxima verossimilhança, o valor da função de verossimilhança no método de máxima verossimilhança restrita é alterado quando uma diferente matriz de contraste é usada para a definição dos efeitos fixos. Dessa forma, o método comum de comparação de modelos ajustados por máxima verossimilhança, o teste da razão de verossimilhança, não é recomendado.

Porém, essa não é a única restrição. Mesmo utilizando o método de máxima verossimilhança no ajuste dos modelos, o teste da razão de verossimilhança usando como referência a distribuição $\chi^{2}$ tende a produzir resultados muito grosseiros. Alguns exemplos apresentados em Pinheiro e Bates (2000) mostram que, quando comparamos um modelo com outro que teve um número grande de parâmetros removido, a inexatidão dos p-valores dada pelo teste da razão de verossimilhança é alta.

Assim, para avaliar a significância dos efeitos fixos, Pinheiro e Bates (2000) recomendam utilizar o teste $\mathrm{T}$ ou $\mathrm{F}$ condicionais para modelos de regressão linear, baseados na estimativa condicional REML da variância, vista em (B.19).

Voltando ao contexto do modelo para a análise dos dados de microarranjos com erros de medida, se desejarmos avaliar hipóteses sobre os níveis do efeito condição do paciente, recomenda-se utilizar o teste $\mathrm{F}$ condicional para modelos mistos, que será apresentado na próxima seção.

\section{Teste F condicional para modelos mistos}

O teste $\mathrm{F}$ dos modelos ANOVA pode ser usado, por exemplo, para avaliar se algum dos efeitos fixos é, em média, significativamente diferente dos outros, quando comparado com a hipótese nula de que todos os efeitos fixos possuem a mesma resposta média.

Como vimos na seção 2.6, para cada gene representado nas lâminas de microarranjos, podemos testar a partir de uma restrição linear (contraste), por exemplo, se os níveis do fator condição do paciente são significativamente diferentes. Após uma correção dos p-valores para múltiplos testes, é possível determinar quais os genes mais diferencialmente expressos para uma certo contraste de interesse.

No modelo (6.3), temos que

$$
\mathrm{E}\left(M^{*}\right)=X \beta
$$

em que, $X$ é uma matriz de dimensão $m n \times p$, formada pelo agrupamento das linhas das matrizes $X_{l}, i=1, \ldots, n$, de dimensão $m \times p$. Assim, a matriz $X$ nos fornece $p$ funções estimáveis e $X$ tem posto $p$.

Vimos em (B.1) que

$$
\hat{\beta}(\theta)=\Psi \sum_{l=1}^{n} X_{l}^{t} \Sigma^{-1} M_{l}^{*} ;
$$

em que,

$$
\Psi=\left(\sum_{l=1}^{n} X_{l}^{t} \Sigma_{l}^{-1} X_{l}\right)^{-1}
$$

é a matriz de covariâncias da distribuição assintótica de $\hat{\beta}$ quando $n \rightarrow \infty$.

Convencionalmente, o estimador de $\Psi$ é obtido substituindo $\sigma^{2}$ pelo seu estimador REML $\hat{\sigma}_{R}^{2}(\theta)$, visto em (B.19). Porém, como pode ser visto em Kenward e Roger (1997), o estimador $\hat{\Psi}$ é um 
estimador enviesado de $\Psi$ e ainda, a própria matriz $\Psi$, por não levar em conta a variabilidade de $\hat{\sigma}$, não é equivalente a $\operatorname{Var}(\hat{\beta})$. Por isso, os autores desse mesmo artigo propuseram uma melhor aproximação da matriz de covariâncias de $\hat{\beta}$ para amostras pequenas.

Consideremos, no entanto, que $\hat{V}(\hat{\beta}) \in R^{p \times p}$ é uma estimativa da matriz de covariâncias dos efeitos fixos.

Suponhamos que queremos fazer inferência sobre $l$ combinações lineares dos elementos de $\beta$ simultaneamente. Para isso, construímos uma matriz $L \beta$ com as $l$ restrições de interesse e testamos a seguinte hipótese nula:

$$
H_{0}=L \beta=0 .
$$

Assim, considerando que

$$
\operatorname{Var}\left(L^{t} \beta\right)=L^{t} \hat{V}(\hat{\beta}) L,
$$

temos que a estatística $F_{M}$ a ser usada para modelos mistos é dada por:

$$
F_{M}=\frac{\left(L^{t} \hat{\beta}\right)^{t} \operatorname{Var}\left(L^{t} \beta\right)\left(L^{t} \hat{\beta}\right)}{l}=\frac{\hat{\beta}^{t} L L^{t} \hat{V}(\hat{\beta}) L L^{t} \hat{\beta}}{l} .
$$

A estatística $F_{M}$ em (6.7) tem aproximadamente uma distribuição $F$ com $\left(\nu_{1}, \nu_{2}\right)$ graus de liberdade, em que $\nu_{1}=l$, ou seja, exatamente o número de termos fixos a serem estimados, e $\nu_{2}$ são os graus de liberdade associados a $\hat{V}(\hat{\beta})$.

Quando $l=1$, a aproximação da distribuição de $F$ pode ser obtida pelo método de aproximação de Satterthwaite (Satterthwaite (1941)). No entanto, para os casos com $l>1$, a interpretação é mais complicada, pois é necessário levar em consideração a estrutura aleatória da matriz $L^{t} \hat{V}(\hat{\beta}) L$. Mais detalhes podem ser vistos em Kenward e Roger (1997)

O p-valor para a hipótese nula é dado por:

$$
P\left(F_{\nu_{1}, \nu_{2}} \geq F_{M}\right)
$$

\subsubsection{O modelo com erros heteroscedásticos}

A modelagem vista na seção 6.1.2, mais especificamente na equação (6.3), faz a suposição de que os erros intra-grupo (intra-lâmina) são homoscedásticos. No entanto, há vários experimentos em que isso não se aplica e o experimento de microarranjos é um deles. Podemos observar que, em diferentes lâminas, o valor da expressão de um local genético está definido por intervalos de comprimentos diferentes, caracterizando que certas lâminas possuem uma variância maior que outras. Assim, a suposição de variância constante nos resíduos não é verificada e o modelo deixa de ser adequado.

Para ilustrar esse problema, mostramos na figura 6.3 os resíduos padronizados,

$$
\frac{\hat{\varepsilon} \hat{l}_{j}}{\left(\hat{\operatorname{Var}}\left(\varepsilon_{l j}\right)\right)^{1 / 2}},
$$

obtidos pelo ajuste do modelo misto homoscedástico (6.3) para uma amostra de expressões de certo um gene. Podemos ver que, nas três condições experimentais ilustradas, os resíduos não apresentam uma variância constante, já que não estão distribuídos uniformemente em relação aos valores de expressões ajustados. Assim, esse modelo utilizado, que faz suposição de homoscedasticidade, não é o mais adequado.

Para modelarmos adequadamente dados heteroscedásticos, precisamos estender o modelo linear de efeitos mistos, visto em (6.3), da seguinte forma:

$$
\begin{gathered}
M_{l}^{*}=X_{l} \beta+Z_{l} \gamma_{l}+\varepsilon_{l}, \quad l=1, \ldots, n \\
\gamma_{l} \sim \mathcal{N}(0, \Phi), \quad \varepsilon_{l} \sim \mathcal{N}\left(0, \sigma^{2} \Lambda_{l}\right)
\end{gathered}
$$




\section{Valores ajustados vs Resíduos padronizados Sem modelagem da variância intra-lâmina}

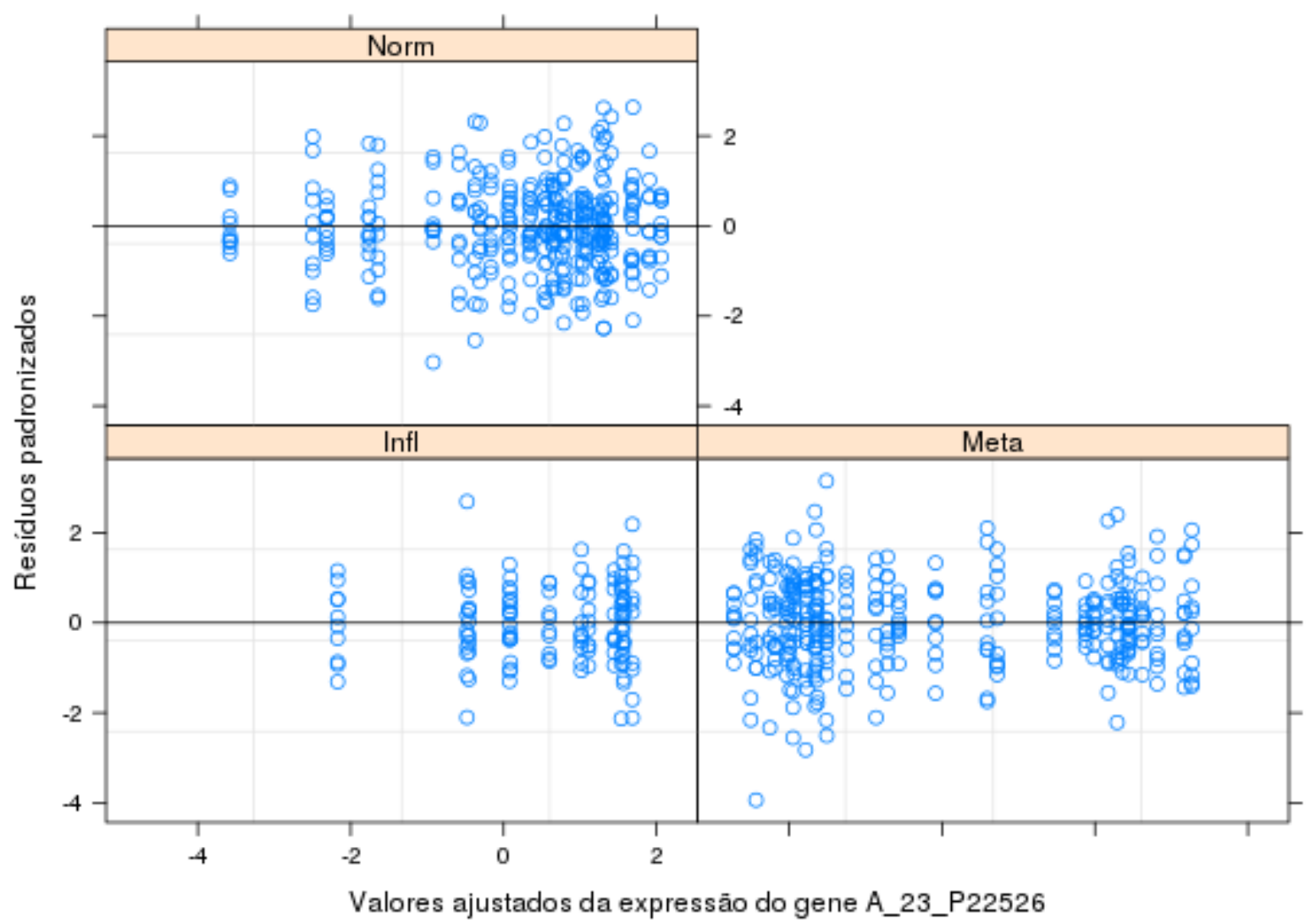

Figura 6.3: Gráfico dos resíduos do ajuste das expressões do gene A_23_P22526 supondo dados com variância constante. Foram coletadas expressões de amostras estomacais nas condições experimentais: normal (Norm), com inflamação (Infl) e com metaplasia (Meta).

em que $\Lambda_{l}$ são matrizes positivas definidas, parametrizadas por um conjunto, geralmente pequeno, de parâmetros $\lambda$.

Ainda é mantida a suposição de que os erros intra-grupo $\varepsilon_{l}$ são independentes para diferentes grupos e independentes dos efeitos aleatórios $\gamma_{l}$.

$\mathrm{Na}$ figura 6.4, ilustramos os resíduos padronizados obtidos pelo ajuste do modelo para erros heteroscedásticos (6.8) para as mesmas expressões utilizadas para gerarmos o gráfico da figura 6.3. Podemos ver que a modelagem da variância foi melhor, já que a variância dos resíduos ficou aproximadamente constante.

No modelo (6.8), a constante $\sigma^{2}$ é mantida fora da matriz $\Lambda$ por razões computacionais. Veremos que assim será possível eliminá-la da função de verossimilhança perfilada. Além disso, com algumas mudanças de variáveis, veremos que os métodos de estimação dos parâmetros e as técnicas computacionais para modelos homoscedásticos podem ser adaptadas para esse modelo estendido.

Como $\Lambda_{l}$ é simétrica e definida positiva, existe a matriz inversível $\Lambda_{l}^{1 / 2}$ tal que:

$$
\begin{gathered}
\Lambda_{l}=\left(\Lambda_{l}^{1 / 2}\right)^{t} \Lambda_{l}^{1 / 2} \\
\Lambda_{l}^{-1}=\Lambda_{l}^{-1 / 2}\left(\Lambda_{l}^{-1 / 2}\right)^{t} .
\end{gathered}
$$

Consideremos as seguintes novas variáveis, obtidas pelas variáveis originais multiplicadas à esquerda por $\left(\Lambda_{l}^{-1 / 2}\right)^{t}$ : 


\section{Valores ajustados vs Resíduos padronizados Com variância intra-lâmina modelada}

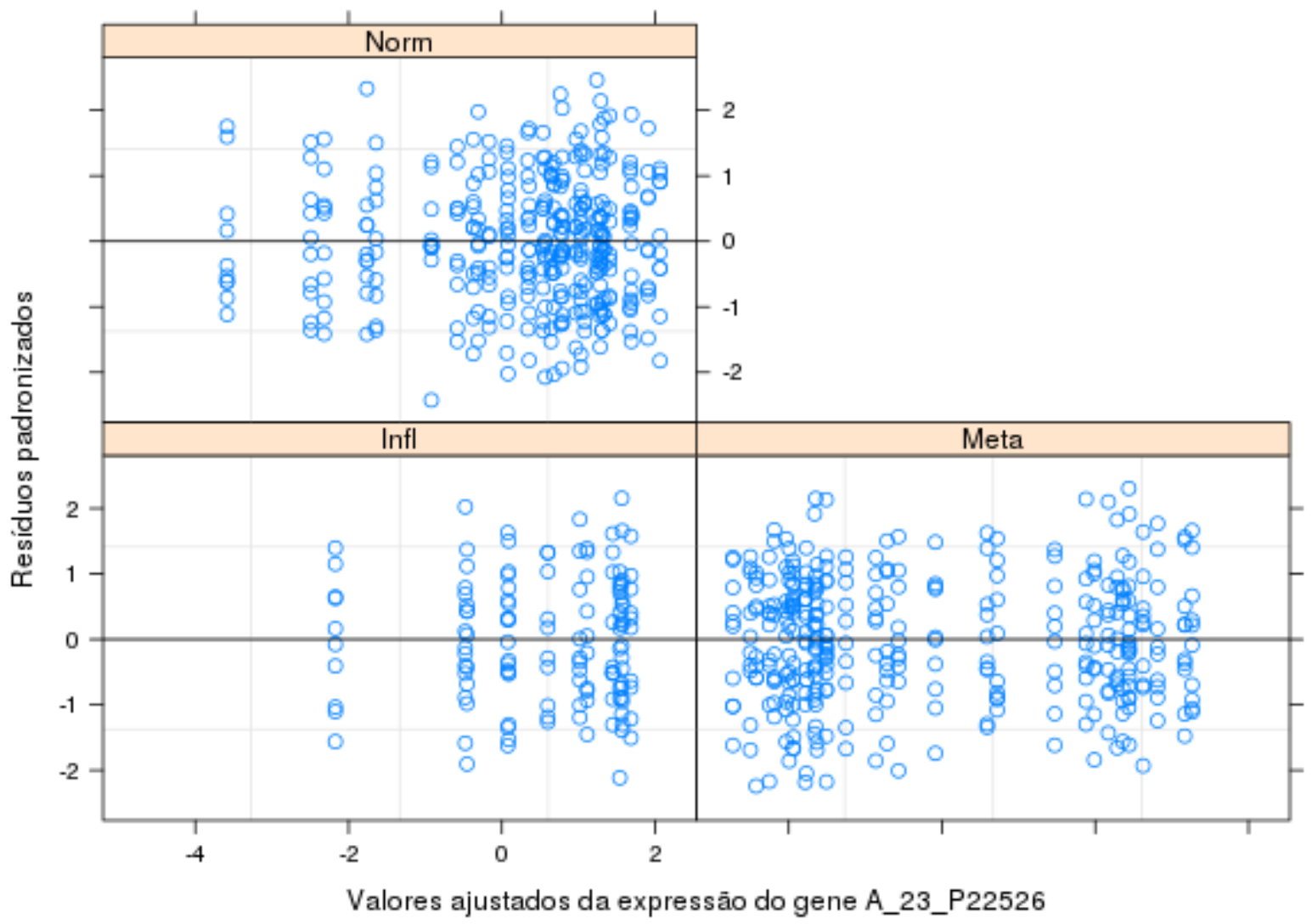

Figura 6.4: Gráfico dos resíduos do ajuste das expressões do gene A_23_P22526 modelando a variância dos resíduos. Foram coletadas expressões de amostras estomacais nas condições experimentais: normal (Norm), com inflamação (Infl) e com metaplasia (Meta).

$$
\begin{aligned}
\tilde{M}_{l}^{*} & =\left(\Lambda_{l}^{-1 / 2}\right)^{t} M_{l}^{*} ; & \tilde{X}_{l} & =\left(\Lambda_{l}^{-1 / 2}\right)^{t} X_{l} ; \\
\tilde{Z}_{l} & =\left(\Lambda_{l}^{-1 / 2}\right)^{t} Z_{l} ; & \tilde{\varepsilon}_{l} & =\left(\Lambda_{l}^{-1 / 2}\right)^{t} \varepsilon_{l} .
\end{aligned}
$$

Fazendo a mudanças de variáveis, temos a seguinte distribuição para os erros intra-grupo:

$$
\tilde{\varepsilon}_{l} \sim \mathcal{N}\left(\left(\Lambda_{l}^{-1 / 2}\right)^{t} 0, \sigma^{2}\left(\Lambda_{l}^{-1 / 2}\right)^{t} \Lambda_{l} \Lambda_{l}^{1 / 2}\right)=\mathcal{N}\left(0, \sigma^{2} I\right) .
$$

Assim, o modelo misto linear estendido (6.8) pode ser reescrito como

$$
\begin{gathered}
\tilde{M}_{l}^{*}=\tilde{X}_{l} \beta+\tilde{Z}_{l} \gamma_{l}+\tilde{\varepsilon}_{l}, \quad l=1, \ldots, n \\
\gamma_{l} \sim(0, \Phi), \quad \tilde{\varepsilon}_{l} \sim \mathcal{N}\left(0, \sigma^{2} I\right), \quad l=1, \ldots, n,
\end{gathered}
$$

que tem a mesma representação do modelo linear básico, ou seja, com erros intra-grupos homoscedásticos (6.3).

Além disso, como o diferencial da transformação linear $\tilde{M}_{l}^{*}=\left(\Lambda_{l}^{-1 / 2}\right)^{t} M_{l}^{*}$ é simplesmente seu determinante, isto é,

$$
\mathrm{d} \tilde{M}_{l}^{*}=\left|\Lambda_{l}^{-1 / 2}\right| \mathrm{d} M_{l}^{*},
$$


a função de verossimilhança correspondente a esse modelo estendido é:

$$
\begin{aligned}
L\left(\beta, \theta, \sigma^{2}, \gamma \mid M^{*}\right) & =\prod_{l=1}^{n} p\left(M_{l}^{*} \mid \beta, \theta, \sigma^{2}, \gamma\right) \\
& =\prod_{l=1}^{n} p\left(\tilde{M}_{l}^{*} \mid \beta, \theta, \sigma^{2}, \gamma\right)\left|\Lambda_{l}^{-1 / 2}\right| \\
& =L\left(\beta, \theta, \sigma^{2}, \gamma \mid \tilde{M}^{*}\right) \prod_{l=1}^{n}\left|\Lambda_{l}^{-1 / 2}\right| .
\end{aligned}
$$

A função de verossimilhança restrita $L_{R}$ correspondente a esse modelo estendido é obtida também de forma similar à obtida anteriormente, isto é, integrando a função de verossimilhança $L$ em relação aos efeitos fixos $\beta$ :

$$
L_{R}\left(\theta, \sigma^{2}, \gamma \mid M^{*}\right)=\int L\left(\beta, \theta, \sigma^{2}, \gamma \mid M^{*}\right) \mathrm{d} \beta=L_{R}\left(\theta, \sigma^{2}, \gamma \mid \tilde{M}^{*}\right) \prod_{l=1}^{n}\left|\Lambda_{l}^{-1 / 2}\right| .
$$

Logo, a função de verossimilhança $L\left(\beta, \theta, \sigma^{2}, \gamma \mid \tilde{M}^{*}\right)$ e a função de verossimilhança restrita $L_{R}\left(\theta, \sigma^{2}, \gamma \mid \tilde{M}^{*}\right)$ correspondem a um modelo de efeitos mistos linear básico e todos os resultados apresentados anteriormente são válidos para o modelo estendido.

A matriz de covariâncias de $M_{l}^{*}$ em (6.8) também pode ser escrita de forma semelhante à matriz de covariâncias do modelo com erros homoscedásticos (6.4), porém, a matriz $\Sigma_{l}$ será um pouco mais complicada:

$$
\begin{aligned}
\operatorname{Cov}\left(M_{l}^{*}\right) & =\operatorname{Cov}\left(Z_{l} \gamma_{l}\right)+\operatorname{Cov}\left(\varepsilon_{l}\right) \\
& =Z_{l} \operatorname{Cov}\left(\gamma_{l}\right) Z_{l}^{t}+\operatorname{Cov}\left(\varepsilon_{l}\right) \\
& =Z_{l} \Phi Z_{l}^{t}+\sigma^{2} \Lambda_{l} \\
& =\sigma^{2}\left(\frac{Z_{l} \Phi Z_{l}^{t}}{\sigma^{2}}+\Lambda_{l}\right)=\sigma^{2} \Sigma_{l}, \quad \text { para } \Sigma_{l}=\left(\frac{Z_{l} \Phi Z_{l}^{t}}{\sigma^{2}}+\Lambda_{l}\right) .
\end{aligned}
$$

em que $\left(Z_{l} \Phi Z_{l}^{t}\right) / \sigma^{2}$ é o componente dos efeitos aleatórios; e $\Lambda_{l}$ é o componente intra-grupo.

Assim, para a modelagem da heteroscedasticidade na prática, é possível obter matrizes $\Sigma_{l}$ similares, mas com diferentes contribuições desses componentes da variância. Ou seja, é possível modelar um complexo componente de efeitos aleatórios, enquanto mantém o componente intra-grupo mais simples, ou o contrário.

Além disso, como a matriz $\Lambda_{l}$ é simétrica e definida positiva, podemos sempre encontrar uma decomposição

$$
\Lambda_{l}=V_{l} C_{l} V_{l},
$$

em que, $V_{l}$ é uma matriz diagonal e $C_{l}$ é a matriz de correlação, com todos os elementos da diagonal iguais a 1 , como pode ser verificado em Pinheiro e Bates (2000). Para que tenhamos unicidade na determinação da matriz $V_{l}$, é exigido que todos os elementos da diagonal de $V_{l}$ sejam positivos.

Assim, temos que

$$
\begin{gathered}
\operatorname{Var}\left(\varepsilon_{l j}\right)=\sigma^{2}\left(V_{l}\right)_{j j}^{2}, \\
\operatorname{corr}\left(\varepsilon_{l j}, \varepsilon_{l k}\right)=\left(C_{l}\right)_{j k}
\end{gathered}
$$

e, portanto, $V_{l}$ descreve a variância e $C_{l}$ descreve a correlação dos erros intra-grupo $\varepsilon_{l}$.

Com essa decomposição, é possível modelar os componentes de variância e de correlação independentemente, além de ser computacionalmente conveniente.

Em nosso estudo, não queremos modelar correlação entre as observações, portanto usaremos uma matriz $C_{l}=I$. 
Podemos definir de forma mais geral a função de variância dos erros dentro de um dado grupo $\gamma_{l}$ como:

$$
\operatorname{Var}\left(\varepsilon_{l} \mid \gamma_{l}\right)=\sigma^{2} g^{2}\left(\mu_{l j}, v_{l j}, \delta\right), \quad l=1, \ldots, n, \quad j=1, \ldots, m,
$$

em que, $g$ é a função de variância que depende de $\mu_{l j}=\mathbb{E}\left(M_{l j}^{*} \mid \gamma_{l}\right)$, do vetor $v_{l j}$ com as possíveis covariáveis da variância e do vetor $\delta$ com os possíveis parâmetros da variância.

Apesar dessa generalização sem bastante flexível porque, através do componente $\mu_{l j}$, permite que a variância intra-grupo dependa dos efeitos fixos $\beta$ e dos efeitos aleatórios $\gamma_{l}$, ela apresenta um problema: os erros intra-grupo e os efeitos aleatórios podem deixar de serem independentes.

Para evitar dependência sobre os efeitos aleatórios não observados, um procedimento sugerido por Davidian e Giltinan (1995) é utilizar no modelo de variância, em vez de $\mu_{l j}$, seus estimadores BLUPs:

$$
\hat{\mu}_{l j}=x_{l_{j}} \beta+z_{l_{j}} \hat{\gamma}_{l}
$$

em que, $\hat{\gamma}_{l}$ são os estimadores dos efeitos aleatórios e $x_{l_{j}}$ e $z_{l_{j}}$ denotam, respectivamente, a $j$-ésima linha da matriz $X_{l}$ e da matriz $Z_{l}$.

Assim, sob a aproximação

$$
\operatorname{Var}\left(\varepsilon_{l} \mid \gamma_{l}\right) \approx \sigma^{2} g^{2}\left(\hat{\mu}_{l j}, v_{l j}, \delta\right), \quad l=1, \ldots, n, \quad j=1, \ldots, m,
$$

assumimos que os erros intra-grupo são independentes dos efeitos aleatórios.

Uma possível função de variância é aquela que admite um valor diferente para cada nível de estratificação dos dados. Assim, supondo que os dados são estratificados em $S$ diferentes grupos, o valor da variância é dado de acordo com o grupo (estrato) $s=1, \ldots, S$ no qual a observação pertence.

Essa função é definida da seguinte maneira:

$$
g\left(s_{l j}, \delta\right)=\delta_{s_{l j}}, s=1, \ldots, S ; \quad l=1, \ldots n ; \quad j=1, \ldots, m .
$$

Com essa função, temos que o elemento $j$ do grupo $l$ e do nível de estratificação $s$ tem variância igual a $\delta_{s_{l j}}$.

O modelo de variância correspondente é definido como:

$$
\operatorname{Var}\left(\varepsilon_{l j}\right)=\sigma^{2} \delta_{s_{l j}}^{2} .
$$

Nessa modelagem temos, porém, $S+1$ variáveis para representar os $S$ possível valores para a variância. Para que o problema seja solúvel, uma abordagem feita Pinheiro e Bates (2000) é definir os parâmetros $\delta_{l}, l=1, \ldots, S$ como $\delta_{1}=1$ e $\delta_{l}, l=2, \ldots, S$ como a razão entre a variância do l-ésimo nível de estratificação e a do primeiro nível.

No caso do experimento de microarranjos com erros de medida, por exemplo, poderíamos escolher uma função de variância que define um valor diferente para cada lâmina. Nesse caso, a estratificação tem número de níveis igual ao número de lâminas. 


\section{Capítulo 7}

\section{Aplicação em dados reais de expressões gênicas}

Neste capítulo, mostraremos uma aplicação da teoria apresentada nos capítulos 3, 4, 5 e 6 em uma base com dados de expressões gênicas reais obtidas em experimentos de microarranjos.

Vimos na seção 2.3, que a análise das expressões dos locais genéticos representados na lâmina de microarranjos é feita comumente pelas suas expressões relativas, ou seja, pelo logaritmo da razão entre as intensidades da amostra de teste e as intensidades da amostra de referência. Essa medida de expressão relativa, que denotamos, para um dado do local genético $i$, por

$$
M_{i}=\log _{2}\left(\frac{R_{i}}{G_{i}}\right),
$$

permite a análise utilizando observações obtidas em várias lâminas de microarranjos, já que o referencial costuma ser sempre o mesmo, ou seja, a mesma amostra de referência $\left(G_{i}\right)$ é hibridizada em todas as lâminas.

Porém, vimos, no capítulo 3, que essa expressão relativa é obtida, convencionalmente, utilizando apenas medidas de tendência central das intensidades de cada canal. Assim, essa estimativa convencional da média de $M_{i}$, que denotamos por $\hat{M}_{i}$ e foi definida na equação $(2.2)$, despreza as informações de variabilidade e, portanto, de imprecisão das medidas das intensidades tanto do canal da amostra de teste como da amostra de referência.

Por essa razões, propomos, também no capítulo 3, duas representações para as expressões relativas dos locais genéticos que consideram as imprecisões das medidas. Nossa primeira proposta, vista na seção 3.1, é uma representação da expressão do local genético obtida por um estimador mais refinado da média de $M_{i}$, que denotamos por $\bar{M}_{i}$ e foi definido na equação (3.7). A segunda representação proposta foi mostrada na seção 3.2. Nessa representação, as expressões gênicas são intervalos que, com algum nível de confiança pré-estabelecido, incluem a média de $M_{i}$. Assim, a expressão relativa de um local genético $i$ deixa de ser representada por um valor pontual e passa a ser representada pelo intervalo $I_{M_{i}}$, definido pela equação (3.1). Nessa abordagem, como mostramos na seção 5.2, carregamos, durante todo o pré-processamento e análise, as informações dos erros das medidas de $M_{i}$.

Queremos, neste capítulo, avaliar o impacto dessas representações nas análises com dados reais. Para isso, vamos comparar os resultados obtidos ao utilizarmos o estimador convencional das médias de $M_{i}$ com os resultados obtidos utilizando os estimadores que levam em consideração as imprecisões das medidas.

Utilizando essas três representações das medidas de expressões gênicas, obtemos três variantes da nossa base de dados. Para cada uma delas, faremos os seguintes pré-processamentos nos dados:

1. remoção da influência das intensidades do fundo: utilizaremos, como discutido na seção 2.4.2, o método normexp. Além de ser considerado o mais adequado para lâminas de microarranjos de dois canais, segundo Ritchie et al. (2007), podemos utilizar com esse método um 
valor de offset, $k$, para deslocar as medidas $M_{i}$ de forma a ficarem positivas e distantes do zero. Isso permite utilizarmos o estimador melhorado da média, $\bar{M}_{i}$, que exige que as intensidades do canal da amostra de teste, $R_{i}$, e do canal da amostra de referência, $G_{i}$, não sejam próximas de zero. Consequentemente, isso também permite utilizarmos os intervalos $I_{M_{i}}$ na representação da expressão gênica, já que eles são inicialmente definidos com o ponto médio dado pela estimativa $\bar{M}_{i}$.

2. normalização das lâminas: utilizaremos o método lowess com as adaptações para dados heteroscedásticos vistas no capítulo 4, pois constatamos que os dados de expressões gênicas possuem essa característica. Assim, utilizaremos o método de mínimos quadrados ponderados com pesos adicionais para penalização dos dados de maior variabilidade. Os parâmetros a serem definidos para o método lowess são o grau do polinômio e a vizinhança de suavização, que denotamos por $\alpha$. Na seção 4.5.1, vimos que utilizar grau um para o polinômio a ser ajustado localmente é o mais adequado. Já na seção 5.1, apresentamos um método para a estimação de $\alpha$. Com o objetivo de compararmos também o efeito do uso do parâmetro de suavização estimado em vez da convencional $(\alpha=0,2)$, faremos a normalização com ambas as opções. Na estimação, usaremos o método 5.1 minimizando o critério HRCp, visto na seção 4.6 .3 , já ele é robusto a dados heteroscedásticos.

Ao final do pré-processamento dessas três variantes da base de dados, teremos seis variantes da base a serem analisadas, já que o passo de normalização dos dados é feito com dois parâmetros de suavização diferentes.

O próximo passo da análise é a determinação dos genes diferencialmente expressos. Nas variantes da base em que os dados são representados apenas pelas médias, usaremos a modelagem convencional vista na seção 2.6. Já para os dados intervalares, faremos a discretização por uma amostragem de 60 observações por intervalo, distribuídas normalmente. Em seguida, ajustaremos o modelo misto, que permite a modelagem das variabilidades tanto intra-lâmina com entre lâminas em fatores aleatórios. Essa modelagem foi apresentada em detalhes no capítulo 6 .

Após determinarmos os genes diferencialmente expressos, discutiremos os resultados e faremos as comparações entre as variantes da nossa base de dados.

As implementações foram realizadas, principalmente, utilizando a versão 2.15 .1 da linguagem $\mathrm{R}$ Team et al. (2008) e os seguintes pacotes:

- MaigesPack (Esteves et al. (2014)), na versão 2.14, para leitura, tratamento e exploração dos dados;

- Limma (Smyth (2005)), na versão 2.14, para a correção do fundo por normexp;

- Locfit (Loader (2007)), na versão 1.5-9.1, para normalização dos dados com lowess; e

- Nlme (Pinheiro et al. (2011)), na versão 3.1-115 do pacote, para o ajuste do modelo misto.

\subsection{Base de dados}

Para este estudo, utilizamos uma base de dados de expressões gênicas obtidas em experimentos de microarranjos da plataforma Agilent. Como pode ser conferido no apêndice C, os métodos apresentados neste trabalho, que são direcionados às lâminas de microarranjos de cDNA, também podem ser aplicados à plataforma Agilent.

Nessa base, temos dados de 103 lâminas de microarranjos, cada uma com 45015 locais genéticos, sendo que 41093 deles são distintos. Em cada uma dessas lâminas, foram hibridizadas simultaneamente uma amostra de referência, com tecido de estômago saudável, e uma amostra de teste com tecido de estômago em uma das seguintes condições: saudável, com inflamação e com metaplasia intestinal de grau II. As 103 lâminas que utilizamos são de pacientes distintos, sendo 35 de pacientes com metaplasia de grau II, 55 saudáveis e 13 com inflamação estomacal. 
Esses experimentos são parte do projeto realizado pelo Hospital Sírio-Libanês, em São Paulo, sob responsabilidade do Dr. Luiz Fernando Lima Reis e com auxílio financeiro da FAPESP (Fundação de Amparo à Pesquisa do Estado de São Paulo). O projeto ocorreu durante o período de outubro de 2010 a agosto de 2012, quando foram coletadas amostras de tecidos de 198 pacientes. Dentre essas amostras, há tecidos de mucosa normal, com inflamação, com metaplasia intestinal e com adenocarcinomas tanto em esôfago como em estômago.

Dessas 198 lâminas, usando critérios de qualidade e unicidade, escolhemos 103 lâminas com amostras de estômagos de pacientes distintos para a nossa aplicação. Com essa base, temos condições de comparar os níveis de expressão dos genes representados por esse 41093 locais genéticos para as condições saudável, inflamação e metaplasia intestinal.

A metaplasia intestinal do estômago caracteriza-se pela substituição da mucosa normal por um tecido colunar do tipo intestinal decorrente do processo inflamatório crônico do estômago. Apesar dos adenocarcinomas do estômago estarem frequentemente associados a processos inflamatórios da mucosa normal, ainda não foi comprovado que a metaplasia intestinal é uma doença pré-maligna, uma vez que a taxa de transformação em adenocarcinomas (a forma mais comum de câncer endometrial) é reduzida. No entanto, essa patologia representa o fator de risco mais importante para o adenocarcinoma. Assim, um dos objetivos desses experimentos é determinar os genes cujas expressões sejam diferenciais entre essas condições fenotípicas e, assim, fornecer evidências da relação entre inflamação, metaplasia e adenocarcinoma do estômago.

As lâminas hibridizadas com essas amostras foram digitalizadas e as imagens processadas pelo programa Agilent Feature Extraction, onde foram obtidas as estatísticas das intensidades dos píxeis tanto dos locais dos genes como dos fundos.

As estatísticas obtidas para ambos os canais, juntamente com as informações dos genes e dos pacientes, compõem a nossa base de dados.

\subsection{Pré-processamento dos dados}

Como vimos na seção 2.4, acredita-se que as intensidades das expressões provenientes de cada canal das imagens dos microarranjos estão sob efeito das intensidades do fundo. Assim, um dos primeiros tratamentos feitos nos dados de expressões gênicas é a remoção dessa influência. O método que utilizamos nesta aplicação é o normexp, discutido na seção 2.4.2, com deslocamento de 50, que é o recomendado por Ritchie et al. (2007).

Após a correção do fundo, determinamos as representações das expressões relativas de cada local genético $i$, dadas por $M_{i}=\log _{2}\left(\frac{R_{i}}{G_{i}}\right)$, apresentadas no capítulo 3. Elas são obtidas:

1. por uma estimativa da média de $M_{i}$, dada pelo estimador convencional $\hat{M}_{i}(2.2)$;

2. por uma estimativa melhorada da média de $M_{i}$, dada por $\bar{M}_{i}(3.7)$; e

3. pelo intervalo $I_{M_{i}}(3.1)$, que contém a estimativa melhorada da média de $M_{i}$, com uma confiança de $95 \%$.

Utilizamos a variância das medidas $M_{i}$, definida na equação (3.8), também como critério de qualidade dos dados. Dentre todas as medidas $M_{i}$, de todas as lâminas, aquelas com uma variância muito maior que as demais poderiam ser consideradas não confiáveis e, por isso, resolvemos descartálas. Nesta aplicação, após uma análise exploratória cuidadosa dos dados, descartamos 0,001\% dos dados de maior variância.

Nos gráficos da figura 7.1, mostramos esses pré-processamentos para quatro lâminas de nossa base dados, duas com amostras de teste de estômago saudável e duas de estômago com metaplasia de grau II. Nos gráficos $M-A$ da primeira coluna, mostramos os dados sem correção do fundo, representadas pelas estimativas das médias de $M_{i}$ e $A_{i}$ convencionais. Na segunda coluna, podemos observar o efeito da correção do fundo usando normexp nos dados representados convencionalmente. 
Por causa do deslocamento utilizado no método, todas as medidas continuaram positivas e afastadas do zero. Podemos observar também, especialmente pelas figuras (7.1a) e (7.1b), que algumas expressões de baixas intensidades tiveram um comportamento irregular. Essa dispersão fica mais intensificada quando as expressões são representadas pelas médias estimadas usando as informações de variabilidade das medidas dos canais, ou seja, usando os estimadores $\bar{M}_{i}$ e $\bar{A}_{i}$, como podemos observar nos gráficos da terceira coluna. Isso mostra que locais com medidas com grande incerteza, seja por estarem confundidas quase integralmente com as intensidades do fundo ou por terem uma variância grande nas medidas das intensidades de cada canal, terão suas expressões diferenciadas após os pré-processamentos. A grande imprecisão nos sinais de baixas intensidades já é conhecida na literatura, como explicam os autores Newton et al. (2001).

O último pré-processamento realizado nesses dados de expressões gênicas foi a normalização intra-lâmina, aplicado para corrigir a variabilidade entre genes, principalmente, removendo o viés causado pela dependência que os corantes têm das intensidades. Como também desejamos comparar o efeito do parâmetro de suavização $(\alpha)$ utilizada no método lowess, realizamos a normalização intralâmina utilizando tanto um valor convencional $(\alpha=0,2)$ como um valor estimado pelo método visto na seção 5.1.4. Devido à heteroscedasticidade dos dados das lâminas de microarranjos, no método de estimação de $\alpha$ foi feita a minimização do critério HRCp.

Os dados das quatro lâminas que tomamos como exemplo para ilustrarmos o efeito da remoção da influência das intensidades do fundo, na figura 7.1, podem ser observados após a normalização intra-lâmina nos gráficos da figura 7.2. Os dados normalizados usando um parâmetro $\alpha$ estimado podem ser vistos nos gráficos da primeira coluna, enquanto os dados normalizados com $\alpha=0,2$ podem ser vistos na segunda coluna. Também podemos observar os intervalos que descrevem as medidas de expressões gênicas com seus erros (originais e provenientes pela estimação da superfície de suavização obtida por lowess). Como fica claro ao compararmos os gráficos 7.2e e 7.2f, esses intervalos são afetados com a escolha do parâmetro de suavização $\alpha$. Temos que os locais genéticos com intensidades muito altas e, pricipalmente, muito baixas são os de maior imprecisão, já que os intervalos são maiores para essas medidas. Assim, com a análise feita a partir desses intervalos que representam as medidas de expressão gênica e suas imprecisões, podemos obter resultados mais adequados. 

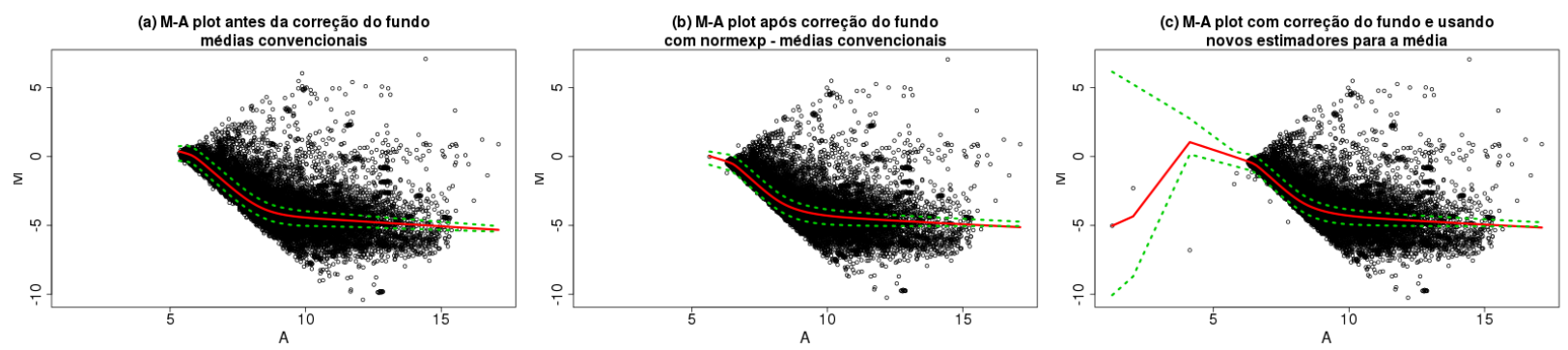

(a) Lâmina de número 64 e identificação 251485069480_1_4, onde foi hibridizada uma amostra de estômago saudável.
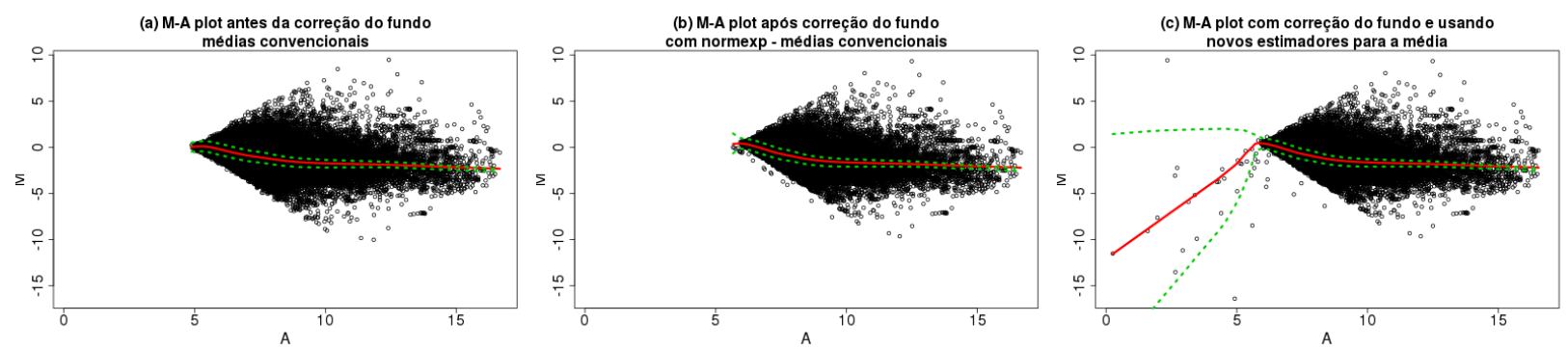

(b) Lâmina de número 90 e identificação 251485069395_1_1, onde foi hibridizada uma amostra de estômago saudável.
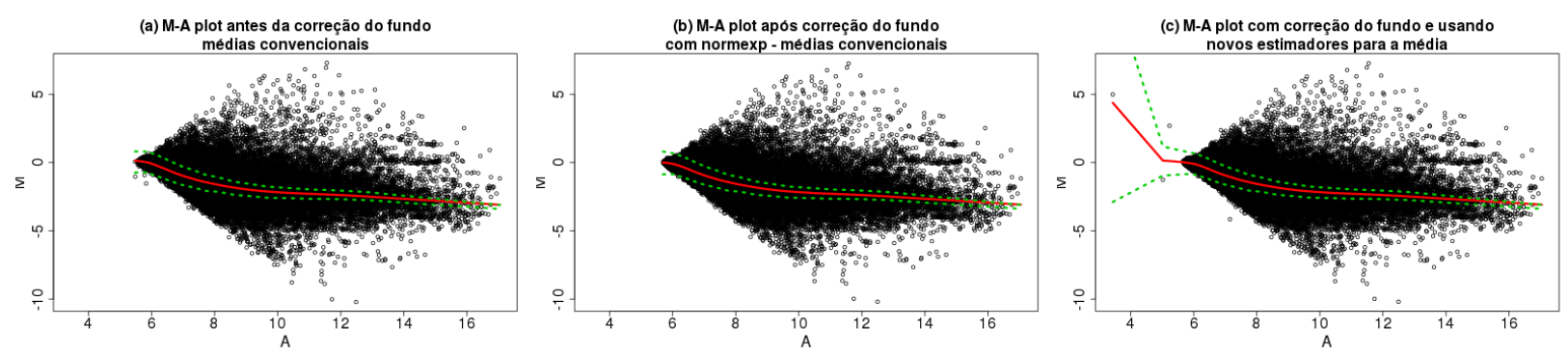

(c) Lâmina de número 30 e identificação 251485069514_1_2, onde foi hibridizada uma amostra de estômago com metaplasia grau II.
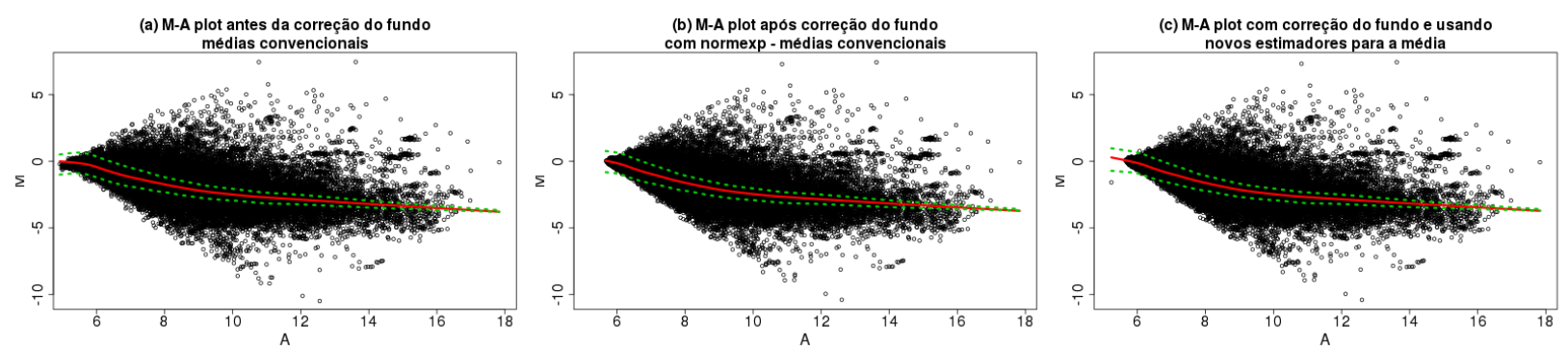

(d) Lâmina de número 27 e identificação 251485069410_1_1, onde foi hibridizada uma amostra de estômago com metaplasia grau II.

Figura 7.1: Gráficos $M-A$ com dados originais e após a remoção das intensidades do fundo usando o método normexp com deslocamento de 50. As medidas $M_{i}$ e $A_{i}$ foram primeiro obtidas usando os estimadores das médias convencionais, $\hat{M}_{i}$ e $\hat{A}_{i}$, e, depois, utilizando os estimadores $\bar{M}_{i}$ e $\bar{A}_{i}$. 
Gráfico M-A após normalização usando Lowess com $\alpha=0.6$ lâmina: 251485069480_1.4

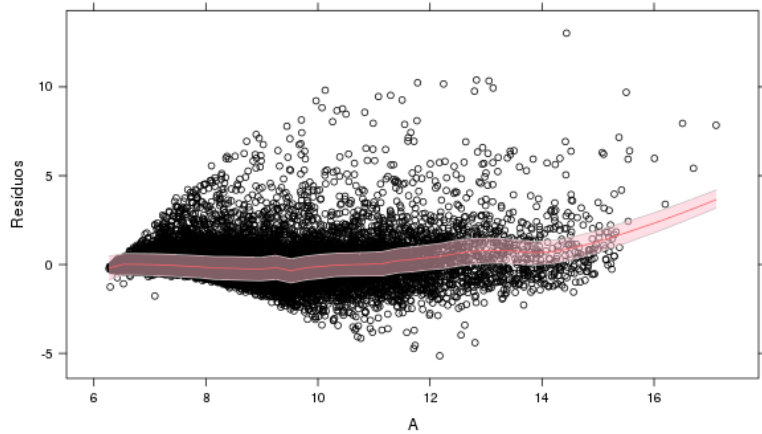

(a) Lâmina de número 64 normalizada com $\alpha=0,6$ Gráfico M-A após normalizaçăo usando Lowess com $\alpha=0.35$ lâmina: 251485069395_1.1

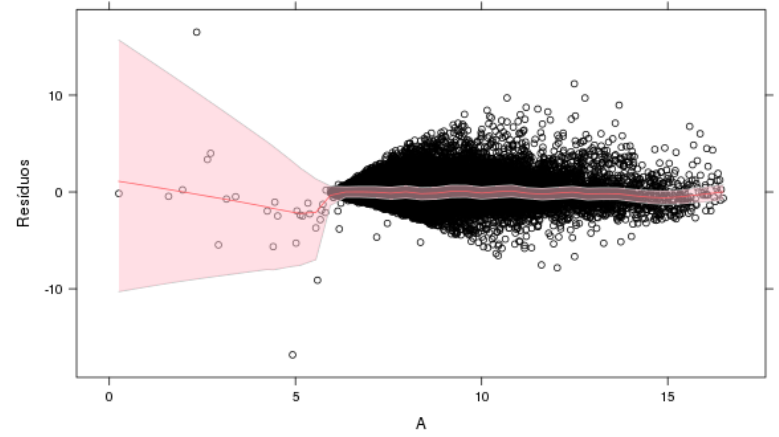

(c) Lâmina de número 90 normalizada com $\alpha=0,35$. Gráfico M-A após normalizaçăo usando Lowess com $\alpha=0.6$ lâmina: 251485069514_1.2

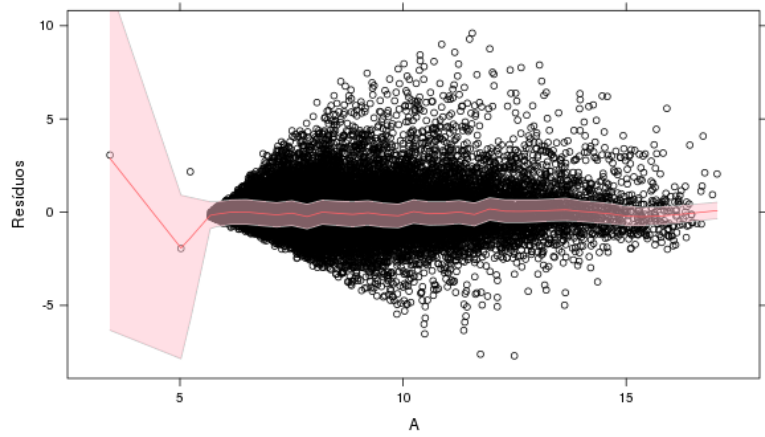

(e) Lâmina de número 30 normalizada $\operatorname{com} \alpha=0,6$. Gráfico M-A após normalizaçāo usando Lowess com $\alpha=0.6$ lâmina: 251485069410_1.1

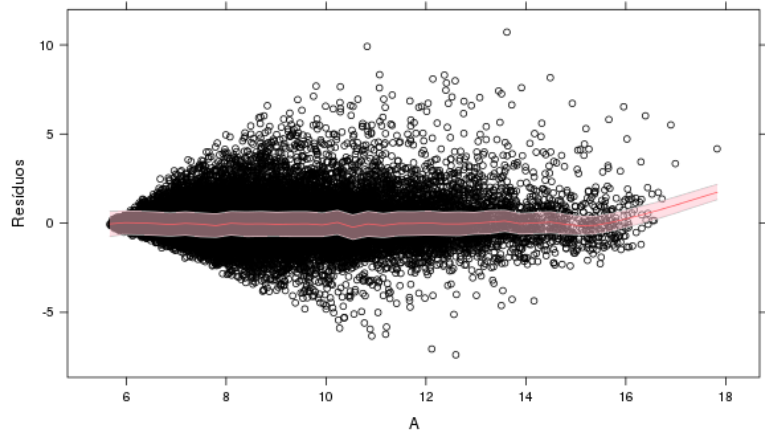

(g) Lâmina de número 27 normalizada com $\alpha=0,6$.
Gráfico M-A após normalização usando Lowess $\operatorname{com} \alpha=0.2$ lâmina: 251485069480_1.4

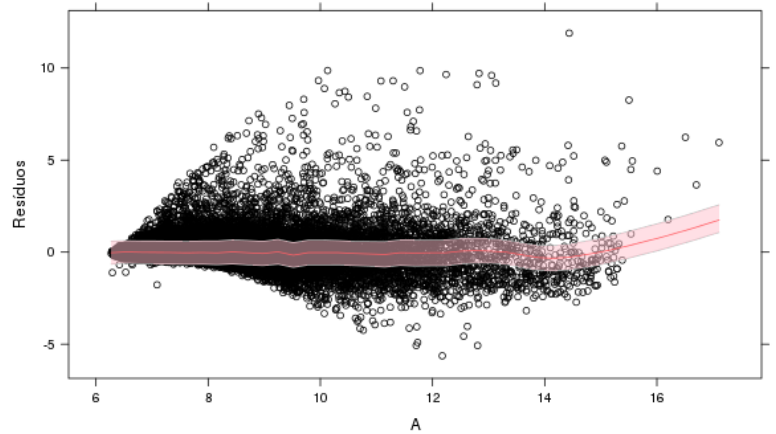

(b) Lâmina de número 64 normalizada $\operatorname{com} \alpha=0$,2. Gráfico M-A após normalizaçăo usando Lowess com $\alpha=0.2$ lâmina: 251485069395_1.1

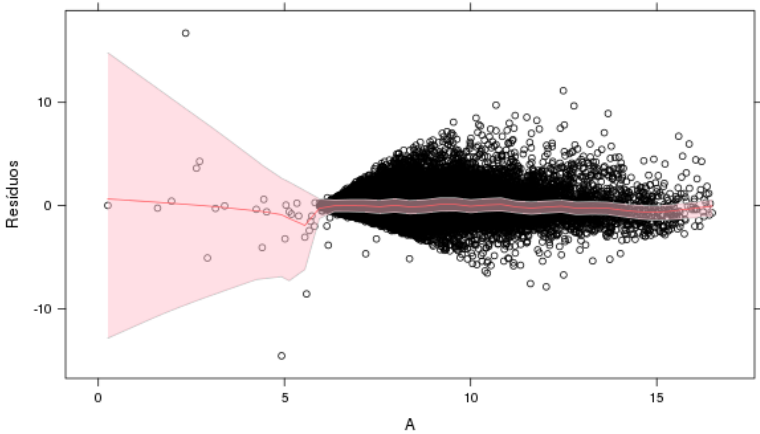

(d) Lâmina de número 90 normalizada $\operatorname{com} \alpha=0$,2. Gráfico M-A após normalizaçăo usando Lowess $\operatorname{com} \alpha=0.2$ lâmina: 251485069514_1.2

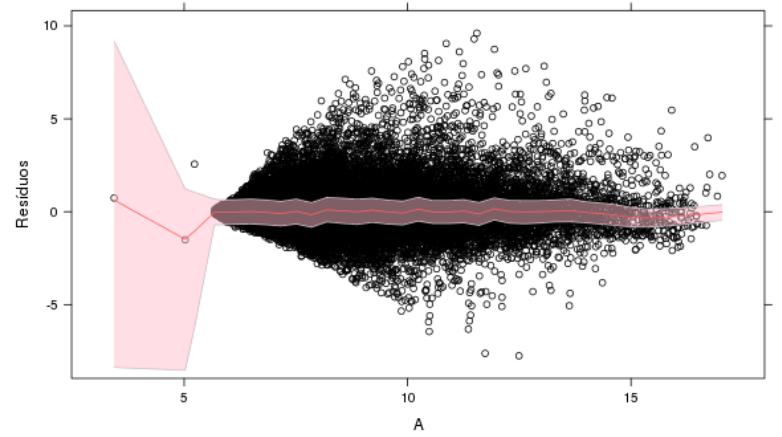

(f) Lâmina de número 30 normalizada com $\alpha=0$,2. Gráfico M-A após normalizaçāo usando Lowess $\operatorname{com} \alpha=0.2$ lâmina: 251485069410_1.1

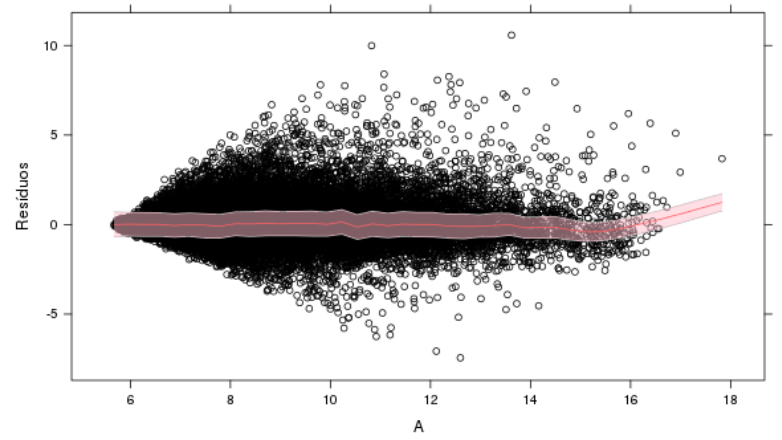

(h) Lâmina de número ${ }^{7} 7$ normalizada $\operatorname{com} \alpha=0$,2.

Figura 7.2: Lâminas normalizadas ressaltando o intervalo das medidas após erros estimados (erro original das medidas acumulado ao o erro da estimação da curva de suavização com lowess). 


\subsection{Determinação dos genes diferencialmente expressos}

Como vimos na seção 2.6, para determinarmos se um gene é diferencialmente expresso entre as condições fenotípicas de interesse, devemos avaliar a significância dos coeficientes que diferenciam essas condições.

Nosso interesse nesta aplicação é determinar os genes diferencialmente expressos em alguma das três condições fenotípicas que temos disponíveis no experimento para as amostras de estômago. Além disso, queremos avaliar as diferenças, se houver, entre os genes obtidos para cada variante da nossa base de dados.

Assim, faremos os testes com os dados de expressão representados pelas três estimativas de $M_{i}$ listadas em 7.2 e normalizados tanto com largura banda convencional $(\alpha=0,2)$ como com parâmetro de suavização estimado pelo método visto na seção 5.1.4.

Para testarmos se alguma das condições fenotípicas das amostras é significativamente diferente das demais, fizemos um ajuste linear às expressões de cada gene utilizando a condição fenotípica como fator fixo. Em seguida, avaliamos as seguintes hipóteses de interesse:

$$
\begin{aligned}
& H_{0_{1}}: \beta_{\text {metaplasia }}-\beta_{\text {saudavel }}=0 ; \\
& H_{0_{2}}: \beta_{\text {metaplasia }}-\beta_{\text {inflamacao }}=0 ; \\
& H_{0_{3}}: \beta_{\text {inflamacao }}-\beta_{\text {saudavel }}=0 .
\end{aligned}
$$

O que, em notação matricial, é equivalente a:

$$
H_{0}:\left(\begin{array}{rrr}
-1 & 0 & 1 \\
0 & -1 & 1 \\
-1 & 1 & 0
\end{array}\right)\left(\begin{array}{c}
\beta_{\text {saudavel }} \\
\beta_{\text {inflamacao }} \\
\beta_{\text {metaplasia }}
\end{array}\right)=\left(\begin{array}{l}
0 \\
0 \\
0
\end{array}\right) .
$$

Para testarmos essas hipóteses nas variantes da base com expressões representadas pela médias, ajustamos um modelo linear simples e obtivemos a estatística $F$ convencional, conforme descrevemos na seção 2.6. Para a variante com dados intervalares, ajustamos o modelo misto descrito no capítulo 6 e utilizamos o teste da estatística $F_{M}$, visto na seção 6.1 .3 , que é o teste $\mathrm{F}$ condicional para modelos mistos. As restrições lineares utilizadas nos testes foram as mesmas.

O resultado dessa análise inicial nos mostrou que, para nenhum gene, podemos rejeitar a hipótese $H_{0_{3}}$. Ou seja, não conseguimos detectar uma diferença estatística entre as amostras de estômagos saudáveis e com inflamação. Assim, considerando que o fenótipo saudável é equivalente ao fenótipo inflamação, as hipóteses $H_{0_{1}}$ e $H_{0_{2}}$ são também equivalentes. Logo, refizemos nossos testes apenas para a hipótese

$$
H_{0}: \beta_{\text {metaplasia }}-\beta_{\text {saudavel }}=0,
$$

utilizando somente as amostras de estômagos com metaplasia de grau II e de estômagos saudáveis. Decidimos, para esta aplicação, não considerar as amostras de estômagos saudáveis e com inflamação como amostras de um mesmo fenótipo.

Consideramos genes diferencialmente expressos aqueles que apresentam o p-valor do teste para $H_{0}$ (7.1), após a correção por FDR, abaixo de um certo valor de corte. Além disso, é comum utilizarmos um filtro pelo fold change absoluto para a seleção de genes que, além de estatisticamente diferentes, possuem uma relevância biológica. Um recurso gráfico muito utilizado para a combinação desses dois critérios é o gráfico Volcano, que pode ser conferido no artigo de Cui e Churchill (2003). O fold change é o logaritmo da razão entre as medidas duas condições ou a média das razões quando há réplicas. Como as medidas de expressões gênicas já estão em escala logarítmica, o cálculo do fold change, nesse caso, é dado por

$$
\operatorname{Med}\left(\mathrm{S}_{1}\right)-\operatorname{Med}\left(\mathrm{S}_{2}\right)
$$

em que Med é o operador média, $S_{1}$ é o conjunto das expressões em uma condição fenotípica, que escolhemos ser a metaplasia do estômago, e $S_{2}$ é o conjunto das expressões da condição fenotípica 
a ser comparada, que escolhemos ser condição do tecido do estômago saudável. Assim, um valor negativo para o fold change indica que o gene está subexpresso na amostra com metaplasia de grau II, em relação à amostra de tecidos saudáveis, e um valor positivo indica o oposto, ou seja, que o gene está superexpresso na condição de metaplasia do estômago. Vale a pena ressaltar que essa medida fold change é também referenciada na literatura como $\log _{2}$ fold change, já que as medidas de expressão gênica estão em base logarítmica.

A escolha do p-valor e do fold change de corte geralmente é arbitrária, sendo que é comum encontrarmos na literatura p-valores de corte de no máximo $5 \%$ e fold change de corte entre 1 e 2 . Como discutido no artigo de Dalman et al. (2012), a escolha desses valores de corte pode alterar a interpretação dos resultados, já que precisamos definir um limiar para a exclusão dos falsos positivos.

Listamos, nas tabelas 7.1 e 7.2, os 20 genes mais diferencialmente expressos, para cada uma das variantes da base de dados. A seleção foi feita usando apenas genes com fold change absoluto maior que 1. Tanto o p-valor como o fold change da análise são mostrados na tabela. A ordenação dos genes é dada pela ordem crescente dos p-valores já corrigidos por FDR para múltiplas comparações.

Podemos observar, por essas tabelas, que as posições dos genes variaram pouco ao utilizarmos tanto uma representação diferente para as expressões gênicas relativas como um valor diferente para o parâmetro de suavização $(\alpha)$ no método de normalização intra-lâmina. Em particular, vemos que os resultados dados para as variantes da base com dados intervalares e com médias melhoradas, quando normalizados usando $\alpha=0,2$, são os mais distintos. Isso fica um pouco mais claro observando os diagramas de Venn da figura 7.3 para os genes apresentados nessas tabelas.

Nos diagramas da figura 7.3a, vemos que há uma intersecção grande entre as variantes da base de dados. Porém, quando realizamos uma normalização com $\alpha=0,2$ e representamos as medidas pela estimativa da média de $M_{i}$ melhorada, $\bar{M}_{i}$, ou por dados intervalares, $I_{M_{i}}$, temos dois genes diferentes: o A1CF (com identificação A_24_P570378 na plataforma Agilent) e o TMEM139 (com identificação A_23_P42909). O p-valor para o teste de $H_{0}$ (7.1), para esses dois genes, é menor quando utilizamos as informações de imprecisões na representação das expressões gênicas e normalizamos os dados com $\alpha=0,2$, porém, a diferença em relação aos p-valores obtidos nas demais variantes da base de dados não é grande. Esses dois genes ocupam uma posição entre a $21^{\mathrm{a}}$ e a $24^{\mathrm{a}}$ nas demais variantes da base de dados. Os outros dois genes que aparecem melhor posicionados nas demais variantes são o HKDC1, com identificação A_23_P52451 e que já estava representado nessa lista pelo local genético de identificação A_23_P202427, e o MEP1A, com identificação A_23_P93122 e que também já estava representado nessa lista pelo local genético de identificação A_24_P154868. Assim, no total, temos 20 genes distintos considerados, em pelo menos uma das variantes da base, como diferencialmente expressos entre as condições de estômago saudável e com metaplasia de grau II. Utilizando a ferramenta (Mi et al. (2013)), geramos o gráfico da figura 7.4, que ilustra a proporção das funções biológicas correspondentes a esses 20 genes.

Para uma melhor visualização desses genes, mostramos, na figura 7.5, destacamos esses genes nos gráficos Volcano de cada uma das variantes da base dados. Em vermelho, são mostrados os genes que estão entre os 20 mais diferentes expressos na variante da base em questão. Em azul, destacamos os genes que foram determinados como um dos 20 mais diferencialmente expressos em alguma das outras variantes da base dados. As linhas mostram que o p-valor desses genes é menor que 0,001 e o fold change é maior que 1 . 


\begin{tabular}{|c|c|c|}
\hline $\begin{array}{l}\text { Dados intervalares } \\
\text { alpha } 0.2\end{array}$ & $\begin{array}{c}\text { Médias melhoradas } \\
\text { alpha } 0.2\end{array}$ & $\begin{array}{c}\text { Médias convencionais } \\
\text { alpha } 0.2\end{array}$ \\
\hline $\begin{array}{c}\text { A_23_P349463 (CHP2) } \\
\text { p-valor: } 2.914 \mathrm{e}-08 \text { FC: } 4.64\end{array}$ & $\begin{array}{c}\text { A_23_P349463 (CHP2) } \\
\text { p-valor: } 2.946 e-08 \text { FC: } 4.64\end{array}$ & $\begin{array}{c}\text { A_23_P349463 (CHP2) } \\
\text { p-valor: } 2.916 e-08 \text { FC: } 4.64\end{array}$ \\
\hline $\begin{array}{c}\text { A_23_P71017 (CLDN3) } \\
\text { p-valor: } 3.311 \mathrm{e}-08 \text { FC: } 2.79\end{array}$ & $\begin{array}{l}\text { A_23_P71017 (CLDN3) } \\
\text { p-valor: } 3.36 \mathrm{e}-08 \text { FC: } 2.79\end{array}$ & $\begin{array}{l}\text { A_23_P71017 (CLDN3) } \\
\text { p-valor: } 3.402 e-08 \text { FC: } 2.79\end{array}$ \\
\hline $\begin{array}{l}\text { A_32_P9368 (EFNA2) } \\
\text { p-valor: } 3.311 \mathrm{e}-08 \text { FC: } 2.34\end{array}$ & $\begin{array}{l}\text { A_32_P9368 (EFNA2) } \\
\text { p-valor: } 3.36 \mathrm{e}-08 \text { FC: } 2.34\end{array}$ & $\begin{array}{c}\text { A_32_P9368 (EFNA2) } \\
\text { p-valor: } 3.402 \mathrm{e}-08 \text { FC: } 2.35\end{array}$ \\
\hline $\begin{array}{c}\text { A_23_P256784 (MUC2) } \\
\text { p-valor: } 9.754 \mathrm{e}-08 \text { FC: } 1.78\end{array}$ & $\begin{array}{c}\text { A_23_P22526 (HEPH) } \\
\text { p-valor: } 9.867 \text { e-08 FC: } 2.63\end{array}$ & $\begin{array}{l}\text { A_23_P256784 (MUC2) } \\
\text { p-valor: } 9.624 \mathrm{e}-08 \text { FC: } 1.78\end{array}$ \\
\hline $\begin{array}{l}\text { A_23_P114947 (RGS2) } \\
\text { p-valor: } 9.754 \mathrm{e}-08 \text { FC: } 2\end{array}$ & $\begin{array}{l}\text { A_23_P256784 (MUC2) } \\
\text { p-valor: } 1.012 \mathrm{e}-07 \text { FC: } 1.78\end{array}$ & $\begin{array}{c}\text { A_23_P114947 (RGS2) } \\
\text { p-valor: } 9.624 \text { e-08 FC: } 2.01\end{array}$ \\
\hline $\begin{array}{c}\text { A_23_P22526 (HEPH) } \\
\text { p-valor: } 9.754 \mathrm{e}-08 \text { FC: } 2.63\end{array}$ & $\begin{array}{l}\text { A_23_P114947 (RGS2) } \\
\text { p-valor: } 1.012 e-07 \text { FC: } 2\end{array}$ & $\begin{array}{c}\text { A_23_P22526 (HEPH) } \\
\text { p-valor: } 9.624 \mathrm{e}-08 \text { FC: } 2.63\end{array}$ \\
\hline $\begin{array}{l}\text { A_23_P49145 (ZG16) } \\
\text { p-valor: } 1.073 \mathrm{e}-07 \text { FC: } 3.83\end{array}$ & $\begin{array}{c}\text { A_23_P49145 (ZG16) } \\
\text { p-valor: } 1.078 \mathrm{e}-07 \text { FC: } 3.83\end{array}$ & $\begin{array}{c}\text { A_23_P49145 (ZG16) } \\
\text { p-valor: } 1.051 \mathrm{e}-07 \text { FC: } 3.83\end{array}$ \\
\hline $\begin{array}{l}\text { A_23_P71880 (SPINK4) } \\
\text { p-valor: } 1.117 \text { e-07 FC: } 3.8\end{array}$ & $\begin{array}{l}\text { A_23_P71880 (SPINK4) } \\
\text { p-valor: } 1.113 \mathrm{e}-07 \text { FC: } 3.8\end{array}$ & $\begin{array}{l}\text { A_23_P71880 (SPINK4) } \\
\text { p-valor: } 1.078 \mathrm{e}-07 \text { FC: } 3.8\end{array}$ \\
\hline $\begin{array}{c}\text { A_23_P213385 (BASP1) } \\
\text { p-valor: } 1.752 \mathrm{e}-07 \text { FC: }-1.27\end{array}$ & $\begin{array}{c}\text { A_23_P213385 (BASP1) } \\
\text { p-valor: } 1.723 \mathrm{e}-07 \text { FC: }-1.27\end{array}$ & $\begin{array}{c}\text { A_23_P213385 (BASP1) } \\
\text { p-valor: } 1.775 e-07 \text { FC: }-1.27\end{array}$ \\
\hline $\begin{array}{c}\text { A_23_P79562 (FABP1) } \\
\text { p-valor: } 2.478 \mathrm{e}-07 \text { FC: } 5.05\end{array}$ & $\begin{array}{l}\text { A_23_P79562 (FABP1) } \\
\text { p-valor: } 2.48 \mathrm{e}-07 \text { FC: } 5.05\end{array}$ & $\begin{array}{l}\text { A_23_P79562 (FABP1) } \\
\text { p-valor: } 2.449 e-07 \text { FC: } 5.05\end{array}$ \\
\hline $\begin{array}{l}\text { A_32_P124708 (ONECUT2) } \\
\text { p-valor: } 2.478 \mathrm{e}-07 \text { FC: } 2.13\end{array}$ & $\begin{array}{c}\text { A_23_P142255 (SHD) } \\
\text { p-valor: } 2.48 \mathrm{e}-07 \text { FC: } 1.94\end{array}$ & $\begin{array}{l}\text { A_32_P124708 (ONECUT2) } \\
\text { p-valor: } 2.449 \mathrm{e}-07 \text { FC: } 2.13\end{array}$ \\
\hline $\begin{array}{l}\text { A_23_P142255 (SHD) } \\
\text { p-valor: } 2.478 \mathrm{e}-07 \text { FC: } 1.94\end{array}$ & $\begin{array}{l}\text { A_32_P124708 (ONECUT2) } \\
\text { p-valor: } 2.502 \mathrm{e}-07 \text { FC: } 2.13\end{array}$ & $\begin{array}{l}\text { A_23_P142255 (SHD) } \\
\text { p-valor: } 2.449 \mathrm{e}-07 \text { FC: } 1.94\end{array}$ \\
\hline $\begin{array}{l}\text { A_23_P60009 (ANXA13) } \\
\text { p-valor: } 2.596 \mathrm{e}-07 \text { FC: } 2.82\end{array}$ & $\begin{array}{l}\text { A_23_P60009 (ANXA13) } \\
\text { p-valor: } 2.589 e-07 \text { FC: } 2.82\end{array}$ & $\begin{array}{l}\text { A_23_P60009 (ANXA13) } \\
\text { p-valor: } 2.532 e-07 \text { FC: } 2.82\end{array}$ \\
\hline $\begin{array}{l}\text { A_23_P202427 (HKDC1) } \\
\text { p-valor: } 2.596 \mathrm{e}-07 \text { FC: } 2.65\end{array}$ & $\begin{array}{l}\text { A_23_P202427 (HKDC1) } \\
\text { p-valor: } 2.589 e-07 \quad F C: 2.65\end{array}$ & $\begin{array}{l}\text { A_23_P202427 (HKDC1) } \\
\text { p-valor: } 2.532 e-07 \text { FC: } 2.65\end{array}$ \\
\hline $\begin{array}{l}\text { A_23_P95851 (TUBAL3) } \\
\text { p-valor: } 2.743 \mathrm{e}-07 \text { FC: } 2.36\end{array}$ & $\begin{array}{l}\text { A_23_P95851 (TUBAL3) } \\
\text { p-valor: } 2.71 \text { e-07 FC: } 2.36\end{array}$ & $\begin{array}{l}\text { A_23_P95851 (TUBAL3) } \\
\text { p-valor: } 2.667 e-07 \text { FC: } 2.35\end{array}$ \\
\hline $\begin{array}{l}\text { A_23_P98876 (SLC39A5) } \\
\text { p-valor: } 2.743 \mathrm{e}-07 \text { FC: } 1.73\end{array}$ & $\begin{array}{l}\text { A_23_P98876 (SLC39A5) } \\
\text { p-valor: } 2.71 \text { e-07 FC: } 1.73\end{array}$ & $\begin{array}{l}\text { A_23_P98876 (SLC39A5) } \\
\text { p-valor: } 2.667 \text { e-07 FC: } 1.74\end{array}$ \\
\hline $\begin{array}{l}\text { A_23_P203698 (MOGAT2) } \\
\text { p-valor: } 4.118 \mathrm{e}-07 \text { FC: } 1.38\end{array}$ & $\begin{array}{l}\text { A_23_P203698 (MOGAT2) } \\
\text { p-valor: } 4.051 \text { e-07 FC: } 1.38\end{array}$ & $\begin{array}{l}\text { A_23_P203698 (MOGAT2) } \\
\text { p-valor: } 3.883 e-07 \text { FC: } 1.37\end{array}$ \\
\hline $\begin{array}{l}\text { A_24_P154868 (MEP1A) } \\
\text { p-valor: } 4.118 \mathrm{e}-07 \text { FC: } 2.53\end{array}$ & $\begin{array}{l}\text { A_24_P154868 (MEP1A) } \\
\text { p-valor: } 4.074 \text { e-07 FC: } 2.53\end{array}$ & $\begin{array}{l}\text { A_24_P154868 (MEP1A) } \\
\text { p-valor: } 3.883 e-07 \text { FC: } 2.53\end{array}$ \\
\hline $\begin{array}{l}\text { A_24_P570378 (A1CF) } \\
\text { p-valor: } 4.43 e-07 \text { FC: } 1.35\end{array}$ & $\begin{array}{c}\text { A_24_P570378 (A1CF) } \\
\text { p-valor: } 4.387 \text { e-07 FC: } 1.35\end{array}$ & $\begin{array}{l}\text { A_23_P52451 (HKDC1) } \\
\text { p-valor: } 4.364 \mathrm{e}-07 \text { FC: } 1.58\end{array}$ \\
\hline $\begin{array}{l}\text { A_23_P42909 (TMEM139) } \\
\text { p-valor: } 4.43 \mathrm{e}-07 \text { FC: } 1.47\end{array}$ & $\begin{array}{l}\text { A_23_P42909 (TMEM139) } \\
\text { p-valor: } 4.387 \text { e-07 FC: } 1.47\end{array}$ & $\begin{array}{l}\text { A_23_P93122 (MEP1A) } \\
\text { p-valor: } 4.364 \mathrm{e}-07 \text { FC: } 2.98\end{array}$ \\
\hline
\end{tabular}

Tabela 7.1: Tabela com os 20 genes mais diferencialmente expressos para as variantes da base de dados que foram normalizadas com o parâmetro de suavização $\alpha$ igual a $0,2$. 


\begin{tabular}{|c|c|c|}
\hline $\begin{array}{l}\text { Dados intervalares } \\
\text { alpha estimado }\end{array}$ & $\begin{array}{l}\text { Médias melhoradas } \\
\text { alpha estimado }\end{array}$ & $\begin{array}{l}\text { Médias convencionais } \\
\text { alpha estimado }\end{array}$ \\
\hline $\begin{array}{c}\text { A_23_P349463 (CHP2) } \\
\text { p-valor: } 3.364 \text { e-08 FC: } 4.62\end{array}$ & $\begin{array}{l}\text { A_23_P349463 (CHP2) } \\
\text { p-valor: } 3.34 \mathrm{e}-08 \text { FC: } 4.62\end{array}$ & $\begin{array}{c}\text { A_23_P349463 (CHP2) } \\
\text { p-valor: } 3.354 \mathrm{e}-08 \text { FC: } 4.62\end{array}$ \\
\hline $\begin{array}{c}\text { A_23_P71017 (CLDN3) } \\
\text { p-valor: } 4.416 e-08 \text { FC: } 2.86\end{array}$ & $\begin{array}{l}\text { A_23_P71017 (CLDN3) } \\
\text { p-valor: } 4.268 \mathrm{e}-08 \text { FC: } 2.86\end{array}$ & $\begin{array}{c}\text { A_23_P71017 (CLDN3) } \\
\text { p-valor: } 3.998 \mathrm{e}-08 \text { FC: } 2.86\end{array}$ \\
\hline $\begin{array}{c}\text { A_32_P9368 (EFNA2) } \\
\text { p-valor: } 4.416 \mathrm{e}-08 \text { FC: } 2.38\end{array}$ & $\begin{array}{l}\text { A_32_P9368 (EFNA2) } \\
\text { p-valor: } 4.268 \mathrm{e}-08 \text { FC: } 2.38\end{array}$ & $\begin{array}{c}\text { A_32_P9368 (EFNA2) } \\
\text { p-valor: } 3.998 \mathrm{e}-08 \text { FC: } 2.39\end{array}$ \\
\hline $\begin{array}{c}\text { A_23_P114947 (RGS2) } \\
\text { p-valor: } 1.099 \text { e-07 FC: } 2.06\end{array}$ & $\begin{array}{l}\text { A_23_P114947 (RGS2) } \\
\text { p-valor: } 1.084 e-07 \quad F C: 2.06\end{array}$ & $\begin{array}{l}\text { A_23_P114947 (RGS2) } \\
\text { p-valor: } 1.042 e-07 \text { FC: } 2.06\end{array}$ \\
\hline $\begin{array}{c}\text { A_23_P22526 (HEPH) } \\
\text { p-valor: } 1.099 \text { e-07 FC: } 2.67\end{array}$ & $\begin{array}{l}\text { A_23_P22526 (HEPH) } \\
\text { p-valor: } 1.084 \mathrm{e}-07 \text { FC: } 2.67\end{array}$ & $\begin{array}{c}\text { A_23_P22526 (HEPH) } \\
\text { p-valor: } 1.042 \mathrm{e}-07 \text { FC: } 2.67\end{array}$ \\
\hline $\begin{array}{c}\text { A_23_P49145 (ZG16) } \\
\text { p-valor: } 1.182 \mathrm{e}-07 \text { FC: } 3.8\end{array}$ & $\begin{array}{c}\text { A_23_P49145 (ZG16) } \\
\text { p-valor: } 1.194 \mathrm{e}-07 \text { FC: } 3.8\end{array}$ & $\begin{array}{l}\text { A_23_P256784 (MUC2) } \\
\text { p-valor: } 1.207 \mathrm{e}-07 \text { FC: } 1.73\end{array}$ \\
\hline $\begin{array}{l}\text { A_23_P71880 (SPINK4) } \\
\text { p-valor: } 1.182 \mathrm{e}-07 \text { FC: } 3.78\end{array}$ & $\begin{array}{l}\text { A_23_P71880 (SPINK4) } \\
\text { p-valor: } 1.194 \mathrm{e}-07 \text { FC: } 3.78\end{array}$ & $\begin{array}{c}\text { A_23_P49145 (ZG16) } \\
\text { p-valor: } 1.207 \text { e-07 FC: } 3.8\end{array}$ \\
\hline $\begin{array}{l}\text { A_23_P256784 (MUC2) } \\
\text { p-valor: } 1.24 \mathrm{e}-07 \text { FC: } 1.73\end{array}$ & $\begin{array}{l}\text { A_23_P256784 (MUC2) } \\
\text { p-valor: } 1.32 \mathrm{e}-07 \text { FC: } 1.73\end{array}$ & $\begin{array}{l}\text { A_23_P71880 (SPINK4) } \\
\text { p-valor: } 1.207 e-07 \text { FC: } 3.78\end{array}$ \\
\hline $\begin{array}{l}\text { A_23_P213385 (BASP1) } \\
\text { p-valor: } 2.238 \mathrm{e}-07 \text { FC: }-1.3\end{array}$ & $\begin{array}{l}\text { A_23_P213385 (BASP1) } \\
\text { p-valor: } 2.232 \mathrm{e}-07 \text { FC: }-1.3\end{array}$ & $\begin{array}{c}\text { A_23_P79562 (FABP1) } \\
\text { p-valor: } 2.797 e-07 \text { FC: } 5.13\end{array}$ \\
\hline $\begin{array}{l}\text { A_23_P79562 (FABP1) } \\
\text { p-valor: } 2.783 e-07 \text { FC: } 5.12\end{array}$ & $\begin{array}{l}\text { A_23_P79562 (FABP1) } \\
\text { p-valor: } 2.787 \text { e-07 FC: } 5.12\end{array}$ & $\begin{array}{l}\text { A_23_P213385 (BASP1) } \\
\text { p-valor: } 3.012 e-07 \text { FC: }-1.29\end{array}$ \\
\hline $\begin{array}{c}\text { A_23_P142255 (SHD) } \\
\text { p-valor: } 3.144 \mathrm{e}-07 \text { FC: } 1.94\end{array}$ & $\begin{array}{c}\text { A_23_P142255 (SHD) } \\
\text { p-valor: } 3.185 e-07 \text { FC: } 1.94\end{array}$ & $\begin{array}{c}\text { A_23_P142255 (SHD) } \\
\text { p-valor: } 3.012 \mathrm{e}-07 \text { FC: } 1.94\end{array}$ \\
\hline $\begin{array}{l}\text { A_23_P60009 (ANXA13) } \\
\text { p-valor: } 3.144 \mathrm{e}-07 \quad \mathrm{FC}: 2.78\end{array}$ & $\begin{array}{l}\text { A_23_P60009 (ANXA13) } \\
\text { p-valor: } 3.185 e-07 \quad F C: 2.78\end{array}$ & $\begin{array}{l}\text { A_23_P60009 (ANXA13) } \\
\text { p-valor: } 3.012 e-07 \text { FC: } 2.78\end{array}$ \\
\hline $\begin{array}{l}\text { A_32_P124708 (ONECUT2) } \\
\text { p-valor: } 3.319 e-07 \quad F C: 2.12\end{array}$ & $\begin{array}{l}\text { A_32_P124708 (ONECUT2) } \\
\text { p-valor: } 3.281 \text { e-07 FC: } 2.12\end{array}$ & $\begin{array}{l}\text { A_23_P202427 (HKDC1) } \\
\text { p-valor: } 3.012 e-07 \text { FC: } 2.63\end{array}$ \\
\hline $\begin{array}{l}\text { A_23_P95851 (TUBAL3) } \\
\text { p-valor: } 3.319 e-07 \text { FC: } 2.32\end{array}$ & $\begin{array}{l}\text { A_23_P202427 (HKDC1) } \\
\text { p-valor: } 3.281 \text { e-07 FC: } 2.62\end{array}$ & $\begin{array}{l}\text { A_32_P124708 (ONECUT2) } \\
\text { p-valor: } 3.086 e-07 \text { FC: } 2.12\end{array}$ \\
\hline $\begin{array}{l}\text { A_23_P202427 (HKDC1) } \\
\text { p-valor: } 3.319 e-07 \quad F C: 2.62\end{array}$ & $\begin{array}{l}\text { A_23_P95851 (TUBAL3) } \\
\text { p-valor: } 3.427 \text { e-07 FC: } 2.32\end{array}$ & $\begin{array}{l}\text { A_23_P95851 (TUBAL3) } \\
\text { p-valor: } 3.305 \mathrm{e}-07 \text { FC: } 2.31\end{array}$ \\
\hline $\begin{array}{l}\text { A_23_P98876 (SLC39A5) } \\
\text { p-valor: } 4.058 \mathrm{e}-07 \text { FC: } 1.7\end{array}$ & $\begin{array}{l}\text { A_23_P98876 (SLC39A5) } \\
\text { p-valor: } 4.022 \mathrm{e}-07 \text { FC: } 1.7\end{array}$ & $\begin{array}{l}\text { A_23_P98876 (SLC39A5) } \\
\text { p-valor: } 3.943 e-07 \text { FC: } 1.7\end{array}$ \\
\hline $\begin{array}{l}\text { A_23_P203698 (MOGAT2) } \\
\text { p-valor: } 4.547 \text { e-07 FC: } 1.34\end{array}$ & $\begin{array}{l}\text { A_23_P203698 (MOGAT2) } \\
\text { p-valor: } 4.498 \mathrm{e}-07 \text { FC: } 1.34\end{array}$ & $\begin{array}{l}\text { A_23_P203698 (MOGAT2) } \\
\text { p-valor: } 4.36 \mathrm{e}-07 \text { FC: } 1.34\end{array}$ \\
\hline $\begin{array}{l}\text { A_24_P154868 (MEP1A) } \\
\text { p-valor: } 4.547 \text { e-07 FC: } 2.49\end{array}$ & $\begin{array}{l}\text { A_24_P154868 (MEP1A) } \\
\text { p-valor: } 4.59 \mathrm{e}-07 \text { FC: } 2.49\end{array}$ & $\begin{array}{l}\text { A_24_P154868 (MEP1A) } \\
\text { p-valor: } 4.36 \mathrm{e}-07 \text { FC: } 2.49\end{array}$ \\
\hline $\begin{array}{l}\text { A_23_P93122 (MEP1A) } \\
\text { p-valor: } 4.547 \text { e-07 FC: } 2.95\end{array}$ & $\begin{array}{l}\text { A_23_P93122 (MEP1A) } \\
\text { p-valor: } 4.59 \mathrm{e}-07 \text { FC: } 2.95\end{array}$ & $\begin{array}{l}\text { A_23_P93122 (MEP1A) } \\
\text { p-valor: } 4.497 \text { e-07 FC: } 2.94\end{array}$ \\
\hline $\begin{array}{l}\text { A_23_P52451 (HKDC1) } \\
\text { p-valor: } 5.381 \text { e-07 FC: } 1.55\end{array}$ & $\begin{array}{l}\text { A_23_P52451 (HKDC1) } \\
\text { p-valor: } 5.429 e-07 \text { FC: } 1.55\end{array}$ & $\begin{array}{l}\text { A_23_P52451 (HKDC1) } \\
\text { p-valor: } 5.304 \mathrm{e}-07 \text { FC: } 1.55\end{array}$ \\
\hline
\end{tabular}

Tabela 7.2: Tabela com os 20 genes mais diferencialmente expressos para as variantes da base de dados que foram normalizadas com um parâmetro de suavização $\alpha$ estimado. 


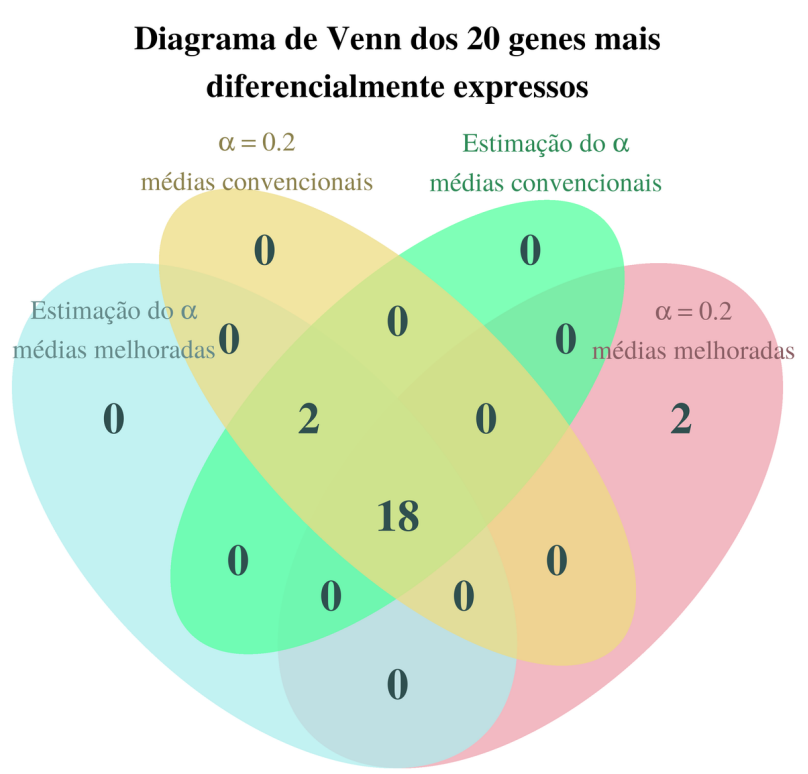

(a) Comparação entre bases com dados representados pelas médias de $M_{i}$ estimadas convencionalmente, com o estimador $\hat{M}_{i}$, e estimadas considerando as imprecisões das medidas, com o estimador $\bar{M}_{i}$.

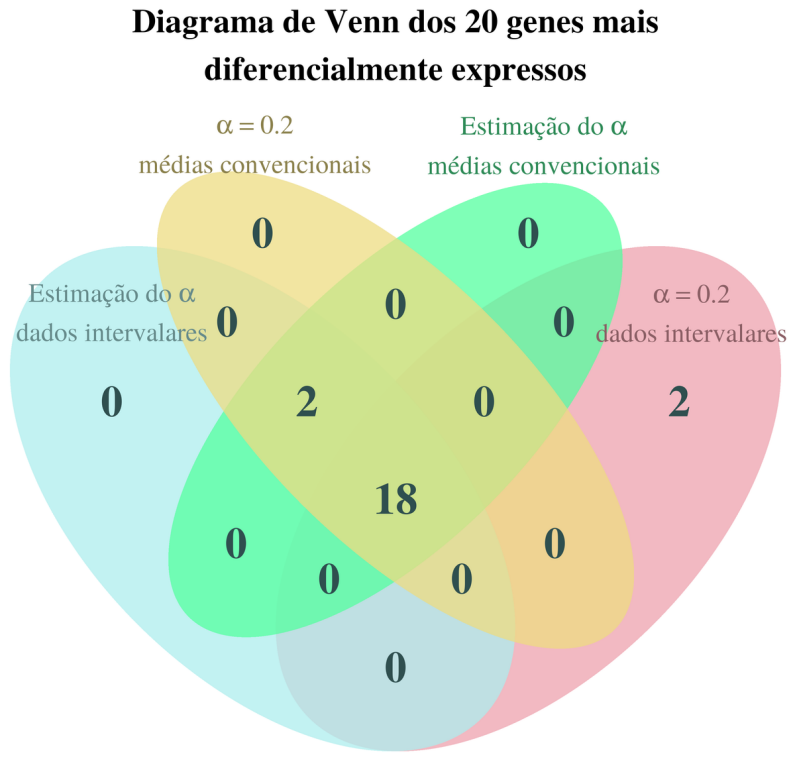

(b) Comparação entre bases com dados representados pelas médias de $M_{i}$ estimadas convencionalmente, com o estimador $\hat{M}_{i}$, e com dados representados por intervalos, indicando que as medidas $M_{i}$ contém um erro.

Figura 7.3: Diagrama de Venn mostrando os 20 genes diferencialmente expressos nas variantes da base de dados pré-processadas que estamos comparando.

\section{Processo Biológico - GO (Gene Ontology)} 20 genes mais diferencialmente expressos

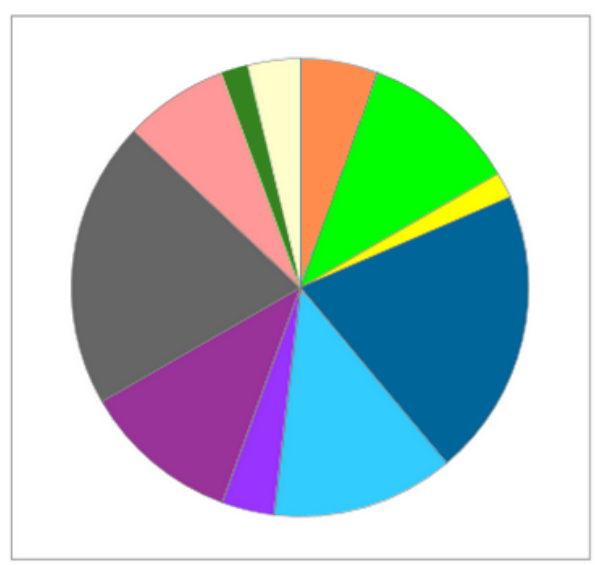

Adesão biológica (GO:0022610)

Regulação biológica (GO:0065007)

Biogênese do componente celular (GO:0071840)

Processo celular (GO:0009987)

[ Processo de desenvolvimento (GO:0032502)

Processo do sistema imunológico (GO:0002376)

Localização (GO:0051179)

Processo metabólico (GO:0008152)

Processo do organismo multicelular (GO:0032501)

Reprodução (GO:0000003)

Resposta ao estímulo (GO:0050896)

Figura 7.4: Gráficos da proporção de ontologias genéticas representadas pela união dos 20 genes mais diferencialmente expressos obtidos para cada variante da base e dados e que podem ser vistos nas tabelas 7.1 e 7.2. 

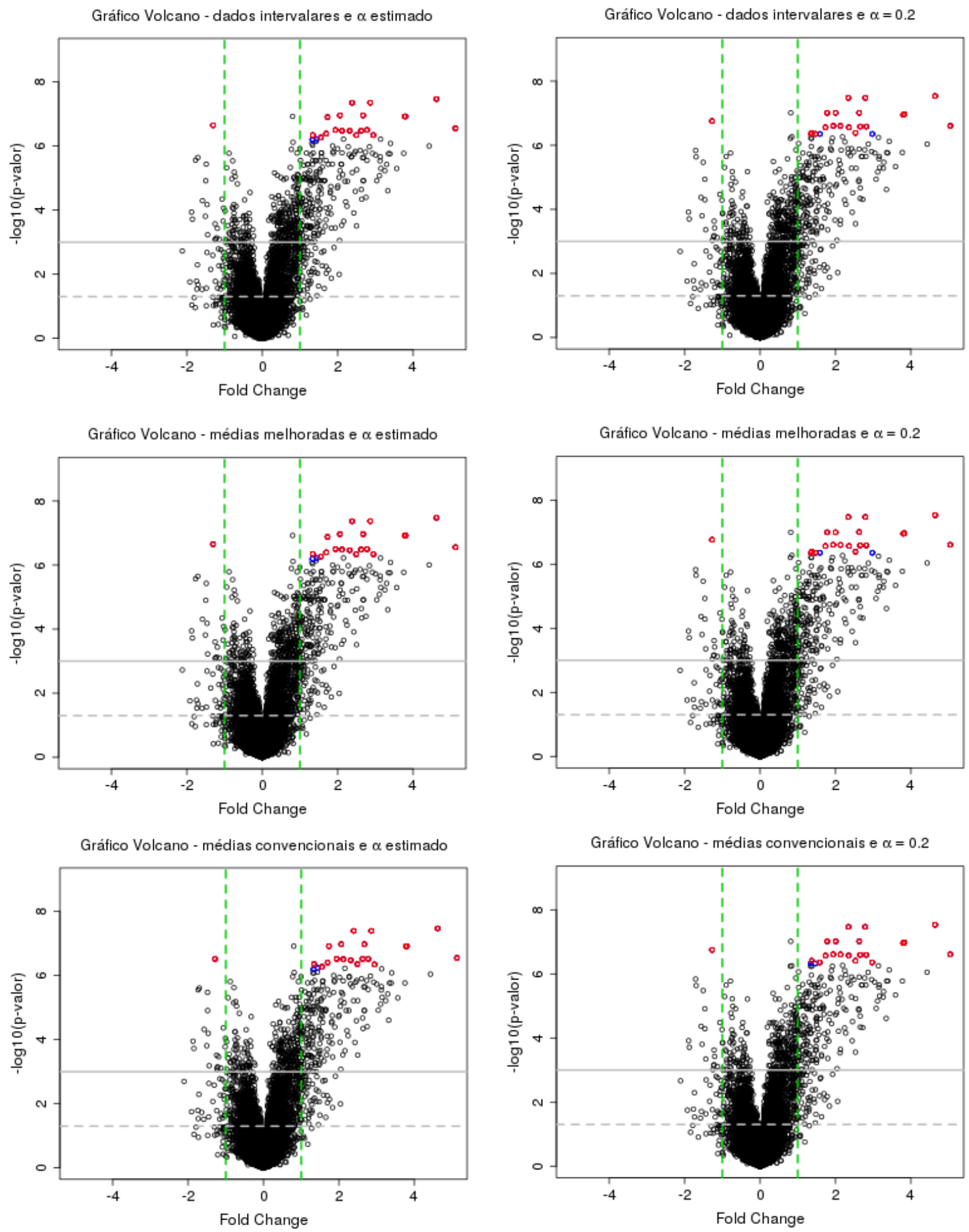

Figura 7.5: Gráficos Volcano para as variantes da base de dados em comparação, destacando, em vermelho, os 20 genes mais diferencialmente expressos e, em azul, os que apareceram na lista dos 20 genes mais diferencialmente expressos apenas nas outras variantes da base. As linhas em cinza marcam os p-valores 0,05 e 0,001. As linhas em verde marcam o fold change igual a 1. 


\subsection{Comparação entre as variantes da base de dados}

Apesar dessas tabelas nos mostrarem que a representação e a normalização impactam a determinação dos genes diferencialmente expressos, não fica muito claro se alguma das abordagens é melhor. Além disso, como os genes obtidos foram praticamente os mesmos, não podemos procurar evidências de que uma abordagem permite a determinação de genes mais significativos do ponto de vista biológico a partir de informações coletadas na literatura. Assim, para obtermos informações mais relevantes sobre o impacto causado pelas variações que propomos nos pré-processamentos, exploramos as características da distribuição dos p-valores, já corrigidos por FDR, do teste para $H_{0}$ (7.1).

Para observarmos as diferenças entre as distribuições dos p-valores determinados a partir dos dados resultantes das diferentes representações e métodos de normalização que estamos comparando, esboçamos o gráfico da figura 7.6. Com ele, conseguimos ver que as densidades dos p-valores obtidos com os dados normalizados com $\alpha=0,2$ assumem valores maiores que as densidades dos p-valores obtidos em dados normalizados com $\alpha$ estimado. Ou seja, temos mais ocorrências de p-valores e, portanto, genes, para um dado p-valor de corte. Porém, não fica clara a diferença entre as variantes com diferentes representações para as expressões gênicas, quando fixamos o método de normalização, nem a diferença entre as variantes quando temos p-valores muito baixos. Por isso, nas figuras 7.7 e 7.8, mostramos, respectivamente, a densidade dos p-valores dos genes que, em pelo menos uma das variantes da base, obtiveram p-valor para o teste de $H_{0}$ abaixo de 0,001 . Já na figura 7.9 , esboçamos a frequência acumulada dos p-valores para cada uma das variantes da base de dados, o que nos indica o quantidade de genes diferencialmente expressos para diferentes p-valores de corte.

Pelo gráfico da figura 7.8, podemos observar que, fixando $\alpha=0,2$, a quantidade de genes com p-valor abaixo de 0,00008, valor indicado pela linha tracejada no gráfico, é maior quando utilizamos dados que foram representados considerando as imprecisões (por intervalos ou pelas médias melhoradas de $M_{i}$ ). Já quando estimamos o valor do parâmetro de suavização $\alpha$ a ser utilizado na normalização, o uso das imprecisões nas representações dos dados tem um efeito contrário, ou seja, faz aumentar o p-valor do teste para $H_{0}$. Assim, nesse caso, temos mais genes diferencialmente expressos nas variantes da base com dados representados pelas médias convencionais.

Uma possível explicação que encontramos para esse comportamento é que os resíduos da correção do viés feita pela normalização com um $\alpha$ estimado acabam tendo uma variabilidade entre eles maior que quando é realizada a normalização $\operatorname{com} \alpha=0,2$. Pelo que constatamos com esta aplicação, os valores estimados para o parâmetro $\alpha$ geralmente é maior que 0,2 e, com isso, acabamos fazendo uma correção menos forte para a remoção do viés dos dados. Esse é justamente o efeito esperado pelo método proposto na seção 5.1.4, já que o parâmetro estimado é aquele que fornece um melhor balanço entre viés e variância. Lembrando que quanto menor é o $\alpha$ da suavização menos enviesada (ou mais ruidosa) é a estimava e lembrando que os valores ajustados serão removidos dos valores originais das medidas, devemos considerar a hipótese de estarmos removendo desses valores uma quantidade que não está associada a apenas uma variação sistemática. Assim, apesar de obtermos p-valores menores para os testes, é possível que a pequena variação dentro do grupo de expressões de mesma condição fenotípica não seja fiel à realidade.

Essas mesmas conclusões podem ser obtidas observando os gráficos da figura 7.10 e 7.11. As curvas em vermelho desses gráficos mostram quantos genes foram determinados como diferencialmente expressos com um p-valor abaixo de cada p-valor de corte e menor ao utilizar a variante da base com dados intervalares. Assim, fixando o parâmetro $\alpha$ da normalização em 0,2 , temos, para p-valores de corte está abaixo de 0,00008 ou entre, aproximadamente, 0,001 e 0,03, mais genes cujo p-valor do teste para $H_{0}$ (7.1) foi menor ao utilizar expressões gênicas intervalares em vez de representadas por médias convencionais. Já quando estimamos o parâmetro de suavização $\alpha$, temos umas diferença não muito grande entre as variantes com dados intervalares e médias convencionais para p-valores de corte abaixo de 0,00001, mas, para p-valores de corte maiores, a diferença aumenta, já que temos muito mais genes com p-valores mais baixos ao utilizarmos as médias convencionais. Finalmente, comparando os gráficos das figuras 7.12 e 7.13, fica ainda mais claro que, para p-valores de corte baixos, as imprecisões podem diminuir os p-valores quando usamos $\alpha=0,2$ na normalização e 
têm efeito contrário, ou seja, podem aumentar os p-valores, quando estimamos esse parâmetro $\alpha$. Também fica claro por esses gráficos a maior redução dos p-valores quando usamos $\alpha=0,2$ na normalização dos dados.

Os diagramas de Venn ilustrados na figura 7.14 mostram as diferenças nas quantidades de genes diferencialmente expressos determinadas para cada uma das variantes da base de dados. Quanto menos genes fora da área comum a todas as variantes da base de dados, mais parecidos foram os resultados obtidos. Para p-valores de corte pequenos, por exemplo, 0,00001, observamos que não há muita diferença entre as variantes da base de dados. Já com p-valores de corte maiores, por exemplo, 0,0001, a diferença nos p-valores dada pela variação do parâmetro de suavização $\alpha$ é bem maior, afetando mais a quantidade de genes determinados como diferencialmente expressos. Em particular, vemos mais genes considerados diferencialmente expressos nas variantes da base com expressões representadas pelas médias convencionais, independente do valor de $\alpha$ utilizado. Esse resultado corrobora a nossa conclusão obtida pela análise do gráfico da figura 7.10 e do gráfico da figura 7.8. Finalmente, com um p-valor de corte ainda maior, por exemplo, 0, 001, temos novamente uma redução dos p-valores ao incorporarmos as imprecisões e obtemos mais genes diferencialmente expressos nessas variantes da base. Com isso, a diferença, em número total de genes diferencialmente expressos, entre as variantes da base de dados é diminuída.

Uma análise ingênua, em que apenas a quantidade de genes diferencialmente expressos é observada, mostra que, com p-valor de corte em 0,03 , as variantes da base com expressões gênicas representadas pelos intervalos ou pelas médias melhoradas de $M_{i}$, quando utilizamos $\alpha=0,2$ na normalização com lowess, é a melhor escolha. Inclusive, como podemos ver nos diagramas de Venn da figura 7.15, essa variação se mantém mesmo considerando apenas os genes com fold change maior que 1. No entanto, é claro que apenas observar a quantidade de genes diferencialmente expressos não nos garante qual metodologia é melhor. É interessante sabermos como essas modificações nos pré-processamento dos dados afetam a determinação dos p-valores dos testes e, consequentemente, a determinação dos genes diferencialmente expressos. Com isso, teremos condições de julgar a relevância dos resultados. 


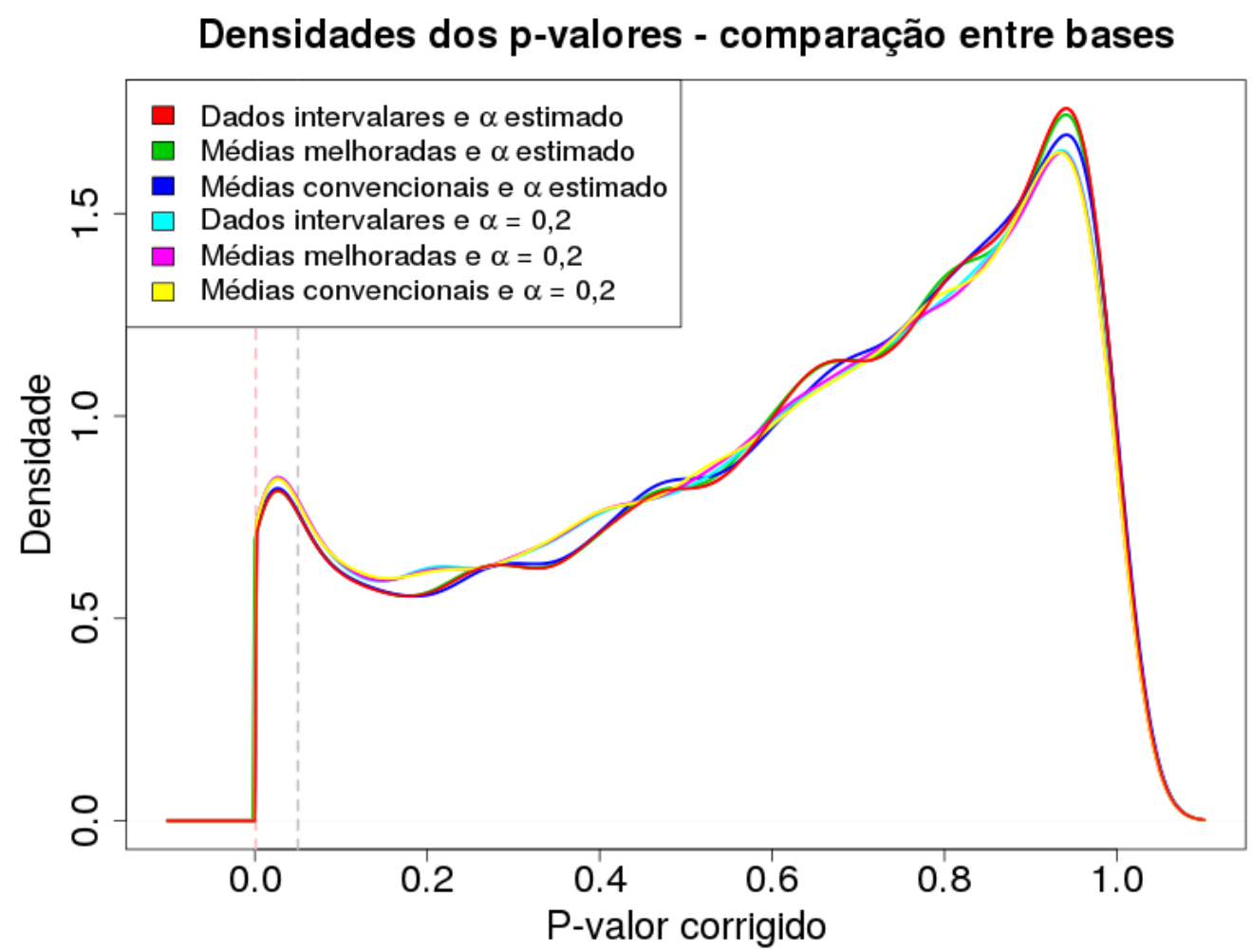

Figura 7.6: Curvas das densidades dos p-valores do teste para $H_{0}$ (7.1), corrigidos por FDR, para as diferentes variantes da base de dados em comparação. As linhas tracejadas da figura indicam o p-valores igual a 0,00008 e 0,001.

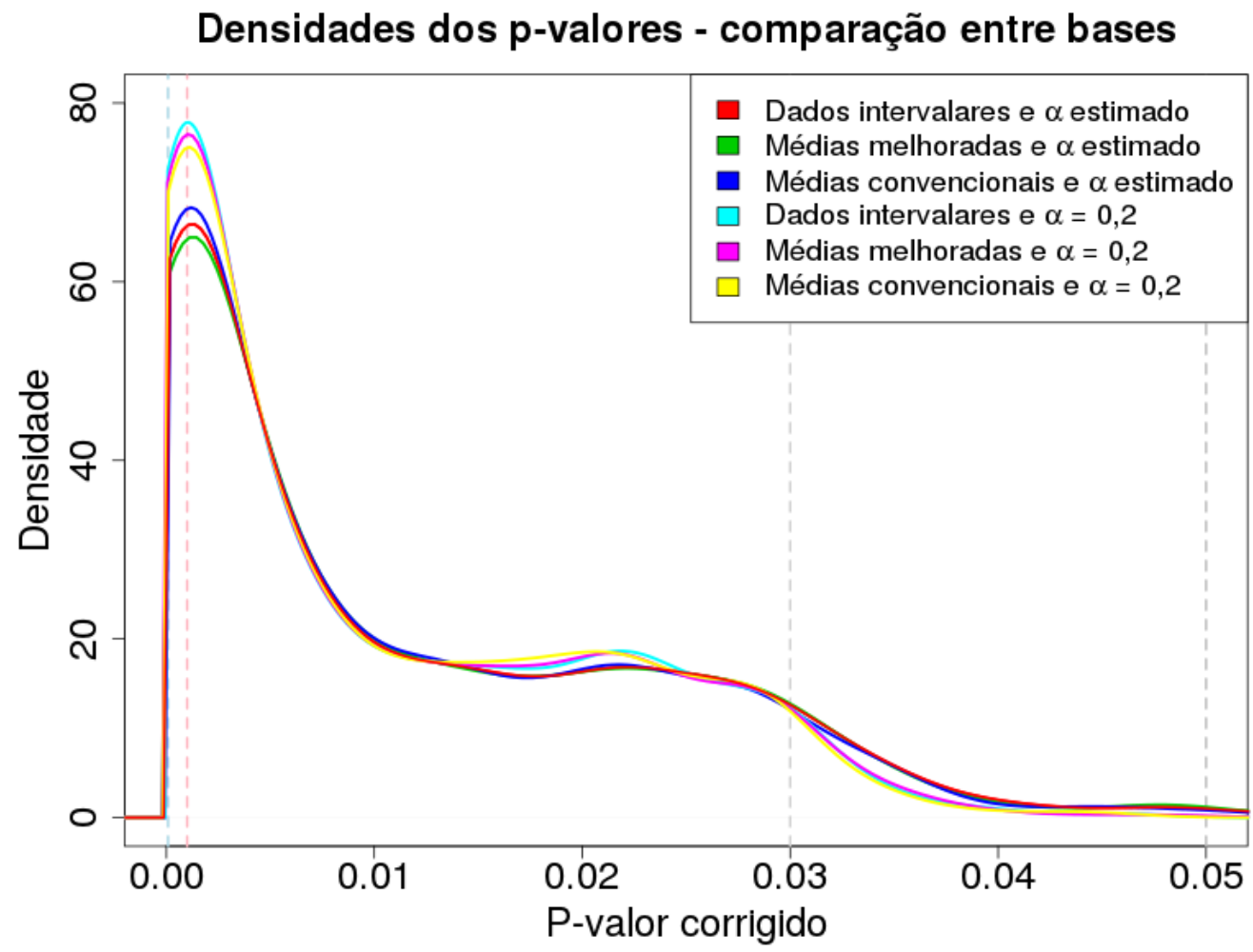

Figura 7.7: Densidades dos p-valores dos testes para os genes que, em pelo menos uma das variantes da base de dados em comparação, foram considerados diferencialmente expressos, com p-valor abaixo de 0,03. As linhas tracejadas da figura indicam o p-valores igual a 0,00008 e 0,001. 


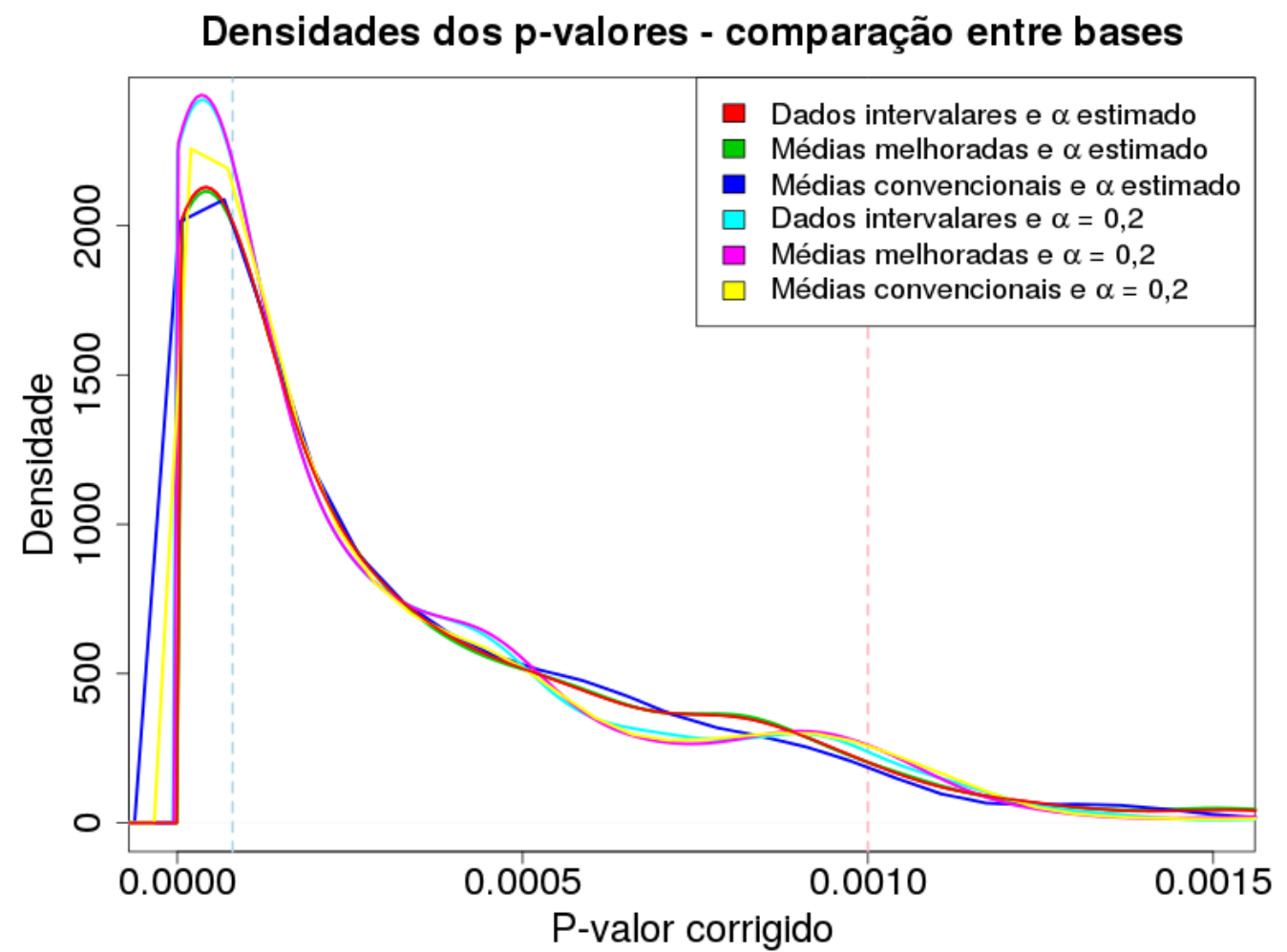

Figura 7.8: Densidades dos p-valores dos testes para os genes que, em pelo menos uma das variantes da base de dados em comparação, foram considerados diferencialmente expressos (p-valor abaixo de 0,001). As linhas tracejadas da figura indicam o p-valores igual a 0,00008 e 0,001.

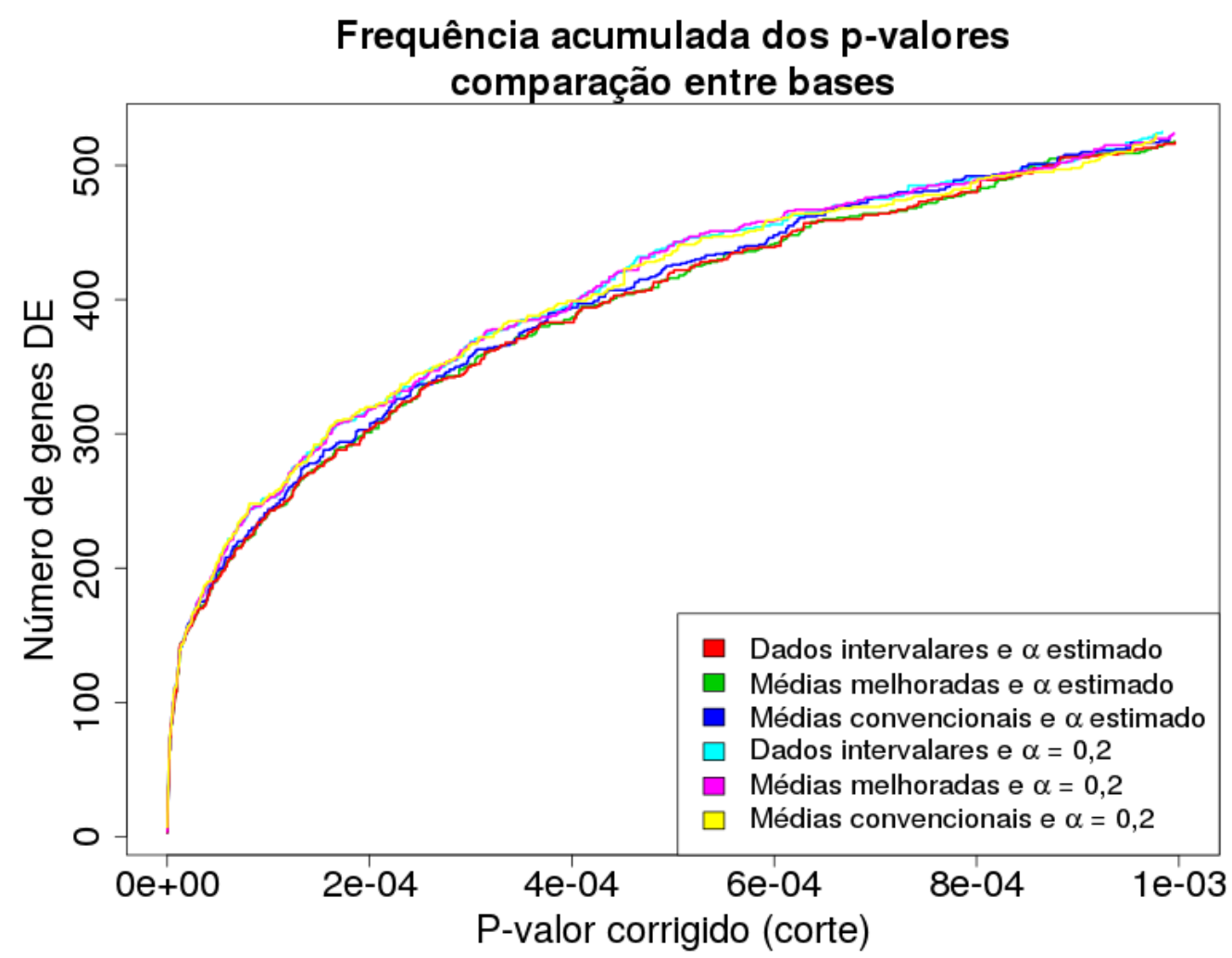

Figura 7.9: Frequência acumulada dos p-valores de acordo com um valor de corte para cada uma das variantes da base de dados em comparação. A frequência acumulada nos indica justamente a quantidade de genes com p-valor abaixo do valor de corte. 


\section{Número de genes com p-valor reduzido nas variantes da base com dados intervalares e com médias convencionais}

$$
\alpha=0,2
$$

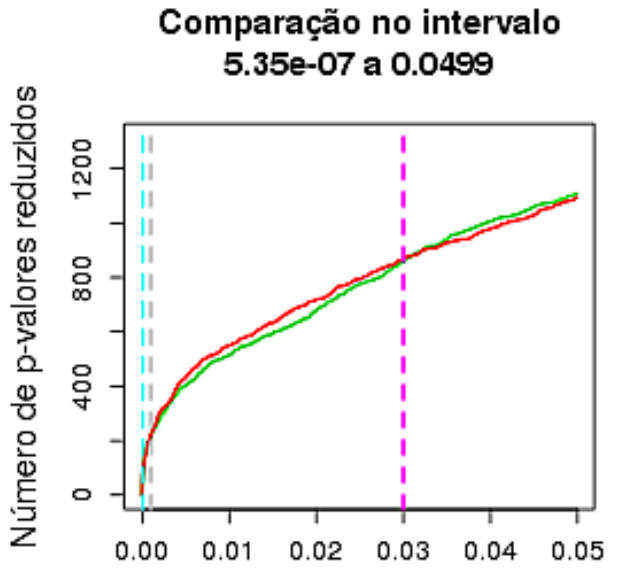

P-valor de corte (ajustado por FDR)

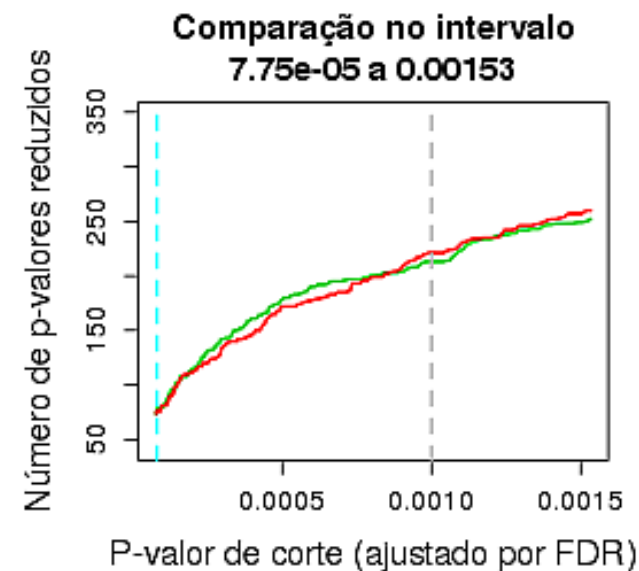

P-valor de corte (ajustado por FDR)

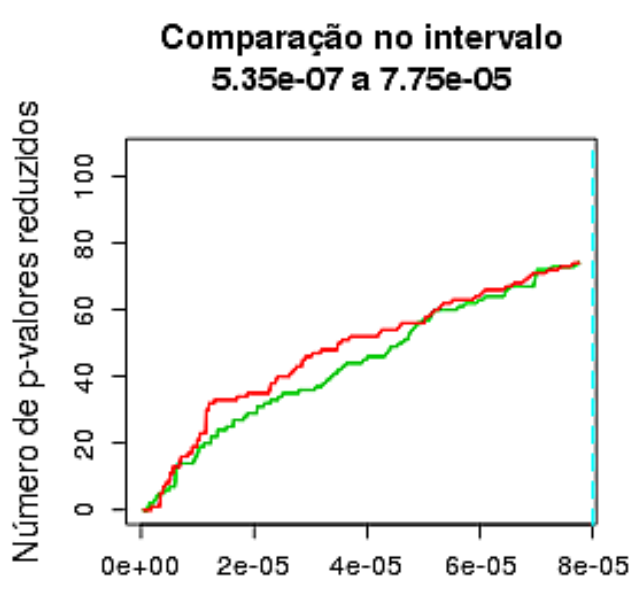

P-valor de corte (ajustado por FDR)

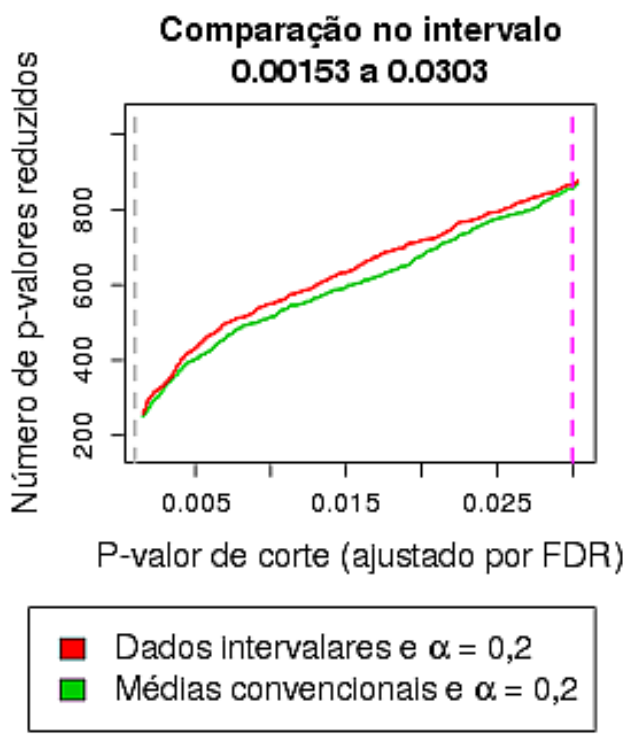

Figura 7.10: Nesses gráficos, levamos em consideração apenas as variantes da base com as expressões gênicas representadas por intervalos e pelas médias de $M_{i}$ dadas convencionalmente, todas normalizadas com um parâmetro de suavização, $\alpha$, igual a 0,2. Assim, fixando o parâmetro de nomalização $(\alpha=0,2)$, as curvas vermelhas mostram quantos genes tiveram um p-valor na variante da base com dados intervalares menor que na variante com médias convencionais. As curvas em verde mostram o contrário, ou seja, quantos genes tiveram o p-valor na variante da base com expressões representadas por médias convencionais menor que o p-valor obtido na variante com médias convencionais. 


\section{Número de genes com p-valor reduzido nas variantes da base com dados intervalares e com médias convencionais \\ $\alpha$ estimado}
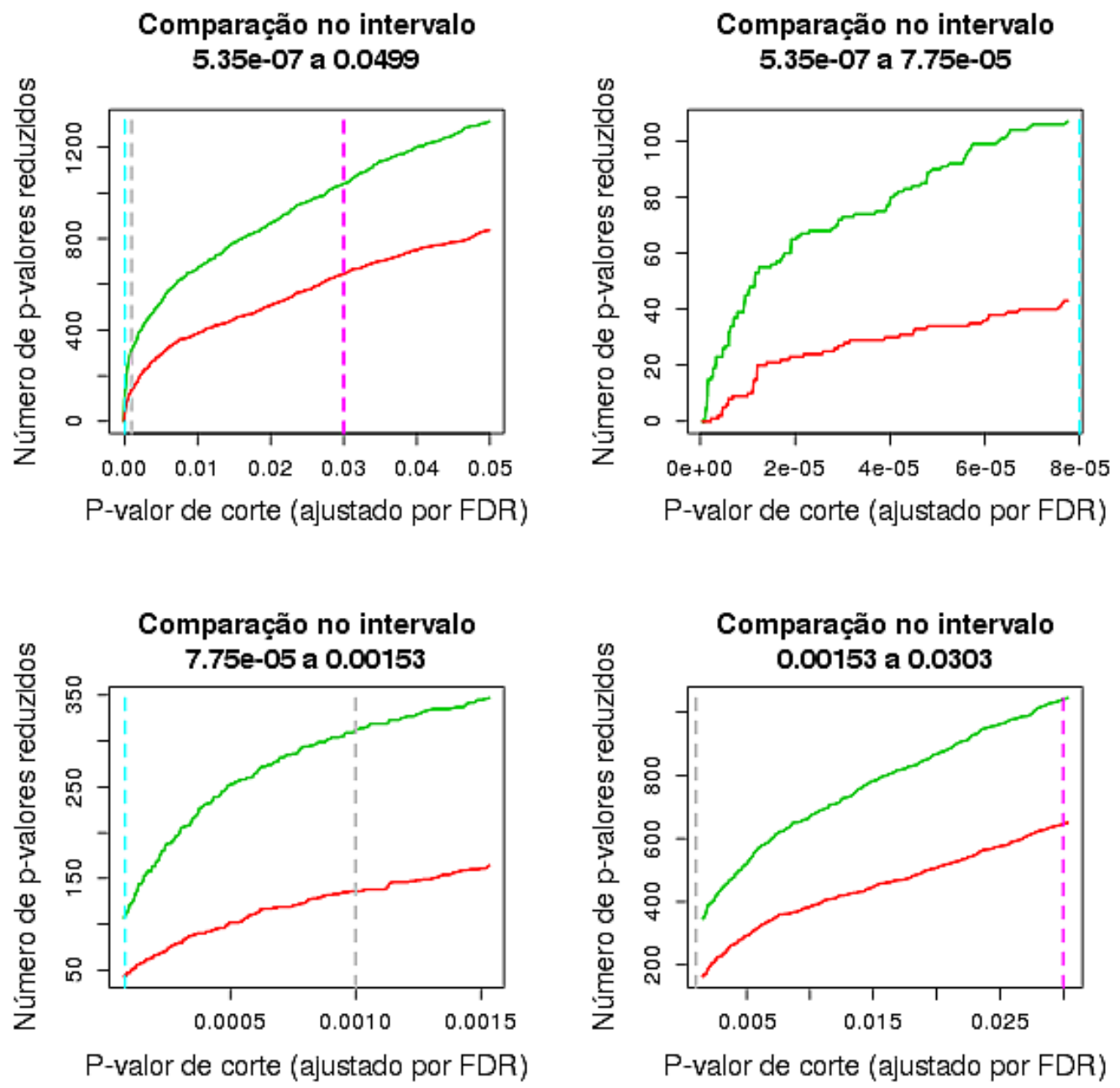

Dados Intervalares e $\alpha$ estimado

Médlas convenclonals e $\alpha$ estlmado

Figura 7.11: Nesses gráficos, levamos em consideração apenas as variantes da base com as expressões gênicas representadas por intervalos e pelas médias de $M_{i}$ dadas convencionalmente, todas normalizadas com um parâmetro de suavização estimado. As curvas vermelhas mostram quantos genes tiveram um p-valor menor na base com dados intervalares e $\alpha$ estimado que na base com médias convencionais e $\alpha$ estimado. As curvas em verde mostram o contrário, ou seja, quantos genes tiveram o p-valor na variante da base com expressões representadas por médias convencionais e normalizadas com a estimado menor que o p-valor obtido na variante com médias convencionais e com $\alpha$ estimado. 


\section{Número de genes com p-valor reduzido nas variantes da base com $\alpha, 0,2$ e $\alpha$ estimado \\ Médias convencionais}
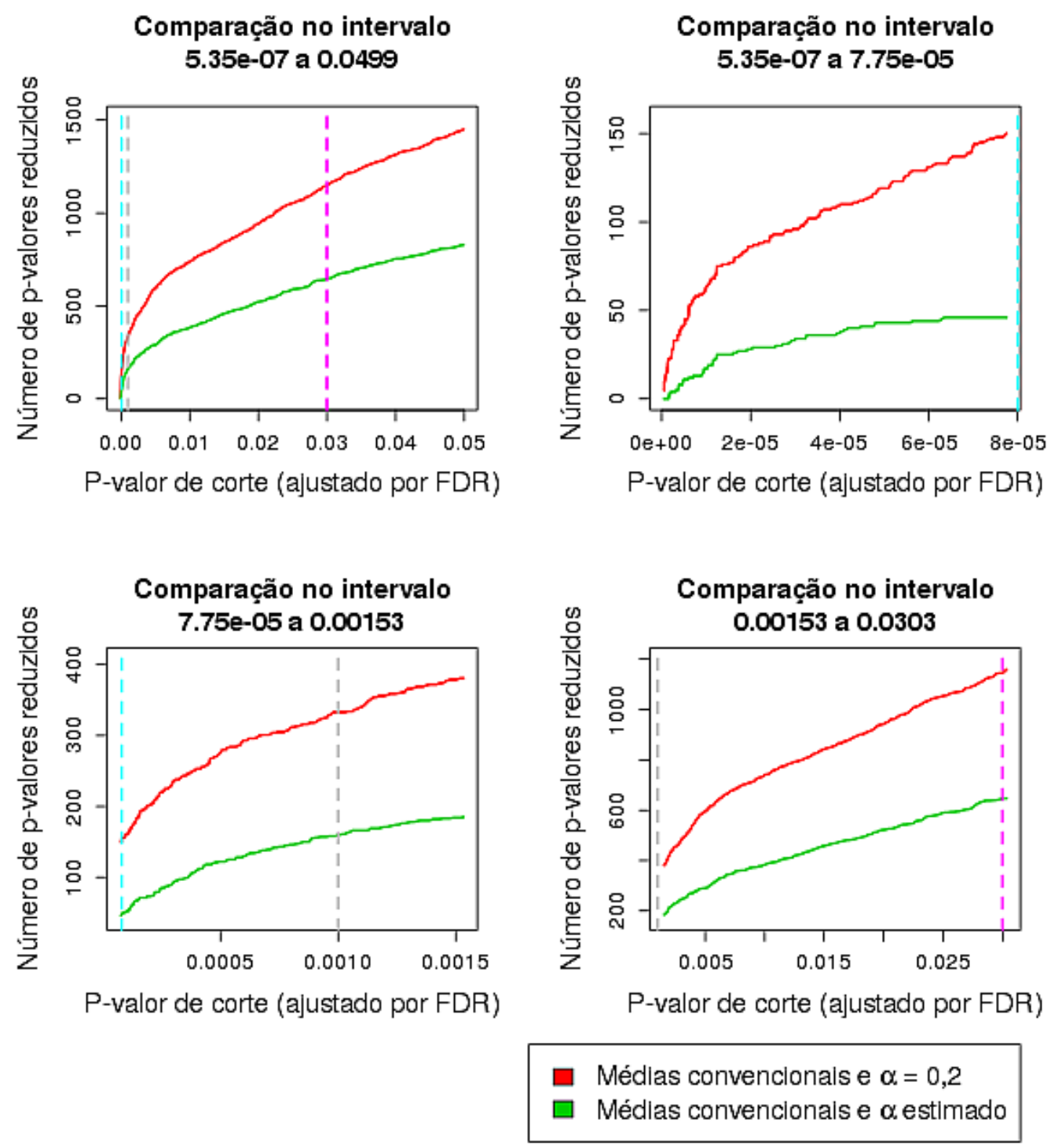

Figura 7.12: Nesses gráficos, fixamos a representação das expressões gênicas dadas pelo estimador média de $M_{i}$ convencional e levamos em consideração essas variantes com normalização usando um parâmetro de normalização, $\alpha$, tanto estimado como igual a 0,2 . As curvas vermelhas mostram quantos genes tiveram um $p$-valor na base com dados normalizados com $\alpha=0,2$ menor que o obtido quando os dados são normalizados usando um $\alpha$ estimado. As curvas em verde mostram o contrário, ou seja, quantos genes tiveram o p-valor na variante com dados normalizados com $\alpha$ estimado menor que o obtido quando os dados foram normalizados com $\alpha=0,2$. 


\section{Número de genes com p-valor reduzido nas variantes da base com $\alpha, 0,2$ e $\alpha$ estimado \\ Dados intervalares}
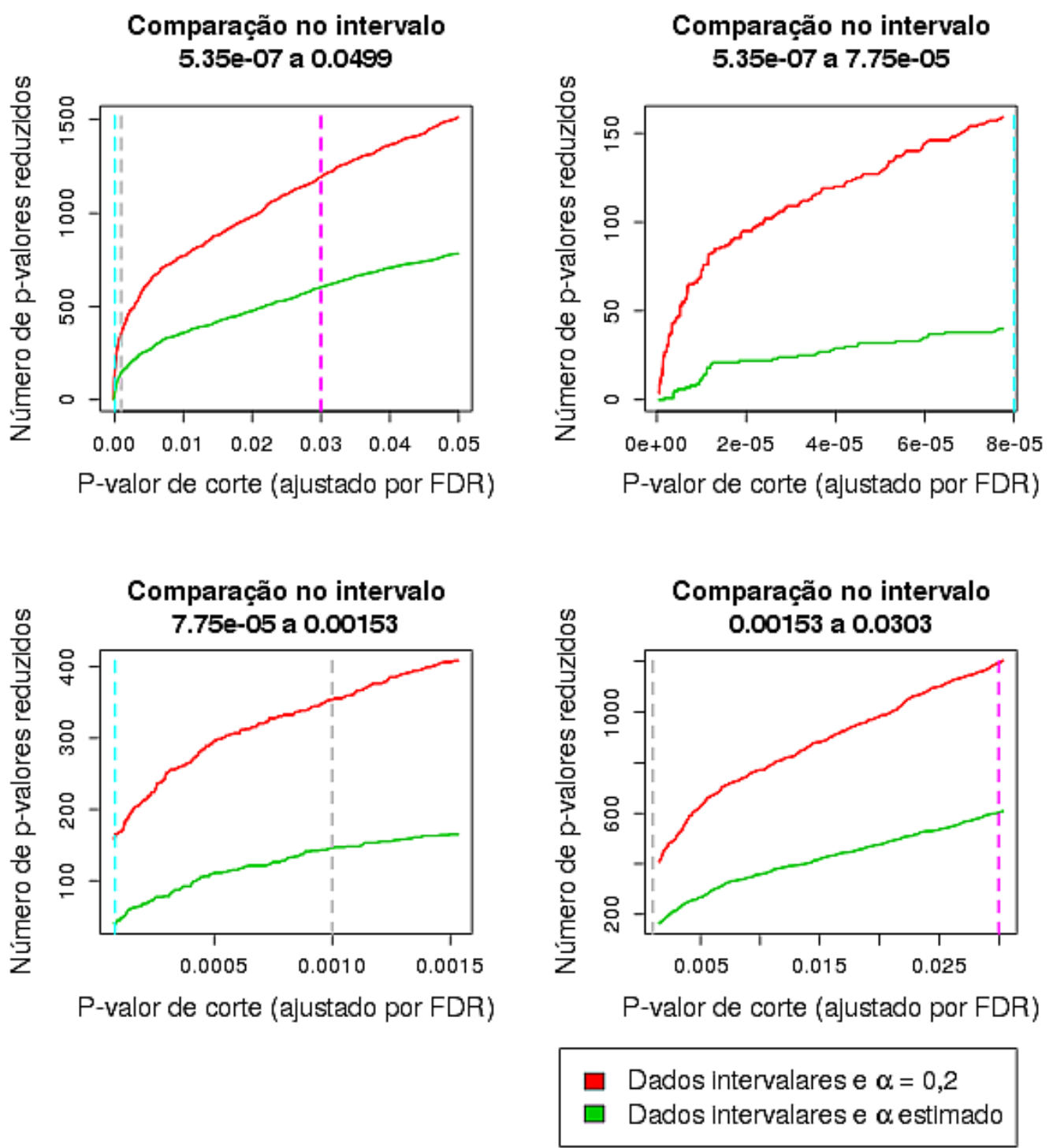

Figura 7.13: Nesses gráficos, fixamos a representação das expressões gênicas por intervalos que incluem a média de $M_{i}$ e levamos em consideração essas variantes com normalização usando um parâmetro de normalização, $\alpha$, tanto estimado como igual a 0,2 . As curvas vermelhas mostram quantos genes tiveram um $p$-valor na base com dados normalizados com $\alpha=0,2$ menor que o obtido quando os dados são normalizados usando um $\alpha$ estimado. As curvas em verde mostram o contrário, ou seja, quantos genes tiveram o p-valor na variante com dados normalizados com $\alpha$ estimado menor que o obtido quando os dados foram normalizados com $\alpha=0,2$. 

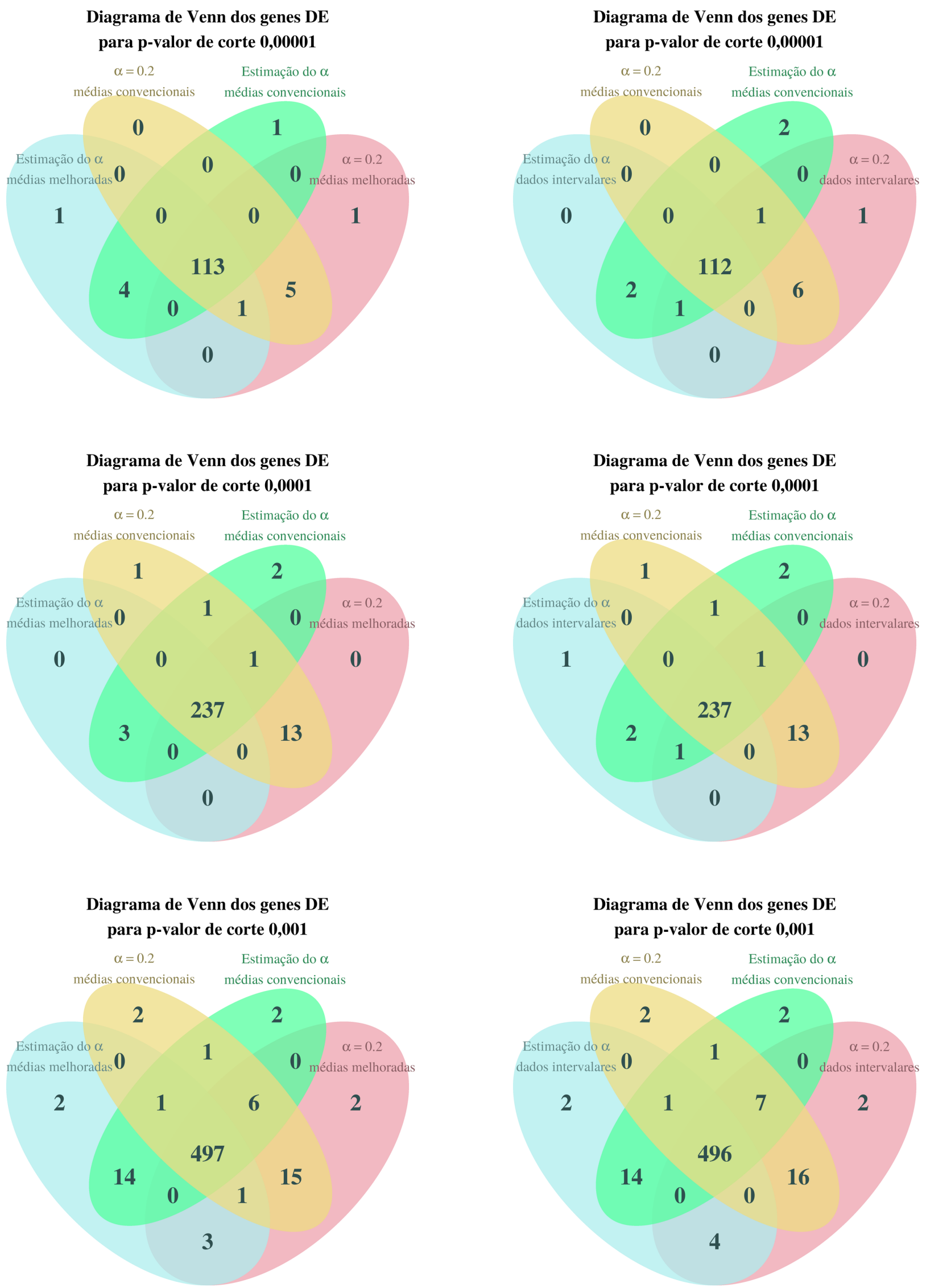

Figura 7.14: Diagrama de Venn entre o número de genes determinados como diferencialmente expressos para as variantes da base com dados. 


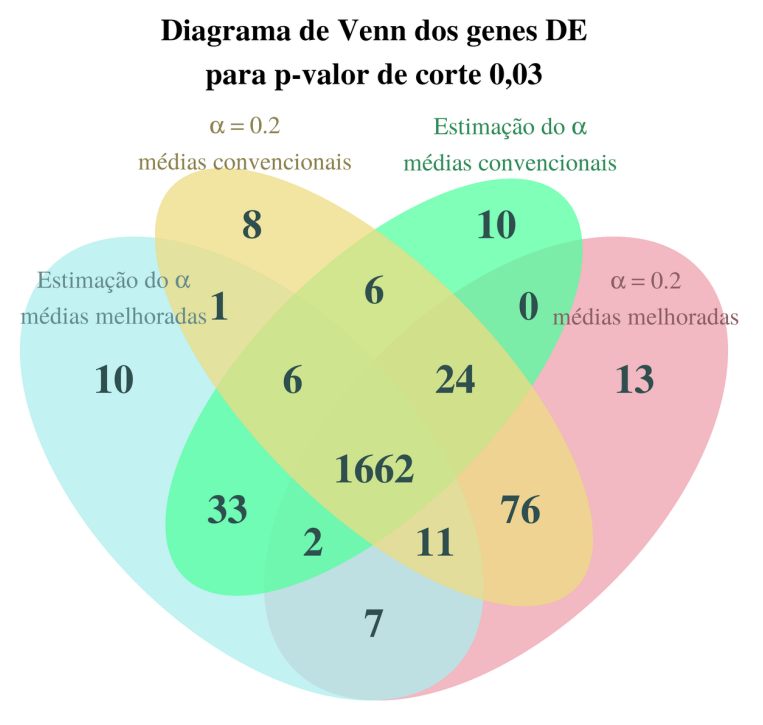

(a) Todos os genes com p-valor abaixo de 0,03.

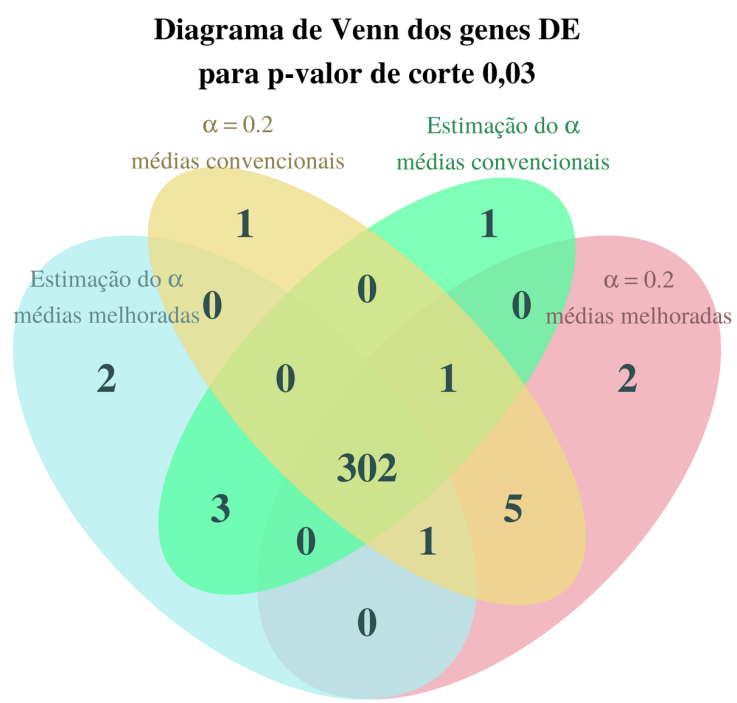

(c) Genes com p-valor abaixo de 0,03 e com fold change maior que 1.

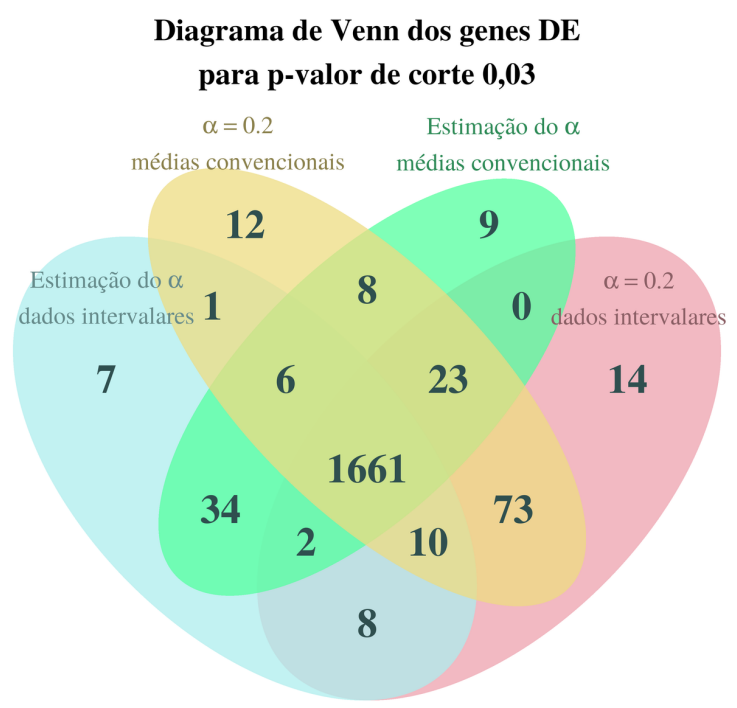

(b) Todos os genes com p-valor abaixo de 0, 03 .

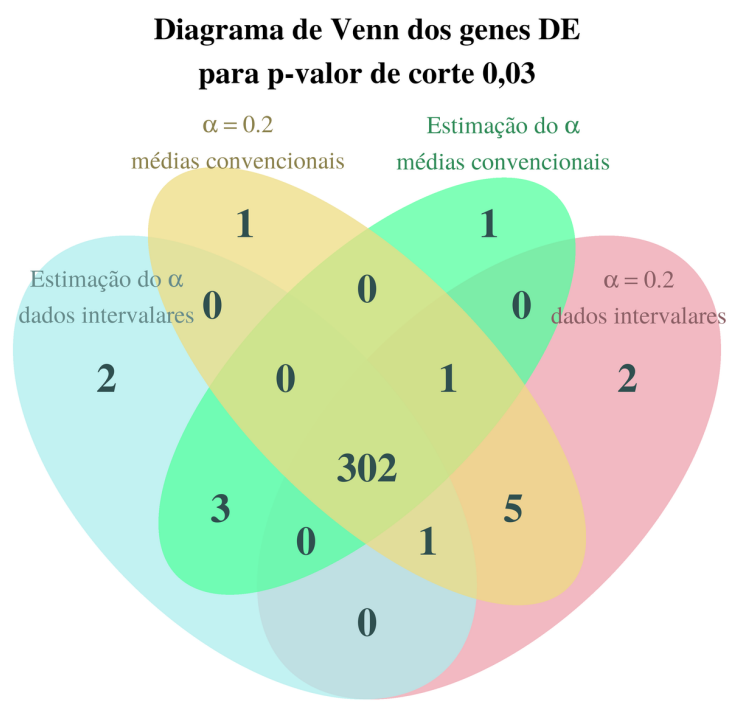

(d) Genes com p-valor abaixo de 0,03 e com fold change maior que 1.

Figura 7.15: Diagrama de Venn entre o número de genes determinados como diferencialmente expressos para as variantes da base com dados. 
Lembrando que na representação das expressões gênicas por intervalos estamos representando uma medida e o seu erro, quanto maior o tamanho do intervalo, maior a imprecisão da medida. Assim, é interessante sabermos se o p-valor do teste para $H_{0}$ muda se, em média, esses tamanhos dos intervalos mudam. Os gráficos das figuras 7.16a e 7.17a nos mostram a relação da média dos tamanhos dos intervalos das medidas com a diferença entre os logaritmos do p-valor obtido com dados intervalares e do p-valor obtido com as médias de $M_{i}$ estimadas convencionalmente. As linhas tracejadas separam os genes com diferença no p-valor maior que 1,5. Genes que estão abaixo da linha do $-1,5$ são aqueles que possuem um $\mathrm{p}$-valor mais que 1,5 vezes menor na variante da base com dados intervalares que na base com as médias convencionais. Genes que estão acima da linha do 1, 5 possuem, na variante da base com as médias convencionais, um p-valor mais que 1,5 menor que na variante com dados intervalares. Podemos ver por esses gráficos que, independente do $\alpha$ utilizado na normalização, não temos uma grande variação no p-valor para dados intervalares de tamanho pequeno, isto é, para medidas de expressões gênicas com pouco erro. Os genes com maior variação no p-valor são, em geral, aqueles com grande imprecisão na medida. No entanto, mesmo com grande imprecisão, a variação no p-valor pode não ser grande. É o caso, por exemplo, do gene CTAGE3P (A_23_P392544), que está destacado em verde nesse gráfico.

Outro fator que trabalhamos na modelagem das expressões dos genes é a heteroscedasticidade, ou seja, a existência de lâminas com diferentes imprecisões (tamanhos dos intervalos). Isso foi bastante discutido no capítulo 6 . Dessa forma, também nos interessa saber se a variação no p-valor ocorre quando há uma grande variância nos tamanhos dos intervalos. Isso é mostrado nos gráficos da figuras $7.16 \mathrm{~b}$ e $7.17 \mathrm{~b}$, para os p-valores obtidos, respectivamente, com dados normalizados com $\alpha=0,2$ e $\alpha$ estimado. Os genes cujos p-valores foram os mais alterados, em geral, possuem uma grande variância nos tamanhos dos intervalos.

Para entendermos melhor como a incorporação das imprecisões nas análises e como o valor do parâmetro de suavização do lowess afetam as estatísticas dos testes para $H_{0}(7.1)$, vamos analisar alguns gráficos dos genes destacados nas figuras 7.16 e 7.17, que, com exceção do CTAGE3P (A_23_P392544), são genes que tiveram o p-valor do teste para $H_{0}$ muito alterado.

Inicialmente, analisaremos o gene CTAGE3P (A_23_P392544), que, como vimos nas figuras 7.16 e 7.17, apesar de ter uma grande média e variância nos tamanhos dos intervalos, não teve seu p-valor muito alterado. Na figura 7.18, mostramos os boxplots das expressões gênicas agrupadas por condição da amostra. Com eles, conseguimos observar o quão distintas são as expressões das amostras de estômagos saudáveis e as expressões das amostras de estômagos com metaplasia de grau II. Para esse gene, em particular, temos que as expressões de estômagos saudáveis representadas pela médias convencionais estão mais dispersas (mais outliers) que quando são representadas pelas estimativas melhoradas de suas médias. Na figura 7.19, vemos que especialmente a média da expressão medida na lâmina 90 foi mais próxima das obtidas nas demais lâminas da mesma condição fenotípica quando estimada considerando as imprecisões. Esse resultado não foi perdido ao utilizarmos um parâmetro diferente para a normalização com lowess. Lembrando que, no teste ANOVA, quanto maior for a variabilidade entre as condições fenotípicas, quando comparada com a variabilidade dentro das condições, maior é a evidência de que as médias das condições são diferentes, entendemos como o p-valor do teste para $H_{0}$ foi reduzido ao utilizarmos as médias melhoradas. Por outro lado, apareceram mais outliers quando utilizamos os dados intervalares. Para entendermos por que isso ocorreu, podemos observar os boxplots das expressões que amostramos do intervalo de cada lâmina, na figura 7.20. Vemos que a expressão medida na lâmina de número 90 possui um grande erro, já que temos expressões amostradas em um intervalo bem maior que nas demais lâminas. Podemos observar essas imprecisões das expressões da lâmina 90 normalizadas, tanto com $\alpha=0,2$ como com $\alpha$ estimado $(\alpha=0,35)$, nos gráficos das figuras 7.2 c e 7.2d. Há uma grande imprecisão para as expressões de baixas intensidades, como é o caso da expressão desse gene. Assim, tivemos novamente a variabilidade aumentada dentro da amostra de expressões de estômagos saudáveis, afetando o p-valor resultante para o teste de $H_{0}$. Porém, como as demais expressões possuem uma variabilidade bem pequenas, o resultado do p-valor não foi muito afetado. Para completarmos a análise desse genes, mostramos, na figura 7.21, as densidades das expressões de cada amostra, para 
cada variantes da base de dados em estudo.

Dentre os genes que mais tiveram seu p-valor aumentado com a incorporação das imprecisões nas análises está o MYB, de identificação A_23_P31073 na plataforma Agilent. Como podemos ver nos gráficos da figura 7.22, as estimativas da média da expressão em uma certa lâmina, dadas por $\overline{M_{i}}$ e $\hat{M}_{i}$, foram muito diferentes. Observando os gráficos das figuras 7.24 e 7.23 , vemos novamente que é uma expressão medida na lâmina de número 90. Sendo uma expressão de intensidade média baixa, está na região de maior imprecisão da lâmina e isso é refletido na estimação de sua média e no intervalo que representa essa medida e seu erro. Assim, como estamos utilizando dados mais imprecisos, temos, para esse gene, uma menor evidência de que a amostra de estômagos saudáveis é diferente da amostra de estômagos com metaplasia de grau II, aumentando o p-valor. Esse aumento foi, nesse caso, significativo, já que poderíamos determinar esse gene como diferencialmente expresso nas variantes da base com expressões representadas pelas médias convencionais ( $\mathrm{p}$-valor do teste foi menor que 0,0075 nos dois métodos de normalização), mas não seria razoável rejeitar a hipótese $H_{0}$ nas outras variantes da base de dados (p-valor foi maior que 0,045 ). As densidades das expressões para cada variante da base de dados, na duas condições das amostras de estômagos que estamos comparando, podem ser vistas na figura 7.25.

Para entendermos o que ocorre quando a imprecisão aumenta a evidência de que as expressões do gene são diferentes entre as condições de estômago saudável e com metaplasia de grau II, vamos analisar os gráficos dos genes FAM174B (A_23_P100001) e NDUFA6-AS1 (A_24_P753454), que foram o que mais tiveram seus p-valores reduzidos ao utilizarmos os dados intervalares e as estimativas melhoradas para as médias.

Pelos gráficos da figura 7.26, vemos que a redução no p-valor do teste de $H_{0}$ para o gene FAM174B (A_23_P100001) foi significativa. Com as expressões representadas pelas médias convencionais, tivemos um p-valor maior que 0,01 , já com as expressões estimadas considerando as imprecisões das medidas, obtivemos um p-valor menor que 0,0005. Vemos, também por esses gráficos, que, como a variabilidade dentro das amostras de cada condição fenotípica não é pequena, a inclusão das imprecisões pouco afetou a variabilidade dentro desses grupos. Por outro lado, a correção feita pela estimativa melhorada das médias das expressões fez aumentar a variabilidade entre a amostra de expressões em estômagos saudáveis e a amostra em estômagos com metaplasia. Assim, para a análise de variância, temos mais evidências de que essas amostras são diferentes. Pelos gráficos das figuras 7.28 e 7.27 , vemos como a variabilidade das expressões de mesma condição fenotípica não é pequena e como a estimativa da expressão medida na lâmina de número 30 aumentou a variabilidade entre expressões de condições fenotípicas diferentes. As expressões normalizadas da lâmina de número 30 podem ser vistas nos gráficos das figura 7.2e e 7.2f. As densidades das expressões para cada condição fenotípica e para cada variante da base de dados podem ser vistas nos gráficos da figura 7.29.

Finalmente, outro gene interessante a se analisar é o NDUFA6-AS1 (A_24_P753454), que também teve uma redução significativa no p-valor ao utilizarmos as imprecisões nas análises, como pode ser visto pelo gráfico da figura 7.30. Temos que o p-valor obtido pelas médias das expressões estimadas convencionalmente foi de aproximadamente 0,032 quando a normalização foi feita com $\alpha=0,2$ e aproximadamente 0,026 quando estimamos o parâmetro na normalização. No entanto, com a estimação melhorada das médias das expressões, esses p-valores caíram para, respectivamente, 0,0004 e 0,0005 . Pelos gráficos das figuras 7.32 e 7.31 vemos que a razão disso foi que as estimativas para as expressões das lâminas 27 e 64 obtidas com o estimador melhorado das médias ficaram mais próximas das expressões medidas nas outras lâminas de mesma condição fenotípica. Com isso, a variabilidade dentro desses grupos ficou menor e, portanto, aumentou a evidência de que as amostras eram, em média, diferentes. Como os intervalos são construídos usando essas estimativas das médias melhoradas, tivemos um p-valor parecido. Apenas teve um leve aumento no p-valor, já que aumentamos um pouco variabilidade dentro dos grupos. As expressões normalizadas das lâminas 27 e 64 podem ser vistas nos gráficos da figura 7.2. 


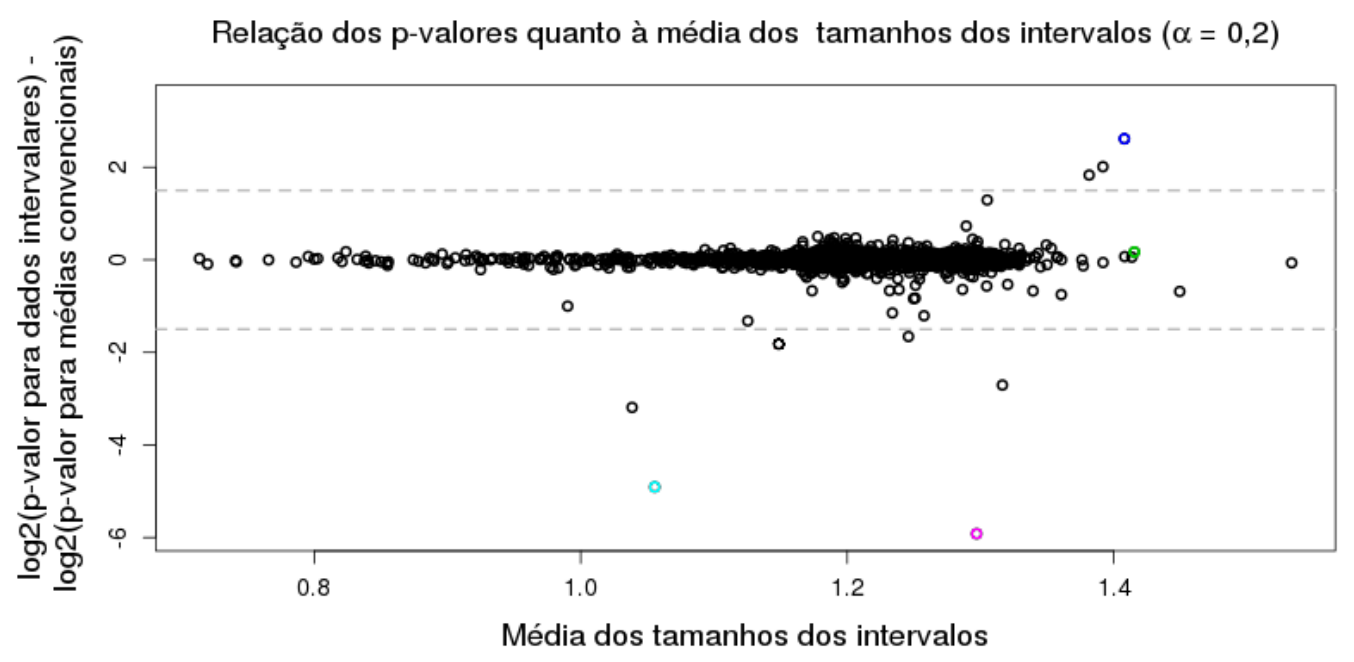

(a) Gráfico mostrando a relação com a média dos tamanhos dos intervalos.

Relação dos p-valores quanto à variância dos tamanhos dos intervalos $(\alpha=0,2)$

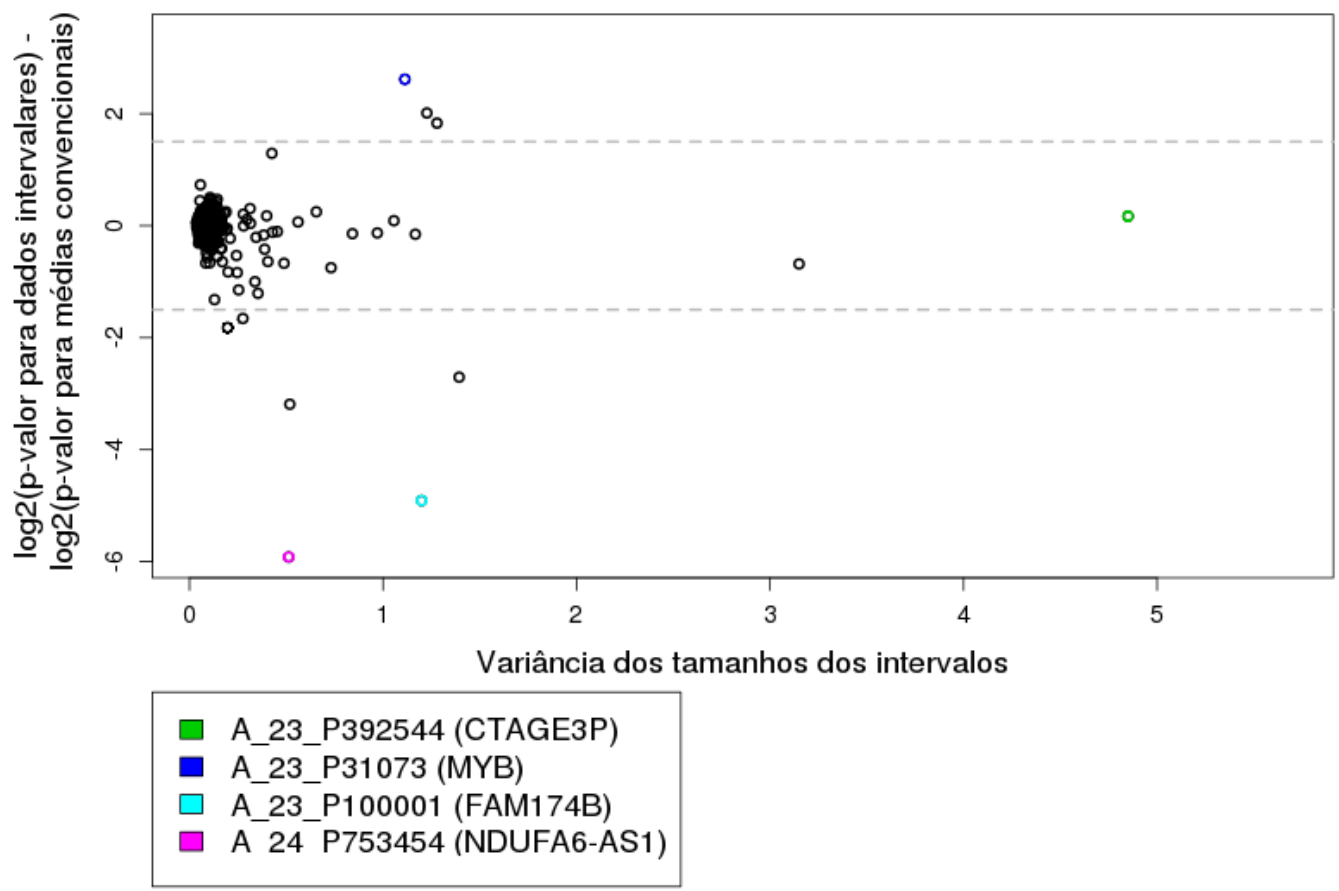

(b) Gráfico mostrando a relação com a variância dos tamanhos dos intervalos.

Figura 7.16: Gráfico mostrando a relação entre a média (a) ou a variância (b) dos tamanhos dos intervalos da amostra de expressões de cada gene e o logaritmo da razão entre o p-valor para esse gene obtido com dados intervalares e o p-valor obtido com dados representados pelas médias convencionais. Todos os dados utilizados nesse gráfico foram normalizados com o parâmetro de suavização do lowess, $\alpha$, igual a 0,2 


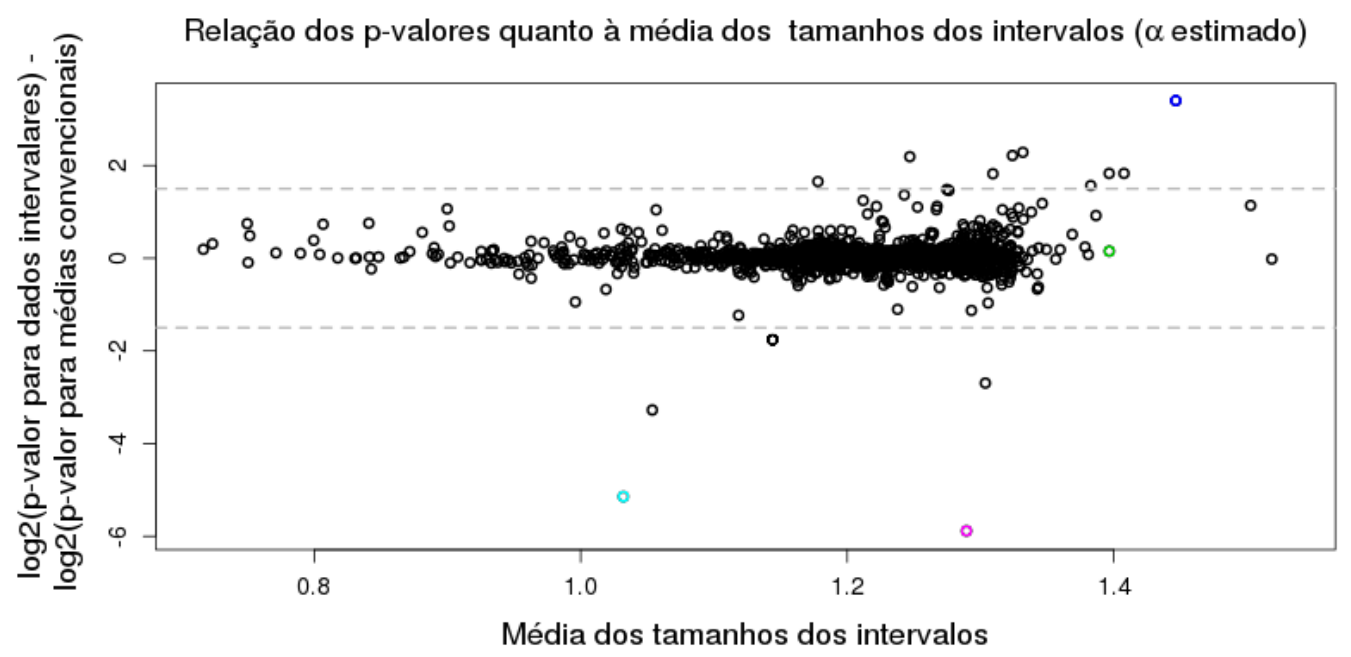

(a) Gráfico mostrando a relação com a média dos tamanhos dos intervalos.

Relação dos $\mathrm{p}$-valores quanto à variância dos tamanhos dos intervalos ( $\alpha$ estimado)

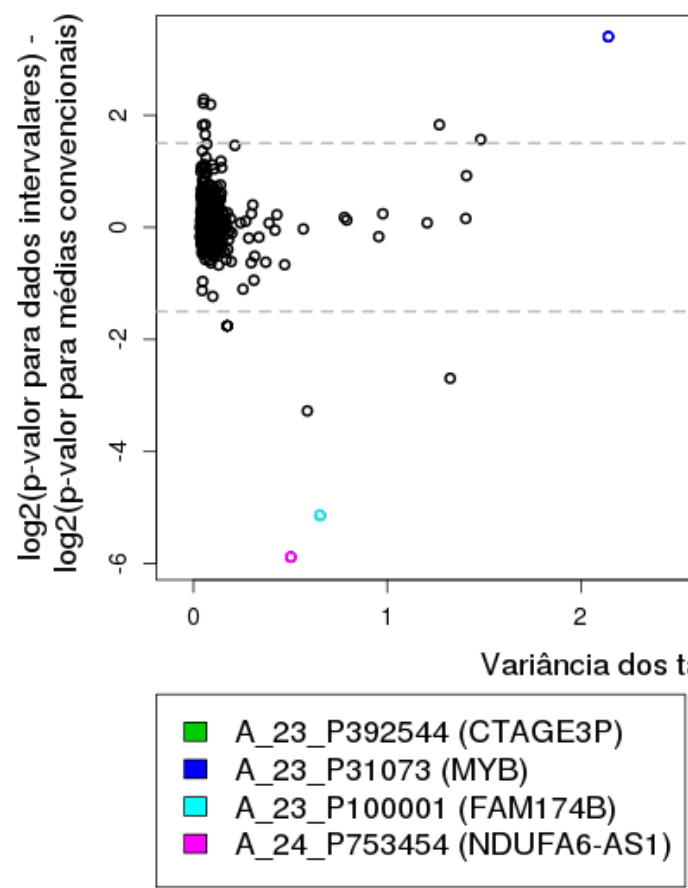

(b) Gráfico mostrando a relação com a variância dos tamanhos dos intervalos.

Figura 7.17: Gráfico mostrando a relação entre a média (a) ou variância (b) dos tamanhos dos intervalos da amostra de expressões de cada gene e o logaritmo da razão entre o p-valor para esse gene obtido com dados intervalares e o p-valor obtido com dados representados pelas médias convencionais. Todos os dados utilizados nesse gráfico foram normalizados com um parâmetro de suavização do lowess, $\alpha$, estimado. 

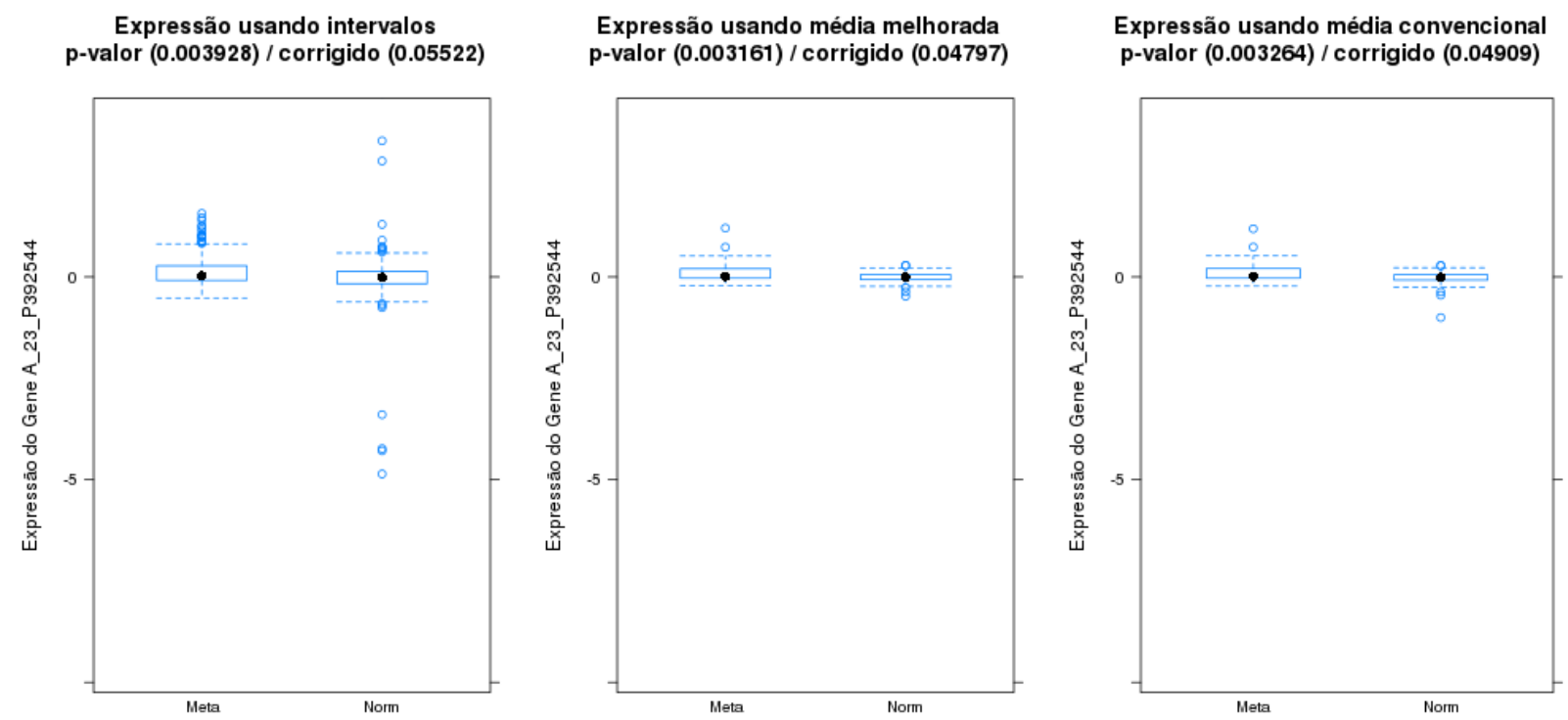

(a) Boxplots com dados obtidos após normalização intra-lâmina usando lowess com $\alpha=0,2$.
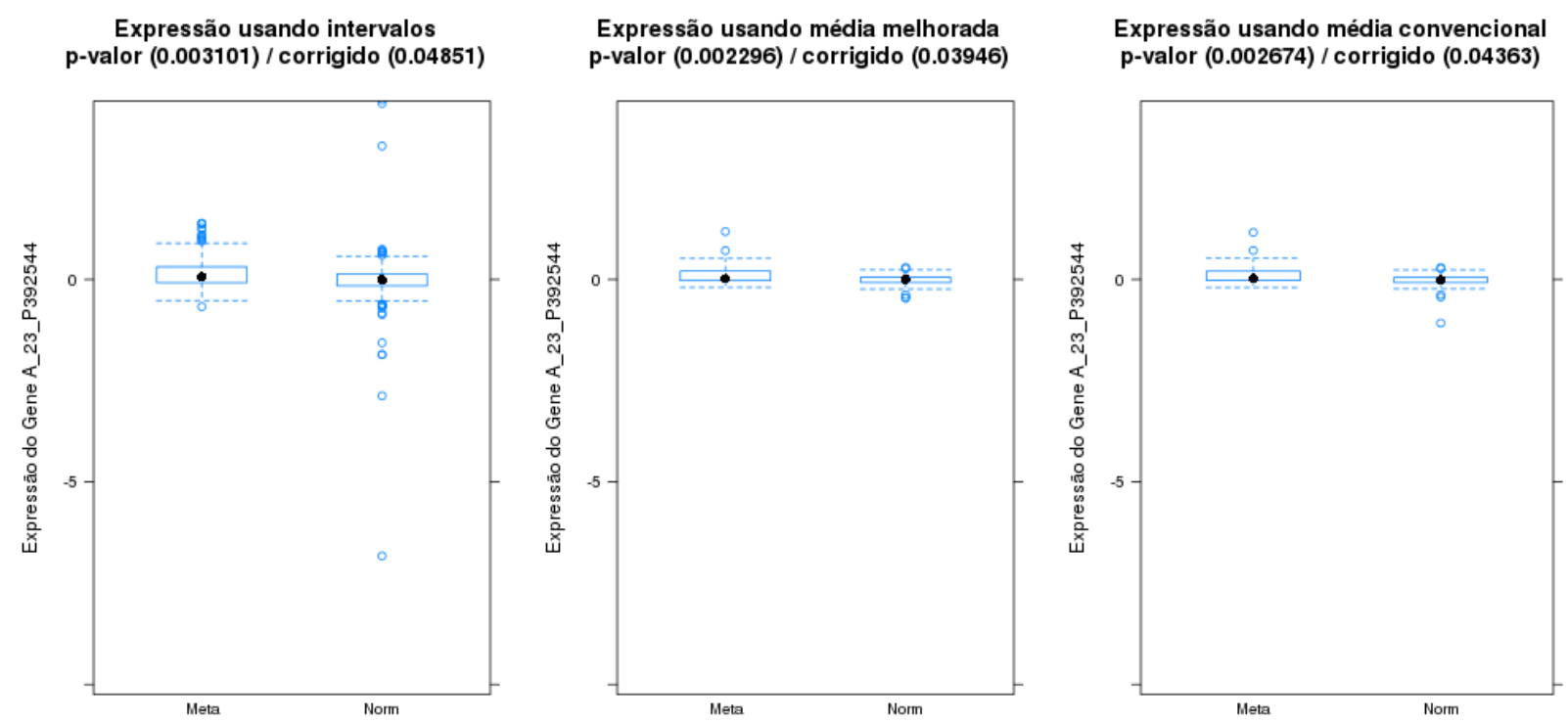

(b) Boxplots com dados obtidos após normalização intra-lâmina usando lowess com a estimado pelo método visto na seção 5.1.4.

Figura 7.18: Mostramos em cada gráfico os boxplots das expressões do gene CTAGE3P (A_23_P392544), de acordo com a condição fenotípica da amostra, para as variantes da base de dados com as expressões do gene representas por intervalos, pela média melhorada (usando o estimador $\bar{M}_{i}$ ) e pela média convencional (usando o estimador $\hat{M}_{i}$ ). Em (a) os dados de todas as lâminas foram normalizados usando lowess com parâmetro de suavização igual a 0,2 e, em (b), usando parâmetro de suavização estimado pelo método visto na seção 5.1.4. 
Comparação entre representações das expressões gênicas parâmetro de suavização do lowess $=0,2$

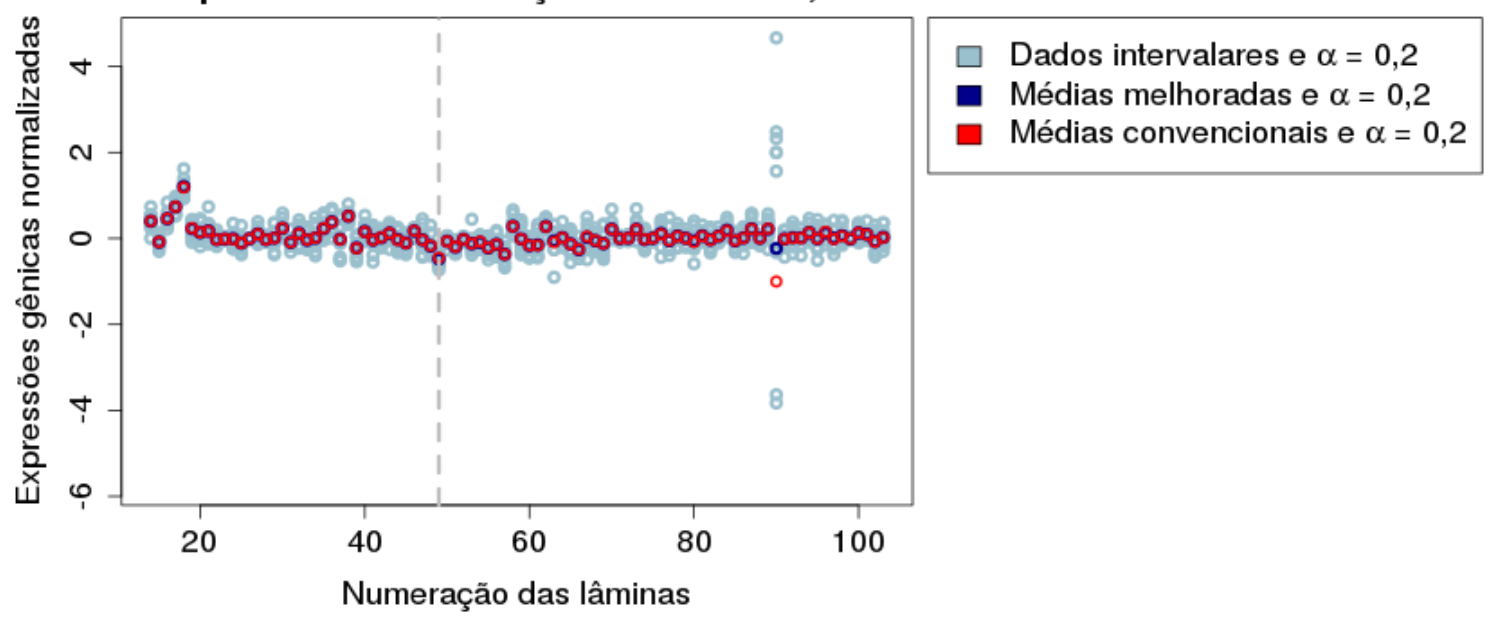

(a) Expressões do gene quando normalizadas em cada lâmina usando lowess com $\alpha=0,2$.

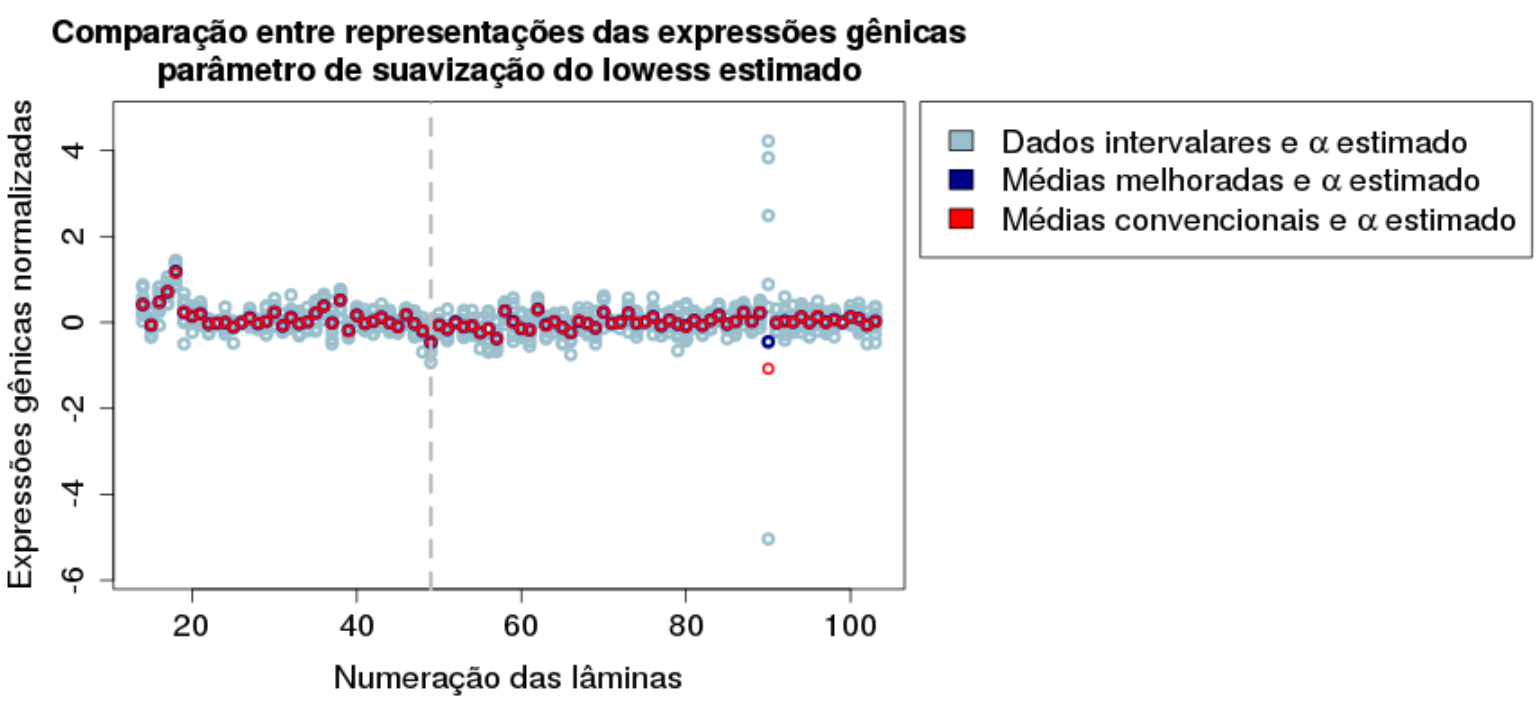

(b) Expressões do gene quando normalizadas em cada lâmina usando lowess com $\alpha$ estimado.

Figura 7.19: Medidas das expressões do gene CTAGE3P (A_23_P392544) amostradas em cada uma das lâminas do experimento, para as representações por estimativas convencionais das médias $M_{i}$, em vermelho, por estimativas melhoradas das médias de $M_{i}$ e por intervalos que incluem essa a média de $M_{i}$, em azul claro. As medidas já sofreram a normalização intra-lâmina com lowess usando tanto parâmetro de suavização igual a 0,2 (a) como com parâmetro de suavização estimado pelo método visto na seção 5.1.4 (b). 

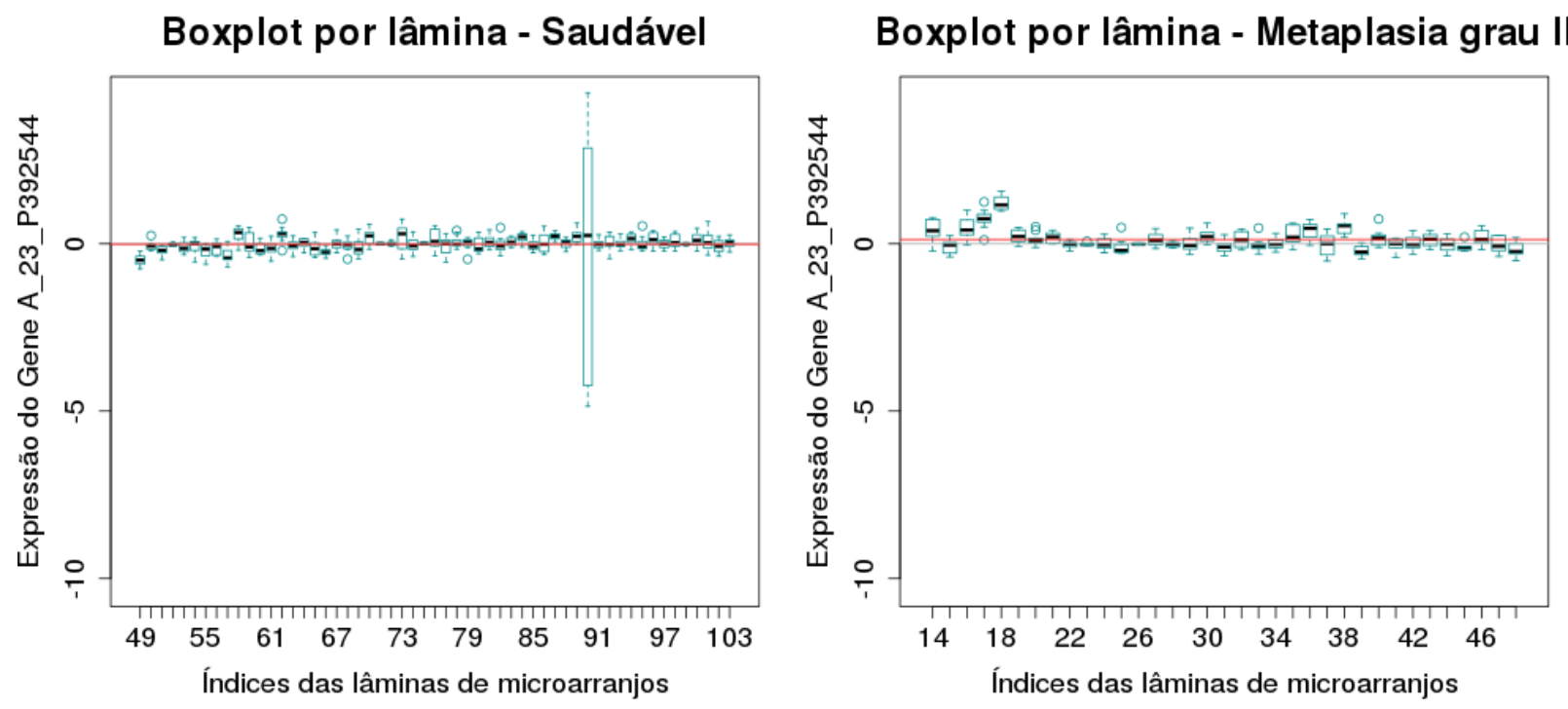

(a) Utilizamos as expressões do gene normalizadas em cada lâmina usando lowess com $\alpha=0,2$.
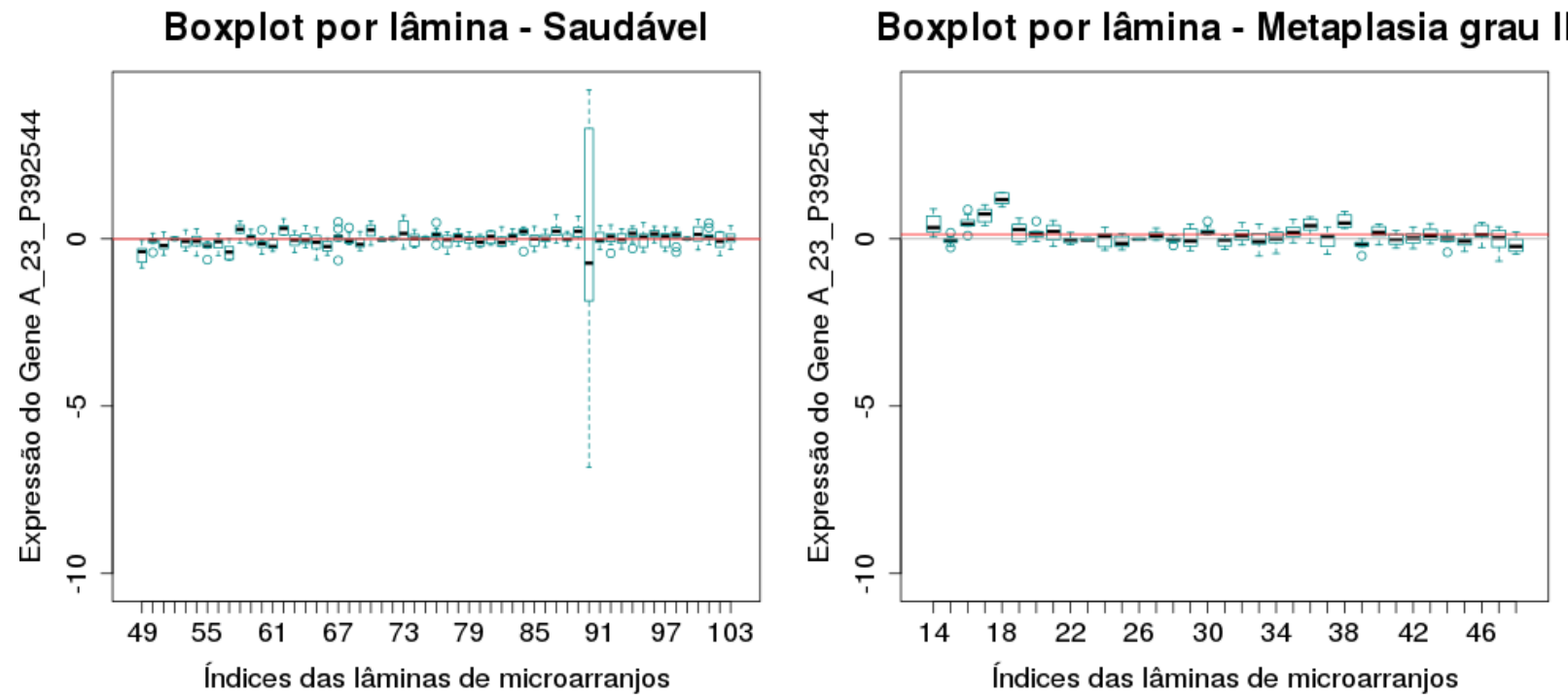

(b) Utilizamos as expressões do gene normalizadas em cada lâmina usando lowess com $\alpha$ estimado pelo método visto na seção 5.1.4.

Figura 7.20: Boxplots das expressões do gene CTAGE3P (A_23_P392544) por lâmina e por condição fenotipica, nas bases de expressões gênicas representadas por intervalos. A partir desse gráfico, podemos ver como é a variância das expressões em cada uma das lâminas e analisar como os intervalos afetam decisão do teste para $H_{0}(7.1)$. 


\section{Densidades do gene A_23_P392544 por condição fenotípica e por método de pré-processamento}

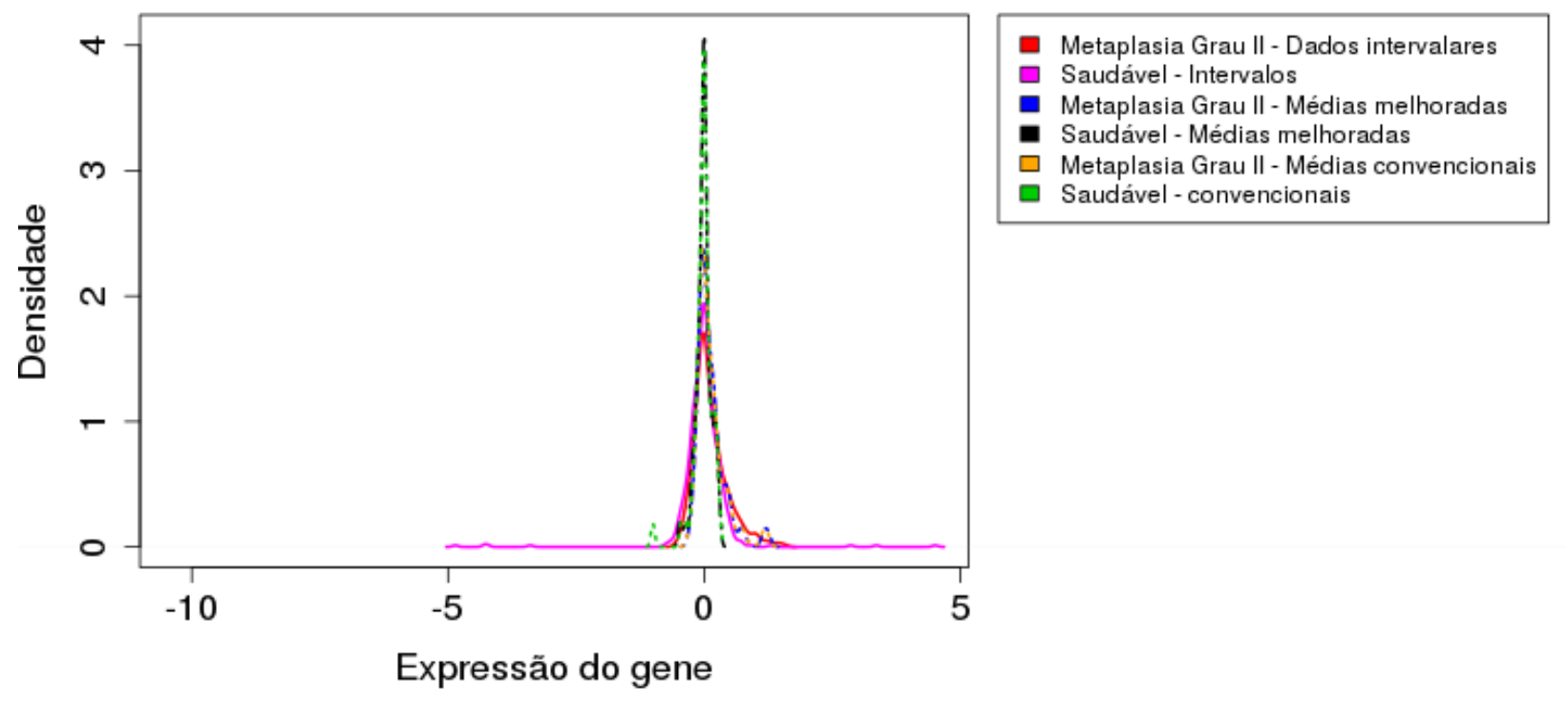

(a) Densidades das expressões do gene quando normalizadas em cada lâmina usando lowess com $\alpha=0,2$.

\section{Densidades do gene A_23_P392544 por condição fenotípica} e por método de pré-processamento

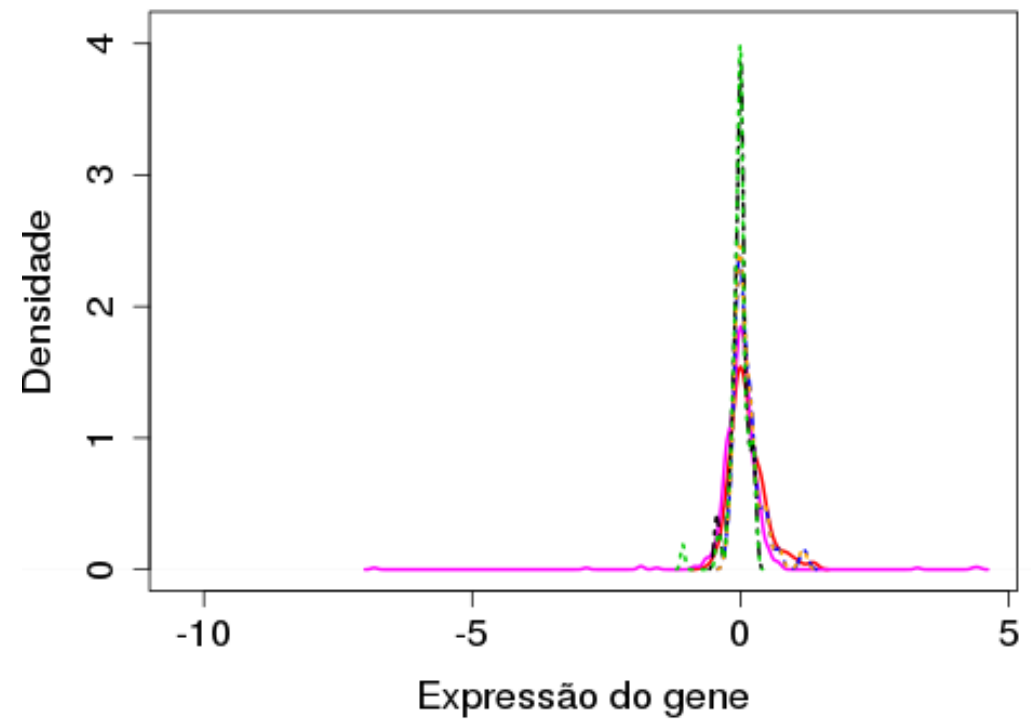

Metaplasia Grau II - Dados intervalares

- Saudável - Intervalos

- Metaplasia Grau II - Médias melhoradas

- Saudável-Médias melhoradas

$\square$ Metaplasia Grau II - Médias convencionais

$\square$ Saudável-convencionais

(b) Densidades das expressões do gene quando normalizadas em cada lâmina usando lowess com $\alpha$ estimado.

Figura 7.21: Comparação entre as densidades das expressões do gene CTAGE3P (A_23_P392544) representadas pelas médias convencionais (com o estimador $\hat{M}_{i}$ ), pelas médias melhoradas (com o estimador $\bar{M}_{i}$ e por intervalos, após normalização intra-lâmina com lowess usando tanto parâmetro de suavização igual a 0,2 como com parâmetro de suavização estimado pelo método visto na seção 5.1.4. 

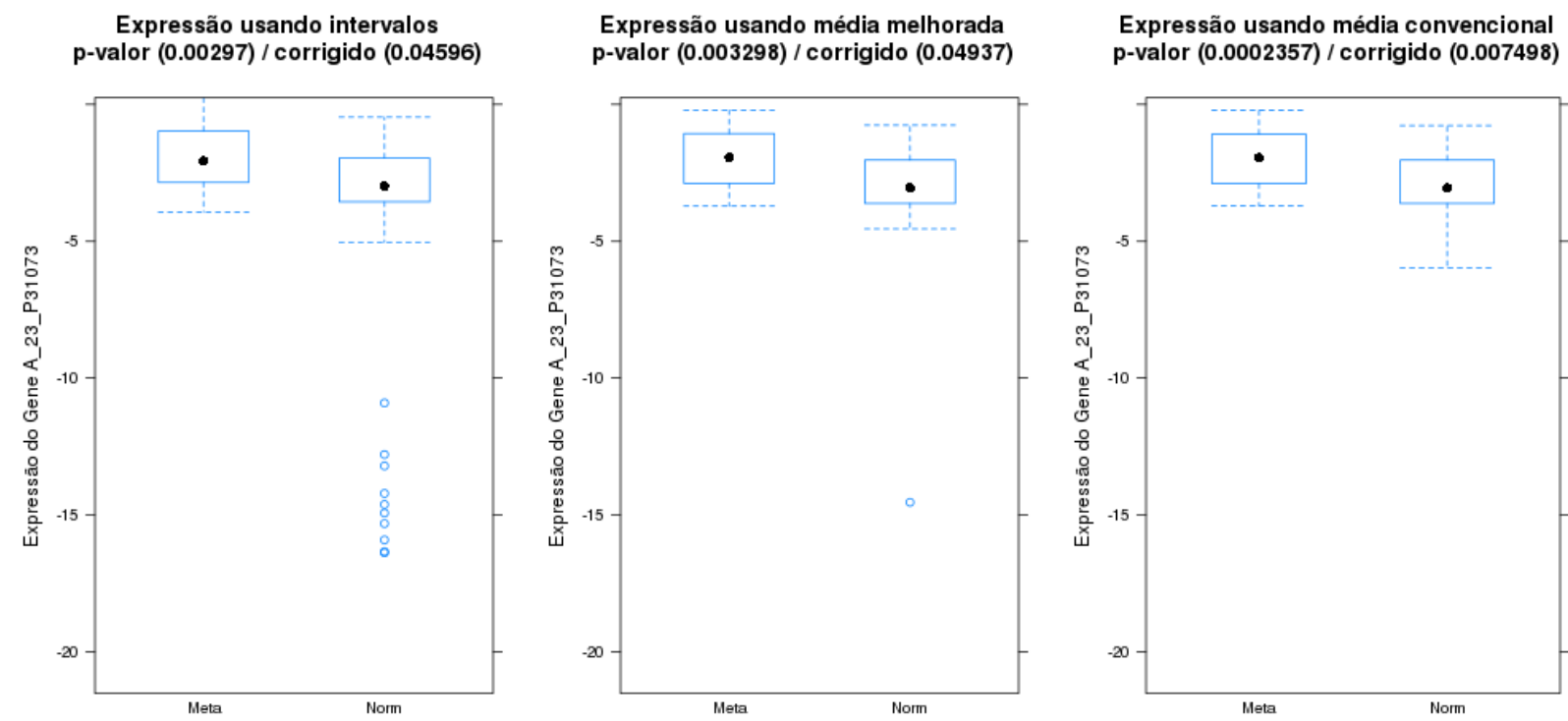

(a) Boxplots com dados obtidos após normalização intra-lâmina usando lowess com $\alpha=0,2$.
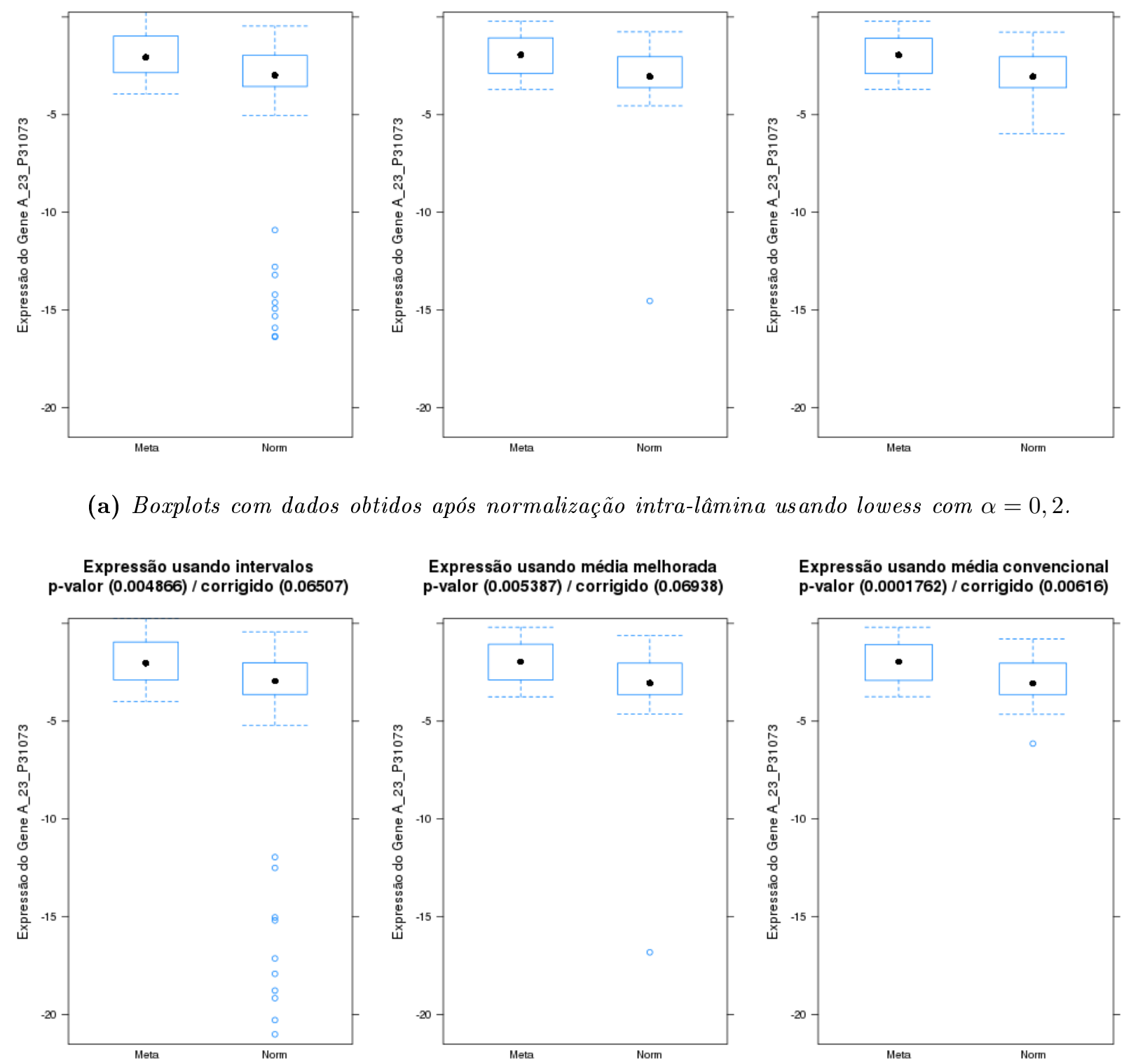

Expressão usando intervalos p-valor (0.004866) / corrigido (0.06507)

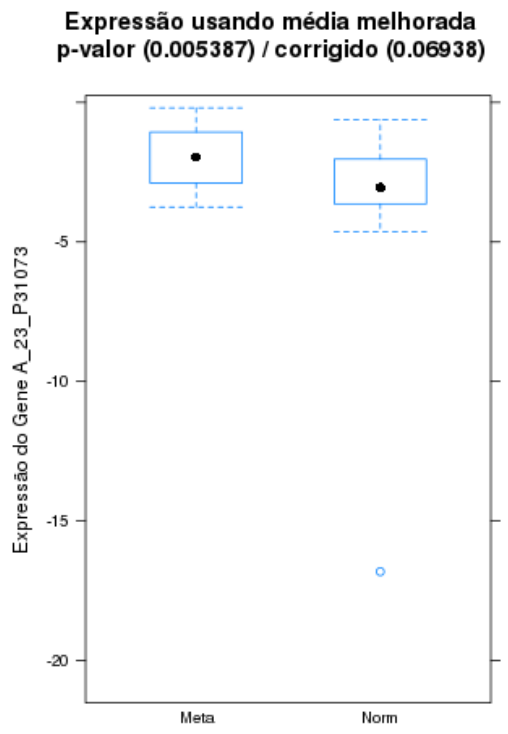

Expressão usando média melhorada p-valor (0.005387) / corrigido (0.06938)

Expressão usando média convencional p-valor (0.0001762) / corrigido (0.00616)

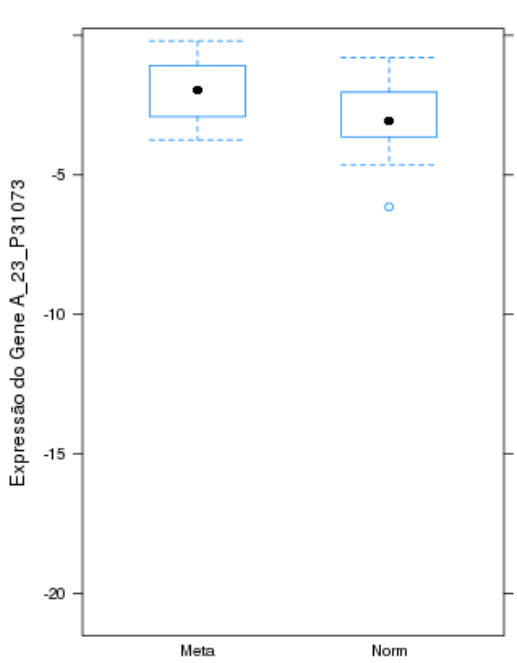

(b) Boxplots com dados obtidos após normalização intra-lâmina usando lowess com $\alpha$ estimado pelo método visto na seção 5.1.4.

Figura 7.22: Mostramos em cada gráfico os boxplots das expressões do gene MYB (A_23_P31073), de acordo com a condição fenotípica da amostra, para as variantes da base de dados com as expressões do gene representas por intervalos, pela média melhorada (usando o estimador $\bar{M}_{i}$ ) e pela média convencional (usando o estimador $\hat{M}_{i}$ ). Em (a) os dados de todas as lâminas foram normalizados usando lowess com parâmetro de suavização igual a 0,2 e, em (b), usando parâmetro de suavização estimado pelo método visto na seção 5.1.4. 
Comparação entre representações das expressões gênicas parâmetro de suavização do lowess $=0,2$

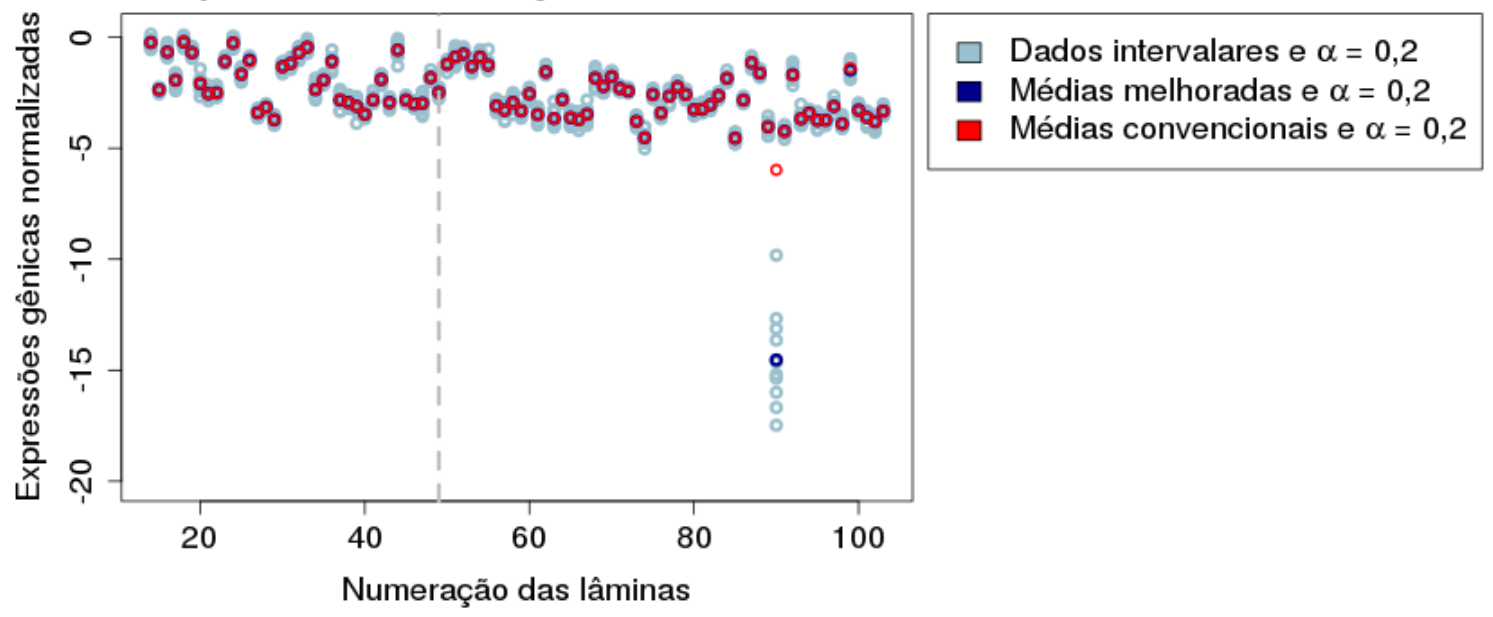

(a) Expressões do gene quando normalizadas em cada lâmina usando lowess com $\alpha=0,2$.

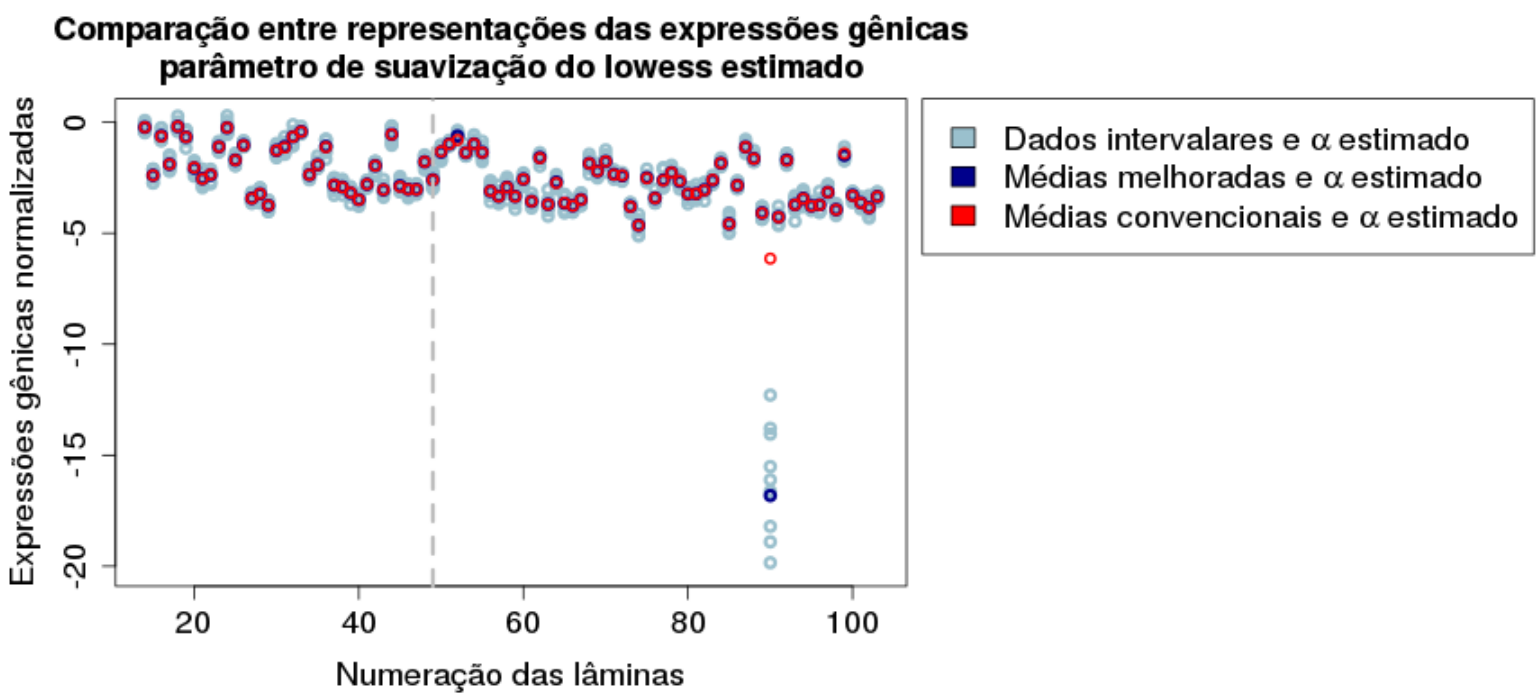

(b) Expressões do gene quando normalizadas em cada lâmina usando lowess com $\alpha$ estimado.

Figura 7.23: Medidas das expressões do gene MYB (A_23_P31073) amostradas em cada uma das lâminas do experimento, para as representações por estimativas convencionais das médias $M_{i}$, em vermelho, por estimativas melhoradas das médias de $M_{i}$ e por intervalos que incluem essa a média de $M_{i}$, em azul claro. As medidas já sofreram a normalização intra-lâmina com lowess usando tanto parâmetro de suavização igual a 0,2 (a) como com parâmetro de suavização estimado pelo método visto na seção 5.1 .4 (b). 


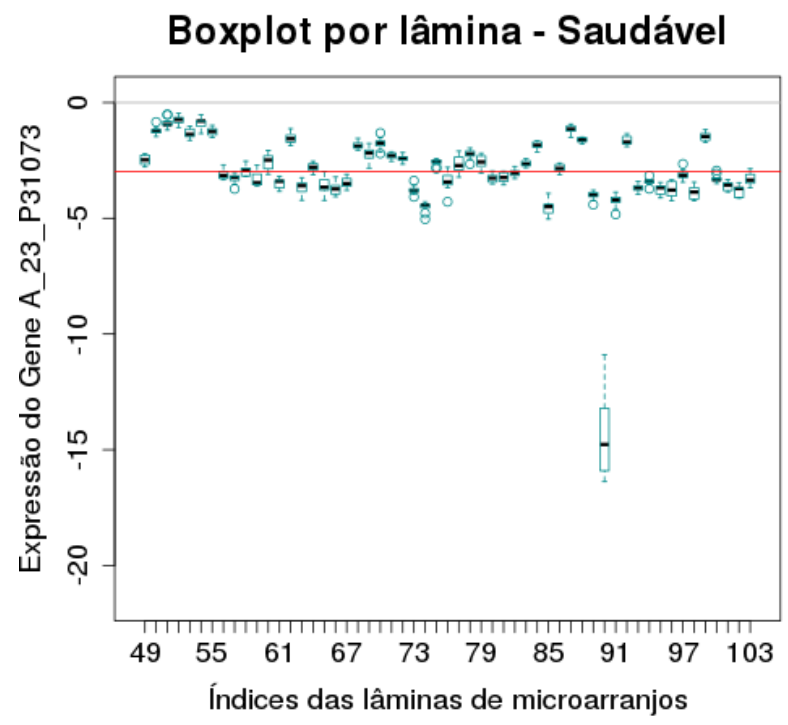

\section{Boxplot por lâmina - Metaplasia grau II}

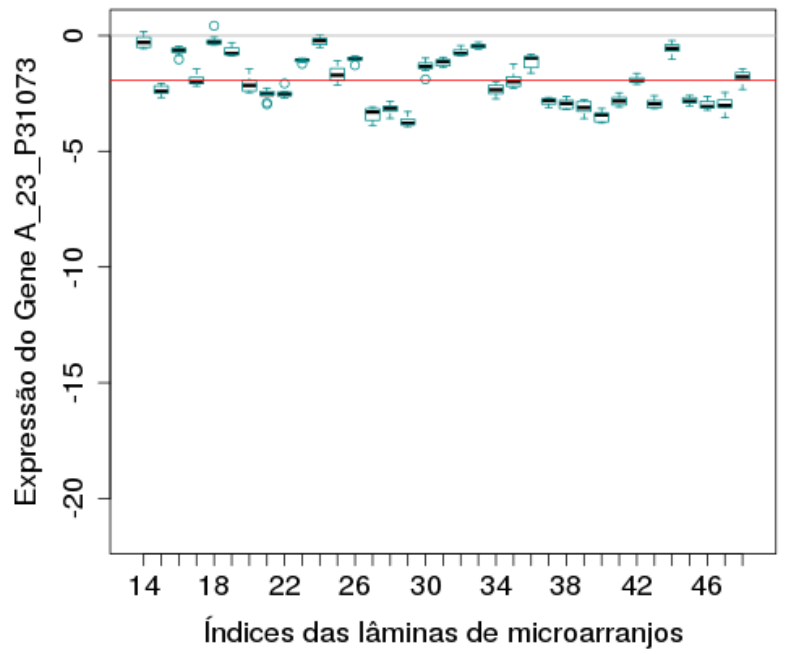

(a) Utilizamos as expressões do gene normalizadas em cada lâmina usando lowess com $\alpha=0,2$.

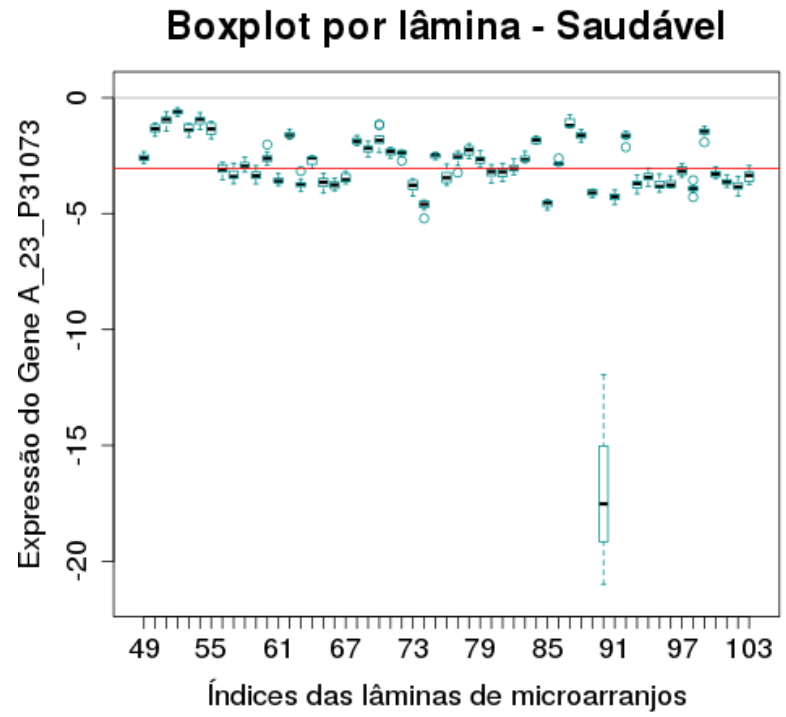

Boxplot por lâmina - Metaplasia grau II

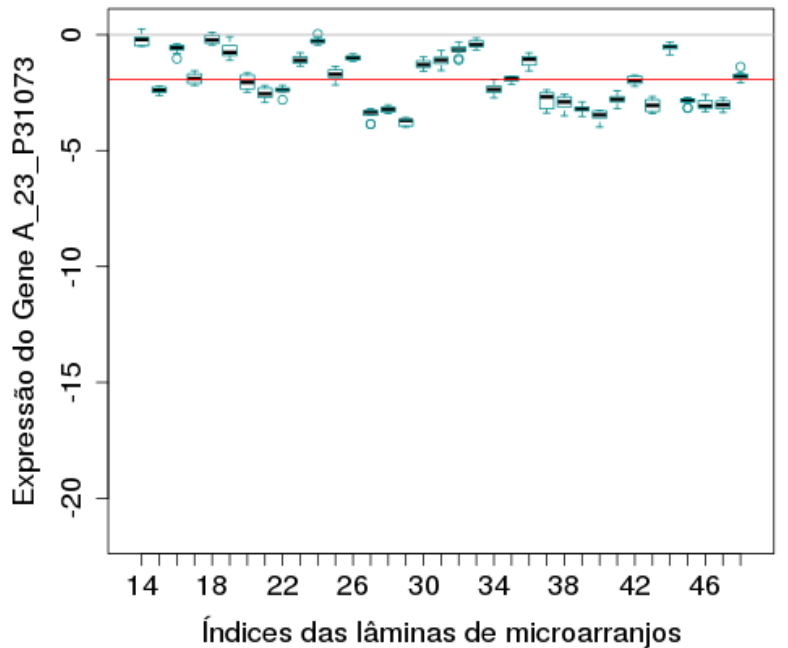

(b) Utilizamos as expressões do gene normalizadas em cada lâmina usando lowess com $\alpha$ estimado pelo método visto na seção 5.1.4.

Figura 7.24: Boxplots das expressões do gene $M Y B$ (A_23_P31073) por lâmina e por condição fenotipica, nas bases de expressões gênicas representadas por intervalos. A partir desse gráfico, podemos ver como é a variância das expressões em cada uma das lâminas e analisar como os intervalos afetam decisão do teste para $H_{0}(7.1)$. 
Densidades do gene A_23_P31073 por condição fenotípica e por método de pré-processamento

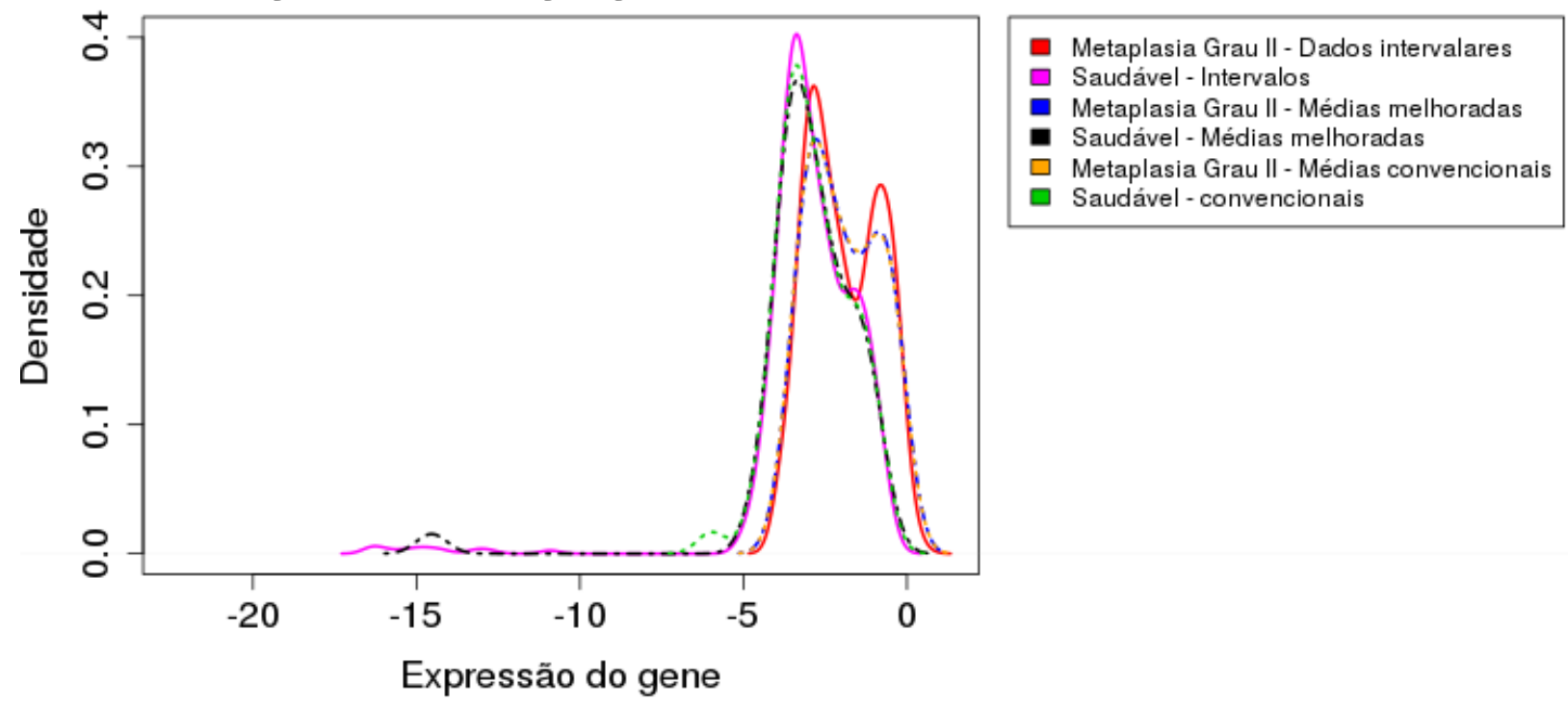

(a) Densidades das expressões do gene quando normalizadas em cada lâmina usando lowess com $\alpha=0,2$.

\section{Densidades do gene A_23_P31073 por condição fenotípica} e por método de pré-processamento

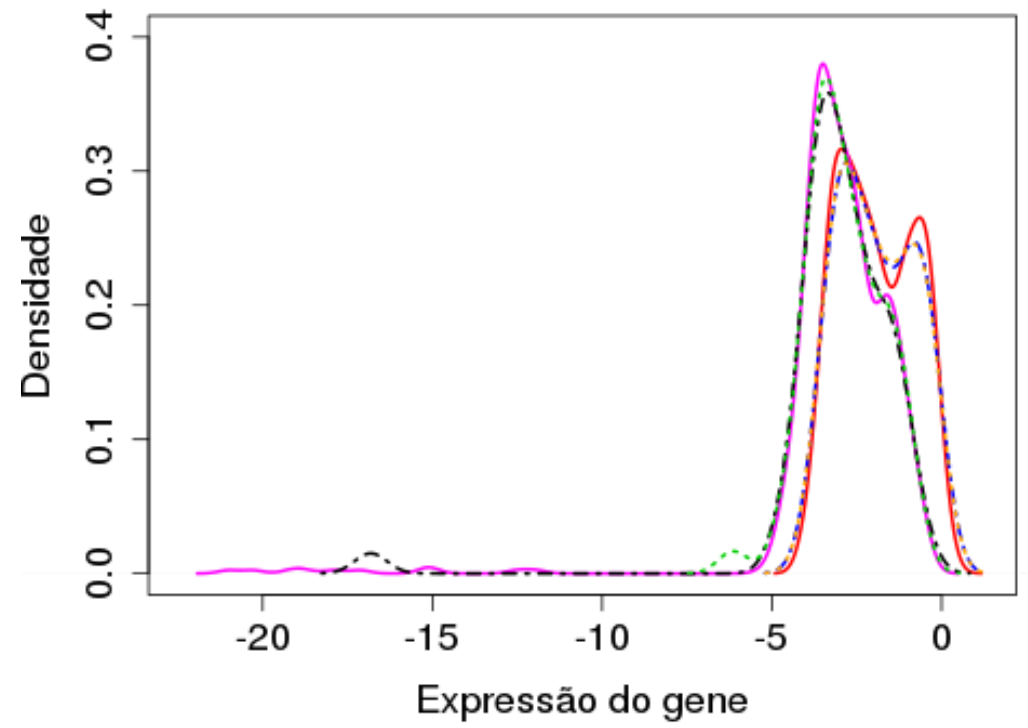

- Metaplasia Grau II - Dados intervalares - Saudável - Intervalos

- Metaplasia Grau II - Médias melhoradas

- Saudável-Médias melhoradas

$\square$ Metaplasia Grau II - Médias convencionais

- Saudável-convencionais

(b) Densidades das expressões do gene quando normalizadas em cada lâmina usando lowess com $\alpha$ estimado.

Figura 7.25: Comparação entre as densidades das expressões do gene $M Y B$ (A_23_P31073) representadas pelas médias convencionais (com o estimador $\hat{M}_{i}$ ), pelas médias melhoradas (com o estimador $\bar{M}_{i}$ e por intervalos, após normalização intra-lâmina com lowess usando tanto parâmetro de suavização igual a 0,2 como com parâmetro de suavização estimado pelo método visto na seção 5.1.4. 
Expressão usando intervalos p-valor (6.195e-06) / corrigido (0.0004816)

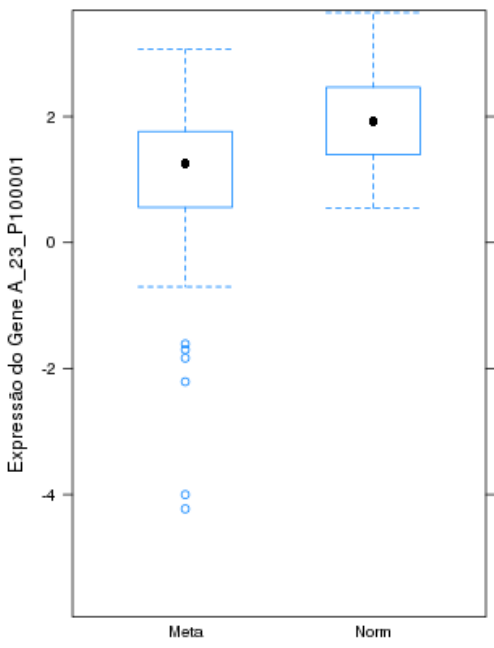

Expressão usando média melhorada p-valor (6.132e-06) / corrigido (0.0004765)

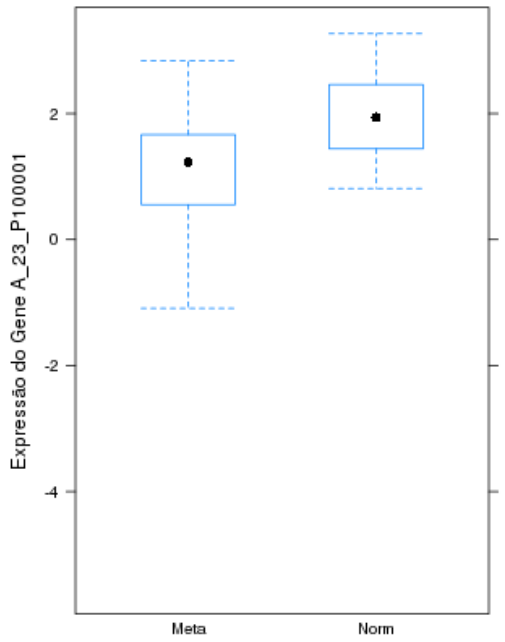

Expressão usando média convencional p-valor (0.000554) / corrigido (0.01445)

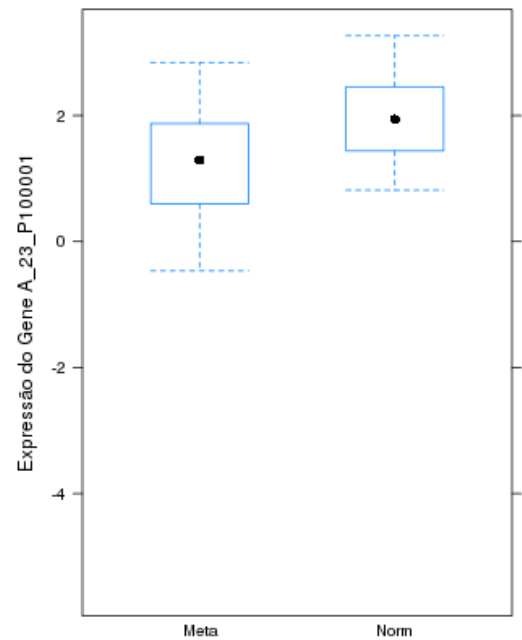

(a) Boxplots com dados obtidos após normalização intra-lâmina usando lowess com $\alpha=0,2$.

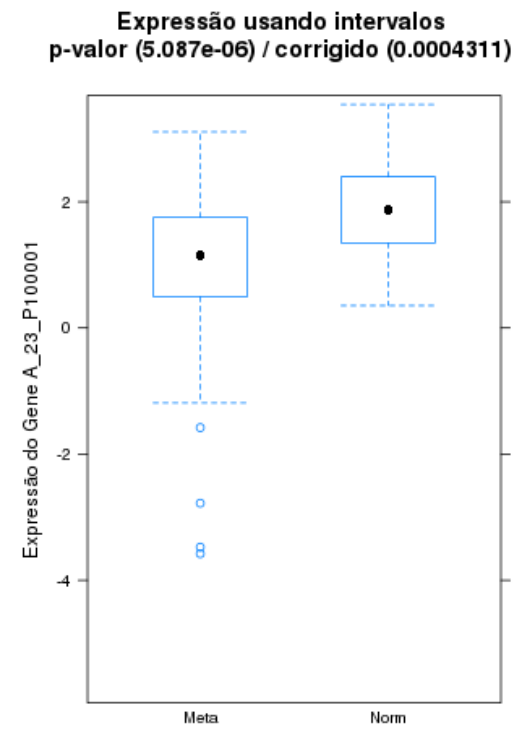

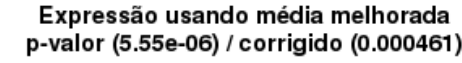

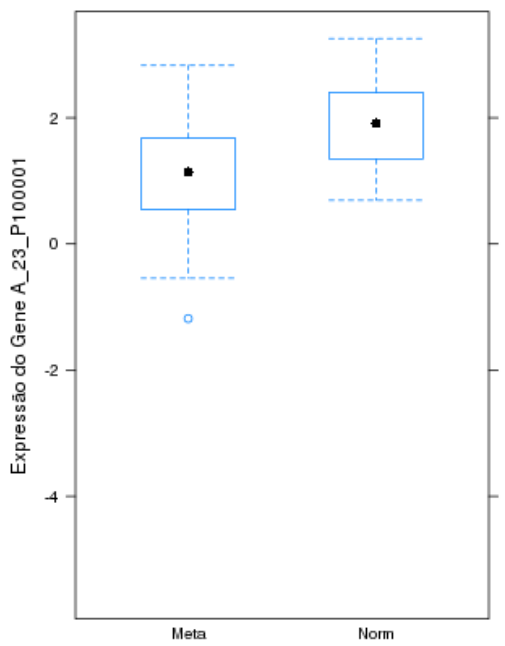

Expressão usando média convencional p-valor (0.0005859) / corrigido (0.0152)

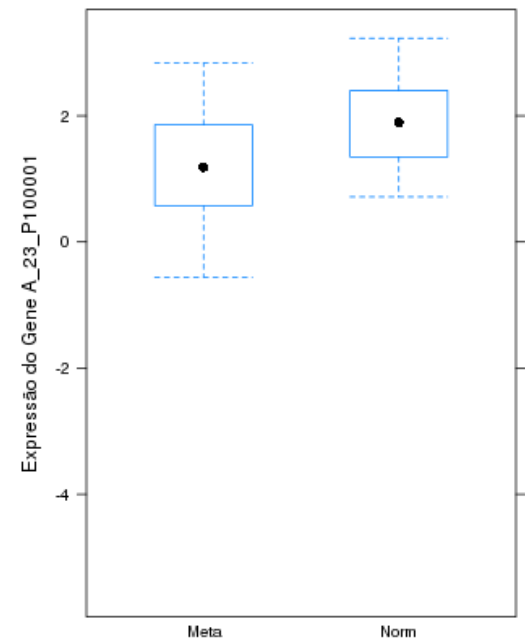

(b) Boxplots com dados obtidos após normalização intra-lâmina usando lowess com $\alpha$ estimado pelo método visto na seção 5.1.4.

Figura 7.26: Mostramos em cada gráfico os boxplots das expressões do gene FAM174B (A_23_P100001), de acordo com a condição fenotípica da amostra, para as variantes da base de dados com as expressões do gene representas por intervalos, pela média melhorada (usando o estimador $\bar{M}_{i}$ ) e pela média convencional (usando o estimador $\hat{M}_{i}$ ). Em (a) os dados de todas as lâminas foram normalizados usando lowess com parâmetro de suavização igual a $0,2 \mathrm{e}$ em (b), usando parâmetro de suavização estimado pelo método visto na seção 5.1.4. 
Comparação entre representações das expressões gênicas parâmetro de suavização do lowess $=0,2$

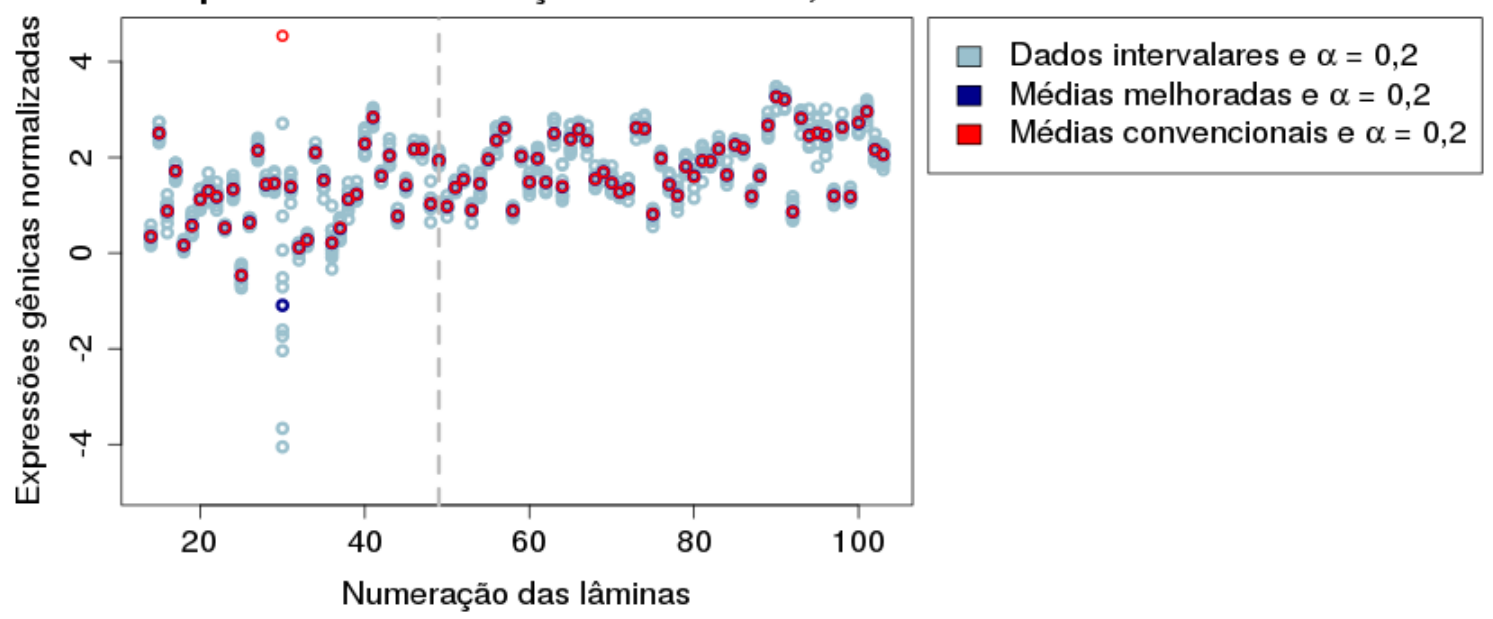

(a) Expressões do gene quando normalizadas em cada lâmina usando lowess com $\alpha=0,2$.

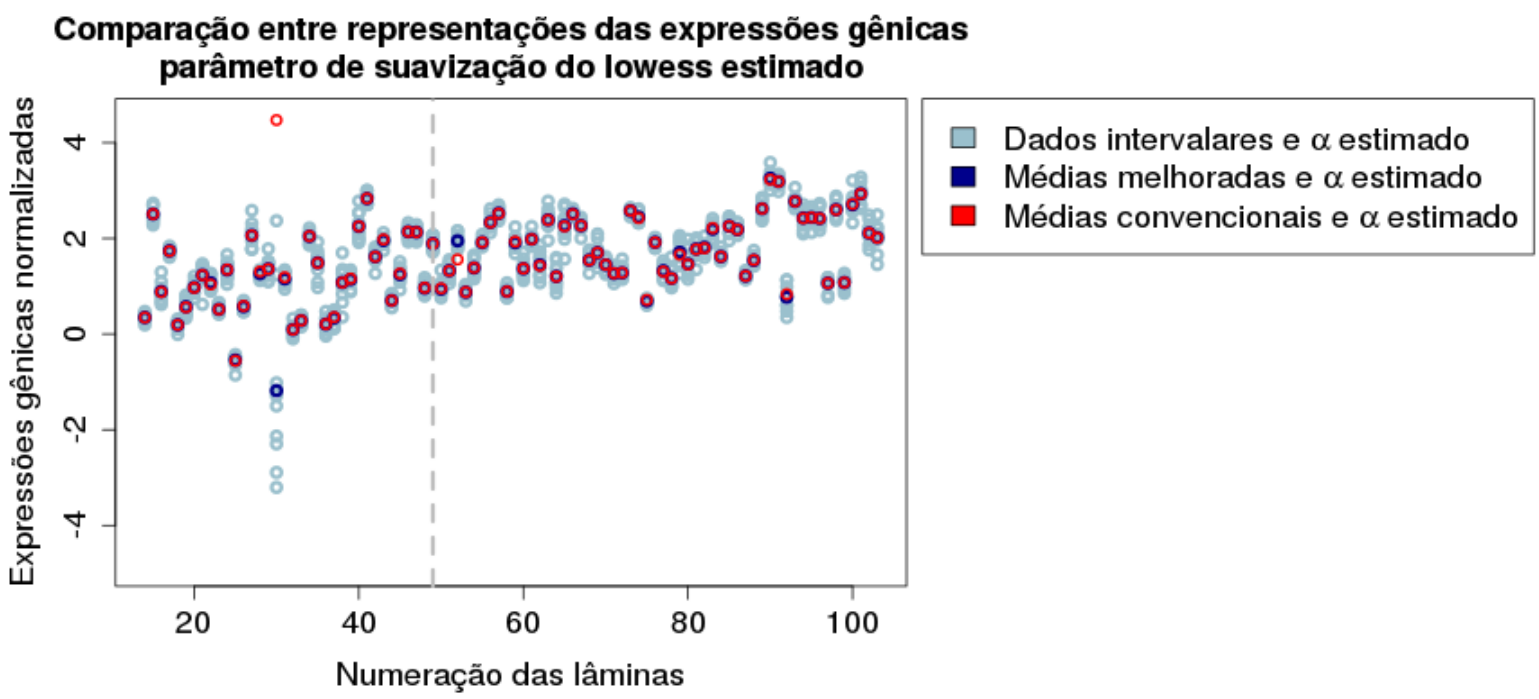

(b) Expressões do gene quando normalizadas em cada lâmina usando lowess com $\alpha$ estimado.

Figura 7.27: Medidas das expressões do gene FAM174B (A_23_P100001) amostradas em cada uma das lâminas do experimento, para as representações por estimativas convencionais das médias $M_{i}$, em vermelho, por estimativas melhoradas das médias de $M_{i}$ e por intervalos que incluem essa a média de $M_{i}$, em azul claro. As medidas já sofreram a normalização intra-lâmina com lowess usando tanto parâmetro de suavização igual a 0,2 (a) como com parâmetro de suavização estimado pelo método visto na seção 5.1.4 (b). 

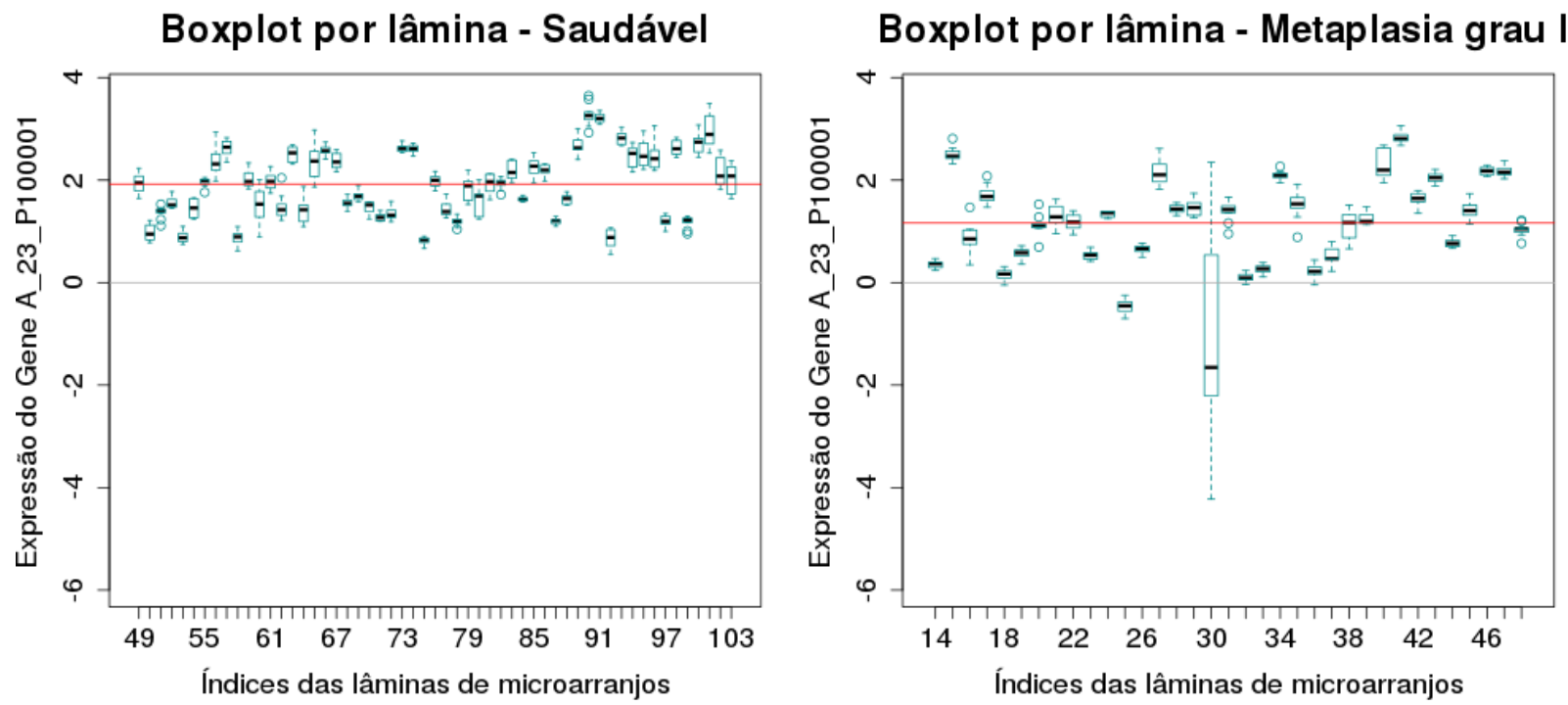

(a) Utilizamos as expressões do gene normalizadas em cada lâmina usando lowess com $\alpha=0,2$.
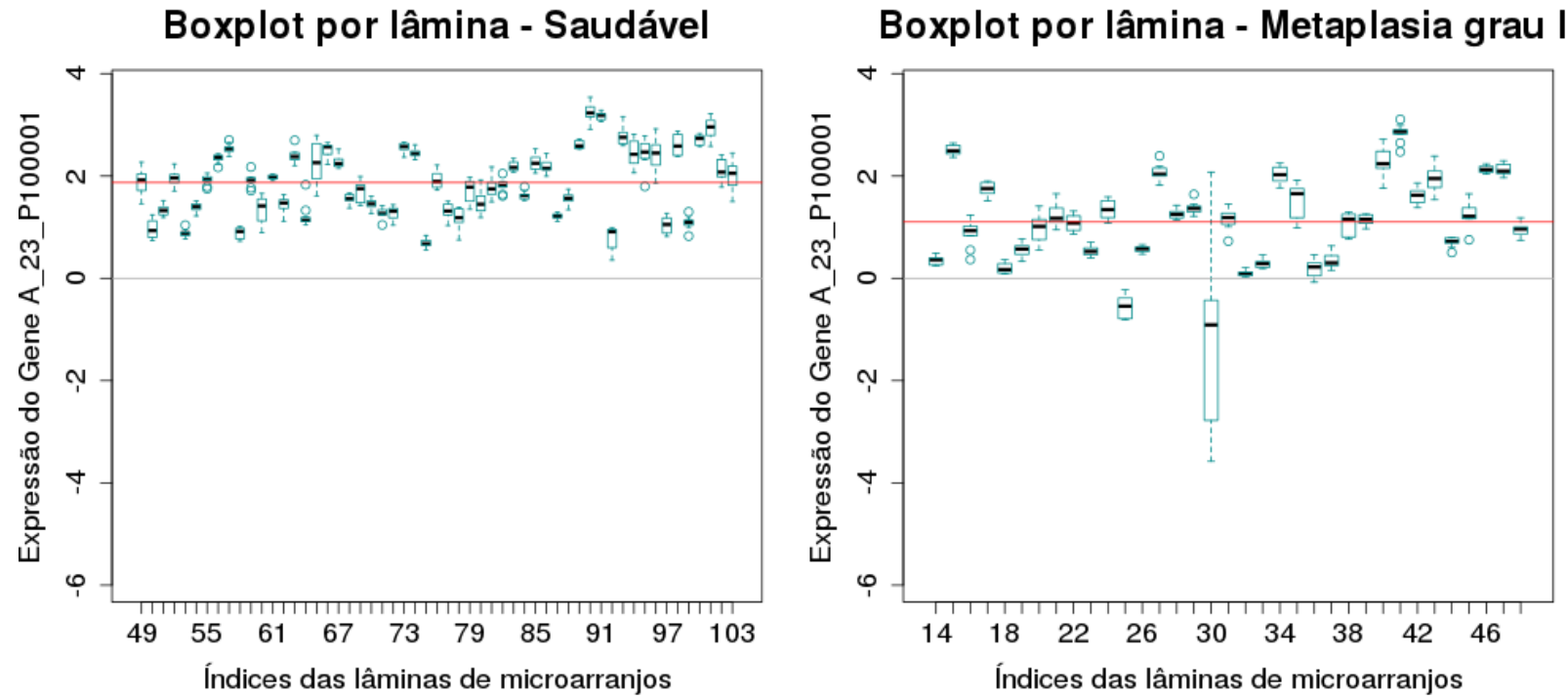

(b) Utilizamos as expressões do gene normalizadas em cada lâmina usando lowess com a estimado pelo método visto na seção 5.1.4.

Figura 7.28: Boxplots das expressões do gene FAM174B (A_23_P100001) por lâmina e por condição fenotipica, nas bases de expressões gênicas representadas por intervalos. A partir desse gráfico, podemos ver como é a variância das expressões em cada uma das lâminas e analisar como os intervalos afetam decisão do teste para $H_{0}$ (7.1). 


\section{Densidades do gene A_23_P100001 por condição fenotípica} e por método de pré-processamento

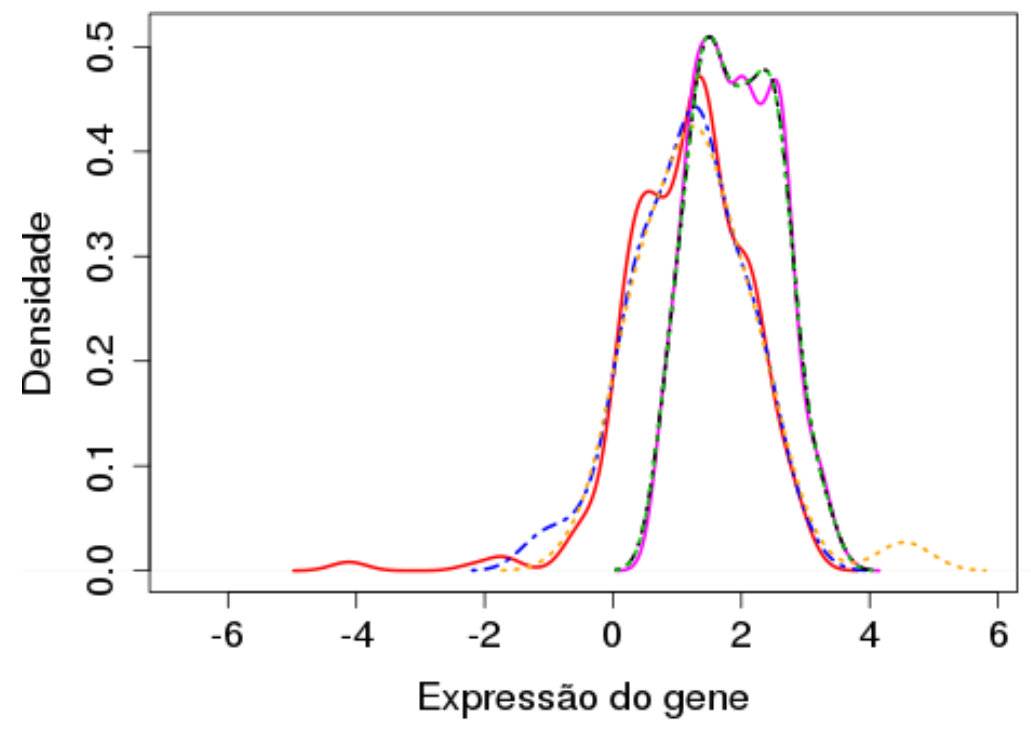

Metaplasia Grau II - Dados intervalares $\square$ Saudável - Intervalos

- Metaplasia Grau II - Médias melhoradas

- Saudável-Médias melhoradas

$\square$ Metaplasia Grau II - Médias convencionais

$\square$ Saudável-convencionais

(a) Densidades das expressões do gene quando normalizadas em cada lâmina usando lowess com $\alpha=0,2$.

\section{Densidades do gene A_23_P100001 por condição fenotípica} e por método de pré-processamento

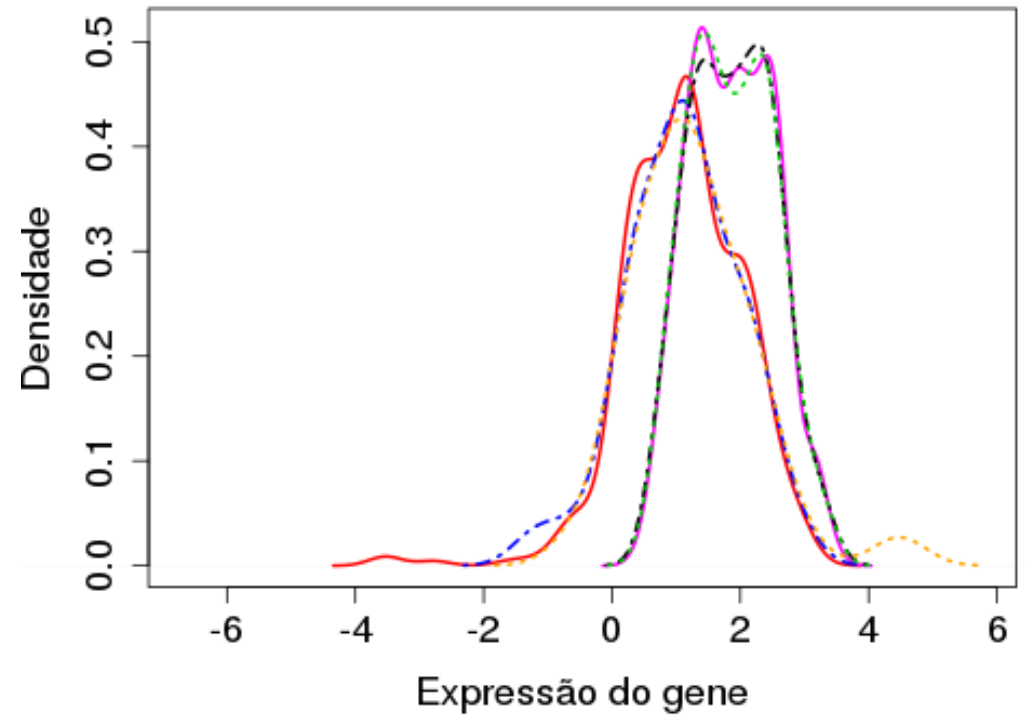

Metaplasia Grau II - Dados intervalares Saudável - Intervalos

- Metaplasia Grau II - Médias melhoradas

- Saudável-Médias melhoradas

- Metaplasia Grau II - Médias convencionais

Saudável-convencionais

(b) Densidades das expressões do gene quando normalizadas em cada lâmina usando lowess com $\alpha$ estimado.

Figura 7.29: Comparação entre as densidades das expressões do gene FAM174B (A_23_P100001) representadas pelas médias convencionais (com o estimador $\hat{M}_{i}$ ), pelas médias melhoradas (com o estimador $\bar{M}_{i}$ e por intervalos, após normalização intra-lâmina com lowess usando tanto parâmetro de suavização igual a 0,2 como com parâmetro de suavização estimado pelo método visto na seção 5.1.4. 
Expressão usando intervalos p-valor (5.482e-06) / corrigido (0.0004424)

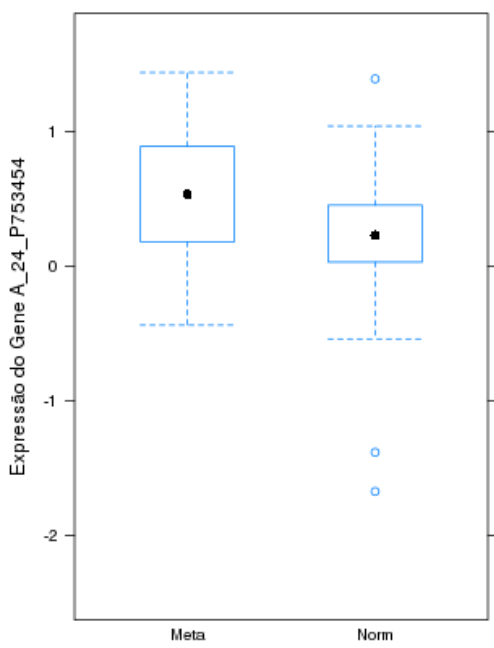

Expressão usando média melhorada p-valor (5.012e-06) / corrigido (0.0004163)

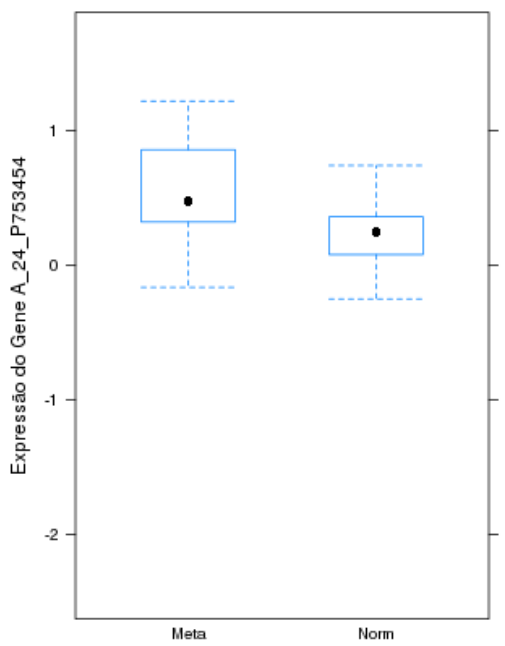

Expressão usando média convencional p-valor (0.001335) / corrigido (0.02671)

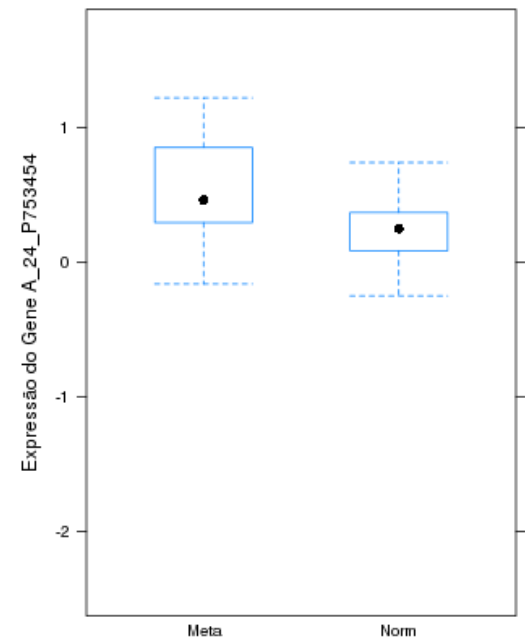

(a) Boxplots com dados obtidos após normalização intra-lâmina usando lowess com $\alpha=0,2$.

Expressão usando intervalos p-valor (7.095e-06) / corrigido (0.000554)

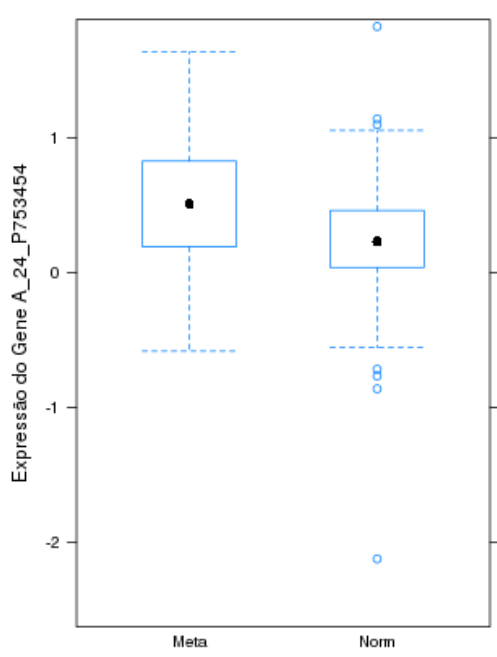

Expressão usando média melhorada p-valor (6.525e-06) / corrigido (0.0005182)

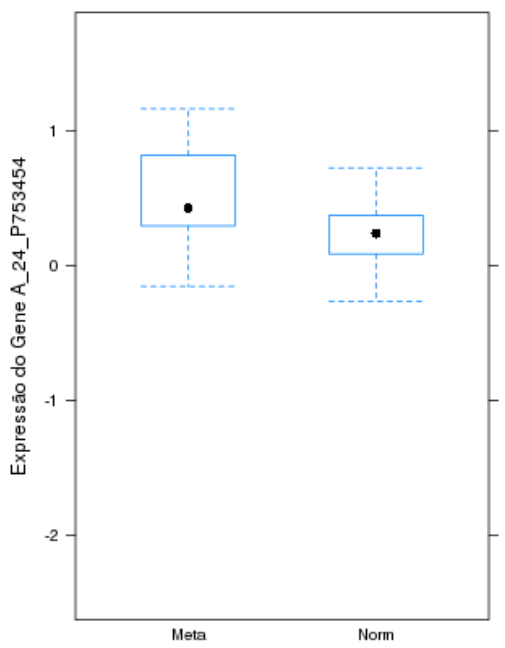

Expressão usando média convencional p-valor (0.001756) / corrigido (0.03265)

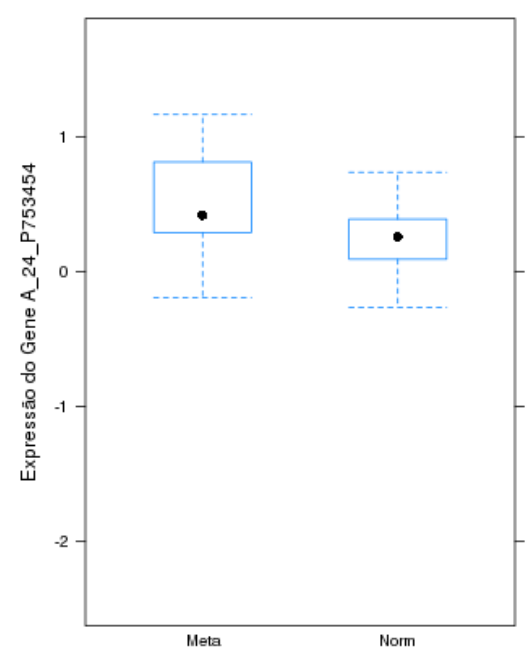

(b) Boxplots com dados obtidos após normalização intra-lâmina usando lowess com $\alpha$ estimado pelo método visto na seção 5.1.4.

Figura 7.30: Mostramos em cada gráfico os boxplots das expressões do gene NDUFA6-AS1 (A_24_P753454), de acordo com a condição fenotípica da amostra, para as variantes da base de dados com as expressões do gene representas por intervalos, pela média melhorada (usando o estimador $\bar{M}_{i}$ ) e pela média convencional (usando o estimador $\hat{M}_{i}$ ). Em (a) os dados de todas as lâminas foram normalizados usando lowess com parâmetro de suavização igual a 0,2 e, em (b), usando parâmetro de suavização estimado pelo método visto na seção 5.1 .4 . 
Comparação entre representações das expressões gênicas parâmetro de suavização do lowess $=0,2$

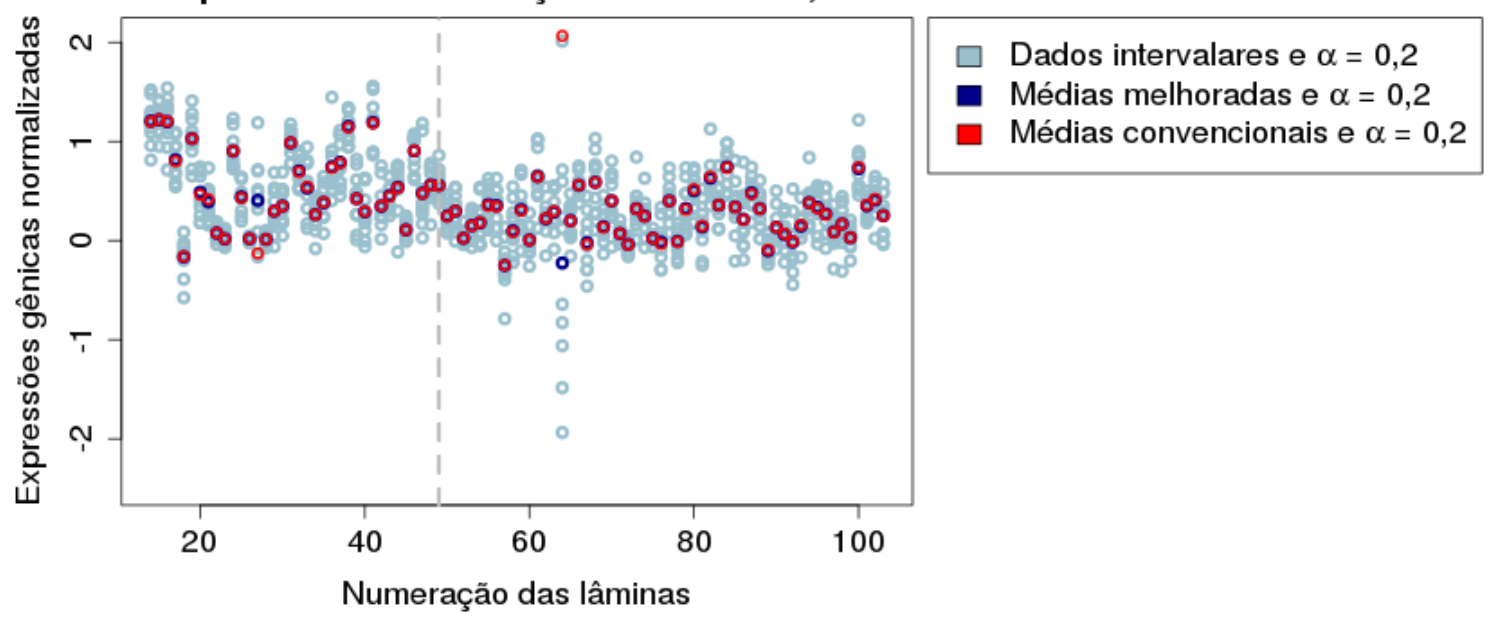

(a) Expressões do gene quando normalizadas em cada lâmina usando lowess com $\alpha=0,2$.

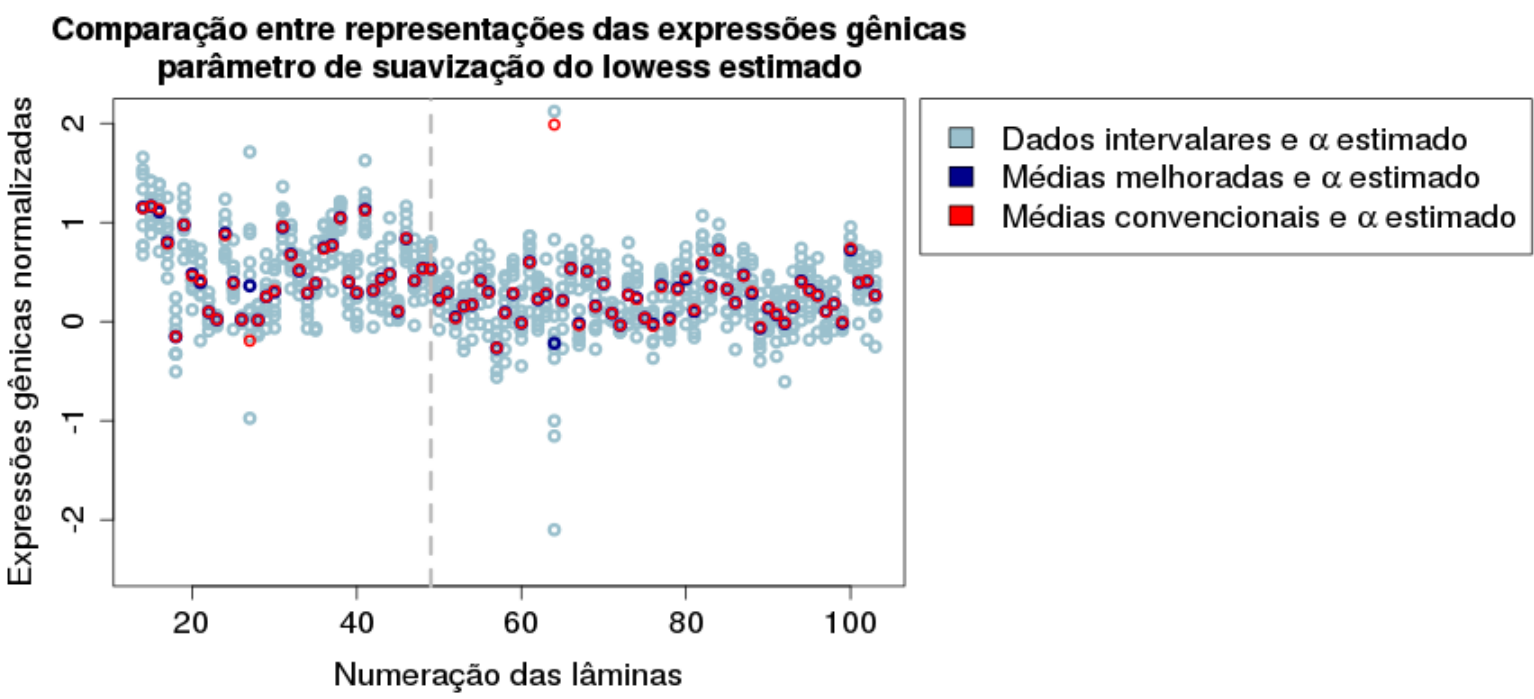

(b) Expressões do gene quando normalizadas em cada lâmina usando lowess com $\alpha$ estimado.

Figura 7.31: Medidas das expressões do gene NDUFA6-AS1 (A_24_P753454) amostradas em cada uma das lâminas do experimento, para as representações por estimativas convencionais das médias $M_{i}$, em vermelho, por estimativas melhoradas das médias de $M_{i}$ e por intervalos que incluem essa a média de $M_{i}$, em azul claro. As medidas já sofreram a normalização intra-lâmina com lowess usando tanto parâmetro de suavização igual a 0,2 (a) como com parâmetro de suavização estimado pelo método visto na seção 5.1.4 (b). 


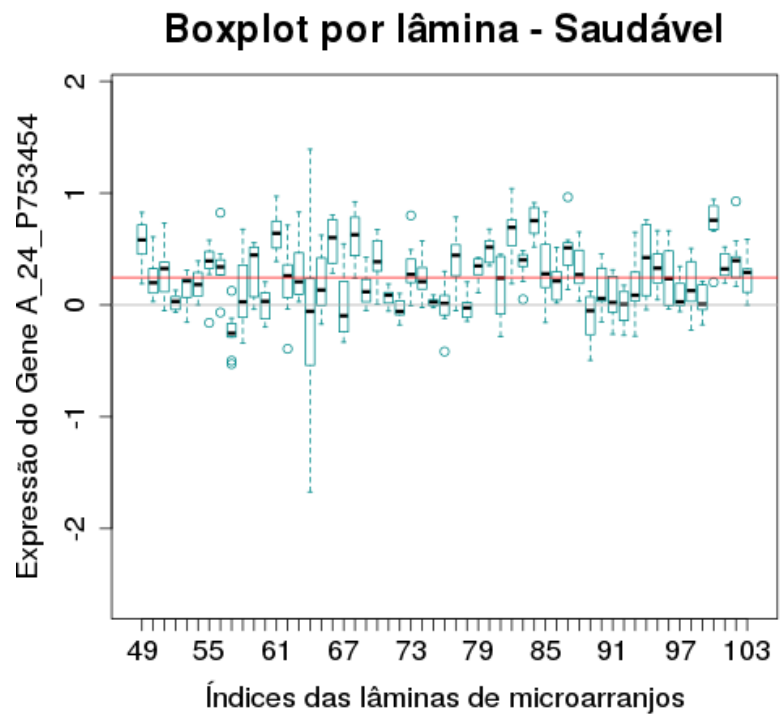

\section{Boxplot por lâmina - Metaplasia grau II}

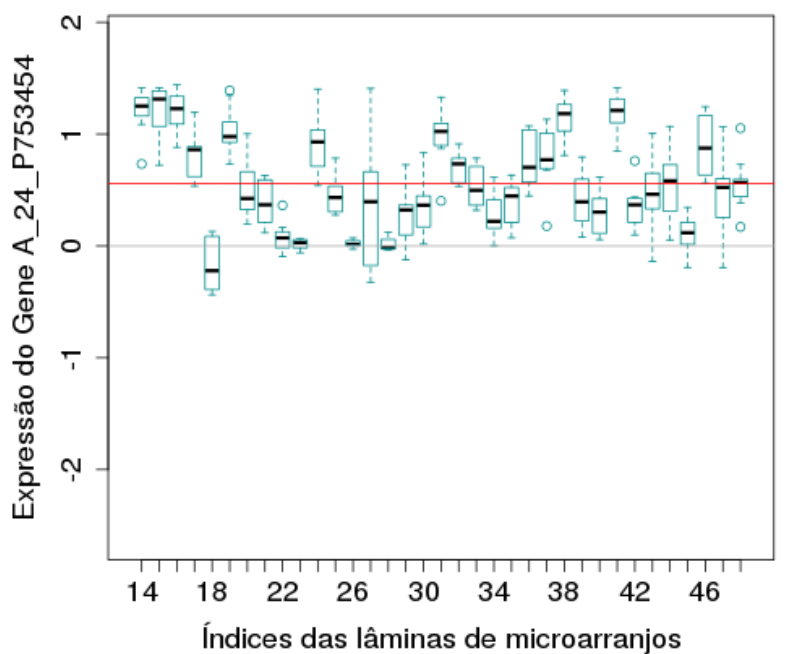

(a) Utilizamos as expressões do gene normalizadas em cada lâmina usando lowess com $\alpha=0,2$.
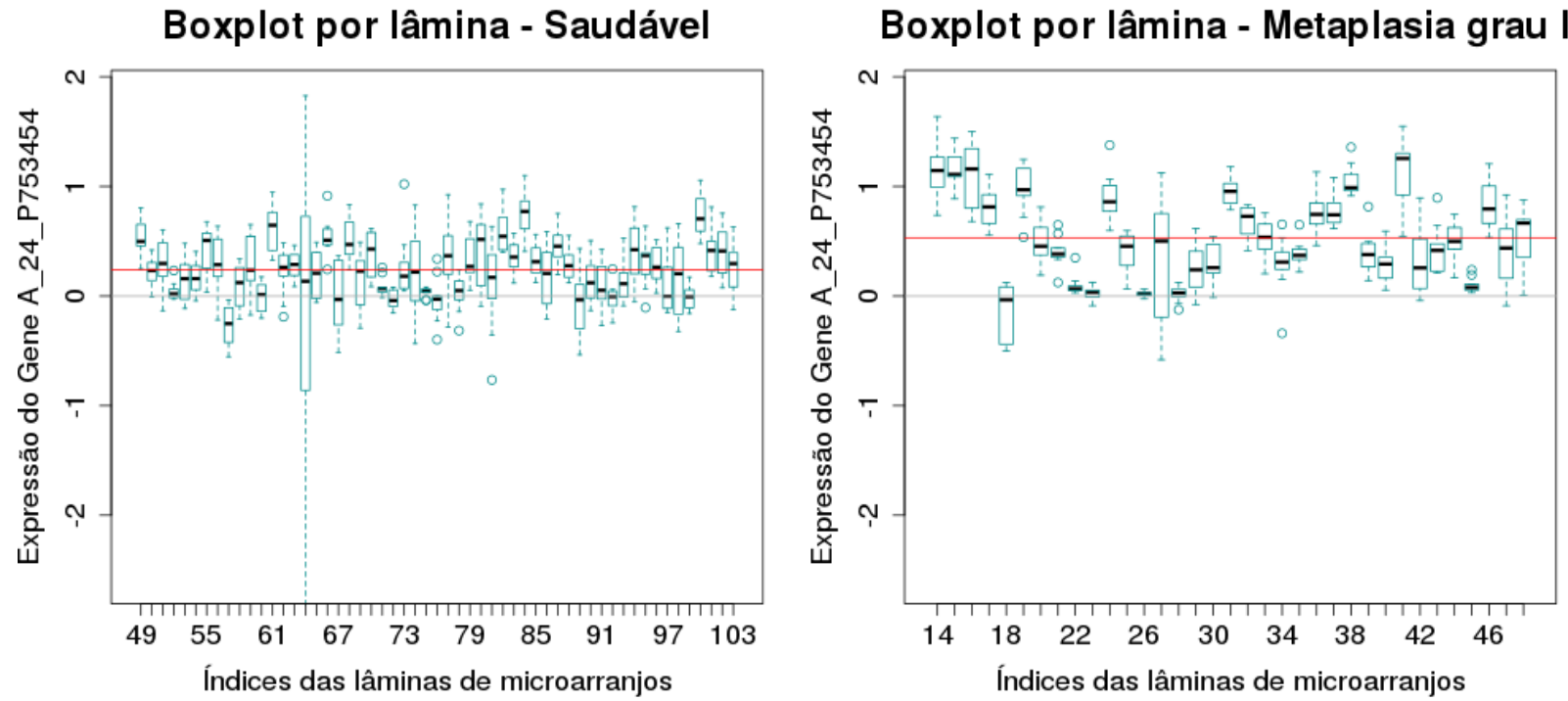

(b) Utilizamos as expressões do gene normalizadas em cada lâmina usando lowess com $\alpha$ estimado pelo método visto na seção 5.1.4.

Figura 7.32: Boxplots das expressões do gene NDUFA6-AS1 (A_24_P753454) por lâmina e por condição fenotipica, nas bases de expressões gênicas representadas por intervalos. A partir desse gráfico, podemos ver como é a variância das expressões em cada uma das lâminas e analisar como os intervalos afetam decisão do teste para $H_{0}(7.1)$. 


\section{Densidades do gene A_24_P753454 por condição fenotípica e por método de pré-processamento}

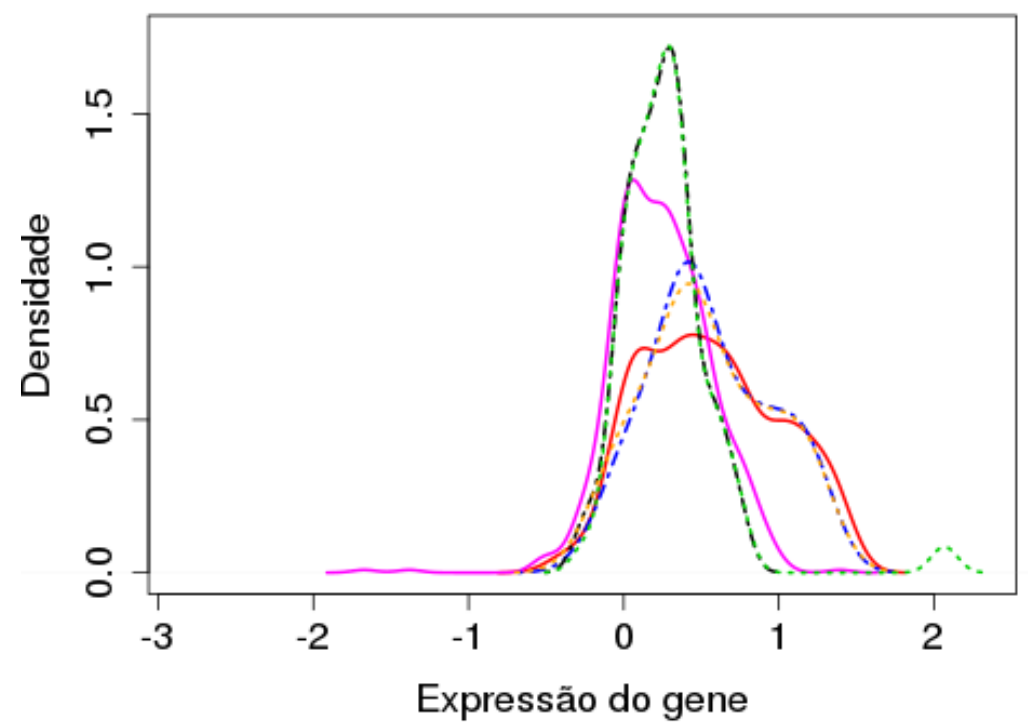

- Metaplasia Grau II - Dados intervalares Saudável - Intervalos

Metaplasia Grau II - Médias melhoradas

Saudável - Médias melhoradas

Metaplasia Grau II - Médias convencionais

Saudável-convencionais

(a) Densidades das expressões do gene quando normalizadas em cada lâmina usando lowess com $\alpha=0,2$.

\section{Densidades do gene A_24_P753454 por condição fenotípica} e por método de pré-processamento

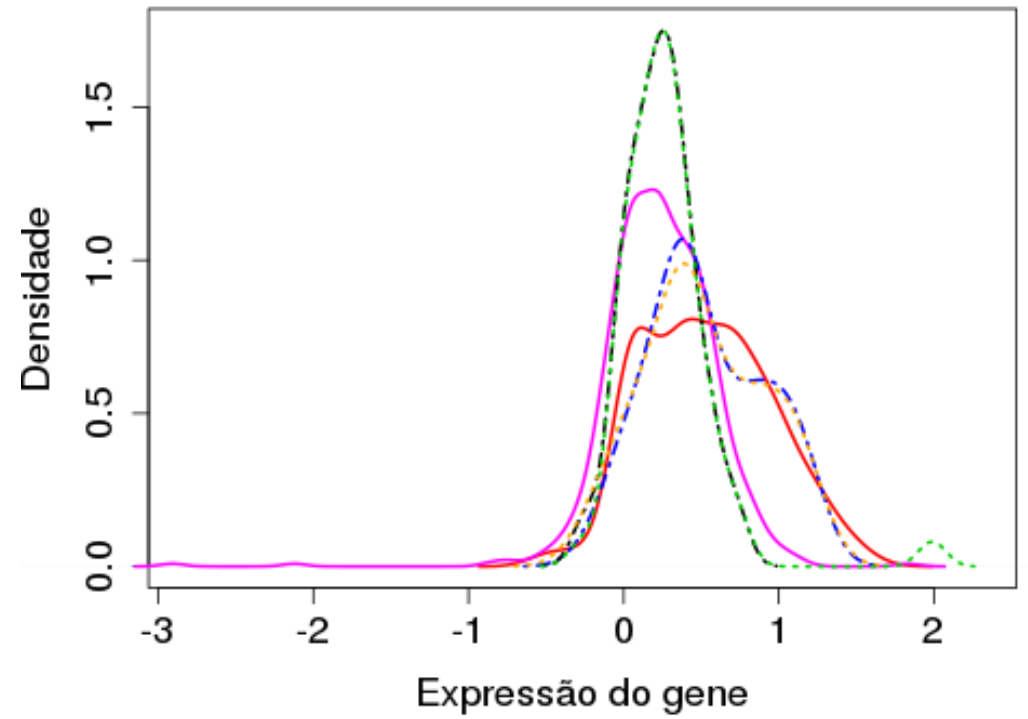

Metaplasia Grau II - Dados intervalares

- Saudável - Intervalos

- Metaplasia Grau II - Médias melhoradas

- Saudável - Médias melhoradas

$\square$ Metaplasia Grau II - Médias convencionais

$\square$ Saudável-convencionais

(b) Densidades das expressões do gene quando normalizadas em cada lâmina usando lowess com $\alpha$ estimado.

Figura 7.33: Comparação entre as densidades das expressões do gene NDUFA6-AS1 (A_24_P753454) representadas pelas médias convencionais (com o estimador $\hat{M}_{i}$ ), pelas médias melhoradas (com o estimador $\bar{M}_{i}$ e por intervalos, após normalização intra-lâmina com lowess usando tanto parâmetro de suavização igual a 0,2 como com parâmetro de suavização estimado pelo método visto na seção 5.1.4. 


\subsection{Genes diferencialmente expressos concordando com a literatura}

Para efeito de completude da análise da base de dados, fizemos uma análise dos genes associados à metaplasia intestinal do estômago, segundo a literatura. De 80 genes associados com a metaplasia intestinal do estômago no projeto Gene Expression Omnibus da NCBI - National Center for Biotechnology Information (Edgar et al. (2002)), constatamos que 9 deles apresentaram p-valor menor que $3 \mathrm{e}-04$ e fold change maior que 1 em todas as variantes da base de dados. Descrevemos abaixo esse genes:

- CLDN3 e CLDN4: segundo os artigos Resnick et al. (2005) e Shang et al. (2012), as claudinas 1, 3, e 4, além do ZO-1 estão fortemente expressas na maioria dos adenocarcinomas gástricos do tipo intestinal. Assim, a superexpressão dessas claudinas durante a carcinogênese gástrica permite o uso como biomarcadores de diagnóstico e possíveis alvos para intervenção terapêutica.

- CDX1 e CDX2: são membros da família de genes que são fatores de transcrição específicos do intestino, com homeobox - segmento de genes homeóticos (reguladores) - do tipo caudal. A infecção crônica com a bactéria Helicobacter pylori é a principal causa da metaplasia intestinal gástrica e a indução anormal dos fatores CDX1 e CDX2 por essa bactéria desempenha um papel fundamental no processo de alteração metaplásica (Fujii et al. (2012)). No artigo Ishikawa et al. (2004), foi constata a superexpressão do CDX2 em metaplasia intestinal.

- CDH17: é um novo biomarcador para metaplasia intestinal, como pode ser visto em Lee et al. (2010). Sua superexpressão pode ser usada como prognóstico para câncer gástrico em estágios recentes.

- DEFA5 (Defensin alpha 5): é outro marcador biológico para a metaplasia intestinal, segundo Lee et al. (2010), pois tem alta expressão nas células de Paneth (uma das principais do epitélio do intestino pequeno) (Ouellette (1997)).

- MUC2: no estudo de Reis et al. (1999), a mucina intestinal MUC2 foi superexpressa em todas as amostras de metaplasia intestinal incompleta (incluindo a do tipo II), principalmente em células caliciformes.

- GUCY2C (Guanylate cyclase 2C): aparece superexpresso em amostras epiteliais com câncer de cólon, segundo Gibbons et al. (2013), coordena a homeostase intestinal, seja epitelial ou mesenquimal, através de circuitos parácrinos mediados pelos fatores TGF- $\beta$ e HGF. Essa sinalização constitui uma ligação direta entre o início do câncer colorretal e a indução da reação estromal desmoplásica.

Além disso, é um marcador biológico da metaplasia intestinal, displasia e adenocarcinoma do trato gastrointestinal, segundo o estudo de Birbe et al. (2005), aparecendo superexpressos em alguns estágios e subtipos dessas doenças.

- REG4: está superexpresso nas células tumorais gástricas e, pelos artigos de Tao et al. (2011) e Oue et al. (2005), pode ser considerado um marcador para o diagnóstico precoce do câncer gástrico.

Com isso, vemos que a inclusão das imprecisões nas análises e da correção mais suave do viés manteve os resultados consistentes com os obtidos pela análise convencional.

\subsection{Genes diferencialmente expressos das vias do câncer}

Para completarmos o objetivo deste trabalho, selecionaremos os genes diferencialmente expressos pertencentes às vias do câncer (com identificação 05200). Nas tabelas 7.3 e 7.4 listamos os 21 genes mais diferencialmente expressos, resultantes da escolha de p-valor de corte igual a 0,01 . Com exceção 
dos genes CDKN2B (representado pelo local genético de identificação A_23_P216812 na plataforma da Agilent) e EGLN1 (com identificação A_23_P343935 na plataforma Agilent), os p-valores do teste para $H_{0}$ foram inferiores a 0,01 em todas as variantes da base de dados.

A posição dos genes nessas listas varia um pouco. É o caso, por exemplo, do gene VEGFB (A_23_P1594) que teve seu p-valor razoavelmente alterado tanto por causa da estimação do parâmetro $\bar{\alpha}$ na normalização quanto por causa da consideração das imprecisões nas análises. Fazendo a comparação do uso de um parâmetro de suavização estimado em relação ao uso de um fixado em 0,2 , a posição desse gene caiu da terceira (com p-valor $=0,00028$ ) para a oitava (com pvalor $=0,0008)$ quando utilizamos as estimativas que consideram as imprecisões e saiu da segunda $($ com p-valor $=0,00023)$ para a quarta posição (com p-valor $=0,00037)$ quando utilizamos as estimativas convencionais para as médias das expressões gênicas. Outro exemplo é o gene EGLN1 (A_23_P343935) que teve p-valor aproximadamente igual a 0,0006 nas variantes em que os dados foram normalizados com $\alpha$ estimado, mas quando a normalização foi feita com $\alpha=0$, 2 , esse p-valor caiu para aproximadamente 0,01 . Com o nosso corte no p-valor de 0,01, esse gene deixaria de aparecer na lista dos genes diferencialmente expressos para a variantes com dados intervalares e normalização usando $\alpha=0,2$.

A partir de informações obtidas na literatura, constatamos que o gene EGLN1 (do inglês, egl nine homolog 1 (C. elegans), também conhecido como PHD2 (do inglês, prolyl hydroxylase domain protein 2), foi determinado no artigo de Jokilehto et al. (2006) como superexpresso em amostras com carcinoma de células escamosas. Como a metaplasia do estômago é conhecida por ser um fator de risco de câncer do estômago e este está relacionado com doenças como o adenocarcinoma, o câncer colorretal e o carcinoma de células escamosas, acreditamos que a determinação de uma expressão maior nas células com metaplasia é um resultado adequado.

Utilizando a ferramenta exploratória ConsensusPathDB Kamburov et al. (2009), que gera gráficos e tabelas sobre as interações de um conjunto de genes a partir de informações de 32 recursos públicos, constatamos que as 13 vias listadas na tabela 7.7 foram significantemente representadas, com p-valor abaixo de 0,01. Essas vias estão descritas na tabela 7.8, em ordem de significância, junto com o número de genes representantes, ou seja, genes que estão na nossa base e foram como considerados diferencialmente expressos, e o número de genes total da via. Na figura 7.34, mostramos as interações entre essas vias. Quanto mais vermelho, mais significante é a ligação ou a via. Quanto maior é o círculo, maior é o número total de genes na via. Uma linha de conexão mais grossa indica que as vias estão sendo conectadas por mais genes.

Para a determinação das listas dos genes mais diferencialmente expressos mostradas nas tabelas 7.3 e 7.4, não fizemos o corte pelo fold change. Utilizando um corte que permite apenas genes com valor absoluto de fold change maior que 0,9, obtivemos 4 genes: PLD1, VEGFB, NOS2, CDKN2B. Eles foram listados, junto com o p-valor e o fold change correspondente, nas tabelas 7.5 e 7.6. Na tabela 7.8, podemos ver as 3 vias associadas a esses 4 genes, enquanto que, na figura 7.35, podemos ver as interações dessas vias.

O gene PLD1 (fosfolipase D1) codifica uma fosfolipase-fosfatidilcolina específica a fim de se obter ácido fosfatídico e colina. Ele pode desempenhar um papel importante na tradução de sinais e no tráfego subcelular. Segundo o artigo de Kang et al. (2011), as fosfolipase D (PLD) tem sido reconhecidas como importantes reguladores da proliferação celular e na tumorigênese. Além disso, como comentam os autores Chen et al. (2012), ele é importante no microambiente do tumor durante a angiogênese de tumores e metástases. Esse genes está também associado com o câncer de mama, sendo relatado como superexpresso nos artigos de Noh et al. (2000) e de Gozgit et al. (2007).

Já o gene VEGFB (fator de crescimento endotelial vascular B, do inglês, vascular endothelial growth factor B), regula a formação de vasos sanguíneos e está envolvido na fisiologia da célula endotelial. Ele foi determinado em nossa aplicação como subexpresso nas amostras de estômago com metaplasia de grau II. Os autores Jayasinghe et al. (2013) avaliaram a expressão do gene VEGFB no carcinomas colorretais e sua relevância na progressão do tumor. Eles concluem a pesquisa defendendo que o gene tem uma importante ligação com o fornecimento de sangue para a sobrevivência de tumores. Já os autores Angelescu et al. (2013) investigaram as expressões dos genes VEGFA e 
VEGFB em cânceres gastro-esofágico. Apesar deles terem constatado que a expressão do gene VEGFA era maior nas amostras com câncer, indicando uma relação com a invasão tumoral, eles não conseguiram encontrar uma diferença significativa na expressão do VEGFB.

O gene NOS2 (óxido nítrico-sintase induzível 2, do inglês, nitric oxide synthase 2, inducible), codifica as enzimas óxido nítrico sintases. O óxido nítrico é um radical livre reativo que atua como mediador em diversos processos biológicos, como neurotransmissão e atividades antimicrobianas e antitumorais. Os autores Li et al. (2002) sugerem nesse artigo que a superexpressão dos genes HIF-1 $\alpha$, GLUT-1 e iNOS (NOS2) são importantes fatores na progressão do câncer gástrico.

O gene CDKN2B encontra-se ao lado do supressor tumoral CDKN2A, numa região que está frequentemente alterada ou removida em uma ampla variedade de tumores. Ele codifica um inibidor de quinases dependentes de ciclina, que forma um complexo com CDK4 ou CDK6 e impede a ativação das quinases CDK. Assim, as proteínas por ele codificadas funcionam como um regulador do crescimento celular e controlam a progressão do ciclo celular G1. Os autores Suzuki et al. (1995) sugerem nesse estudo que os genes CDKN2A e CDKN2B sofrem mutações em cânceres de esôfago humanos primários.

Ainda temos pouco estudos disponíveis na literatura sobre metaplasia intestinal do estômago. No entanto a relação com o câncer de estômago e com as doenças a ele associadas nos ofereceram algumas evidências de que os resultados obtidos foram adequados. 


\begin{tabular}{|c|c|c|}
\hline $\begin{array}{l}\text { Dados intervalares } \\
\text { alpha } 0.2\end{array}$ & $\begin{array}{l}\text { Médias melhoradas } \\
\text { alpha } 0.2\end{array}$ & $\begin{array}{l}\text { Médias convencionais } \\
\text { alpha } 0.2\end{array}$ \\
\hline $\begin{array}{l}\text { A_23_P155335 (PLD1) } \\
\text { p-valor: } 6.504 \mathrm{e}-05 \text { FC: } 1.01\end{array}$ & $\begin{array}{l}\text { A_23_P155335 (PLD1) } \\
\text { p-valor: } 6.522 \mathrm{e}-05 \text { FC: } 1.01\end{array}$ & $\begin{array}{l}\text { A_23_P155335 (PLD1) } \\
\text { p-valor: } 6.416 \mathrm{e}-05 \text { FC: } 1.01\end{array}$ \\
\hline $\begin{array}{l}\text { A_23_P61945 (MITF) } \\
\text { p-valor: } 0.000254 \text { FC: }-0.684\end{array}$ & $\begin{array}{l}\text { A_23_P61945 (MITF) } \\
\text { p-valor: } 0.0002583 \text { FC: }-0.684\end{array}$ & $\begin{array}{l}\text { A_23_P1594 (VEGFB) } \\
\text { p-valor: } 0.0002307 \text { FC: }-0.92\end{array}$ \\
\hline $\begin{array}{c}\text { A_23_P398774 (PLD1) } \\
\text { p-valor: } 0.0002563 \text { FC: } 0.438\end{array}$ & $\begin{array}{c}\text { A_23_P398774 (PLD1) } \\
\text { p-valor: } 0.000259 \text { FC: } 0.438\end{array}$ & $\begin{array}{c}\text { A_23_P398774 (PLD1) } \\
\text { p-valor: } 0.0002472 \text { FC: } 0.436\end{array}$ \\
\hline $\begin{array}{l}\text { A_23_P1594 (VEGFB) } \\
\text { p-valor: } 0.0002885 \text { FC: }-0.905\end{array}$ & $\begin{array}{l}\text { A_23_P1594 (VEGFB) } \\
\text { p-valor: } 0.0002708 \text { FC: }-0.905\end{array}$ & $\begin{array}{c}\text { A_23_P61945 (MITF) } \\
\text { p-valor: } 0.0002535 \text { FC: }-0.684\end{array}$ \\
\hline $\begin{array}{c}\text { A_23_P436138 (MAX) } \\
\text { p-valor: } 0.0004069 \text { FC: } 0.446\end{array}$ & $\begin{array}{l}\text { A_23_P436138 (MAX) } \\
\text { p-valor: } 0.0003981 \text { FC: } 0.446\end{array}$ & $\begin{array}{c}\text { A_23_P436138 (MAX) } \\
\text { p-valor: } 0.0003716 \text { FC: } 0.448\end{array}$ \\
\hline $\begin{array}{c}\text { A_23_P502464 (NOS2) } \\
\text { p-valor: } 0.0004816 \quad \text { FC: } 1.39\end{array}$ & $\begin{array}{c}\text { A_23_P502464 (NOS2) } \\
\text { p-valor: } 0.0004949 \text { FC: } 1.39\end{array}$ & $\begin{array}{l}\text { A_23_P502464 (NOS2) } \\
\text { p-valor: } 0.0004867 \text { FC: } 1.39\end{array}$ \\
\hline $\begin{array}{l}\text { A_24_P360674 (CDKN2B) } \\
\text { p-valor: } 0.0005366 \text { FC: } 0.999\end{array}$ & $\begin{array}{l}\text { A_24_P360674 (CDKN2B) } \\
\text { p-valor: } 0.0005359 \text { FC: } 0.999\end{array}$ & $\begin{array}{l}\text { A_24_P360674 (CDKN2B) } \\
\text { p-valor: } 0.0005276 \text { FC: } 1\end{array}$ \\
\hline $\begin{array}{c}\text { A_24_P96403 (RUNX1) } \\
\text { p-valor: } 0.0007275 \text { FC: }-0.56\end{array}$ & $\begin{array}{c}\text { A_24_P96403 (RUNX1) } \\
\text { p-valor: } 0.0006889 \text { FC: }-0.56\end{array}$ & $\begin{array}{l}\text { A_24_P96403 (RUNX1) } \\
\text { p-valor: } 0.0007471 \text { FC: }-0.556\end{array}$ \\
\hline $\begin{array}{l}\text { A_23_P219176 (RXRA) } \\
\text { p-valor: } 0.0009635 \text { FC: } 0.268\end{array}$ & $\begin{array}{c}\text { A_23_P219176 (RXRA) } \\
\text { p-valor: } 0.0009907 \text { FC: } 0.268\end{array}$ & $\begin{array}{l}\text { A_23_P219176 (RXRA) } \\
\text { p-valor: } 0.001094 \text { FC: } 0.266\end{array}$ \\
\hline $\begin{array}{l}\text { A_23_P210176 (ITGA6) } \\
\text { p-valor: } 0.001584 \text { FC: } 0.604\end{array}$ & $\begin{array}{l}\text { A_23_P210176 (ITGA6) } \\
\text { p-valor: } 0.001633 \text { FC: } 0.604\end{array}$ & $\begin{array}{l}\text { A_23_P210176 (ITGA6) } \\
\text { p-valor: } 0.00153 \text { FC: } 0.607\end{array}$ \\
\hline $\begin{array}{l}\text { A_23_P63896 (FAS) } \\
\text { p-valor: } 0.002064 \text { FC: } 0.424\end{array}$ & $\begin{array}{l}\text { A_23_P149678 (PIAS3) } \\
\text { p-valor: } 0.00229 \text { FC: }-0.562\end{array}$ & $\begin{array}{l}\text { A_23_P149678 (PIAS3) } \\
\text { p-valor: } 0.002266 \text { FC: }-0.562\end{array}$ \\
\hline $\begin{array}{c}\text { A_23_P149678 (PIAS3) } \\
\text { p-valor: } 0.002217 \text { FC: }-0.562\end{array}$ & $\begin{array}{c}\text { A_23_P63896 (FAS) } \\
\text { p-valor: } 0.002422 \text { FC: } 0.424\end{array}$ & $\begin{array}{c}\text { A_23_P63896 (FAS) } \\
\text { p-valor: } 0.002533 \text { FC: } 0.422\end{array}$ \\
\hline $\begin{array}{l}\text { A_32_P208076 (ITGA2) } \\
\text { p-valor: } 0.002574 \text { FC: } 0.47\end{array}$ & $\begin{array}{l}\text { A_32_P208076 (ITGA2) } \\
\text { p-valor: } 0.002624 \text { FC: } 0.47\end{array}$ & $\begin{array}{l}\text { A_32_P208076 (ITGA2) } \\
\text { p-valor: } 0.002605 \text { FC: } 0.469\end{array}$ \\
\hline $\begin{array}{c}\text { A_23_P396858 (FZD8) } \\
\text { p-valor: } 0.002909 \text { FC: }-0.614\end{array}$ & $\begin{array}{l}\text { A_23_P396858 (FZD8) } \\
\text { p-valor: } 0.002827 \text { FC: }-0.614\end{array}$ & $\begin{array}{l}\text { A_23_P396858 (FZD8) } \\
\text { p-valor: } 0.00272 \text { FC: }-0.616\end{array}$ \\
\hline $\begin{array}{l}\text { A_23_P151426 (FOXO1) } \\
\text { p-valor: } 0.003812 \text { FC: }-0.536\end{array}$ & $\begin{array}{l}\text { A_23_P151426 (FOXO1) } \\
\text { p-valor: } 0.003941 \text { FC: }-0.536\end{array}$ & $\begin{array}{c}\text { A_23_P151426 (FOXO1) } \\
\text { p-valor: } 0.003869 \text { FC: }-0.537\end{array}$ \\
\hline $\begin{array}{l}\text { A_24_P123190 (PLD1) } \\
\text { p-valor: } 0.004173 \text { FC: } 0.497\end{array}$ & $\begin{array}{l}\text { A_24_P123190 (PLD1) } \\
\text { p-valor: } 0.004176 \text { FC: } 0.497\end{array}$ & $\begin{array}{l}\text { A_23_P211957 (TGFBR2) } \\
\text { p-valor: } 0.004077 \text { FC: }-0.367\end{array}$ \\
\hline $\begin{array}{l}\text { A_24_P55971 (VEGFB) } \\
\text { p-valor: } 0.004256 \text { FC: }-0.544\end{array}$ & $\begin{array}{l}\text { A_24_P55971 (VEGFB) } \\
\text { p-valor: } 0.004192 \text { FC: }-0.544\end{array}$ & $\begin{array}{l}\text { A_24_P55971 (VEGFB) } \\
\text { p-valor: } 0.004187 \text { FC: }-0.543\end{array}$ \\
\hline $\begin{array}{l}\text { A_23_P211957 (TGFBR2) } \\
\text { p-valor: } 0.004305 \text { FC: }-0.366\end{array}$ & $\begin{array}{l}\text { A_23_P211957 (TGFBR2) } \\
\text { p-valor: } 0.004236 \text { FC: }-0.366\end{array}$ & $\begin{array}{l}\text { A_24_P123190 (PLD1) } \\
\text { p-valor: } 0.004474 \text { FC: } 0.491\end{array}$ \\
\hline $\begin{array}{c}\text { A_23_P206359 (CDH1) } \\
\text { p-valor: } 0.007431 \text { FC: } 0.608\end{array}$ & $\begin{array}{l}\text { A_23_P206359 (CDH1) } \\
\text { p-valor: } 0.007118 \text { FC: } 0.608\end{array}$ & $\begin{array}{l}\text { A_23_P206359 (CDH1) } \\
\text { p-valor: } 0.007082 \text { FC: } 0.608\end{array}$ \\
\hline $\begin{array}{l}\text { A_23_P343935 (EGLN1) } \\
\text { p-valor: } 0.01017 \text { FC: } 0.47\end{array}$ & $\begin{array}{l}\text { A_23_P343935 (EGLN1) } \\
\text { p-valor: } 0.009339 \text { FC: } 0.47\end{array}$ & $\begin{array}{l}\text { A_23_P343935 (EGLN1) } \\
\text { p-valor: } 0.009206 \text { FC: } 0.471\end{array}$ \\
\hline $\begin{array}{l}\text { A_23_P216812 (CDKN2B) } \\
\text { p-valor: } 0.01095 \text { FC: } 0.243\end{array}$ & $\begin{array}{l}\text { A_23_P216812 (CDKN2B) } \\
\text { p-valor: } 0.01103 \text { FC: } 0.243\end{array}$ & $\begin{array}{l}\text { A_23_P216812 (CDKN2B) } \\
\text { p-valor: } 0.009708 \text { FC: } 0.245\end{array}$ \\
\hline
\end{tabular}

Tabela 7.3: Tabela com os 21 genes das vias do câncer mais diferencialmente expressos para as variantes da base de dados que foram normalizadas com o parâmetro de suavização $\alpha$ igual a 0,2 . 


\begin{tabular}{|c|c|c|}
\hline $\begin{array}{l}\text { Dados intervalares } \\
\text { alpha estimado }\end{array}$ & $\begin{array}{l}\text { Médias melhoradas } \\
\text { alpha estimado }\end{array}$ & $\begin{array}{l}\text { Médias convencionais } \\
\text { alpha estimado }\end{array}$ \\
\hline $\begin{array}{c}\text { A_23_P155335 (PLD1) } \\
\text { p-valor: } 6.442 \mathrm{e}-05 \text { FC: } 1.03\end{array}$ & $\begin{array}{l}\text { A_23_P155335 (PLD1) } \\
\text { p-valor: } 6.578 \mathrm{e}-05 \text { FC: } 1.03\end{array}$ & $\begin{array}{l}\text { A_23_P155335 (PLD1) } \\
\text { p-valor: } 6.714 \mathrm{e}-05 \text { FC: } 1.03\end{array}$ \\
\hline $\begin{array}{c}\text { A_23_P61945 (MITF) } \\
\text { p-valor: } 0.0002557 \text { FC: }-0.686\end{array}$ & $\begin{array}{l}\text { A_23_P398774 (PLD1) } \\
\text { p-valor: } 0.0002521 \text { FC: } 0.432\end{array}$ & $\begin{array}{c}\text { A_23_P398774 (PLD1) } \\
\text { p-valor: } 0.0002402 \text { FC: } 0.431\end{array}$ \\
\hline $\begin{array}{c}\text { A_23_P398774 (PLD1) } \\
\text { p-valor: } 0.0002585 \text { FC: } 0.432\end{array}$ & $\begin{array}{c}\text { A_23_P61945 (MITF) } \\
\text { p-valor: } 0.0002676 \text { FC: }-0.686\end{array}$ & $\begin{array}{l}\text { A_23_P61945 (MITF) } \\
\text { p-valor: } 0.0002664 \text { FC: }-0.68\end{array}$ \\
\hline $\begin{array}{c}\text { A_23_P436138 (MAX) } \\
\text { p-valor: } 0.0004947 \text { FC: } 0.428\end{array}$ & $\begin{array}{c}\text { A_23_P436138 (MAX) } \\
\text { p-valor: } 0.0004922 \text { FC: } 0.428\end{array}$ & $\begin{array}{c}\text { A_23_P1594 (VEGFB) } \\
\text { p-valor: } 0.0003769 \text { FC: }-0.939\end{array}$ \\
\hline $\begin{array}{l}\text { A_23_P502464 (NOS2) } \\
\text { p-valor: } 0.0005262 \text { FC: } 1.37\end{array}$ & $\begin{array}{c}\text { A_23_P502464 (NOS2) } \\
\text { p-valor: } 0.0005502 \text { FC: } 1.37\end{array}$ & $\begin{array}{l}\text { A_23_P436138 (MAX) } \\
\text { p-valor: } 0.0004357 \text { FC: } 0.43\end{array}$ \\
\hline $\begin{array}{l}\text { A_24_P360674 (CDKN2B) } \\
\text { p-valor: } 0.0006138 \text { FC: } 0.979\end{array}$ & $\begin{array}{l}\text { A_24_P360674 (CDKN2B) } \\
\text { p-valor: } 0.0006128 \text { FC: } 0.979\end{array}$ & $\begin{array}{c}\text { A_23_P502464 (NOS2) } \\
\text { p-valor: } 0.0005179 \text { FC: } 1.37\end{array}$ \\
\hline $\begin{array}{c}\text { A_24_P96403 (RUNX1) } \\
\text { p-valor: } 0.0008009 \text { FC: }-0.557\end{array}$ & $\begin{array}{c}\text { A_24_P96403 (RUNX1) } \\
\text { p-valor: } 0.0007848 \text { FC: }-0.557\end{array}$ & $\begin{array}{l}\text { A_24_P360674 (CDKN2B) } \\
\text { p-valor: } 0.0005925 \text { FC: } 0.981\end{array}$ \\
\hline $\begin{array}{l}\text { A_23_P1594 (VEGFB) } \\
\text { p-valor: } 0.0008553 \text { FC: }-0.954\end{array}$ & $\begin{array}{l}\text { A_23_P1594 (VEGFB) } \\
\text { p-valor: } 0.0008391 \text { FC: }-0.954\end{array}$ & $\begin{array}{l}\text { A_24_P96403 (RUNX1) } \\
\text { p-valor: } 0.0007142 \text { FC: }-0.555\end{array}$ \\
\hline $\begin{array}{l}\text { A_23_P210176 (ITGA6) } \\
\text { p-valor: } 0.001671 \text { FC: } 0.633\end{array}$ & $\begin{array}{l}\text { A_23_P210176 (ITGA6) } \\
\text { p-valor: } 0.001595 \text { FC: } 0.633\end{array}$ & $\begin{array}{l}\text { A_23_P210176 (ITGA6) } \\
\text { p-valor: } 0.001435 \text { FC: } 0.637\end{array}$ \\
\hline $\begin{array}{l}\text { A_23_P219176 (RXRA) } \\
\text { p-valor: } 0.001683 \text { FC: } 0.251\end{array}$ & $\begin{array}{l}\text { A_23_P219176 (RXRA) } \\
\text { p-valor: } 0.001702 \text { FC: } 0.251\end{array}$ & $\begin{array}{l}\text { A_23_P219176 (RXRA) } \\
\text { p-valor: } 0.001714 \text { FC: } 0.25\end{array}$ \\
\hline $\begin{array}{l}\text { A_23_P149678 (PIAS3) } \\
\text { p-valor: } 0.002159 \text { FC: }-0.554\end{array}$ & $\begin{array}{c}\text { A_23_P149678 (PIAS3) } \\
\text { p-valor: } 0.002284 \text { FC: }-0.554\end{array}$ & $\begin{array}{l}\text { A_23_P149678 (PIAS3) } \\
\text { p-valor: } 0.002371 \text { FC: }-0.551\end{array}$ \\
\hline $\begin{array}{c}\text { A_32_P208076 (ITGA2) } \\
\text { p-valor: } 0.002556 \text { FC: } 0.482\end{array}$ & $\begin{array}{c}\text { A_32_P208076 (ITGA2) } \\
\text { p-valor: } 0.002525 \text { FC: } 0.482\end{array}$ & $\begin{array}{l}\text { A_32_P208076 (ITGA2) } \\
\text { p-valor: } 0.00275 \text { FC: } 0.478\end{array}$ \\
\hline $\begin{array}{l}\text { A_23_P63896 (FAS) } \\
\text { p-valor: } 0.002657 \text { FC: } 0.415\end{array}$ & $\begin{array}{l}\text { A_23_P396858 (FZD8) } \\
\text { p-valor: } 0.002821 \text { FC: }-0.601\end{array}$ & $\begin{array}{l}\text { A_23_P396858 (FZD8) } \\
\text { p-valor: } 0.002803 \text { FC: }-0.602\end{array}$ \\
\hline $\begin{array}{l}\text { A_23_P396858 (FZD8) } \\
\text { p-valor: } 0.002676 \text { FC: }-0.601\end{array}$ & $\begin{array}{c}\text { A_23_P63896 (FAS) } \\
\text { p-valor: } 0.002945 \text { FC: } 0.415\end{array}$ & $\begin{array}{c}\text { A_23_P63896 (FAS) } \\
\text { p-valor: } 0.002959 \text { FC: } 0.413\end{array}$ \\
\hline $\begin{array}{l}\text { A_24_P123190 (PLD1) } \\
\text { p-valor: } 0.004035 \text { FC: } 0.49\end{array}$ & $\begin{array}{l}\text { A_24_P123190 (PLD1) } \\
\text { p-valor: } 0.004049 \text { FC: } 0.49\end{array}$ & $\begin{array}{l}\text { A_24_P123190 (PLD1) } \\
\text { p-valor: } 0.004334 \text { FC: } 0.484\end{array}$ \\
\hline $\begin{array}{c}\text { A_24_P55971 (VEGFB) } \\
\text { p-valor: } 0.004344 \text { FC: }-0.547\end{array}$ & $\begin{array}{l}\text { A_24_P55971 (VEGFB) } \\
\text { p-valor: } 0.00439 \text { FC: }-0.547\end{array}$ & $\begin{array}{c}\text { A_24_P55971 (VEGFB) } \\
\text { p-valor: } 0.004369 \text { FC: }-0.545\end{array}$ \\
\hline $\begin{array}{l}\text { A_23_P151426 (FOXO1) } \\
\text { p-valor: } 0.005581 \text { FC: }-0.532\end{array}$ & $\begin{array}{c}\text { A_23_P151426 (FOXO1) } \\
\text { p-valor: } 0.005637 \text { FC: }-0.532\end{array}$ & $\begin{array}{l}\text { A_23_P151426 (FOXO1) } \\
\text { p-valor: } 0.005227 \text { FC: }-0.535\end{array}$ \\
\hline $\begin{array}{l}\text { A_23_P343935 (EGLN1) } \\
\text { p-valor: } 0.006585 \text { FC: } 0.497\end{array}$ & $\begin{array}{c}\text { A_23_P343935 (EGLN1) } \\
\text { p-valor: } 0.006398 \text { FC: } 0.497\end{array}$ & $\begin{array}{l}\text { A_23_P343935 (EGLN1) } \\
\text { p-valor: } 0.006084 \text { FC: } 0.499\end{array}$ \\
\hline $\begin{array}{c}\text { A_23_P206359 (CDH1) } \\
\text { p-valor: } 0.007105 \text { FC: } 0.616\end{array}$ & $\begin{array}{c}\text { A_23_P206359 (CDH1) } \\
\text { p-valor: } 0.007124 \text { FC: } 0.616\end{array}$ & $\begin{array}{l}\text { A_23_P206359 (CDH1) } \\
\text { p-valor: } 0.006479 \text { FC: } 0.619\end{array}$ \\
\hline $\begin{array}{l}\text { A_23_P211957 (TGFBR2) } \\
\text { p-valor: } 0.008641 \text { FC: }-0.357\end{array}$ & $\begin{array}{l}\text { A_23_P211957 (TGFBR2) } \\
\text { p-valor: } 0.00904 \text { FC: }-0.357\end{array}$ & $\begin{array}{l}\text { A_23_P211957 (TGFBR2) } \\
\text { p-valor: } 0.008438 \text { FC: }-0.357\end{array}$ \\
\hline $\begin{array}{l}\text { A_23_P216812 (CDKN2B) } \\
\text { p-valor: } 0.01148 \text { FC: } 0.239\end{array}$ & $\begin{array}{l}\text { A_23_P216812 (CDKN2B) } \\
\text { p-valor: } 0.01157 \text { FC: } 0.239\end{array}$ & $\begin{array}{l}\text { A_23_P216812 (CDKN2B) } \\
\text { p-valor: } 0.01003 \text { FC: } 0.242\end{array}$ \\
\hline
\end{tabular}

Tabela 7.4: Tabela com os 21 genes das vias do câncer mais diferencialmente expressos para as variantes da base de dados que foram normalizadas com um parâmetro de suavização $\alpha$ estimado. 


\begin{tabular}{|c|c|c|}
\hline $\begin{array}{l}\text { Dados intervalares } \\
\text { alpha } 0.2\end{array}$ & $\begin{array}{l}\text { Médias melhoradas } \\
\text { alpha } 0.2\end{array}$ & $\begin{array}{l}\text { Médias convencionais } \\
\text { alpha } 0.2\end{array}$ \\
\hline $\begin{array}{c}\text { A_23_P155335 (PLD1) } \\
\text { p-valor: } 6.504 \mathrm{e}-05 \text { FC: } 1.01\end{array}$ & $\begin{array}{c}\text { A_23_P155335 (PLD1) } \\
\text { p-valor: } 6.522 \mathrm{e}-05 \text { FC: } 1.01\end{array}$ & $\begin{array}{l}\text { A_23_P155335 (PLD1) } \\
\text { p-valor: } 6.416 \mathrm{e}-05 \text { FC: } 1.01\end{array}$ \\
\hline $\begin{array}{l}\text { A_23_P1594 (VEGFB) } \\
\text { p-valor: } 0.0002885 \text { FC: }-0.905\end{array}$ & $\begin{array}{c}\text { A_23_P1594 (VEGFB) } \\
\text { p-valor: } 0.0002708 \text { FC: }-0.905\end{array}$ & $\begin{array}{l}\text { A_23_P1594 (VEGFB) } \\
\text { p-valor: } 0.0002307 \text { FC: }-0.92\end{array}$ \\
\hline $\begin{array}{c}\text { A_23_P502464 (NOS2) } \\
\text { p-valor: } 0.0004816 \text { FC: } 1.39\end{array}$ & $\begin{array}{c}\text { A_23_P502464 (NOS2) } \\
\text { p-valor: } 0.0004949 \text { FC: } 1.39\end{array}$ & $\begin{array}{c}\text { A_23_P502464 (NOS2) } \\
\text { p-valor: } 0.0004867 \text { FC: } 1.39\end{array}$ \\
\hline $\begin{array}{l}\text { A_24_P360674 (CDKN2B) } \\
\text { p-valor: } 0.0005366 \text { FC: } 0.999\end{array}$ & $\begin{array}{l}\text { A_24_P360674 (CDKN2B) } \\
\text { p-valor: } 0.0005359 \text { FC: } 0.999\end{array}$ & $\begin{array}{l}\text { A_24_P360674 (CDKN2B) } \\
\text { p-valor: } 0.0005276 \text { FC: } 1\end{array}$ \\
\hline
\end{tabular}

Tabela 7.5: Tabela com genes mais diferencialmente expressos das vias do câncer, com p-valor menor que 0,01 e fold change maior que 0,9 ou menor que -0,9, obtidos nas variantes da base de dados que foram normalizados com o parâmetro de suavização $\alpha=0,2$.

\begin{tabular}{|c|c|c|}
\hline $\begin{array}{c}\text { Dados intervalares } \\
\text { alpha estimado }\end{array}$ & $\begin{array}{c}\text { Médias melhoradas } \\
\text { alpha estimado }\end{array}$ & $\begin{array}{c}\text { Médias convencionais } \\
\text { alpha estimado }\end{array}$ \\
\hline A_23_P155335 (PLD1) & A_23_P155335 (PLD1) & A_23_P155335 (PLD1) \\
p-valor: 6.442e-05 FC: 1.03 & p-valor: 6.578e-05 FC: 1.03 & p-valor: $6.714 \mathrm{e}-05$ FC: 1.03 \\
\hline A_23_P502464 (NOS2) & A_23_P502464 (NOS2) & A_23_P1594 (VEGFB) \\
p-valor: 0.0005262 FC: 1.37 & p-valor: 0.0005502 FC: 1.37 & p-valor: 0.0003769 FC: -0.939 \\
\hline A_24_P360674 (CDKN2B) & A_24_P360674 (CDKN2B) & A_23_P502464 (NOS2) \\
p-valor: 0.0006138 FC: 0.979 & p-valor: 0.0006128 FC: 0.979 & p-valor: 0.0005179 FC: 1.37 \\
A_23_P1594 (VEGFB) & A_23_P1594 (VEGFB) & A_24_P360674 (CDKN2B) \\
p-valor: 0.0008553 FC: -0.954 & p-valor: 0.0008391 FC: -0.954 & p-valor: 0.0005925 FC: 0.981 \\
\hline
\end{tabular}

Tabela 7.6: Tabela com genes mais diferencialmente expressos das vias do câncer, com p-valor menor que 0,01 e fold change maior que 0,9 ou menor que -0,9, obtidos nas variantes da base de dados que foram normalizados com o parâmetro de suavização $\alpha$ estimado. 


$\begin{array}{lcc}\text { Nome da via } & \mathrm{N}^{0} \text { de representantes } & \mathrm{N}^{0} \text { de genes na via } \\ \text { Vias do câncer } & 27 & 16 \\ \text { Carcinoma de pequenas células de pulmão } & 86 & 6 \\ \text { Regulação da sinalização nuclear SMAD2/3 } & 77 & 5 \\ \text { Eventos de tráfego da Arf6 } & 47 & 4 \\ \text { Desregulação transcricional no câncer } & 179 & 5 \\ \text { Câncer de tireoide } & 29 & 2 \\ \text { Via de sinalização PI3K-Akt } & 346 & 4 \\ \text { Via do câncer pancreático integrado } & 168 & 3 \\ \text { Via do câncer de mama integrado } & 61 & 2 \\ \text { Câncer pancreático } & 66 & 2 \\ \text { Via do receptor do fator de } & 455 & 4 \\ \text { crescimento epidérmico 1 (EGFR1) } & 225 & 3 \\ \text { Proteoglicanos no câncer } & 463 & 4 \\ \text { Hemostase } & \end{array}$

Tabela 7.7: As treze vias significantemente representadas (com q-valor abaixo de 1\%) pelos 21 genes da via do câncer que aparecem como diferencialmente expressos (p-valor abaixo de 0,01 sem filtragem por fold change).

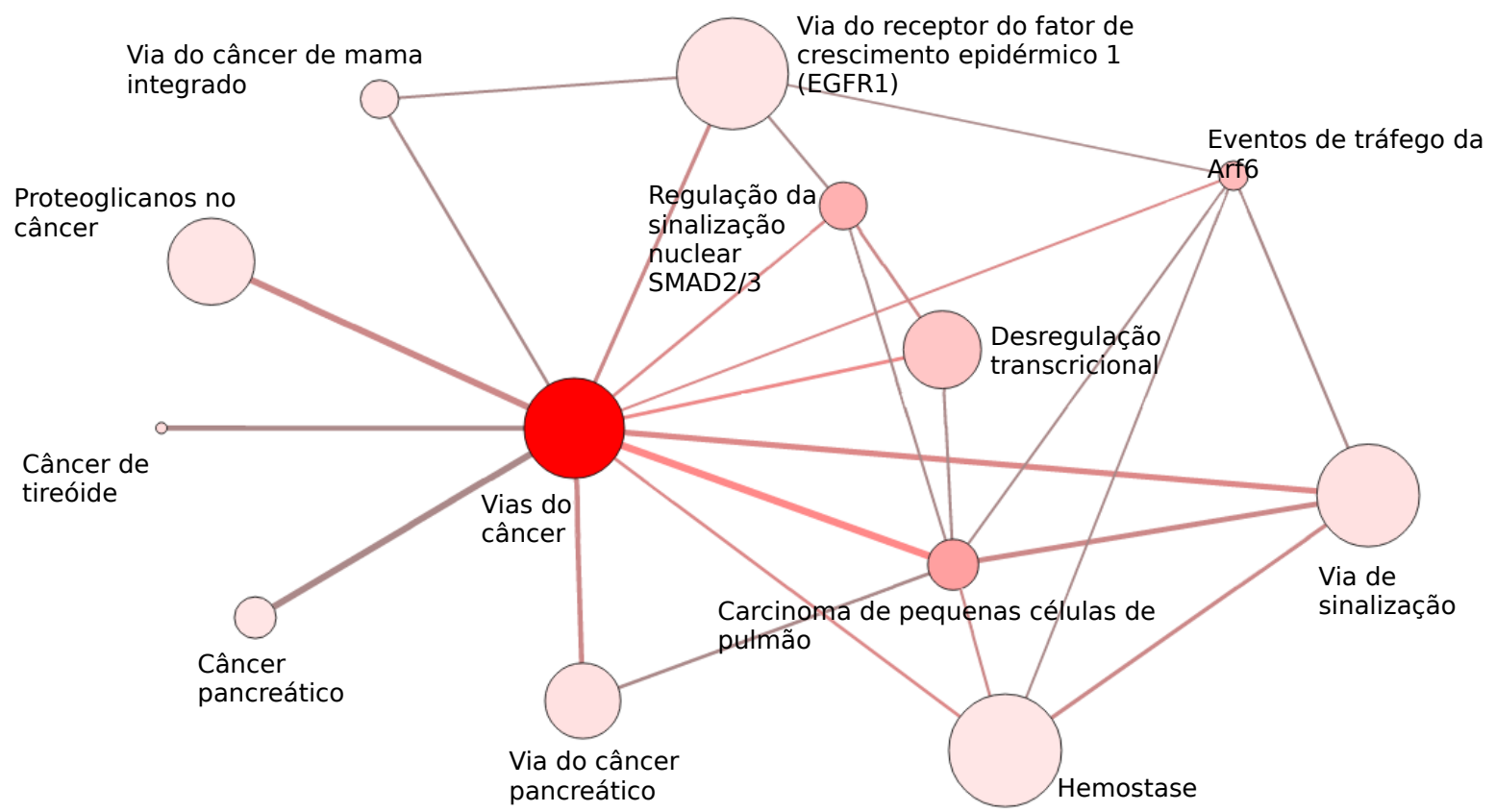

Figura 7.34: Relações entre as vias genéticas mostradas como significantemente representadas pelos genes listados na tabela 7.7. Imagem gerada pela ferramenta ConsensusPathDB Kamburov et al. (2009). 


$\begin{array}{lcc}\text { Nome da via } & \mathrm{N}^{\circ} \text { de representantes } & \mathrm{N}^{\circ} \text { de genes na via } \\ \text { Vias do câncer } & 4 & 327 \\ \text { Via de sinalização Ras } & 2 & 86 \\ \text { Carcinoma de pequenas células de pulmão } & 2 & 227\end{array}$

Tabela 7.8: As três vias significantemente representadas (com q-valor abaixo de 1\%) pelos 4 genes da via do câncer que aparecem como diferencialmente expressos (p-valor abaixo de 0,01 e fold change absoluto maior que 0.9).

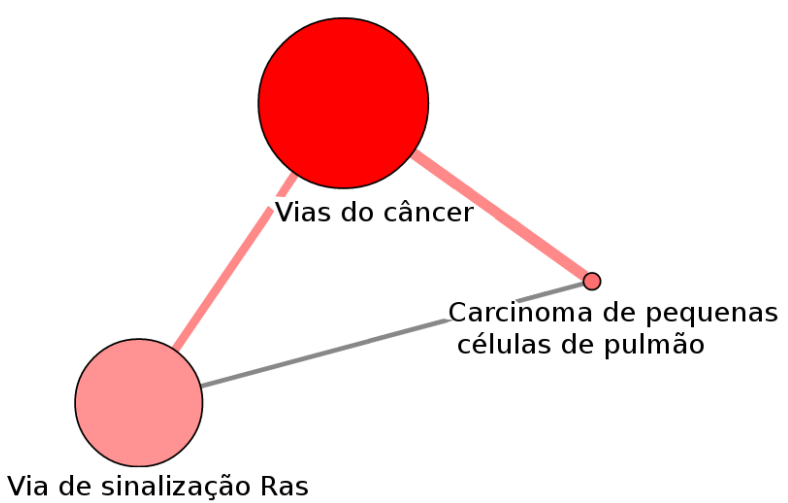

Figura 7.35: Relações entre as vias genéticas mostradas como significantemente representadas pelos genes listados na tabela 7.8. Imagem gerada pela ferramenta ConsensusPathDB Kamburov et al. (2009). 


\section{Capítulo 8}

\section{Conclusão}

Uma das maiores dificuldades da análise de experimentos de microarranjos é a determinação de medidas para as expressões gênicas que representem apenas a variabilidade biológica das amostras. Durante todo o experimento de microarranjos, desde a preparação das lâminas para a hibridização até a digitalização e extração dos níveis de intensidade de cada local genético, são introduzidos muitos ruídos das medidas das expressões gênicas. A análise deve ser feita a partir de dados que não correspondem a apenas a variabilidade de interesse, ou seja, a biológica. Qualquer ruído que não for devidamente removido, compromete a análise. Por isso, como vimos na seção 1.1, há tantos estudos para a determinação de um modelo que leve em conta todas essas variações e consiga, com alta confiabilidade, resíduos que representem apenas a variabilidade que estamos interessados.

O que nos motivou a fazermos este estudo é que muitas das estatísticas disponibilizadas pelos programas de análise das imagens dos microarranjos são desprezadas nas análises convencionais. Dentre elas, as medidas de variabilidade das intensidades de cada canal da lâmina. Assim, neste trabalho, propomos duas representações da expressão gênica que levam em consideração essas medidas de variabilidade e também mostramos como realizar as transformações nesses dados de forma a obtermos valores residuais que representem, de forma mais fiel, a variabilidade sem os erros sistêmicos.

Ambas as nossas propostas de representação da expressão gênica são estimativas para a média da variável $M_{i}$, que foi inicialmente proposta por Brown et al. (2001) e é dada, como vimos na equação (2.1), pelo logaritmo da razão entre as intensidades do canal da amostra de teste, $R_{i}$, e o canal da amostra de referência, $G_{i}$. A estimativa da média de $M_{i}$ é muito utilizada nas análises de dados de microarranjos de dois canais, porém a estimativa convencional, que denotamos nesse trabalho por $\hat{M}_{i}(2.2)$, é dada apenas utilizando uma medida de tendência central das intensidades de cada canal, como a média ou a mediana.

Dado que a variável $M_{i}$ é uma função das variáveis $R_{i}$ e $G_{i}$, utilizamos a extensão do Método Delta para o caso multivariado para obtermos uma estimativa de sua média a partir da expansão de Taylor de ordem dois dessa função. Nesse caso, utilizamos tanto as médias como as medidas de variância e covariância das intensidades dos canais para obtermos a média da expressão gênica. Essa estimativa, que denotamos por $\bar{M}_{i}(3.7)$, foi utilizada como nossa primeira representação da expressão gênica que leva em consideração a variabilidade das intensidades dos canais.

A segunda representação que propomos foi pelo intervalo que inclui, com uma confiança de, por exemplo, $95 \%$, a média de $M_{i}$. Para isso, utilizamos a estimativa $\bar{M}_{i}$ (3.7) para média e uma estimativa da variância também obtida utilizando o Método Delta multivariado, como pode ser visto na seção 3.2 .

Como comentamos, as medidas de expressão gênica observadas no experimento estão sob efeito de erros sistemáticos. As duas principais causas desses erros são a influência das intensidades do fundo e a dependência que o corante tem das intensidades.

Para a remoção do efeito das intensidades do fundo, usamos o método normexp com deslocamento de 50, um método bem conhecido na literatura e considerado o melhor para dados de experimentos de dois canais, segundo Ritchie et al. (2007). O deslocamento, que geralmente é re- 
comendado apanas para a redução da variabilidade das medidas de intensidades baixas, teve um papel essencial no nosso estudo, pois as representações que propomos para as expressões gênicas fazem a suposição de que as intensidades de cada canal são distantes do zero.

A remoção do viés causado pela dependência do corante é feita em um processo conhecido por normalização intra-lâmina. Como a estimação do viés é geralmente feita pelo método lowess, mostramos, nos capítulos 4 e 5, como utilizá-lo na normalização tanto dos dados representados pelas médias como também quando representados por intervalos. Levando em conta as características dos dados de expressão gênica, propomos um algoritmo de seleção dos parâmetros do lowess, em especial, a largura de banda $\alpha$, que determina a vizinhança de suavização. Com esse algoritmo, viabilizamos a aplicação do método lowess de forma adequada em todas as lâminas do experimento. Mostramos também como adaptar o método lowess e a seleção de seus parâmetros quando os dados são heteroscedásticos, uma característica quase sempre vista nos dados gênicos.

Com os dados pré-processados, podemos determinar os genes diferencialmente expressos, um dos maiores interesses da análise de expressões gênicas. A determinação desse genes a partir da análise das médias das expressões gênicas já é bem conhecida e fizemos uma breve discussão sobre ela na seção 2.6. Para a análise das expressões gênicas representadas por intervalos, mostramos, no capítulo 6, como podemos utilizar o modelo misto. Vimos como podemos discretizar os intervalos e, assim, obter as observações nos moldes de um experimento de medidas repetidas. Novamente, como os dados gênicos apresentam heteroscedasticidade, mostramos o modelo misto estendido, que permite a modelagem da função dessa variância.

Por fim, no capítulo 7, aplicamos os métodos de análise de expressões gênicas com erros de medida vistos nos capítulos 3 a 6 em uma base com dados de amostras de estômagos saudáveis, com inflamação e com metaplasia intestinal. Com o intuito de avaliar o impacto das representações da expressão gênica propostas e também o impacto do uso de uma largura de banda estimada no método de normalização, avaliamos e comparamos os resultados obtidos para cada uma das variantes resultantes da base de dados. Vimos que, nessa base de dados, essas modificações afetaram diretamente a determinação dos genes diferencialmente expressos. $\mathrm{O}$ uso de um parâmetro de suavização estimado para a normalização foi o fator que mais impactou na determinação dos genes diferencialmente expressos, já que os p-valores dos testes para médias iguais entre as amostras de expressões gênicas de estômagos saudáveis e com metaplasia de grau II foram maiores que os obtidos a partir dos dados normalizados com o parâmetro fixado em 0,2. Apesar dessas diferenças, os resultados obtidos entre todas as variantes da base de dados foram similares.

A análise para as amostras de estômagos com inflamação não nos permitiu rejeitar a hipótese de que esse fenótipo é igual ao das amostras de estômagos saudáveis. No entanto, após uma análise cuidadosa dos dados, conseguimos, para todas as variantes da base de dados, determinar muitos genes diferencialmente expressos (com p-valor abaixo de $0,001 \%$ e fold change absoluto maior que $0,9)$ entre as amostras de estômagos saudáveis e com metaplasia de grau II. Como os estudos com metaplasia intestinal do estômago não são escassos na literatura, não pudemos confirmar todos os resultados obtidos, porém, muitos deles estavam associados com doenças relacionadas, como com o câncer de estômago.

Como as diferenças entre as variantes da base com dados representadas pelas estimativas que consideram as imprecisões não foram muito grandes, não conseguimos resultados concretos para confirma o poder dessas abordagens. O uso do parâmetro de suavização do lowess estimado provocou um efeito maior, reduzindo o número de genes determinados como diferencialmente expressos quando escolhemos um p-valor de corte não muito pequeno.. No entanto, diante dos estudos apresentados especialmente no capítulo 4, acreditamos que a estimação desse parâmetro deve sempre feita para que a estimação do viés na normalização das lâminas seja a mais adequada possível, minimizando, portanto, tanto a perda de informações como a inclusão de novos ruídos.

Uma última consideração que devemos fazer sobre as conclusões desse trabalho é que elas foram principalmente baseadas em resultados obtidos em uma aplicação a uma única base de dados. Assim, com proposta de trabalho futuro, sugerimos a aplicação em mais bases de dados para a verificação da consistência dessas conclusões que obtivemos. Também sugerimos o uso dessas incertezas 
estimadas na determinação de classificadores moleculares, que também é de grande interesse da comunidade científica, e também a avalização do impacto dessa abordagem em relação à abordagem convencional. 


\section{Apêndice A}

\section{Resoluções e verificações}

\section{A.1 Resolução do problema de mínimos quadrados ponderados para a estimação de $\hat{\beta}$}

Consideremos $\beta \doteq\left(\beta_{\alpha}\right)_{|\alpha| \leq q}$ o vetor dos coeficientes da expansão de Taylor de ordem $q$, ao redor do ponto $x_{0} \in \mathbb{R}^{p}$, ordenado lexigraficamente. A estimativa desse vetor de coeficientes pode ser dada a partir da minimização da soma dos resíduos ponderados, ou seja,

$$
\hat{\beta}\left(x_{0}\right) \doteq\left(\hat{\beta}_{\alpha}\right)_{|\alpha| \leq q}\left(x_{0}\right)=\underset{\beta}{\arg \min } J_{x_{0}}(\beta)
$$

onde a função objetivo $J_{x_{0}}$ é dada por:

$$
J_{x_{0}}(\beta)=\sum_{i=1}^{n} \frac{\varphi_{i}}{\sigma^{2}\left(X_{i}\right)}\left(Y_{i}-\sum_{|\alpha| \leq q} \beta_{\alpha}\left(X_{i}-x_{0}\right)^{\alpha}\right)^{2}
$$

Para a minimização de $J_{x_{0}}(\beta)$, usaremos notação matricial. Para isso, considere:

- o vetor das funções bases polinomiais $F(v)=\left(v^{\alpha}\right)$, para $|\alpha| \leq q$, ordenado lexicograficamente;

- a aplicação linear $A$, onde $a_{i j}=\pi_{j}\left(F\left(X_{i}-x_{0}\right)\right)$;

- a aplicação linear $\tilde{P}$, definida pela matriz diagonal $n \times n$, onde $\tilde{p}_{i i}=\sqrt{\varphi_{i}}$, isto é, a raiz quadrada do peso dado a $X_{i}$ para a determinação da vizinhança de suavização;

- a aplicação linear $\tilde{S}$, definida pela matriz diagonal $n \times n$, onde $\tilde{s}_{i i}=1 / \sigma\left(X_{i}\right)$, isto é, o inverso do desvio padrão de $Y_{i}$, para a penalização das observações com maior variabilidade; e

- o vetor $y=\left(Y_{1}, \ldots, Y_{n}\right)$, com as observações independentes da variável resposta $Y$.

Assim, podemos escrever a soma dos quadrados dos resíduos como:

$$
\begin{aligned}
J_{x_{0}}(\beta) & =\sum_{i=1}^{n} \frac{\varphi_{i}}{\sigma^{2}\left(X_{i}\right)}\left(Y_{i}-F\left(X_{i}-x_{0}\right) \beta\right)^{2} \\
& =\langle\tilde{S} \tilde{P}(y-A \beta), \tilde{S} \tilde{P}(y-A \beta)\rangle \\
& =\|\tilde{S} \tilde{P}(y-A \beta)\|^{2} . \\
& =\|\tilde{S} \tilde{P} y\|^{2}-2\langle\tilde{S} \tilde{P} y, \tilde{S} \tilde{P} A \beta\rangle+\|\tilde{S} \tilde{P} A \beta\|^{2}
\end{aligned}
$$

O diferencial de primeira ordem de $J_{x_{0}}$ no ponto $\beta$, aplicado em $v$ é:

$$
D_{\beta} J_{x_{0}}(v)=-2\langle\tilde{S} \tilde{P} y, \tilde{S} \tilde{P} A(v)\rangle+2\langle\tilde{S} \tilde{P} A \beta, \tilde{S} \tilde{P} A(v)\rangle
$$


Enquanto o diferencial se segunda ordem de $J_{x_{0}}$ no ponto $\beta$, aplicado em $v$ é:

$$
D_{\beta}\left(D_{\beta} J_{x_{0}}\right)=2\langle\tilde{S} \tilde{P} A(v), \tilde{S} \tilde{P} A(v)\rangle=2\|\tilde{S} \tilde{P} A(v)\|^{2}>0
$$

Assim, para $D_{\beta} J_{x_{0}}=0$ temos:

$$
A^{t} \tilde{S}^{t} \tilde{S} \tilde{P}^{t} \tilde{P} A \hat{\beta}\left(x_{0}\right)=A^{t} \tilde{S}^{t} \tilde{S} \tilde{P}^{t} \tilde{P} y
$$

Assumindo que $A$ tem posto completo e, assim, $A^{t} \tilde{S}^{t} \tilde{S} \tilde{P} t \tilde{P} A$ é positiva definida, a única solução $\hat{\beta}\left(x_{0}\right)$ que minimiza $J_{x_{0}}$, ou seja, que anula $D_{\beta} J_{x_{0}}$, é dada por:

$$
\begin{aligned}
\hat{\beta}\left(x_{0}\right) & =\left(A^{t} \tilde{S}^{t} \tilde{S} \tilde{P}^{t} \tilde{P} A\right)^{-1} A^{t} \tilde{S}^{t} \tilde{S} \tilde{P}^{t} \tilde{P} y \\
& =\left(A^{t} V W A\right)^{-1} A^{t} V W y,
\end{aligned}
$$

onde $W$ é a aplicação linear definida pela matriz diagonal $n \times n$, onde $w_{i i}=\varphi_{i}$, e $V$ é a aplicação linear definida pela matriz diagonal $n \times n$, onde $v_{i i}=1 / \sigma^{2}\left(X_{i}\right)$.

Dessa forma, temos que:

$$
\hat{\mu}_{x_{0}}\left(x_{0}\right)=\hat{\beta}_{(0, \ldots, 0)}\left(x_{0}\right)=e_{1}^{t} \hat{\beta}\left(x_{0}\right)=e_{1}^{t}\left(A^{t} V W A\right)^{-1} A^{t} V W y
$$

Assim, podemos definir o diagrama de pesos:

$$
l\left(x_{0}\right)^{t} \doteq e_{1}^{t}\left(A^{t} V W A\right)^{-1} A^{t} V W .
$$

Resultando que

$$
\hat{\mu}_{x_{0}}\left(x_{0}\right)=\hat{\beta}_{(0, \ldots, 0)}\left(x_{0}\right)=l\left(x_{0}\right)^{t} y=\sum_{i=1}^{n} \pi_{i}\left(l\left(x_{0}\right)\right) Y_{i}
$$

Isso mostra que a estimativa $\hat{\mu}_{x_{0}}\left(x_{0}\right)$ é linear em $y$, como queríamos.

\section{A.2 Decomposição viés-variância do erro quadrático médio do es- timador}

O erro quadrático médio é definido por:

$$
\mathbb{E}\left((\mu(x)-\hat{\mu}(x))^{2}\right) .
$$
forma:

Lembrando que $\operatorname{Vies}(\hat{\mu})=\mathbb{E}(\hat{\mu})-\mu(x)$, o erro quadrático médio pode ser decomposto da seguinte

$$
\begin{aligned}
\mathbb{E}\left[(\mu-\hat{\mu})^{2}\right] & =\mathbb{E}\left[(\mu-\mathbb{E}(\hat{\mu})+\mathbb{E}(\hat{\mu})-\hat{\mu})^{2}\right] \\
& =\mathbb{E}\left[(\mu-\mathbb{E}(\hat{\mu}))^{2}\right]+2 \mathbb{E}[(\mu-\mathbb{E}(\hat{\mu}))(\mathbb{E}(\hat{\mu})-\hat{\mu})]+\mathbb{E}\left[(\mathbb{E}(\hat{\mu})-\hat{\mu})^{2}\right] \\
& =\operatorname{Vies}(\hat{\mu})^{2}+\operatorname{Var}(\hat{\mu})
\end{aligned}
$$

Pois,

$$
\begin{aligned}
\mathbb{E}[(\mu-\mathbb{E}(\hat{\mu}))(\mathbb{E}(\hat{\mu})-\hat{\mu})] & =\mathbb{E}\left[\hat{\mu} \mathbb{E}(\hat{\mu})-\mathbb{E}(\hat{\mu})^{2}-\hat{\mu} \mu+\mu \mathbb{E}(\hat{\mu})\right] \\
& =\mathbb{E}(\hat{\mu})^{2}-\mathbb{E}(\hat{\mu})^{2}-\mu \mathbb{E}(\hat{\mu})+\mu \mathbb{E}(\hat{\mu}) \\
& =0
\end{aligned}
$$

Essa é a conhecida decomposição viés-variância do erro quadrático médio. 


\section{A.3 Estimação da variância das observações $Y_{i}$ quando ela é cons- tante}

Uma forma de obtermos a estimativa de $\sigma^{2}$ é calculando a esperança da soma dos quadrados dos resíduos, isto é,

$$
\sum_{i=1}^{n} \mathbb{E}\left(\hat{\varepsilon}_{i}^{2}\right)=\mathbb{E}\left[\sum_{i=1}^{n}\left(Y_{i}-\hat{\mu}\left(X_{i}\right)\right)^{2}\right] .
$$

a partir da decomposição viés-variância de $\mathbb{E}\left[\left(Y_{i}-\hat{\mu}\left(X_{i}\right)\right)^{2}\right]$.

Para isso, usaremos que:

$$
\begin{aligned}
& \mu\left(X_{i}\right)=\mathbb{E}\left(Y_{i}\right) ; \\
& \mathbb{E}\left[\left(Y_{i}-\mu\left(X_{i}\right)\right)^{2}\right]=\operatorname{Var}\left(Y_{i}\right) ; \\
& \mathbb{E}\left[\left(\mu\left(X_{i}\right)-\mathbb{E}\left(\hat{\mu}\left(X_{i}\right)\right)\right]^{2}=\operatorname{Vies}^{2}\left(\hat{\mu}\left(X_{i}\right)\right) ;\right. \\
& \mathbb{E}\left[\mathbb{E}\left(\hat{\mu}\left(X_{i}\right)\right)-\hat{\mu}\left(X_{i}\right)\right]^{2}=\operatorname{Var}\left(\hat{\mu}\left(X_{i}\right)\right) ;
\end{aligned}
$$

e que

$$
\begin{aligned}
2 \mathbb{E}[ & \left.\left(Y_{i}-\mathbb{E}\left(Y_{i}\right)\right)-\left(\mathbb{E}\left(Y_{i}\right)-\mathbb{E}\left(\hat{\mu}\left(X_{i}\right)\right)\right)\right]+2 \mathbb{E}\left[\left(Y_{i}-\mathbb{E}\left(\hat{\mu}\left(X_{i}\right)\right)\right)-\left(\mathbb{E}\left(\hat{\mu}\left(X_{i}\right)\right)-\hat{\mu}\left(X_{i}\right)\right)\right] \\
= & 2\left(\mathbb{E}\left[Y_{i}\right]^{2}-\mathbb{E}\left[Y_{i} \mathbb{E}\left(\hat{\mu}\left(X_{i}\right)\right)\right]-\mathbb{E}\left[Y_{i}\right]^{2}+\mathbb{E}\left[Y_{i}\right] \mathbb{E}\left[\hat{\mu}\left(X_{i}\right)\right]+\mathbb{E}\left[Y_{i} \mathbb{E}\left(\hat{\mu}\left(X_{i}\right)\right)\right]-\right. \\
& \left.\mathbb{E}\left[Y_{i} \hat{\mu}\left(X_{i}\right)\right]-\mathbb{E}\left[\hat{\mu}\left(X_{i}\right)\right]^{2}+\mathbb{E}\left[\hat{\mu}\left(X_{i}\right)\right]^{2}\right) \\
= & -2\left(\mathbb{E}\left[Y_{i} \hat{\mu}\left(X_{i}\right)\right]-\mathbb{E}\left[Y_{i}\right] \mathbb{E}\left[\hat{\mu}\left(X_{i}\right)\right]\right) \\
= & -2 \operatorname{Cov}\left(Y_{i}, \hat{\mu}\left(X_{i}\right)\right) .
\end{aligned}
$$

Com isso, concluímos a decomposição:

$$
\begin{aligned}
\mathbb{E}\left[\left(Y_{i}-\hat{\mu}\left(X_{i}\right)\right)^{2}\right] & =\mathbb{E}\left[\left(\left(\left(Y_{i}-\mu\left(X_{i}\right)\right)+\left(\mu\left(X_{i}\right)-\mathbb{E}\left(\hat{\mu}\left(X_{i}\right)\right)\right)+\left(\mathbb{E}\left(\hat{\mu}\left(X_{i}\right)-\hat{\mu}\left(X_{i}\right)\right)\right)^{2}\right]\right.\right. \\
& =\operatorname{Var}\left(Y_{i}\right)+\operatorname{Vies}^{2}\left(\hat{\mu}\left(X_{i}\right)\right)+\operatorname{Var}\left(\hat{\mu}\left(X_{i}\right)\right)-2 \operatorname{Cov}\left(Y_{i}, \hat{\mu}\left(X_{i}\right)\right) .
\end{aligned}
$$

Isso mostra a dependência do viés da estimativa $\hat{\mu}\left(X_{i}\right)$ no cálculo da esperança do resíduo quadrado.

Para desenvolvermos essa expressão, usaremos agora a suposição de homoscedasticidade.

Como vimos em 4.8 , a variância de $\hat{\mu}(x)$ é dada por:

$$
\operatorname{Var}(\hat{\mu}(x))=\sum_{i=1}^{n} \pi_{i}(l(x))^{2} \sigma^{2}\left(X_{i}\right)
$$

Com a suposição de que $\sigma^{2}\left(X_{i}\right)=\sigma^{2} \forall i=1, \ldots, n$, temos que:

$$
\operatorname{Var}\left(\hat{\mu}\left(X_{i}\right)\right)=\sigma^{2}\left\|l\left(X_{i}\right)\right\|^{2}
$$

Lembrando que $\operatorname{Cov}\left(Y_{i}, Y_{j}\right)=0, \forall j \neq i$, pois as observações $Y_{i}$ são independentes, também usaremos o seguinte resultado: 


$$
\begin{aligned}
\operatorname{Cov}\left(Y_{i}, \hat{\mu}\left(X_{i}\right)\right) & =\operatorname{Cov}\left(Y_{i}, \sum_{i=1}^{n} \pi_{i}\left(l\left(X_{i}\right)\right) Y_{i}\right) \\
& =\pi_{i}\left(l\left(X_{i}\right)\right) \operatorname{Cov}\left(Y_{i}, Y_{i}\right)+\sum_{\substack{j=1 \\
j \neq i}}^{n} \pi_{j}\left(l\left(X_{i}\right)\right) \operatorname{Cov}\left(Y_{i}, Y_{j}\right) \\
& =\pi_{i}\left(l\left(X_{i}\right)\right) \operatorname{Var}\left(Y_{i}\right) \\
& =\sigma^{2} \pi_{i}\left(l\left(X_{i}\right)\right) .
\end{aligned}
$$

Assim, temos que:

$$
\begin{aligned}
\mathbb{E}\left[\sum_{i=1}^{n}\left(Y_{i}-\hat{\mu}\left(X_{i}\right)\right)^{2}\right] & =\sum_{i=1}^{n}\left[\operatorname{Var}\left(Y_{i}\right)+\operatorname{Vies}^{2}\left(\hat{\mu}\left(X_{i}\right)\right)+\operatorname{Var}\left(\hat{\mu}\left(X_{i}\right)\right)-2 \operatorname{Cov}\left(Y_{i}, \hat{\mu}\left(X_{i}\right)\right)\right] \\
& =\sum_{i=1}^{n}\left[\sigma^{2}+\operatorname{Vies}^{2}\left(\hat{\mu}\left(X_{i}\right)\right)+\sigma^{2}\left\|l\left(X_{i}\right)\right\|^{2}-2 \sigma^{2} \pi_{i}\left(l\left(X_{i}\right)\right)\right] \\
& =\sigma^{2}\left(n+\nu_{2}-2 \nu_{1}\right)+\sum_{i=1}^{n} \operatorname{Vies}^{2}\left(\hat{\mu}\left(X_{i}\right)\right) .
\end{aligned}
$$

A estimativa da variância das observações $Y_{i}$ é novamente dada assumindo que a estimava $\hat{\mu}\left(X_{i}\right)$ é não enviesada. Assim, temos:

$$
\hat{\operatorname{Var}}\left(Y_{i}\right)=\hat{\sigma}^{2} \doteq \frac{1}{n+\nu_{2}-2 \nu_{1}}\left[\sum_{i=1}^{n}\left(Y_{i}-\hat{\mu}\left(X_{i}\right)\right)^{2}\right] .
$$

Observe que

$$
n+\nu_{2}-2 \nu_{1}=\operatorname{tr}\left(\left(I_{n}-L\right)\left(I_{n}-L\right)^{t}\right)
$$

são os graus de liberdade residuais.

\section{A.4 Determinação do critério VCG}

Para determinarmos a estimativa VCG precisamos considerar o seguinte resultado:

Seja $\pi_{i}\left(l\left(X_{i}\right)\right)$ a $i$-ésima coordenada do diagrama de pesos. Se $\pi_{i}\left(l\left(X_{i}\right)\right)<1$, então vale que:

$$
\hat{\mu}_{-i}\left(X_{i}\right)=\frac{\hat{\mu}\left(X_{i}\right)-\pi_{i}\left(l\left(X_{i}\right)\right) Y_{i}}{1-\pi_{i}\left(l\left(X_{i}\right)\right)}
$$

A demonstração pode ser conferida em Loader (1999).

Assim, temos:

$$
\begin{aligned}
\operatorname{VC}(\hat{\mu}) & =\frac{1}{n} \sum_{i=1}^{n}\left(Y_{i}-\left(\frac{\hat{\mu}\left(X_{i}\right)-\pi_{i}\left(l\left(X_{i}\right)\right) Y_{i}}{1-\pi_{i}\left(l\left(X_{i}\right)\right)}\right)\right)^{2} \\
& =\frac{1}{n} \sum_{i=1}^{n}\left(\frac{Y_{i}-Y_{i} \pi_{i}\left(l\left(X_{i}\right)\right)-\hat{\mu}\left(X_{i}\right)+\pi_{i}\left(l\left(X_{i}\right)\right) Y_{i}}{1-\pi_{i}\left(l\left(X_{i}\right)\right)}\right)^{2} \\
& =\frac{1}{n} \sum_{i=1}^{n}\left(\frac{Y_{i}-\hat{\mu}\left(X_{i}\right)}{1-\pi_{i}\left(l\left(X_{i}\right)\right)}\right)^{2}
\end{aligned}
$$

Para obter a aproximação VCG, basta substituir $\pi_{i}\left(l\left(X_{i}\right)\right)$ do denominador da expressão do VC pela sua média, isto é, por $\sum_{i=1}^{n} \pi_{i}\left(l\left(X_{i}\right)\right) / n=\nu_{1} / n$.

Assim, temos: 


$$
\begin{aligned}
\operatorname{VCG}(\hat{\mu}) & =\frac{1}{n} \sum_{i=1}^{n}\left(\frac{Y_{i}-\hat{\mu}\left(X_{i}\right)}{1-\nu_{1} / n}\right)^{2} \\
& =\frac{1}{n}\left(\frac{n^{2}}{n^{2}-2 \nu_{1} n+\nu_{1}^{2}}\right) \sum_{i=1}^{n}\left(Y_{i}-\hat{\mu}\left(X_{i}\right)\right)^{2} \\
& =\frac{n}{\left(n-\nu_{1}\right)^{2}} \sum_{i=1}^{n}\left(Y_{i}-\hat{\mu}\left(X_{i}\right)\right)^{2}
\end{aligned}
$$

\section{A.5 Verificação do não enviesamento da estimativa Cp}

O critério $\mathrm{Cp}$ nos dá uma estimativa não enviesada de $\mathrm{R}(\mu, \hat{\mu})$, dado por:

$$
\mathrm{R}(\mu, \hat{\mu})=\frac{1}{\sigma^{2}} \sum_{i=1}^{n} \mathbb{E}\left[\left(\hat{\mu}\left(X_{i}\right)-\mu\left(X_{i}\right)\right)^{2}\right] .
$$

Isto é, $\mathbb{E}(\mathrm{Cp}(\hat{\mu}))=\mathbb{E}(\mathrm{R}(\hat{\mu}, \mu))$.

Para verificarmos, determinaremos inicialmente $\mathbb{E}(\mathrm{R}(\hat{\mu}, \mu))$ usando a decomposição de viésvariância para erro quadrático médio entre $\mu$ e $\hat{\mu}$ aplicadas em $X_{i}$. Assim, temos:

$$
\begin{aligned}
\mathbb{E}\left[\left(\hat{\mu}\left(X_{i}\right)-\mu\left(X_{i}\right)\right)^{2}\right] & =\operatorname{Vies}^{2}\left(\hat{\mu}\left(X_{i}\right)\right)+\operatorname{Var}\left(\hat{\mu}\left(X_{i}\right)\right) \\
& =\operatorname{Vies}^{2}\left(\hat{\mu}\left(X_{i}\right)\right)+\sigma^{2}\left\|l\left(X_{i}\right)\right\|^{2}
\end{aligned}
$$

Com isso, temos:

$$
\begin{aligned}
\mathbb{E}(\mathrm{R}(\hat{\mu}, \mu)) & =\frac{1}{\sigma^{2}} \sum_{i=1}^{n}\left(\operatorname{Vies}^{2}\left(\hat{\mu}\left(X_{i}\right)\right)+\sigma^{2}\left\|l\left(X_{i}\right)\right\|^{2}\right) \\
& =\frac{1}{\sigma^{2}}\left(\sum_{i=1}^{n}\left(\operatorname{Vies}^{2}\left(\hat{\mu}\left(X_{i}\right)\right)+\sigma^{2} \sum_{i=1}^{n}\left\|l\left(X_{i}\right)\right\|^{2}\right)\right. \\
& =\frac{1}{\sigma^{2}} \sum_{i=1}^{n}\left(\operatorname{Vies}^{2}\left(\hat{\mu}\left(X_{i}\right)\right)\right)+\nu_{2}
\end{aligned}
$$

Para determinarmos $\mathbb{E}(\mathrm{Cp}(\hat{\mu}))$, podemos usar a decomposição de $\mathbb{E}\left[\sum_{i=1}^{n}\left(Y_{i}-\hat{\mu}\left(X_{i}\right)\right)^{2}\right]$ obtida em (A.1).

Com isso, temos:

$$
\begin{aligned}
\mathbb{E}(\operatorname{Cp}(\hat{\mu})) & =\frac{1}{\sigma^{2}} \sum_{i=1}^{n}\left[\operatorname{Var}\left(Y_{i}\right)+\operatorname{Vies}^{2}\left(\hat{\mu}\left(X_{i}\right)\right)+\operatorname{Var}\left(\hat{\mu}\left(X_{i}\right)\right)-2 \operatorname{Cov}\left(Y_{i}, \hat{\mu}\left(X_{i}\right)\right)\right]-n+2 \nu_{1} \\
& =\frac{1}{\sigma^{2}}\left[\sigma^{2}\left(n+\nu_{2}-2 \nu_{1}\right)+\operatorname{Vies}^{2}\left(\hat{\mu}\left(X_{i}\right)\right)\right]-n+2 \nu_{1} \\
& =\frac{1}{\sigma^{2}} \sum_{i=1}^{n} \operatorname{Vies}^{2}\left(\hat{\mu}\left(X_{i}\right)\right)+\nu_{2} .
\end{aligned}
$$

$\mathrm{E}$, assim, concluímos que $\mathbb{E}(\mathrm{Cp}(\hat{\mu}))=\mathbb{E}(\mathrm{R}(\hat{\mu}, \mu))$, como queríamos. 


\section{A.6 Verificação do não enviesamento da estimativa HRCp}

O critério HRCp nos dá, a menos de uma constante, uma estimativa não enviesada de $\mathrm{R}(\mu, \hat{\mu})$, dado por:

$$
\mathrm{R}(\mu, \hat{\mu})=\sum_{i=1}^{n} \mathbb{E}\left[\left(\hat{\mu}\left(X_{i}\right)-\mu\left(X_{i}\right)\right)^{2}\right] .
$$

Isto é, $\mathbb{E}(\operatorname{HRCp}(\hat{\mu}))=\mathbb{E}(\mathrm{R}(\hat{\mu}, \mu))+\sum_{i=1}^{n} \sigma^{2}\left(X_{i}\right)$.

Para verificarmos, determinaremos inicialmente $\mathbb{E}(\mathrm{R}(\hat{\mu}, \mu))$ usando a decomposição de viésvariância para erro quadrático médio entre $\mu$ e $\hat{\mu}$ aplicadas em $X_{i}$. Assim, temos:

$$
\begin{aligned}
\mathbb{E}\left[\left(\hat{\mu}\left(X_{i}\right)-\mu\left(X_{i}\right)\right)^{2}\right] & =\operatorname{Vies}^{2}\left(\hat{\mu}\left(X_{i}\right)\right)+\operatorname{Var}\left(\hat{\mu}\left(X_{i}\right)\right) \\
& =\operatorname{Vies}^{2}\left(\hat{\mu}\left(X_{i}\right)\right)+\sum_{i=1}^{n} \pi_{i}\left(l\left(X_{i}\right)\right)^{2} \operatorname{Var}\left(Y_{i}\right) \\
& =\operatorname{Vies}^{2}\left(\hat{\mu}\left(X_{i}\right)\right)+\operatorname{tr}\left(\mathrm{L}^{t} \mathrm{~L} \Sigma\right),
\end{aligned}
$$

em que $\Sigma$ é uma matriz diagonal com entradas iguais a $\operatorname{Var}\left(Y_{i}\right)=\sigma^{2}\left(X_{i}\right)$ e L é a matriz de predição da estimativa $\hat{\mu}$.

Portanto,

$$
\begin{aligned}
\mathbb{E}(\mathrm{R}(\hat{\mu}, \mu)) & =\sum_{i=1}^{n}\left(\operatorname{Vies}^{2}\left(\hat{\mu}\left(X_{i}\right)\right)+\operatorname{tr}\left(\mathrm{L}^{t} \mathrm{~L} \Sigma\right)\right) \\
& =\sum_{i=1}^{n}\left(\operatorname{Vies}^{2}\left(\hat{\mu}\left(X_{i}\right)\right)+n \operatorname{tr}\left(\mathrm{L}^{t} \mathrm{~L} \Sigma\right)\right.
\end{aligned}
$$

Para determinarmos $\mathbb{E}(\operatorname{HRCp}(\hat{\mu}))$, podemos usar a decomposição de $\mathbb{E}\left[\sum_{i=1}^{n}\left(Y_{i}-\hat{\mu}\left(X_{i}\right)\right)^{2}\right]$ obtida em (A.1).

Com isso, temos:

$$
\begin{aligned}
\mathbb{E}(\operatorname{HRCp}(\hat{\mu})) & =\sum_{i=1}^{n}\left(\operatorname{Var}\left(Y_{i}\right)+\operatorname{Vies}^{2}\left(\hat{\mu}\left(X_{i}\right)\right)+\operatorname{Var}\left(\hat{\mu}\left(X_{i}\right)\right)-2 \operatorname{Cov}\left(Y_{i}, \hat{\mu}\left(X_{i}\right)\right)\right)+2 \operatorname{tr}(\Sigma \mathrm{L}) \\
& =\sum_{i=1}^{n}\left(\sigma^{2}\left(X_{i}\right)+\operatorname{Vies}^{2}\left(\hat{\mu}\left(X_{i}\right)\right)+\sum_{i=1}^{n} \pi_{i}\left(l\left(X_{i}\right)\right)^{2} \sigma^{2}\left(X_{i}\right)-2 \pi_{i}\left(l\left(X_{i}\right)\right) \sigma^{2}\left(X_{i}\right)\right)+2 \operatorname{tr}(\Sigma \mathrm{L}) \\
& =\sum_{i=1}^{n} \sigma^{2}\left(X_{i}\right)+\sum_{i=1}^{n} \operatorname{Vies}^{2}\left(\hat{\mu}\left(X_{i}\right)\right)+n \operatorname{tr}\left(\mathrm{L}^{t} \mathrm{~L} \Sigma\right)-2 \operatorname{tr}(\Sigma \mathrm{L})+2 \operatorname{tr}(\Sigma \mathrm{L}) \\
& =\sum_{i=1}^{n} \sigma^{2}\left(X_{i}\right)+\sum_{i=1}^{n} \operatorname{Vies}^{2}\left(\hat{\mu}\left(X_{i}\right)\right)+n \operatorname{tr}\left(\mathrm{L}^{t} \mathrm{~L} \Sigma\right) \\
& =\sum_{i=1}^{n} \sigma^{2}\left(X_{i}\right)+\mathbb{E}(\mathrm{R}(\hat{\mu}, \mu)) .
\end{aligned}
$$

$\mathrm{E}$, assim, concluímos que $\mathbb{E}(\operatorname{HRCp}(\hat{\mu}))=\sum_{i=1}^{n} \sigma^{2}\left(X_{i}\right)+\mathbb{E}(\mathrm{R}(\hat{\mu}, \mu))$, como queríamos. 


\section{Apêndice B}

\section{Estimação dos parâmetros por máxima verossimilhança}

A função de verossimilhança, denotada por $L$, é a função densidade de probabilidade dos dados, quando esses estão fixados, condicionada a certos parâmetros. Assim, ela é definida por:

$$
L\left(\beta, \theta, \sigma^{2} \mid M^{*}\right)=p\left(M^{*} \mid \beta, \theta, \sigma^{2}\right) .
$$

Dessa forma, precisamos determinar os parâmetros $\beta, \sigma^{2}$ e os demais parâmetros necessários para determinar a matriz de covariâncias $\Phi$, que serão representados por $\theta$.

As expressões analíticas dessas estimativas podem ser obtidas reescrevendo o modelo (6.3) da seguinte forma:

$$
M_{l}^{*}=X_{l} \beta+Z_{l} \gamma_{l}+\varepsilon_{l}=X_{l} \beta+\varepsilon_{l}^{*}, \quad l=1, \ldots, n,
$$

em que definimos $\varepsilon_{l}^{*} \doteq Z_{l} \gamma_{l}+\varepsilon_{l}$.

Como os componentes aleatórios $\gamma_{l}$ e $\varepsilon_{l}$ são independentes e com distribuição normal multivariada, a soma deles também é uma normal multivariada, com média 0 e matriz de covariâncias dada por (6.4), ou seja:

$$
\begin{aligned}
\operatorname{Cov}\left(\varepsilon_{l}^{*}\right) & =\operatorname{Cov}\left(Z_{l} \gamma_{l}+\varepsilon_{l}\right) \\
& =\operatorname{Cov}\left(M_{l}^{*}\right) \\
& =\sigma^{2} \Sigma_{l} .
\end{aligned}
$$

Então, $M_{l}^{*}$ são também independentes e seguem uma distribuição normal multivariada com média $X_{l} \beta$ e matriz de covariâncias $\sigma^{2} \Sigma_{l}$. Logo, a função densidade de probabilidade condicional de $M_{l}^{*}$ é dada por:

$$
p\left(M_{l}^{*} \mid \beta, \theta, \sigma^{2}\right)=\frac{1}{\left(\sigma \sqrt{2 \pi \operatorname{det}\left(\Sigma_{l}\right)}\right)^{m}} e^{-\frac{\left(M_{l}^{*}-X_{l} \beta\right)^{t} \Sigma_{l}^{-1}\left(M_{l}^{*}-X_{l} \beta\right)}{2 \sigma^{2}}} .
$$

Como pode ser verificado em Pinheiro e Bates (2000), temos que, para dados valores de $\theta$, os valores de $\beta$ e $\sigma^{2}$ que maximizam a função de verossimilhança são:

$$
\begin{gathered}
\hat{\beta}(\theta)=\left(\sum_{l=1}^{n} X_{l}^{t} \Sigma_{l}^{-1} X_{l}\right)^{-1} \sum_{l=1}^{n} X_{l}^{t} \Sigma_{l}^{-1} M_{l}^{*} ; \\
\hat{\sigma}^{2}(\theta)=\frac{\sum_{l=1}^{n}\left(M_{l}^{*}-X_{l} \hat{\beta}(\theta)\right)^{t} \Sigma_{l}^{-1}\left(M_{l}^{*}-X_{l} \hat{\beta}(\theta)\right)}{n m} .
\end{gathered}
$$

Essas expressões são importantes apenas para fins teóricos, mas computacionalmente elas são muito difíceis. 
Na seção B, veremos com mais detalhes uma abordagem bastante utilizada na prática, conhecida como pseudodado (Pinheiro e Bates (2000), em que são adicionadas pseudo-observações ao modelo e, assim, altera-se a contribuição da distribuição marginal dos efeitos aleatórios. Com a representação com pseudodados, veremos que a função de verossimilhança dos parâmetros, para dado um conjunto de dados $M_{l}^{*}$, será simplificada, possibilitando a estimação de $\beta, \theta$ e $\sigma^{2}$ em um algoritmo de otimização.

No entanto, como veremos também em mais detalhes na seção B, para simplificar o algoritmo de maximização, determina-se primeiro estimativas para os parâmetros $\beta$ e $\sigma^{2}$, condicionadas a $\theta$. As estimativas, $\hat{\beta}(\theta)$ e $\hat{\sigma}^{2}(\theta)$, que maximizam $L\left(\beta, \theta, \sigma^{2} \mid M^{*}\right)$, são então usadas para obtermos uma função de verossimilhança que depende apenas do parâmetro $\theta$ :

$$
L\left(\theta \mid M^{*}\right)=L\left(\hat{\beta}(\theta), \theta, \hat{\sigma}^{2}(\theta) \mid M^{*}\right) .
$$

Essa função, chamada de função de verossimilhança perfilada, reduz a dimensão do problema, por isso simplifica a computação.

Combinando técnicas de decomposição matricial, como a decomposição $Q R$ (Francis (1961) e Francis (1962)), é possível avaliar o valor da função de verossimilhança perfilada de forma computacionalmente rápida. Mais detalhes sobre a solução computacional podem ser vistos em Bates e Pinheiro (1998) e Pinheiro e Bates (2000).

\section{Estimação dos parâmetros}

Vimos que a função de verossimilhança $L$ é a função densidade de probabilidade para os dados fixados, condicionada a certos parâmetros. Ou seja:

$$
L\left(\beta, \theta, \sigma^{2} \mid M^{*}\right)=p\left(M^{*} \mid \beta, \theta, \sigma^{2}\right),
$$

em que $p$ é densidade de probabilidade e $M^{*} \in \mathbb{R}^{n m}$ é o vetor com todas as respostas.

Lembrando que os valores dos efeitos aleatórios $\gamma_{l}$ são parte do modelo e não são conhecidos, devemos integrar a densidade condicional $p\left(M^{*} \mid \beta, \theta, \sigma^{2}\right)$ em relação à densidade marginal dos efeitos aleatórios, obtendo, assim, a densidade marginal dos dados. Usando que as variáveis aleatórias $\gamma_{l}$ e $\varepsilon_{l}$ são independentes entre si, temos que:

$$
\begin{aligned}
L\left(\beta, \theta, \sigma^{2} \mid M^{*}\right) & =\prod_{l=1}^{n} p\left(M_{l}^{*} \mid \beta, \theta, \sigma^{2}\right) \\
& =\prod_{l=1}^{n} \int p\left(M_{l}^{*} \mid \gamma_{l}, \beta, \sigma^{2}\right) p\left(\gamma_{l} \mid \theta, \sigma^{2}\right) \mathrm{d} \gamma_{l} .
\end{aligned}
$$

A distribuição de probabilidade condicional das respostas $M_{l}^{*} \in \mathbb{R}^{m}$, quando fixada a lâmina $l$ e o efeito aleatório $\gamma_{l}$, é a seguinte normal multivariada:

$$
p\left(M_{l}^{*} \mid \gamma_{l}, \beta, \sigma^{2}\right)=\frac{1}{(\sigma \sqrt{2 \pi})^{m}} e^{-\frac{\left\|M_{l}^{*}-X_{l} \beta-Z_{l} \gamma_{l}\right\|^{2}}{2 \sigma^{2}}} .
$$

A densidade marginal de $\gamma_{l}$ também é uma normal multivariada:

$$
\begin{aligned}
p\left(\gamma_{l} \mid \theta, \sigma^{2}\right) & =\frac{1}{(\sqrt{2 \pi})^{q} \sqrt{|\Phi|}} e^{-\gamma_{l}^{t} \Phi^{-1} \gamma_{l}} \\
& =\frac{1}{(\sigma \sqrt{2 \pi})^{q}|1 / \operatorname{det}(\Delta)|} e^{-\frac{\left\|\Delta \gamma_{l}\right\|^{2}}{2 \sigma^{2}}},
\end{aligned}
$$

em que $\Delta$, conhecido como fator de precisão relativo, é qualquer matriz que satisfaça:

$$
\sigma^{2} \Phi^{-1}=\Delta^{t} \Delta
$$


Seu nome vem do fato de expressar a relação entre a matriz de precisão dos efeitos aleatórios $\Phi^{-1}$ e a precisão do erros intra-grupo, $1 / \sigma^{2}$. Sendo $\Phi$ uma matriz definida positiva, existe, embora não seja única, uma matriz $\Delta$ que satisfaz (B.6). Uma possibilidade para $\Delta$ é o fator Cholesky de $\sigma^{2} \Phi^{-1}$.

Substituindo em (B.3) as expressões para as densidades condicionais obtidas em (B.4) e (B.5), podemos reescrever a função de verossimilhança como:

$$
L\left(\beta, \theta, \sigma^{2} \mid M^{*}\right)=\prod_{l=1}^{n} \frac{|\operatorname{det}(\Delta)|}{\sigma(\sqrt{2 \pi})^{m}} \int \frac{1}{(\sigma \sqrt{2 \pi})^{q}} e^{-\frac{\left(\left\|M_{l}^{*}-X_{l} \beta-Z_{l} \gamma_{l}\right\|^{2}+\left\|\Delta \gamma_{l}\right\|^{2}\right)}{2 \sigma^{2}}} \mathrm{~d} \gamma_{l} .
$$

O numerador da exponencial da função de verossimilhança em (B.7) tem a forma de soma dos quadrados residuais penalizados, em que o primeiro termo,

$$
\left\|M_{l}^{*}-X_{l} \beta-Z_{l} \gamma_{l}\right\|^{2}
$$

é exatamente a soma dos quadrados dos resíduos para o l-ésimo fator de agrupamento ( $l$-ésima lâmina) e o termo adicional,

$$
\left\|\Delta \gamma_{l}\right\|^{2}
$$

pode ser visto como uma penalidade para o tamanho do vetor de efeitos aleatórios $\gamma_{l}$.

Em uma abordagem conhecida por pseudodado, podemos reescrever esse termo de penalização como

$$
\left\|\Delta \gamma_{l}\right\|^{2}=\left\|0+0 \beta-\Delta \gamma_{l}\right\|^{2}
$$

e, assim, obtemos

$$
\begin{aligned}
\left\|M_{l}^{*}-X_{l} \beta-Z_{l} \gamma_{l}\right\|^{2}+\left\|\Delta \gamma_{l}\right\|^{2} & =\left\|M_{l}^{*}-X_{l} \beta-Z_{l} \gamma_{l}\right\|^{2}+\left\|0+0 \beta-\Delta \gamma_{l}\right\|^{2} \\
& =\left\|\tilde{M}_{l}^{*}-\tilde{X}_{l} \beta-\tilde{Z}_{l} \gamma_{l}\right\|^{2},
\end{aligned}
$$

em que os novos componentes, $\tilde{M}_{l}^{*}, \tilde{X}_{l}$ e $\tilde{Z}_{l}$ são obtidos adicionando pseudo-observações aos dados originais:

$$
\tilde{M}_{l}^{*}=\left(M_{l}^{*}, 0\right), \quad \tilde{X}_{l}=\left(X_{l}, 0\right), \quad \tilde{Z}_{l}=\left(Z_{l}, \Delta\right),
$$

sendo que $\Delta$ é o fator de precisão relativo definido em (B.6).

Utilizando esses novos componentes, podemos reescrever a expressão da função de verossimilhança obtida em (B.7), alterando, assim, a contribuição da distribuição dos efeitos aleatórios:

$$
L\left(\beta, \theta, \sigma^{2} \mid M^{*}\right)=\prod_{l=1}^{n} \frac{|\operatorname{det}(\Delta)|}{\sigma(\sqrt{2 \pi})^{m}} \int \frac{1}{(\sigma \sqrt{2 \pi})^{q}} e^{-\frac{\left\|\tilde{M}_{l}^{*}-\tilde{X}_{l} \beta-\tilde{z}_{l} \gamma_{l}\right\|^{2}}{2 \sigma^{2}}} \mathrm{~d} \gamma_{l} .
$$

A norma quadrada dos resíduos que aparecem na exponencial da expressão da verossimilhança obtida em (B.9) pode ser reescrita da seguinte forma:

$$
\begin{aligned}
\left\|\tilde{M}_{l}^{*}-\tilde{X}_{l} \beta-\tilde{Z}_{l} \gamma_{l}\right\|^{2}= & \left\|\tilde{M}_{l}^{*}-\tilde{X}_{l} \beta-\tilde{Z}_{l} \gamma_{l}+\tilde{Z}_{l} \hat{\gamma}_{l}-\tilde{Z}_{l} \hat{\gamma}_{l}\right\|^{2} \\
= & \left\|\left(\tilde{M}_{l}^{*}-\tilde{X}_{l} \beta-\tilde{Z}_{l} \hat{\gamma}_{l}\right)+\left(\tilde{Z}_{l} \hat{\gamma}_{l}-\tilde{Z}_{l} \gamma_{l}\right)\right\|^{2} \\
= & \left\|\tilde{M}_{l}^{*}-\tilde{X}_{l} \beta-\tilde{Z}_{l} \hat{\gamma}_{l}\right\|^{2}+\left\|\tilde{Z}_{l}\left(\gamma_{l}-\hat{\gamma}_{l}\right)\right\|^{2}+ \\
& \quad 2\left\langle\left[\left(\tilde{M}_{l}^{*}-\tilde{X}_{l} \beta\right)-\tilde{Z}_{l} \hat{\gamma}_{l}\right],\left(\tilde{Z}_{l} \hat{\gamma}_{l}-\tilde{Z}_{l} \gamma_{l}\right)\right\rangle .
\end{aligned}
$$


No entanto, o último termo é igual a zero, pois

$$
\begin{aligned}
& \left\langle\left[\left(\tilde{M}_{l}^{*}-\tilde{X}_{l} \beta\right)-\tilde{Z}_{l} \hat{\gamma}_{l}\right],\left(\tilde{Z}_{l} \hat{\gamma}_{l}-\tilde{Z}_{l} \gamma_{l}\right)\right\rangle= \\
& \quad\left\langle\left(\tilde{M}_{l}^{*}-\tilde{X}_{l} \beta\right), \tilde{Z}_{l} \hat{\gamma}_{l}\right\rangle-\left\langle\tilde{Z}_{l} \hat{\gamma}_{l}, \tilde{Z}_{l} \hat{\gamma}_{l}\right\rangle+\left\langle\left(\tilde{M}_{l}^{*}-\tilde{X}_{l} \beta\right), \tilde{Z}_{l} \gamma_{l}\right\rangle-\left\langle\tilde{Z}_{l} \hat{\gamma}_{l}, \tilde{Z}_{l} \gamma_{l}\right\rangle
\end{aligned}
$$

e, considerando o resultado da teoria do problema de mínimos quadrados convencional, em que obtemos que a estimativa dos efeitos aleatórios, $\hat{\gamma}_{l}$, é igual a

$$
\hat{\gamma}_{l}=\left(\tilde{Z}_{l}^{t} \tilde{Z}_{l}\right)^{-1} \tilde{Z}_{l}^{t}\left(\tilde{M}_{l}^{*}-\tilde{X}_{l} \beta\right),
$$

temos que o segundo produto interno é igual ao primeiro,

$$
\begin{aligned}
\left\langle\tilde{Z}_{l} \hat{\gamma}_{l}, \tilde{Z}_{l} \hat{\gamma}_{l}\right\rangle & =\hat{\gamma}_{l}^{t} \tilde{Z}_{l}^{t} \tilde{Z}_{l}\left(\tilde{Z}_{l}^{t} \tilde{Z}_{l}\right)^{-1} \tilde{Z}_{l}^{t}\left(\tilde{M}_{l}^{*}-\tilde{X}_{l} \beta\right) \\
& =\hat{\gamma}_{l}^{t} \tilde{Z}_{l}^{t}\left(\tilde{M}_{l}^{*}-\tilde{X}_{l} \beta\right) \\
& =\left\langle\left(\tilde{M}_{l}^{*}-\tilde{X}_{l} \beta\right), \tilde{Z}_{l} \hat{\gamma}_{l}\right\rangle,
\end{aligned}
$$

e o quarto produto interno é igual ao terceiro,

$$
\begin{aligned}
\left\langle\tilde{Z}_{l} \hat{\gamma}_{l}, \tilde{Z}_{l} \gamma_{l}\right\rangle & =\left\langle\tilde{Z}_{l} \gamma_{l}, \tilde{Z}_{l} \hat{\gamma}_{l}\right\rangle \\
& =\gamma_{l}^{t} \tilde{Z}_{l}^{t} \tilde{Z}_{l}\left(\tilde{Z}_{l}^{t} \tilde{Z}_{l}\right)^{-1} \tilde{Z}_{l}^{t}\left(\tilde{M}_{l}^{*}-\tilde{X}_{l} \beta\right) \\
& =\gamma_{l}^{t} \tilde{Z}_{l}^{t}\left(\tilde{M}_{l}^{*}-\tilde{X}_{l} \beta\right) \\
& =\left\langle\left(\tilde{M}_{l}^{*}-\tilde{X}_{l} \beta\right), \tilde{Z}_{l} \gamma_{l}\right\rangle .
\end{aligned}
$$

Assim, podemos remover o último termo da expressão (B.10) e obtemos a seguinte decomposição da norma quadrada dos resíduos:

$$
\begin{aligned}
\left\|\tilde{M}_{l}^{*}-\tilde{X}_{l} \beta-\tilde{Z}_{l} \gamma_{l}\right\|^{2} & =\left\|\tilde{M}_{l}^{*}-\tilde{X}_{l} \beta-\tilde{Z}_{l} \hat{\gamma}_{l}\right\|^{2}+\left\|\tilde{Z}_{l}\left(\gamma_{l}-\hat{\gamma}_{l}\right)\right\|^{2} \\
& =\left\|\tilde{M}_{l}^{*}-\tilde{X}_{l} \beta-\tilde{Z}_{l} \hat{\gamma}_{l}\right\|^{2}+\left(\gamma_{l}-\hat{\gamma}_{l}\right)^{t} \tilde{Z}_{l}^{t} \tilde{Z}_{l}\left(\gamma_{l}-\hat{\gamma}_{l}\right) .
\end{aligned}
$$

A exponencial da equação (B.9) pode ser dividida em dois fatores, um para cada termo da expressão da norma dos resíduos obtida em (B.12). Como o primeiro fator não depende de $\gamma_{l}$, podemos tirá-lo para fora da integral. Assim, obtemos:

$$
\begin{aligned}
& \int \frac{1}{(\sigma \sqrt{2 \pi})^{q}} e^{-\frac{\left\|\tilde{M}_{l}^{*}-\tilde{X}_{l} \beta-\tilde{z}_{l} \gamma_{l}\right\|^{2}}{2 \sigma^{2}}} \mathrm{~d} \gamma_{l} \\
& =e^{-\frac{\left\|\tilde{M}_{l}^{*}-\tilde{X}_{l} \beta-\tilde{Z}_{l} \hat{\gamma}_{l}\right\|^{2}}{2 \sigma^{2}}} \int \frac{1}{(\sigma \sqrt{2 \pi})^{q}} e^{\frac{-\left(\gamma_{l}-\hat{\gamma}_{l}\right)^{t} \tilde{z}_{l}^{t} \tilde{z}_{l}\left(\gamma_{l}-\hat{\gamma}_{l}\right)}{2 \sigma^{2}}} \mathrm{~d} \gamma_{l}
\end{aligned}
$$

A integral da exponencial do segundo termo é, a menos de uma constante, a integral da função densidade da normal multivariada, que é igual a 1. Podemos, então, fazer o seguinte truque para obtermos essa constante: 


$$
\begin{aligned}
& \frac{\sqrt{\left|\tilde{Z}_{l}^{t} \tilde{Z}_{l}\right|}}{\sqrt{\left|\tilde{Z}_{l}^{t} \tilde{Z}_{l}\right|}} \int \frac{1}{(\sigma \sqrt{2 \pi})^{q}} e^{\frac{-\left(\gamma_{l}-\hat{\gamma}_{l}\right)^{t} \tilde{Z}_{l}^{t} \tilde{z}_{l}\left(\gamma_{l}-\hat{\gamma}_{l}\right)}{2 \sigma^{2}}} \mathrm{~d} \gamma_{l} \\
& =\frac{1}{\sqrt{\left|\tilde{Z}_{l}^{t} \tilde{Z}_{l}\right|}} \int \frac{1}{(\sigma \sqrt{2 \pi})^{q}\left(\left|\tilde{Z}_{l}^{t} \tilde{Z}_{l}\right|\right)^{-1}} e^{\frac{-\left(\gamma_{l}-\hat{\gamma}_{l}\right)^{t} \tilde{z}_{l}^{t} \tilde{Z}_{l}\left(\gamma_{l}-\hat{\gamma}_{l}\right)}{2 \sigma^{2}}} \mathrm{~d} \gamma_{l} \\
& =\frac{1}{\sqrt{\left|\tilde{Z}_{l}^{t} \tilde{Z}_{l}\right|}} .
\end{aligned}
$$

Assim, a expressão da integral (B.13) pode ser reescrita como:

$$
\int \frac{1}{(\sigma \sqrt{2 \pi})^{q}} e^{-\frac{\left\|\tilde{M}_{l}^{*}-\tilde{X}_{l} \beta-\tilde{Z}_{l} \gamma_{l}\right\|^{2}}{2 \sigma^{2}}} \mathrm{~d} \gamma_{l}=\frac{1}{\sqrt{\left|\tilde{Z}_{l}^{t} \tilde{Z}_{l}\right|}} e^{-\frac{\left\|\tilde{M}_{l}^{*}-\tilde{X}_{l} \beta-\tilde{Z}_{l} \hat{\gamma}_{l}\right\|^{2}}{2 \sigma^{2}}} .
$$

Considerando que para todas as lâminas temos a mesma quantidade $m$ de réplicas, temos $\sum_{l=1}^{n} m=n m$. Então, voltando à expressão da função de verossimilhança obtida em (B.9), substituímos a integral pela expressão obtida em (B.14) e obtemos a função de verossimilhança simplificada:

$$
\begin{gathered}
L\left(\beta, \theta, \sigma^{2} \mid M^{*}\right)=\prod_{l=1}^{n} \frac{|\operatorname{det}(\Delta)|}{\sigma(\sqrt{2 \pi})^{m}} \frac{1}{\sqrt{\left|\tilde{Z}_{l}^{t} \tilde{Z}_{l}\right|}} e^{-\frac{\left\|\tilde{M}_{l}^{*}-\tilde{X}_{l} \beta-\tilde{Z}_{l} \hat{\gamma}_{l}\right\|^{2}}{2 \sigma^{2}}} \\
=\frac{1}{\sigma(\sqrt{2 \pi})^{n m}} e^{-\frac{\sum_{l=1}^{n}\left\|\tilde{M}_{l}^{*}-\tilde{x}_{l} \beta-\tilde{Z}_{l} \hat{\gamma}_{l}\right\|^{2}}{2 \sigma^{2}}} \prod_{l=1}^{n} \frac{|\operatorname{det}(\Delta)|}{\sqrt{\left|\tilde{Z}_{l}^{t} \tilde{Z}_{l}\right|}}
\end{gathered}
$$

Com a função de verossimilhança simplificada (B.15), já é possível obter, em um problema de otimização, os valores dos parâmetros $\beta, \theta$ e $\sigma^{2}$. Entretanto, uma abordagem mais simples é obter estimativas condicionais para os parâmetros $\beta(\theta)$ e $\sigma^{2}(\theta)$ e, assim, maximizar $L\left(\beta, \theta, \sigma^{2}\right)$ para um dado $\theta$. A função de verossimilhança com os valores estimados $\hat{\beta}(\theta)$ e $\hat{\sigma}^{2}(\theta)$ é conhecida como função de verossimilhança perfilada.

Para obter os valores de $\hat{\beta}(\theta)$ e $\hat{\sigma}^{2}(\theta)$, podemos utilizar a teoria clássica de regressão linear, já que os termos que envolvem esses parâmetros na equação (B.15) já estão na forma esperada.

Um cuidado, no entanto, é estimar $\beta$ junto com os efeitos aleatórios $\gamma_{l}$, já que as estimativas por mínimos quadrados de $\beta$ dependem de $\gamma_{l}$, e $\gamma_{l}$, por sua vez, depende de $\beta$.

Assim, temos que:

$$
\left(\hat{\gamma}_{1}, \hat{\gamma}_{2}, \ldots, \hat{\gamma}_{n}, \hat{\beta}\right)=\underset{\gamma_{1}, \gamma_{2}, \ldots, \gamma_{n}, \beta}{\arg \min }\left\|M_{e}^{*}-X_{e}\left(\gamma_{1}, \gamma_{2}, \ldots, \gamma_{n}, \beta\right)\right\|^{2},
$$

em que, $\left(\hat{\gamma}_{1}, \hat{\gamma}_{2}, \ldots, \hat{\gamma}_{n}, \hat{\beta}\right) \in \mathbb{R}^{n+p}$ é o vetor com os parâmetros estimados. O operador linear $X_{e}$, definido pela matriz $2(m+q) \times q(n+1)$, e o vetor das respostas aumentado $M_{e}^{*} \in \mathbb{R}^{2 n}$, são da seguinte forma:

$$
X_{e}=\left(\begin{array}{ccccc}
Z_{1} & 0 & \cdots & 0 & X_{1} \\
\Delta & 0 & \cdots & 0 & 0 \\
0 & Z_{2} & \cdots & 0 & X_{2} \\
0 & \Delta & \cdots & 0 & 0 \\
\vdots & \vdots & \vdots & \vdots & \vdots \\
0 & 0 & \cdots & Z_{n} & X_{n} \\
0 & 0 & \cdots & \Delta & 0
\end{array}\right) \quad e \quad M_{e}^{*}=\left(\begin{array}{c}
M_{1}^{*} \\
0 \\
M_{2}^{*} \\
0 \\
\vdots \\
M_{n}^{*} \\
0
\end{array}\right)
$$

A solução para esse problema de otimização é:

$$
\left(\hat{\gamma}_{1}, \hat{\gamma}_{2}, \ldots, \hat{\gamma}_{n}, \hat{\beta}\right)=\left(X_{e}^{t} X_{e}\right)^{-1} X_{e}^{t} M_{e}^{*}
$$


Da teoria de regressão linear, também obtemos a estimativa de máxima verossimilhança para $\sigma^{2}$, que é dada por:

$$
\hat{\sigma}^{2}=\frac{\left\|M_{e}^{*}-X_{e}\left(\hat{\gamma}_{1}, \hat{\gamma}_{2}, \ldots, \hat{\gamma}_{n}, \hat{\beta}\right)\right\|^{2}}{n m} .
$$

Alguns métodos computacionais, como decomposição $Q R$, fazem uso da esparsidade dessas matrizes e tornam o cálculo desses estimadores computacionalmente eficiente. Mais detalhes podem ser vistos em Bates e Pinheiro (1998).

Substituindo a estimativa $\hat{\sigma}^{2}$ em (B.15), obtemos a função de verossimilhança perfilada. Como o numerador da exponencial se cancela com o numerador da estimativa $\hat{\sigma}^{2}$, temos:

$$
L(\theta)=L\left(\hat{\beta}(\theta), \theta, \hat{\sigma}^{2}(\theta)\right)=\frac{e^{\frac{-n m}{2}}}{(\hat{\sigma}(\theta) \sqrt{2 \pi})^{n m}} \prod_{l=1}^{n} \frac{|\operatorname{det}(\Delta)|}{\sqrt{\left|\tilde{Z}_{l}^{t} \tilde{Z}_{l}\right|}} .
$$

Lembrando ainda que $\tilde{Z}=\left(Z_{l}, \Delta\right)($ B.8), podemos obter a expressão para a função de verossimilhança perfilada apenas com os dados originais:

$$
L(\theta)=L\left(\hat{\beta}(\theta), \theta, \hat{\sigma}^{2}(\theta)\right)=\frac{e^{\frac{-n m}{2}}}{(\hat{\sigma}(\theta) \sqrt{2 \pi})^{n m}} \prod_{l=1}^{n} \frac{|\operatorname{det}(\Delta)|}{\sqrt{\left|Z_{l}^{t} Z_{l}+\Delta^{t} \Delta\right|}} .
$$

A estimativa de máxima verossimilhança $\hat{\theta}$ é obtida, comumente, maximizando o logaritmo da função de verossimilhança perfilada (B.18) em relação à $\theta$. Com essa estimativa, podemos obter as estimativas $\hat{\beta}(\hat{\theta})$ e $\hat{\sigma}^{2}(\hat{\theta})$.

Embora não sejam formalmente parâmetros do modelo, é possível obter estimativas dos efeitos aleatórios $\gamma_{l}(\theta)$. Quando esses estimadores são obtidos condicionados ao valor estimado de $\beta(\theta)$, são considerados BLUPs (Best Linear Unbiased Predictors). Na prática, o vetor desconhecido $\theta$ é substituído pela sua estimativa de máxima verossimilhança $\hat{\theta}$, assim, obtemos estimativas BLUPs $\hat{\gamma}_{l}(\hat{\theta})$.

\section{Estimativa enviesada da variância}

Podemos observar que o denominador da expressão da estimativa de máxima verossimilhança para $\sigma^{2}$, em (B.16), é $n m$, não $n m-p$. Ou seja, os graus de liberdade são obtidos sem considerar a existência dos efeitos fixos, tornando a estimação enviesada. Com isso, a estimação dos componentes de variância é geralmente subestimada pelo método de máxima verossimilhança.

Os autores Patterson e Thompson (1971) desenvolveram um método para obter as estimativas não enviesadas para os componentes da variância baseado no princípio da máxima verossimilhança, chamado máxima verossimilhança restrita ou residual (REML - Restricted (or Residual) Maximum Likelihood).

Muitos autores, incluindo Harville (1977), preferem usar o método de máxima verossimilhança restrita para estimar essas quantidades aleatórias.

O critério de estimação da função de máxima verossimilhança restrita é definida, usando a notação de Laird e Ware (1982), por uma função $L_{R}$ que não depende de $\beta$ :

$$
L_{R}\left(\theta, \sigma^{2} \mid y\right)=\int L\left(\beta, \theta, \sigma^{2} \mid y\right) \mathrm{d} \beta .
$$

Nesse critério, assume-se uma distribuição a priori localmente uniforme para os efeitos fixos $\beta$ e, assim, integra-se a função de verossimilhança $L$ convencional em relação a $\beta$.

Com técnicas semelhantes às usadas no método de estimação por máxima verossimilhança, conseguimos obter a seguinte expressão para a variância condicional estimada:

$$
\hat{\sigma}_{R}^{2}(\theta)=\frac{\left\|M_{e}^{*}-X_{e}\left(\hat{\gamma}_{1}, \hat{\gamma}_{2}, \ldots, \hat{\gamma}_{n}, \hat{\beta}\right)\right\|^{2}}{n m-p} .
$$


Assim como antes, podemos obter o valor estimado da máxima verossimilhança restrita, maximizando a função de verossimilhança restrita perfilada em relação à $\theta$ apenas. A partir da estimativa $\hat{\theta}_{R}$, é possível obter uma estimativa para $\sigma^{2}$, dada por $\hat{\sigma}^{2}\left(\hat{\theta}_{R}\right)$.

Os componentes aleatórios $\gamma_{l}$ podem ser estimados também substituindo $\theta$ por $\hat{\theta}_{R}$, sendo assim consideradas também estimativas BLUPs.

Além disso, como pode ser visto em Pinheiro e Bates (2000), é possível dar um bom chute para a estimativa de $\beta$, se avaliarmos a expressão de $\hat{\beta}(\theta)$, obtida pelo método de máxima verossimilhança, utilizando $\hat{\theta}_{R}$ como estimativa de $\theta$. 
APÊNDICE B 


\section{Apêndice C}

\section{Breve introdução à tecnologia Agilent}

A Agilent Technologies, juntamente com Rosetta Biosoftware, combinou algumas das melhores características da tecnologia de microarranjos de cDNA e da tecnologia da Affymetrix e está sendo bem aceita no mercado.

Da tecnologia de microarranjos de cDNA, foi herdada a característica de que cada local da lâmina corresponde a um gene e que é possível hibridizar duas amostras simultaneamente na lâmina de microarranjos.

No entanto, diferentemente da tecnologia com microarranjos de cDNA, em que fragmentos de clones de moléculas de DNA complementar (cDNA), amplificados por reação em cadeia da polimerase (PCR), são depositados em locais específicos da lâmina, na tecnologia Agilent, sequências pequenas de DNA ou até genes inteiros são sintetizadas diretamente na lâmina.

Essa característica, conhecida como fabricação in situ, foi herdada da tecnologia da Affymetrix (Santa Clara, CA). Ela traz uma grande vantagem em relação aos microarranjos de cDNA já que, como não há mais a necessidade dos processos de clonagem, amplificação e de depósito dos fragmentos nas lâminas, que introduzem muito ruído, os experimentos são mais confiáveis. Também, com essa tecnologia, é possível a fabricação de lâminas de alta densidade, no sentido de que, em lâminas pequenas, é possível ter uma grande quantidade de locais genéticos representados.

Como discutido em Drăghici (2012), o método de fabricação da Affymetrix, em que os fragmentos de DNA são construídos base por base usando máscaras fotolitográficas, apresenta desvantagens. Uma delas é que o comprimento das sequências de DNA construídas é limitado. Isso porque existe uma probabilidade, embora pequena, de introduzir um erro em cada passo da fabricação. Por causa disso, são necessários vários locais genéticos para representar um gene, tornando a análise dos dados muito mais difícil quando comparada à realizada nos experimentos de microarranjos de cDNA. Na tecnologia da Affymetrix, também não é possível hibridizar duas amostras diferentes na mesma lâmina. Se desejarmos estudar a diferença entre expressões gênicas de duas amostras, precisaremos realizar duas hibridações separadamente.

A técnica utilizada pela Agilent elimina essas desvantagens. Conhecida como ink-jet, a tecnologia utiliza a ideia das impressoras coloridas à tinta. Quatro cartuchos são carregados com diferentes nucleotídeos (A, C, G e T) e, conforme a cabeça de impressão se move ao longo do subtrato do arranjo, nucleotídeos específicos são depositados nos locais necessários formando as sequências de DNA. Com essa tecnologia é possível construir fragmentos muito grandes e, assim, ter apenas um local genético para representar cada gene. Também é possível hibridizar duas amostras simultaneamente, tornando essa tecnologia muito parecida com a dos microarranjos de cDNA, mas com bem menos erros, já que cada fragmento é sintetizado diretamente na lâmina.

Devido às semelhanças com a tecnologia já bem conhecida e trabalhada dos microarranjos de cDNA, podemos utilizar os mesmos métodos de análise para os dados da plataforma Agilent. Isso inclui os métodos apresentados neste trabalho, que são direcionados às lâminas de microarranjos de cDNA. Além disso, como pode ser visto em Zahurak et al. (2007), os procedimentos já comumente usados em microarranjos de cDNA têm apresentado resultados muitos bons, até mesmo melhores que os métodos de pré-processamento fornecidos pela Agilent. 
APÊNDICE C 


\section{Referências Bibliográficas}

Angelescu et al. (2013) Cristina Angelescu, Florin Burada, Mihai Ioana, Radu Angelescu, Emil Moraru, Anca Riza, Sanda Marchian, Francisc Mixich, Mihai Cruce e Adrian Săftoiu. Vegf-a and vegf-b mrna expression in gastro-oesophageal cancers. Clinical and Translational Oncology, 15 (4):313-320. Citado na pág. 126

Bakewell e Wit (2005) David J Bakewell e Ernst Wit. Weighted analysis of microarray gene expression using maximum-likelihood. Bioinformatics, 21(6):723-729. Citado na pág. 3

Barr e Sherrill (1999) Donald R Barr e E Todd Sherrill. Mean and variance of truncated normal distributions. The American Statistician, 53(4):357-361. Citado na pág. 13

Bates e Pinheiro (1998) Douglas M Bates e José C Pinheiro. Computational methods for multilevel modelling. Madison, WI: University of Wisconsin. Citado na pág. 144, 148

Benjamini e Hochberg (1995) Yoav Benjamini e Yosef Hochberg. Controlling the false discovery rate: a practical and powerful approach to multiple testing. Journal of the Royal Statistical Society. Series B (Methodological), páginas 289-300. Citado na pág. 18

Beran (1988) Rudolf Beran. Prepivoting test statistics: a bootstrap view of asymptotic refinements. Journal of the American Statistical Association, 83(403):687-697. Citado na pág. 62

Berry e Feldman (1985) William D Berry e Stanley Feldman. Multiple regression in practice. Number 50. Sage. Citado na pág. 35

Birbe et al. (2005) Ruth Birbe, Juan P Palazzo, Rhonda Walters, David Weinberg, Stephanie Schulz e Scott A Waldman. Guanylyl cyclase c is a marker of intestinal metaplasia, dysplasia, and adenocarcinoma of the gastrointestinal tract. Human pathology, 36(2):170-179. Citado na pág. 125

Brown et al. (2001) Carl S Brown, Paul C Goodwin e Peter K Sorger. Image metrics in the statistical analysis of dna microarray data. Proceedings of the National Academy of Sciences, 98 (16):8944-8949. Citado na pág. 1, 2, 10, 11, 133

Casella e Berger (1990) George Casella e Roger L Berger. Statistical inference, volume 70. Duxbury Press Belmont, CA. Citado na pág. 19

Chan e Chang (2009) Shih-Huang Chan e Wan-Chi Chang. A robust ratio estimator of gene expression via inverse-variance weighting for cdna microarray images. Computational Statistics G3 Data Analysis, 53(5):1577-1589. Citado na pág. 3

Chen et al. (2012) Qin Chen, Tsunaki Hongu, Takanobu Sato, Yi Zhang, Wahida Ali, Julie-Ann Cavallo, Adrianus van der Velden, Huasong Tian, Gilbert Di Paolo, Bernhard Nieswandt et al. Key roles for the lipid signaling enzyme phospholipase $\mathrm{d} 1$ in the tumor microenvironment during tumor angiogenesis and metastasis. Science signaling, 5(249):ra79. Citado na pág. 126

Chen et al. (1997) Yidong Chen, Edward R Dougherty e Michael L Bittner. Ratio-based decisions and the quantitative analysis of cdna microarray images. Journal of Biomedical optics, 2(4):364374. Citado na pág. 3,11 
Cleveland (1979) William S Cleveland. Robust locally weighted regression and smoothing scatterplots. Journal of the American statistical association, 74(368):829-836. Citado na pág. 38, 40

Cleveland e Devlin (1988) W.S. Cleveland e S.J. Devlin. Locally weighted regression: an approach to regression analysis by local fitting. Journal of the American Statistical Association, 83 (403):596-610. Citado na pág. 40, 41, 51, 54, 55, 56

Cui e Churchill (2003) Xiangqin Cui e Gary A Churchill. Statistical tests for differential expression in cdna microarray experiments. Genome Biol, 4(4):210. Citado na pág. 89

Dalman et al. (2012) Mark R Dalman, Anthony Deeter, Gayathri Nimishakavi e Zhong-Hui Duan. Fold change and p-value cutoffs significantly alter microarray interpretations. BMC bioinformatics, 13(Suppl 2):S11. Citado na pág. 90

Davidian e Giltinan (1995) Marie Davidian e David M Giltinan. Nonlinear models for repeated measurement data, volume 62. CRC Press. Citado na pág. 81

de Carvalho et al. (2004) Francisco de AT de Carvalho, Eufrasio de A Lima Neto e Camilo P Tenorio. A new method to fit a linear regression model for interval-valued data. Em KI 2004: Advances in Artificial Intelligence, páginas 295-306. Springer. Citado na pág. 65, 67

Devereux et al. (1998) TR Devereux, JI Risinger e JC Barrett. Mutations and altered expression of the human cancer genes: what they tell us about causes. IARC scientific publications, (146): 19-42. Citado na pág. 5

Drăghici (2012) Sorin Drăghici. Statistics and Data Analysis for Microarrays Using $R$ and Bioconductor, volume 4. CRC Press. Citado na pág. 8, 11, 56, 151

Dror (2001) Ron Dror. Noise models in gene array analysis. Report in fulfillment of the area exam requirement in the MIT Department of Electrical Engineering and Computer Science. Citado na pág. 3

Dudoit et al. (2002) Sandrine Dudoit, Yee Hwa Yang, Matthew J Callow e Terence P Speed. Statistical methods for identifying differentially expressed genes in replicated cdna microarray experiments. Statistica sinica, 12(1):111-140. Citado na pág. 8, 56

Edgar et al. (2002) Ron Edgar, Michael Domrachev e Alex E Lash. Gene expression omnibus: Ncbi gene expression and hybridization array data repository. Nucleic acids research, 30(1):207-210. Citado na pág. 125

Esteves et al. (2014) Gustavo H Esteves, Roberto Hirata Jr, E Jordao Neves, Maintainer Gustavo H Esteves, TwoChannel biocViews Microarray, ConnectTools Preprocessing e Cluster DifferentialExpression. Package 'maigespack'. Citado na pág. 84

Fan e Gijbels (1996) J Fan e I Gijbels. Local polynomial modelling and its applications. Chapman, Hall, London. Citado na pág. 32, 44

Fan e Gijbels (1992) Jianqing Fan e Irene Gijbels. Variable bandwidth and local linear regression smoothers. The Annals of Statistics, páginas 2008-2036. Citado na pág. 47

Flachaire (2001) Emmanuel Flachaire. The wild bootstrap, tamed at last. LSE STICERD Research Paper, (58). Citado na pág. 63

Francis (1961) John GF Francis. The qr transformation a unitary analogue to the $1 \mathrm{r}$ transformation-part 1. The Computer Journal, 4(3):265-271. Citado na pág. 144

Francis (1962) John GF Francis. The qr transformation-part 2. The Computer Journal, 4(4): 332-345. Citado na pág. 144 
Fujii et al. (2012) Yumiko Fujii, Kyoko Yoshihashi, Hidekazu Suzuki, Shuichi Tsutsumi, Hiroyuki Mutoh, Shin Maeda, Yukinori Yamagata, Yasuyuki Seto, Hiroyuki Aburatani e Masanori Hatakeyama. Cdx1 confers intestinal phenotype on gastric epithelial cells via induction of stemnessassociated reprogramming factors sall4 and klf5. Proceedings of the National Academy of Sciences, 109(50):20584-20589. Citado na pág. 125

Gibbons et al. (2013) Ahmara V Gibbons, Jieru E Lin, Gilbert W Kim, Glen P Marszalowicz, Peng Li, Brian A Stoecker, Erik S Blomain, Satish Rattan, Adam E Snook, Stephanie Schulz et al. Intestinal gucy2c prevents tgf- $\beta$ secretion coordinating desmoplasia and hyperproliferation in colorectal cancer. Cancer research, 73(22):6654-6666. Citado na pág. 125

Glejser (1969) Herbert Glejser. A new test for heteroskedasticity. Journal of the American Statistical Association, 64(325):316-323. Citado na pág. 35

Goldfeld e Quandt (1965) Stephen M Goldfeld e Richard E Quandt. Some tests for homoscedasticity. Journal of the American Statistical Association, 60(310):539-547. Citado na pág. 35

Gozgit et al. (2007) JM Gozgit, BT Pentecost, SA Marconi, RSJ Ricketts-Loriaux, CN Otis e KF Arcaro. Pld1 is overexpressed in an er-negative mcf-7 cell line variant and a subset of phospho-akt-negative breast carcinomas. British journal of cancer, 97(6):809-817. Citado na pág. 126

Harville (1977) David A Harville. Maximum likelihood approaches to variance component estimation and to related problems. Journal of the American Statistical Association, 72(358):320-338. Citado na pág. 76,148

Hegde et al. (2000) Priti Hegde, Rong Qi, Kristie Abernathy, Cheryl Gay, Sonia Dharap, Renee Gaspard, JE Hughes, Erik Snesrud, Norman Lee e John Quackenbush. A concise guide to cdna microarray analysis. Biotechniques, 29(3):548-563. Citado na pág. 11

Horowitz (2001) Joel L Horowitz. The bootstrap. Handbook of econometrics, 5:3159-3228. Citado na pág. 60

Hughes et al. (2000) Timothy R Hughes, Matthew J Marton, Allan R Jones, Christopher J Roberts, Roland Stoughton, Christopher D Armour, Holly A Bennett, Ernest Coffey, Hongyue Dai, Yudong D He et al. Functional discovery via a compendium of expression profiles. Cell, 102 (1):109-126. Citado na pág. 1

Ishikawa et al. (2004) Akira Ishikawa, Motoko Sasaki, Shusaku Ohira, Tetsuo Ohta, Koji Oda, Yuji Nimura, Miin-Fu Chen, Yi-Yin Jan, Ta-Sen Yeh e Yasuni Nakanuma. Aberrant expression of cdx2 is closely related to the intestinal metaplasia and muc2 expression in intraductal papillary neoplasm of the liver in hepatolithiasis. Laboratory investigation, 84(5):629-638. Citado na pág. 125

Jain et al. (2003) Nitin Jain, Jayant Thatte, Thomas Braciale, Klaus Ley, Michael O'Connell e Jae K Lee. Local-pooled-error test for identifying differentially expressed genes with a small number of replicated microarrays. Bioinformatics, 19(15):1945-1951. Citado na pág. 3

Jayasinghe et al. (2013) Caren Jayasinghe, Nektaria Simiantonaki e Charles James Kirkpatrick. Vegf-b expression in colorectal carcinomas and its relevance for tumor progression. Histology and histopathology, 28(5):647-653. Citado na pág. 126

Jokilehto et al. (2006) Terhi Jokilehto, Krista Rantanen, Marjaana Luukkaa, Pekka Heikkinen, Reidar Grenman, Heikki Minn, Pauliina Kronqvist e Panu M Jaakkola. Overexpression and nuclear translocation of hypoxia-inducible factor prolyl hydroxylase phd2 in head and neck squamous cell carcinoma is associated with tumor aggressiveness. Clinical cancer research, 12(4): 1080-1087. Citado na pág. 126 
Kamburov et al. (2009) Atanas Kamburov, Christoph Wierling, Hans Lehrach e Ralf Herwig. Consensuspathdb-a database for integrating human functional interaction networks. Nucleic acids research, 37(suppl 1):D623-D628. Citado na pág. 126, 131, 132

Kang et al. (2011) Dong Woo Kang, Kang-Yell Choi et al. Phospholipase d meets wnt signaling: a new target for cancer therapy. Cancer research, 71(2):293-297. Citado na pág. 126

Kenward e Roger (1997) Michael G Kenward e James H Roger. Small sample inference for fixed effects from restricted maximum likelihood. Biometrics, páginas 983-997. Citado na pág. 76, 77

Kooperberg et al. (2002) Charles Kooperberg, Thomas G Fazzio, Jeffrey J Delrow e Toshio Tsukiyama. Improved background correction for spotted dna microarrays. Journal of Computational Biology, 9(1):55-66. Citado na pág. 11, 12

Laird e Ware (1982) Nan M Laird e James H Ware. Random-effects models for longitudinal data. Biometrics, páginas 963-974. Citado na pág. 148

Lee et al. (2010) Hyuk-Joon Lee, Ki Taek Nam, Heae Surng Park, Min A Kim, Bonnie J LaFleur, Hiroyuki Aburatani, Han-Kwang Yang, Woo Ho Kim e James R Goldenring. Gene expression profiling of metaplastic lineages identifies $\mathrm{CDH17}$ as a prognostic marker in early stage gastric cancer. Gastroenterology, 139(1):213-225. Citado na pág. 125

Leite e Singer (1990) J.G. Leite e J.M. Singer. Métodos assintóticos em estatística: Fundamentos e aplicações. Citado na pág. 19

Li e Wong (2001) Cheng Li e Wing Hung Wong. Model-based analysis of oligonucleotide arrays: expression index computation and outlier detection. Proceedings of the National Academy of Sciences, 98(1):31-36. Citado na pág. 3

Li et al. (2002) Qing-Lin Li, Kosei Ito, Chohei Sakakura, Hiroshi Fukamachi, Ken ichi Inoue, XinZi Chi, Kwang-Youl Lee, Shintaro Nomura, Chang-Woo Lee, Sang-Bae Han, Hwan-Mook Kim, Wun-Jae Kim, Hiromitsu Yamamoto, Namiko Yamashita, Takashi Yano, Toshio Ikeda, Shigeyoshi Itohara, Johji Inazawa, Tatsuo Abe, Akeo Hagiwara, Hisakazu Yamagishi, Asako Ooe, Atsushi Kaneda, Takashi Sugimura, Toshikazu Ushijima, Suk-Chul Bae e Yoshiaki Ito. Causal relationship between the loss of \{RUNX3\} expression and gastric cancer. Cell, 109(1):113 - 124. ISSN 00928674. doi: http://dx.doi.org/10.1016/S0092-8674(02)00690-6. URL http://www.sciencedirect. com/science/article/pii/S0092867402006906. Citado na pág. 127

Littell (2006) Ramon C Littell. SAS for mixed models. SAS institute. Citado na pág. 76

Liu e Okui (2013) Qingfeng Liu e Ryo Okui. Heteroscedasticity-robust cp model averaging. The Econometrics Journal, 16(3):463-472. Citado na pág. 51

Liu et al. (1988) Regina Y Liu et al. Bootstrap procedures under some non-iid models. The Annals of Statistics, 16(4):1696-1708. Citado na pág. 62

Loader (2007) Catherine Loader. Locfit: Local regression, likelihood and density estimation. $R$ package version, páginas $1-5$. Citado na pág. 84

Loader (2012) Catherine Loader. Smoothing: Local regression techniques. Em Handbook of Computational Statistics, páginas 571-596. Springer. Citado na pág. 47, 48

Loader (1999) Clive Loader. Local regression and likelihood, volume 47. springer New York. Citado na pág. $40,44,51,55,56,140$

Mallows (1973) Colin L Mallows. Some comments on cp. Technometrics, 15(4):661-675. Citado na pág. 51,56 
Martin Bland e Altman (1986) J Martin Bland e DouglasG Altman. Statistical methods for assessing agreement between two methods of clinical measurement. The lancet, 327(8476): 307-310. Citado na pág. 9

Mi et al. (2013) Huaiyu Mi, Anushya Muruganujan e Paul D Thomas. Panther in 2013: modeling the evolution of gene function, and other gene attributes, in the context of phylogenetic trees. Nucleic acids research, 41(D1):D377-D386. Citado na pág. 90

Neter et al. (1996) John Neter, Michael H Kutner, Christopher J Nachtsheim e William Wasserman. Applied linear statistical models, volume 4. Irwin Chicago. Citado na pág. 72

Newton et al. (2001) Michael A Newton, Christina M Kendziorski, Craig S Richmond, Frederick R. Blattner e Kam-Wah Tsui. On differential variability of expression ratios: improving statistical inference about gene expression changes from microarray data. Journal of computational biology, 8(1):37-52. Citado na pág. 2, 86

Noh et al. (2000) Dong-Young Noh, Soo-Jung Ahn, Ryung-Ah Lee, In Park, Jae-Ho Kim, PannGhill Suh, Sung-Ho Ryu, Kweon-Haeng Lee e Joong-Soo Han. Overexpression of phospholipase d1 in human breast cancer tissues. Cancer letters, 161(2):207-214. Citado na pág. 126

Nunez-Garcia et al. (2004) Javier Nunez-Garcia, Vassilios Mersinias, Kwang-Hyun Cho, Colin P Smith e Olaf Wolkenhauer. A study of the statistical distribution of the intensity of pixels within spots of dna microarrays: What is the appropriate single-valued representative? Appl Bioinformatics, 2:229-239. Citado na pág. 3

Oue et al. (2005) Naohide Oue, Yoshitsugu Mitani, Phyu Phyu Aung, Chouhei Sakakura, Yukio Takeshima, Mayumi Kaneko, Tsuyoshi Noguchi, Hirofumi Nakayama e Wataru Yasui. Expression and localization of reg iv in human neoplastic and non-neoplastic tissues: Reg iv expression is associated with intestinal and neuroendocrine differentiation in gastric adenocarcinoma. The Journal of pathology, 207(2):185-198. Citado na pág. 125

Ouellette (1997) ANDRE J Ouellette. Paneth cells and innate immunity in the crypt microenvironment. Gastroenterology, 113(5):1779-1784. Citado na pág. 125

Patterson e Thompson (1971) H Desmond Patterson e Robin Thompson. Recovery of interblock information when block sizes are unequal. Biometrika, 58(3):545-554. Citado na pág. 76, 148

Pinheiro et al. (2011) J Pinheiro, D Bates, S DebRoy e D Sarkar. R development core team. 2010. nlme: linear and nonlinear mixed effects models. $\mathrm{r}$ package version 3.1-97. R Foundation for Statistical Computing, Vienna. Citado na pág. 76, 84

Pinheiro e Bates (2000) José C Pinheiro e Douglas M Bates. Mixed effects models in $S$ and S-PLUS. Springer. Citado na pág. $76,80,81,143,144,149$

Quackenbush (2002) John Quackenbush. Microarray data normalization and transformation. Nature genetics, 32:496-501. Citado na pág. 2

Reis et al. (1999) Celso A Reis, Leonor David, Pelayo Correa, Fatima Carneiro, Carme de Bolós, Elsa Garcia, Ulla Mandel, Henrik Clausen e Manuel Sobrinho-Simões. Intestinal metaplasia of human stomach displays distinct patterns of mucin (muc1, muc2, muc5ac, and muc6) expression. Cancer research, 59(5):1003-1007. Citado na pág. 125

Resnick et al. (2005) Murray B Resnick, Mariuxi Gavilanez, Eric Newton, Tamako Konkin, Baishali Bhattacharya, Deborah E Britt, Edmond Sabo e Steven F Moss. Claudin expression in gastric adenocarcinomas: a tissue microarray study with prognostic correlation. Human pathology, 36(8):886-892. Citado na pág. 125 
Ritchie et al. (2007) Matthew E Ritchie, Jeremy Silver, Alicia Oshlack, Melissa Holmes, Dileepa Diyagama, Andrew Holloway e Gordon K Smyth. A comparison of background correction methods for two-colour microarrays. Bioinformatics, 23(20):2700-2707. Citado na pág. 14, 30, 83, 85, 133

Rocke e Durbin (2001) David M Rocke e Blythe Durbin. A model for measurement error for gene expression arrays. Journal of computational biology, 8(6):557-569. Citado na pág. 3

Rocke e Durbin (2003) David M Rocke e Blythe Durbin. Approximate variance-stabilizing transformations for gene-expression microarray data. Bioinformatics, 19(8):966-972. Citado na pág. 14

Ruppert e Wand (1994) David Ruppert e Matthew P Wand. Multivariate locally weighted least squares regression. The annals of statistics, páginas 1346-1370. Citado na pág. 43, 44, 47, 48

Satterthwaite (1941) Franklin E Satterthwaite. Synthesis of variance. Psychometrika, 6(5): 309-316. Citado na pág. 77

Scharpf et al. (2007) Robert B Scharpf, Christine A Iacobuzio-Donahue, Julie B Sneddon e Giovanni Parmigiani. When should one subtract background fluorescence in 2-color microarrays? Biostatistics, 8(4):695-707. Citado na pág. 11, 12

Shang et al. (2012) Xiying Shang, Xinjian Lin, Edwin Alvarez, Gerald Manorek e Stephen B Howell. Tight junction proteins claudin-3 and claudin-4 control tumor growth and metastases. Neoplasia (New York, NY), 14(10):974. Citado na pág. 125

Silver et al. (2009) Jeremy D Silver, Matthew E Ritchie e Gordon K Smyth. Microarray background correction: maximum likelihood estimation for the normal-exponential convolution. $B i$ ostatistics, 10(2):352-363. Citado na pág. 12, 14

Smyth (2005) Gordon K Smyth. Limma: linear models for microarray data. Em Bioinformatics and computational biology solutions using $R$ and Bioconductor, páginas 397-420. Springer. Citado na pág. 16,84

Smyth e Speed (2003) Gordon K Smyth e Terry Speed. Normalization of cdna microarray data. Methods, 31(4):265-273. Citado na pág. 56

Suzuki et al. (1995) Hiroyuki Suzuki, Xiaoling Zhou, Jing Yin, Jungi Lei, HaL Yan Jiang, Yukiko Suzuki, Tim Chan, Gregory J Hannon, Wolfgang J Mergner, John M Abraham et al. Intragenic mutations of cdkn2b and cdkn2a in primary human esophageal cancers. Human molecular genetics, 4(10):1883-1887. Citado na pág. 127

Tao et al. (2011) Hou-Quan Tao, Xu-Jun He, Ying-Yu Ma, Hui-Ju Wang, Ying-Jie Xia, Zai-Yuan Ye e Zhong-Sheng Zhao. Evaluation of reg4 for early diagnosis and prognosis of gastric cancer. Human pathology, 42(10):1401-1409. Citado na pág. 125

Team et al. (2008) RDevelopment Core Team et al. R: A language and environment for statistical computing. Vienna, Austria: R Foundation for Statistical Computing, páginas 1-1731. Citado na pág. 84

Theilhaber et al. (2001) Joachim Theilhaber, Steven Bushnell, Amanda Jackson e Rainer Fuchs. Bayesian estimation of fold-changes in the analysis of gene expression: the pfold algorithm. Journal of Computational Biology, 8(6):585-614. Citado na pág. 3

Tibshirani (1984) Robert J Tibshirani. Bootstrap confidence intervals. Relatório técnico, DTIC Document. Citado na pág. 61

Tran et al. (2002) Peter H Tran, Daniel A Peiffer, Yongchol Shin, Lauren M Meek, James P Brody e Ken WY Cho. Microarray optimizations: increasing spot accuracy and automated identification of true microarray signals. Nucleic Acids Research, 30(12):e54-e54. Citado na pág. 3 
Tu et al. (2002) Y Tu, G Stolovitzky e U Klein. Quantitative noise analysis for gene expression microarray experiments. Proceedings of the National Academy of Sciences, 99(22):14031-14036. Citado na pág. 3

Weng et al. (2006) Lee Weng, Hongyue Dai, Yihui Zhan, Yudong He, Sergey B Stepaniants e Douglas E Bassett. Rosetta error model for gene expression analysis. Bioinformatics, 22(9): 1111-1121. Citado na pág. 3

Wu et al. (1986) Chien-Fu Jeff Wu et al. Jackknife, bootstrap and other resampling methods in regression analysis. the Annals of Statistics, 14(4):1261-1295. Citado na pág. 62

Wu e P. Xing (2008) Wei Wu e Eric P. Xing. A survey of cdna microarray normalization and a comparison by k-nn classification. Methods in microarray normalization, páginas 81-129. Citado na pág. 8

Yang et al. (2002) Yee Hwa Yang, Sandrine Dudoit, Percy Luu, David M Lin, Vivian Peng, John Ngai e Terence P Speed. Normalization for cdna microarray data: a robust composite method addressing single and multiple slide systematic variation. Nucleic acids research, 30(4):e15-e15. Citado na pág. 6

Yang et al. (2000) Y.H. Yang, S. Dudoit, P. Luuc e T.P. Speed. Normalization for cdna microarray data. Citado na pág. $2,15,16,56$

Ye (1998) Jianming Ye. On measuring and correcting the effects of data mining and model selection. Journal of the American Statistical Association, 93(441):120-131. Citado na pág. 50

Zahurak et al. (2007) Marianna Zahurak, Giovanni Parmigiani, Wayne Yu, Robert Scharpf, David Berman, Edward Schaeffer, Shabana Shabbeer e Leslie Cope. Pre-processing agilent microarray data. BMC bioinformatics, 8(1):142. Citado na pág. 151 